\title{
Nutrition transition in urban Kenya: The role of supermarkets and nutritional knowledge
}

\author{
Dissertation \\ to obtain the doctoral degree \\ in the International Ph. D. Program for Agricultural Sciences in Goettingen (IPAG) \\ at the Faculty of Agricultural Sciences, \\ Georg-August-University Goettingen, Germany
}

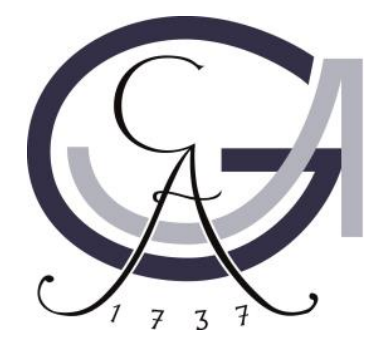

presented by

Kathrin Maria Demmler

born in Worms, Germany

Goettingen, March 2017 
D7

$1^{\text {st }}$ supervisor: Prof. Dr. Matin Qaim

$2^{\text {nd }}$ supervisor: Prof. Stephan Klasen, Ph.D.

$3^{\text {rd }}$ supervisor: Prof. Dr. Sebastian Vollmer

Date of dissertation: $18^{\text {th }}$ May 2017. 


\section{Summary}

$\mathrm{N}$

utrition transition is described as a shift in demographic and epidemiologic patterns; fostered through economic development, globalization, urbanization, and technological improvements. Depending on the stage of transition in a given society, changes in lifestyle and eating habits lead to an increased intake of processed foods, saturated and total fats, salt, sugar, and energy-dense beverages. Many developing countries are undergoing such a nutrition transition, which contributes to emerging problems in their health systems. For a long time, the elimination of undernutrition has been a top priority of development policies in low-income countries. Worldwide, it is estimated that $24 \%$ of all children under-five are currently stunted, mainly caused by sustained episodes of energy and micronutrient deficiencies. There has been remarkable progress in reducing this prevalence; still the number of stunted children continues to increase in African countries. While globally undernutrition and stunting are declining, overweight, obesity, and nutrition-related non-communicable diseases (NR-NCD) such as diabetes and hypertension are growing epidemically. The large majority of the worldwide NCD-related deaths occur in low- and middle-income countries. Especially for some African countries like Kenya, where stunting is still widespread and overweight and obesity are increasing rapidly, it is of immense importance to analyze and understand driving factors and prevent malnutrition in all its forms.

Against this background, this dissertation presents three essays dealing with the ongoing nutrition transition and malnutrition in Kenya. In the first two essays, we investigate the influence of supermarket purchase on adult's nutrition, diet, and health. In the third essay, we study the link between different types of maternal nutrition knowledge and child and adolescents' nutritional outcomes.

Kenya has experienced a rapid growth of supermarkets in recent years. Overall, the share of national grocery sales through supermarkets in Kenya is about 10\%; with big cities already having a much higher share. At the same time, the country is struggling with many nutrition and health-related issues. While $35 \%$ of the children under-five are stunted, NR-NCDs are also a growing concern. More than $26 \%$ of all adults in Kenya are either overweight or obese. The national prevalence of diabetes and hypertension is estimated at $2.5 \%$ and $35 \%$, respectively. 
The first two essays are motivated by the hypothesis that the rapid spread of supermarkets in developing countries contributes to the observed nutrition transition and thus causes changes in nutrition and health. Recent research revealed significant effects of supermarket purchase on dietary choices and the body mass index (BMI) in various developing countries. However to our knowledge the question whether supermarket purchase affects the prevalence of NR-NCDs has not been analyzed up till now. We add to the literature by using detailed health data and indicators of NR-NCDs. In addition, existing studies only had cross-sectional data available, so that possible bias due to unobserved heterogeneity remains an issue in the analysis of supermarket impacts. Here, we address this issue with panel data for dietary choices and BMI. Related to our third essay, maternal nutrition knowledge has been identified as one important factor to shape a healthy living environment for the whole household and to improve child nutrition. While associations between maternal nutrition knowledge and young children's nutritional outcomes are well documented, it is much less understood, what type of maternal nutrition knowledge matters most and what are possible impacts on older children and adolescents.

The first essay investigates the effects of supermarket purchase on BMI, as well as on health indicators such as fasting blood glucose (FBG), blood pressure (BP), and the metabolic syndrome. To this end, we use cross-section observational data from urban Kenya collected in 2015. Demographic, anthropometric, and bio-medical data were collected from 550 randomly selected adults. Supermarket purchase is defined as any food purchase done in supermarkets during the last 30 days. Instrumental variable (IV) regressions are applied to control for confounding factors and establish causality between supermarket purchase, BMI, and health. We find that supermarket purchase leads to higher BMI and an increased probability of being overweight or obese. Supermarket purchase is also related to significantly higher levels of FBG and a higher likelihood of suffering from pre-diabetes and the metabolic syndrome. Effects on BP cannot be observed. We conclude that supermarkets and their food sales strategies seem to have direct effects on people's health. In addition to increasing overweight and obesity, supermarkets contribute to FBG, pre-diabetes, and the metabolic syndrome.

In the second essay, we analyze robust effects of supermarket shopping on BMI and the probability of being overweight or obese. Further, we investigate the relationship of supermarket 
shopping on the share of energy from highly processed foods and the energy consumption of different food groups (unprocessed staples, fruits/vegetables, meats/fish, dairy/eggs and vegetable oils). For this analysis, we use panel data collected in 2012 and 2015. Econometric analysis is carried out with an unbalanced panel comprising 1,199 observations of male and female adults with differing supermarket access and use. Using fixed effects (FE) estimations, we find that supermarket shopping significantly increases adult's BMI through changed diets. Supermarket shopping decreases the energy consumption from unprocessed staples, fresh fruits, and vegetables and increases energy consumption from dairy, vegetable oil, processed meat products, and highly processed foods. The data suggest that the BMI-increasing effect of supermarket shopping is primarily due to changed dietary composition, rather than higher total energy consumption. As 'unhealthy' foods are also available in traditional retail outlets, the contribution of supermarkets might be of an additional character driven by lager package sizes, pricing, advertising, and placing strategies.

The third essay examines the link between maternal nutrition knowledge and long-term nutritional outcomes of children and adolescents between 5-18 years, focusing on whether associations differ depending on the type of maternal nutrition knowledge. We use panel data from urban Kenya collected in 2012 and 2015. After controlling for confounding factors, we find that maternal nutrition knowledge, measured in terms of an aggregated nutrition knowledge score, is positively associated with children's height-for-age Z-score (HAZ). However, further disaggregation by type of maternal nutrition knowledge reveals important differences. The strongest positive association with child HAZ is found for maternal nutrition knowledge about the health consequences of not following recommended dietary practices.

All three essays contribute to the existing literature about the links between transforming food systems and nutrition in developing countries. Concrete empirical research on such links is relatively scarce. Beyond nutrition, we also broadened the scope and analyzed effects of supermarket shopping on health and NR-NCDs. The results have immediate policy-relevance. Policy interventions should be designed such that positive effects of supermarket growth are strengthened, while negative nutrition and health impacts are avoided to the extent possible. One concrete idea could be to improve the offer and placement of fresh foods in supermarkets located in small urban centers. Furthermore, our results on the role of nutrition knowledge suggest that 
nutrition education should especially focus on raising awareness of the health risks associated with unsuitable dietary practices. As shown, awareness of such health risks among mothers and caretakers can help to improve long-term nutritional outcomes of children and adolescents. 


\section{Acknowledgements}

First of all, I want to thank my supervisor Prof. Matin Qaim, for his tremendous support, inspiration, and insightful guidance during the entire period of my doctoral studies. He always found time for critical feedback and discussions and strongly supported me in my own (scientific) development and learning. I would also like to thank Prof. Stephan Klasen and Prof. Sebastian Vollmer, my second and third supervisors, for their thoughtful advice and useful critique concerning my work. I am grateful to Dr. Olivier Ecker, my counterpart at the International Food Policy Research Institute (IFPRI), who hosted me during my research stay at IFPRI in Washington, DC, and who closely cooperated with me especially on the second paper. My grateful thanks are also extended to Dr. Bethelhem Debela, for the very fruitful and inspiring teamwork we had on the third paper.

This research was financially supported by the German Research Foundation (Deutsche Forschungsgemeinschaft, DFG) as part of the GlobalFood Research Training Group (RTG). This financial support is gratefully acknowledged. I appreciate the valuable support and advice I received from Dr. Simon Kimenju and Dr. Ramona Rischke. They allowed me to use their data collected in Kenya in 2012 and provided useful insights for my own data collection in 2015. Furthermore, the support in fieldwork provided by the University of Nairobi, particular by Dr. Jonathan Nzuma and the motivated team of enumerators and health personal, is greatly appreciated. I am very thankful for all assistance I had during and after data collection by student assistants, local Kenyan authorities, community health workers and all the study participants in the three towns of $\mathrm{Ol} \mathrm{Kalou,} \mathrm{Mwea,} \mathrm{and} \mathrm{Njabini.} \mathrm{You} \mathrm{are} \mathrm{indispensable} \mathrm{for} \mathrm{all} \mathrm{studies} \mathrm{we} \mathrm{are}$ doing and I highly acknowledge your contribution to this research.

The GlobalFood RTG and our chair family have not only provided me an international scientific environment with outstanding possibilities and fruitful discussions; both have been places of friendship and social interactions and I am grateful and proud to be part of these teams. My special thanks are extended to our office, the lively discussions, bad jokes, and the joy you broad to my (working) life. Lutz, Dirk, and Malte, thank you for a great office atmosphere and your friendship! 
Further, I would like to thank my brother and close friends Chrissi, Ela, Lisi, Stemmi, and Timmsen J. Katz for their support, creative ideas, and their honest friendship. Peter and Otto, your distraction, patience, humor, and love have been essential to me and my work. Finally, I am grateful to my parents who enabled and always supported me in this long time of studying and research and who encouraged me to proceed. 


\section{Table of Contents}

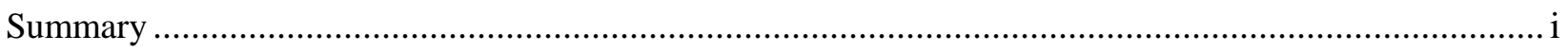

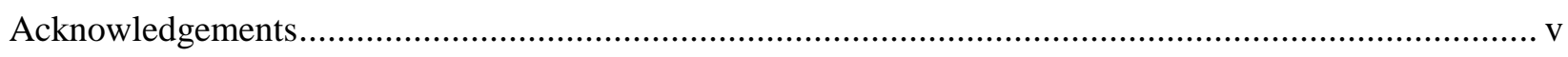

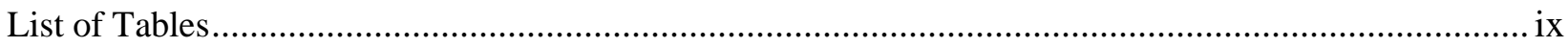

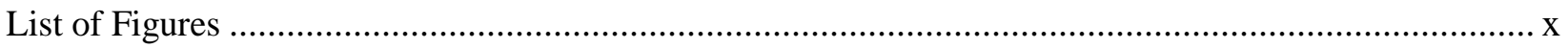

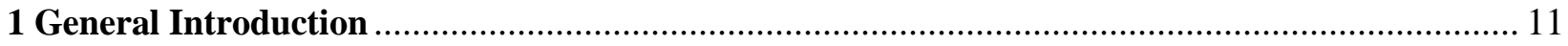

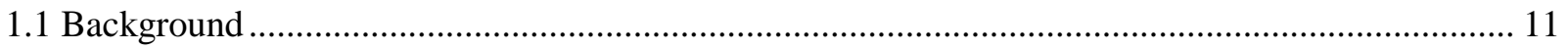

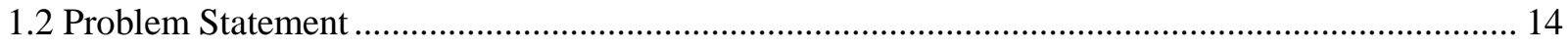

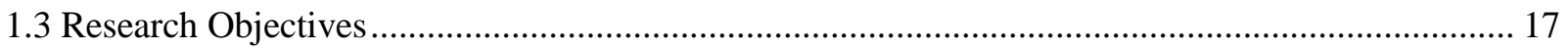

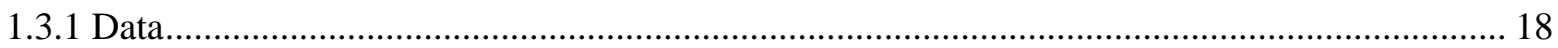

2 Supermarket Purchase Contributes to Nutrition-Related Non-Communicable Diseases in Urban

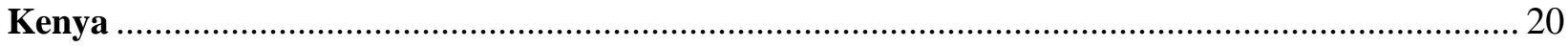

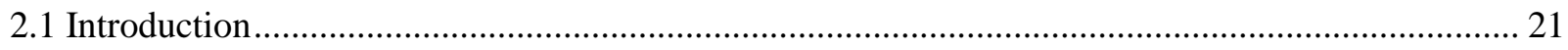

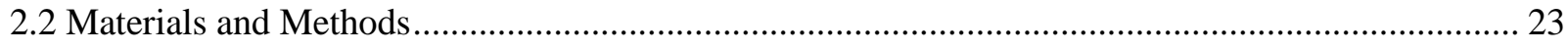

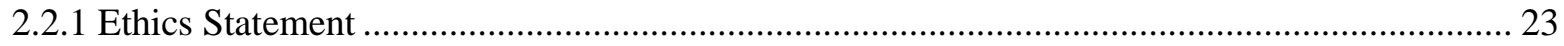

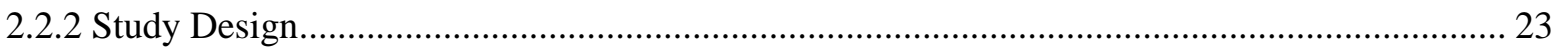

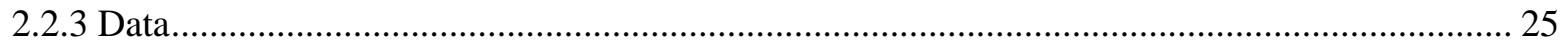

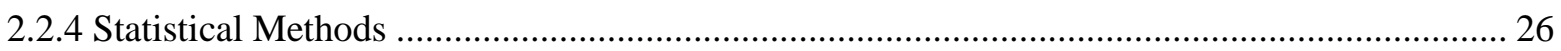

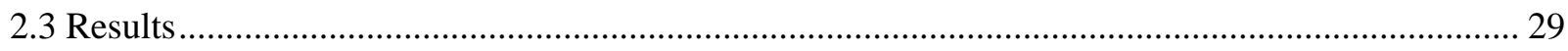

2.3.1 Supermarket Effects on Nutrition and Health.................................................................. 31

2.3.2 Other Factors influencing Nutrition and Health Outcomes ................................................... 32

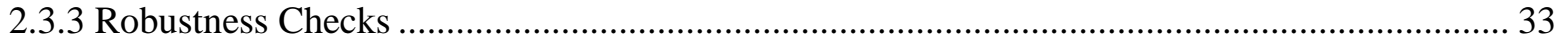

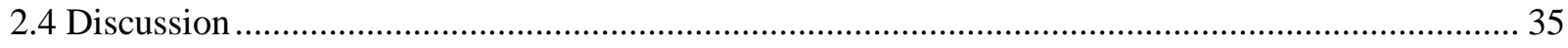

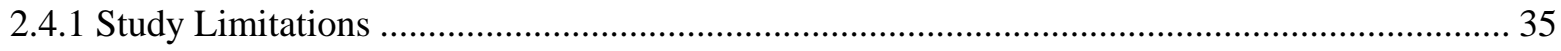

2.4.2 Rising Rates of Nutrition-Related Non-Communicable Diseases ............................................ 35

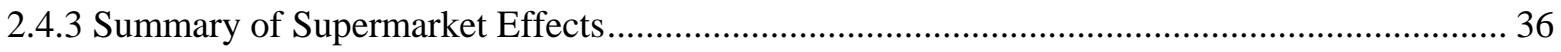

2.4.4 Expected Mechanisms of Supermarket Effects .................................................................. 37

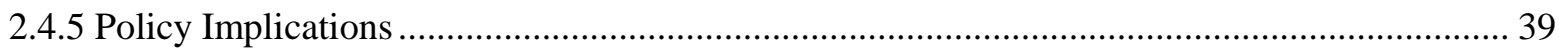

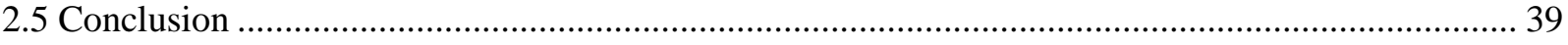

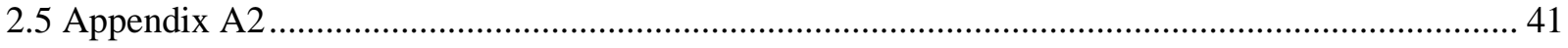

3 Supermarket Shopping and Nutritional Outcomes: A Panel Data Analysis for Urban Kenya...... 49

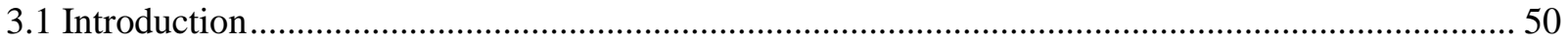

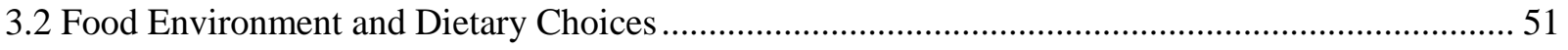

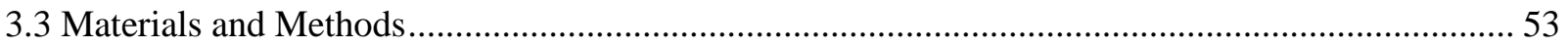

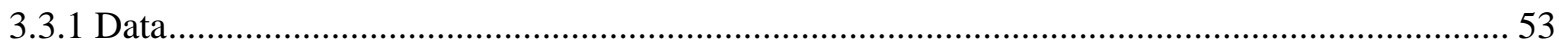




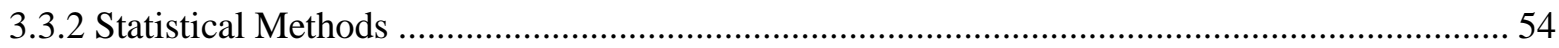

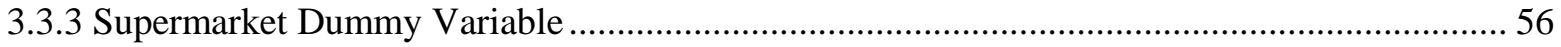

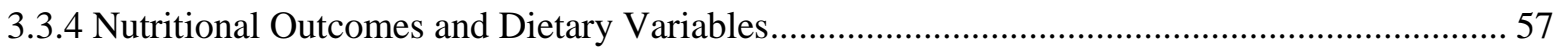

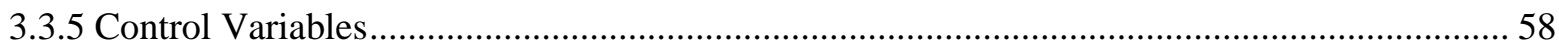

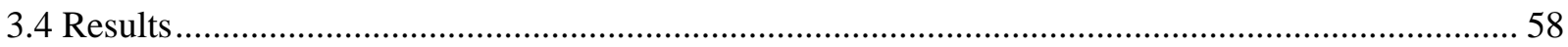

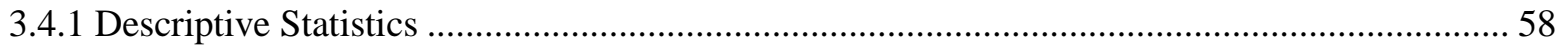

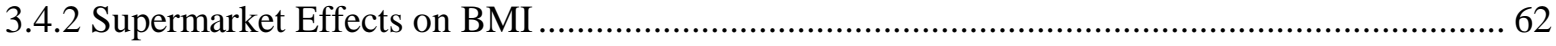

3.4.3 Supermarket Effects on the Prevalence of Overweight/Obesity ............................................. 64

3.4.4 Supermarket Effects on Dietary Choices ........................................................................... 65

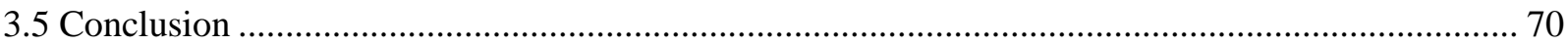

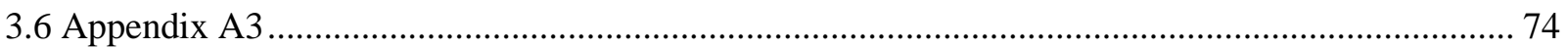

4 Maternal Nutrition Knowledge and Child Nutritional Outcomes in Urban Kenya ..................... 79

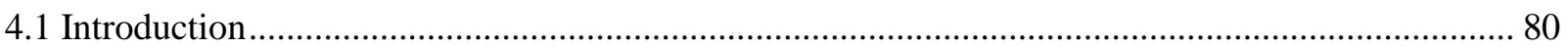

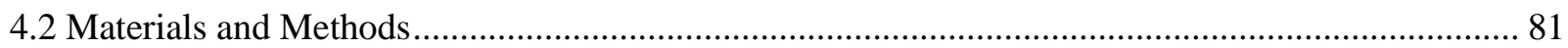

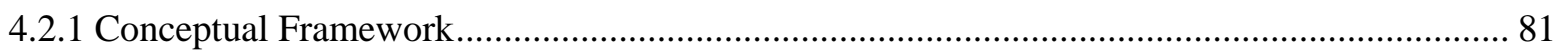

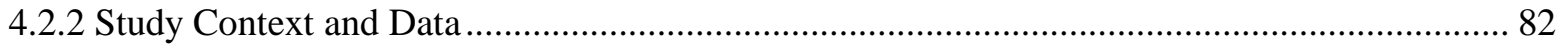

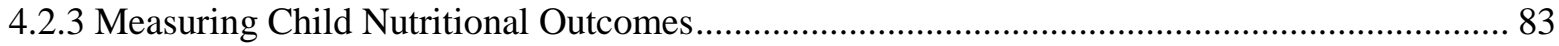

4.2.4 Measuring Maternal Nutrition Knowledge.......................................................................... 84

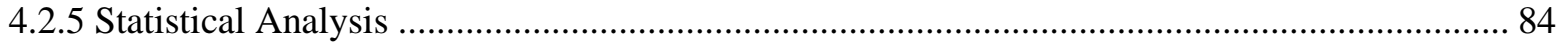

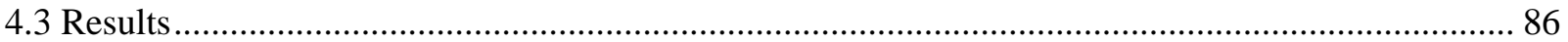

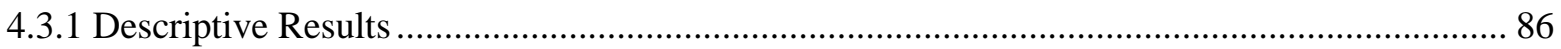

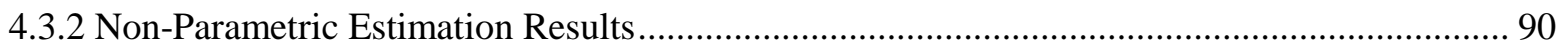

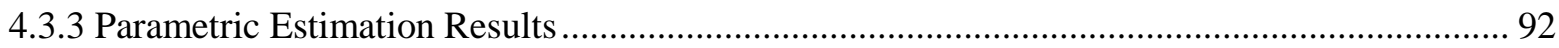

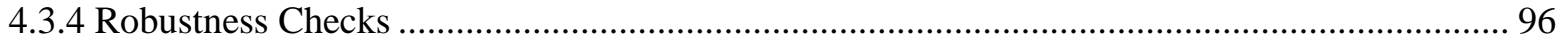

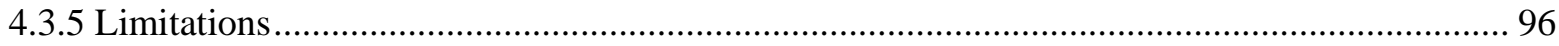

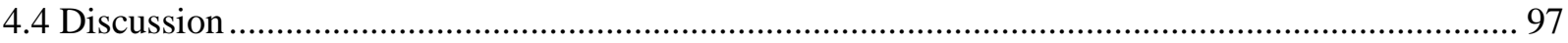

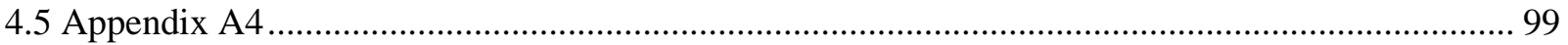

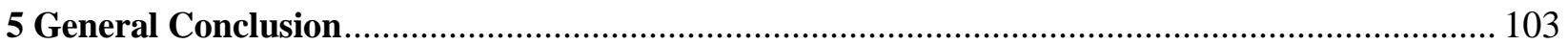

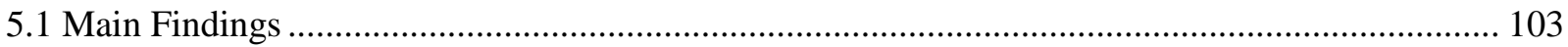

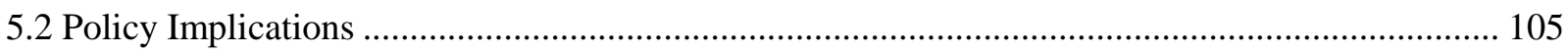

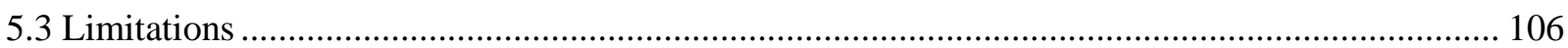

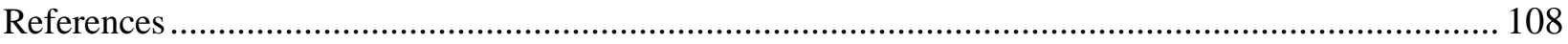

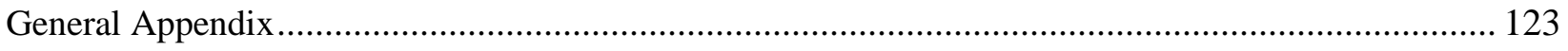

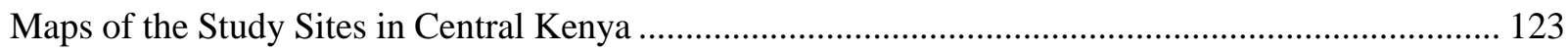

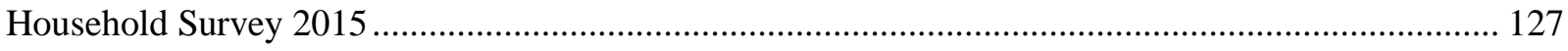




\section{List of Tables}

Table 2.1. Descriptive statistics for adults in households that buy and do not buy food in supermarkets .. 30

Table 2.2. Regression results forthe effects of supermarkets on BMI, fasting blood glucose, systolic and diastolic blood pressure

Table 2.3. Regression results for the effects of supermarkets on the probability of being overweight/obese, pre-diabetic, pre-hypertensive, and suffering from metabolic syndrome.

Table 2.4. Regression results for the effects of supermarket purchase (\%) on BMI, fasting blood glucose, systolic and diastolic blood pressure

Table 2.5. Regression results for the effects of supermarket purchase (\%) on the probability of being overweight/obese, pre-diabetic, pre-hypertensive, and suffering from metabolic syndrome.... 34

Table A2.1. First stage results of instrumental variable model ................................................................ 41

Table A2.2. Validity test of instrument in models for continuous nutrition and health outcomes.............. 42

Table A2.3. Validity test of instrument in models for binary nutrition and health outcomes

Table A2.4. Regression results for the effects of supermarkets on BMI, fasting blood glucose, systolic and diastolic blood pressure comparing OLS and IV estimations

Table A2.5. Regression results for the effects of supermarkets on the probability of being overweight/obese, pre-diabetic, pre-hypertensive, and suffering from metabolic syndrome comparing OLS and IV estimations

Table A2.6. Regression results for the effects of supermarkets on the probability of being overweight/obese, pre-diabetic, pre-hypertensive, and suffering from metabolic syndrome comparing probit and IV probit estimations

Table A2.7. Full regression results for the effects of supermarket purchase (\%) on BMI, fasting blood glucose, systolic and diastolic blood pressure

Table A2.8. Full regression results for the effects of supermarket purchase (\%) on the probability of being overweight/obese, pre-diabetic, pre-hypertensive, and suffering from metabolic syndrome.... 47

Table A2.9. Regression results for the effects of supermarkets on BMI with panel data model ............... 48

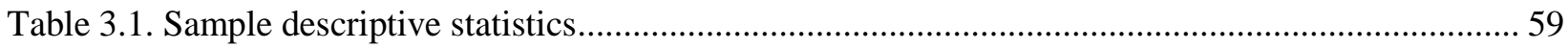

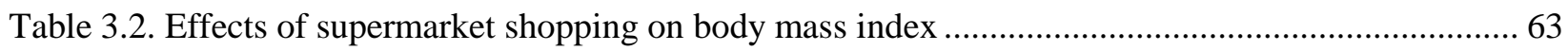

Table 3.3. Effects of supermarket shopping on the probability of being overweight/obese 65

Table 3.4. Effects of supermarket shopping on the share of energy consumed from highly processed foods

Table 3.5. Effects of supermarket shopping on energy consumption from different food groups ............. 68

Table A3.1. Comparison of balanced panel with excluded and newly included observations in 2015 ...... 74

Table A3.2. Different sources of food and their characteristics ................................................................. 75

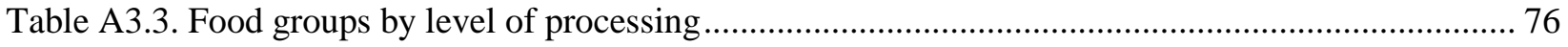

Table A3.4. Comparison of total sample with supermarket switchers .................................................... 77

Table A3.5. Effects of supermarket shopping on body mass index with additional controls .................... 78

Table 4.1. Nutrition knowledge questions and percentages of correct answers ...................................... 87

Table 4.2. Number of correct responses and maternal nutrition knowledge scores ................................. 88

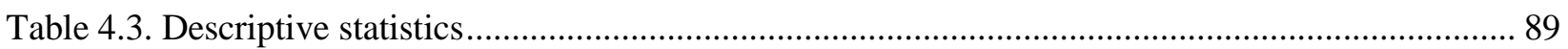


Table 4.4. Association between aggregate maternal nutrition knowledge and child HAZ 93

Table 4.5. Association between different types of maternal nutrition knowledge and child HAZ 95

Table A4. 1. Association between maternal nutrition knowledge and child HAZ (alternative knowledge indicator)

Table A4.2. Descriptive statistics by maternal nutrition knowledge (alternative cutoff point for high and low nutrition knowledge) 100

Table A4.3. Attrition probit model and HAZ regression after controlling for possible attrition bias 102

\section{List of Figures}

Figure 1.1. Map of Kenya with the study sites in the Counties Nyandarua and Kirinyaga.

Figure 2.1. Comparison of mean food consumption within last $30 \mathrm{~d}$ in households that buy and do not buy food in supermarkets $(n=433)$..

Figure 3.1. Differences in nutritional outcomes between individuals shopping and not shopping in supermarkets.

Figure 3.2. Quantity of food consumed from different food groups and food sources............................. 69

Figure 4.1. Relationship between maternal nutrition knowledge and child HAZ.................................. 91

Figure A4.1. Kernel density of HAZ by alternative definition of nutrition knowledge threshold........... 101

Figure A.1. Map of Ol Kalou in Nyandarua County....................................................................... 124

Figure A.2. Map of Njabini in Nyandarua County......................................................................... 125

Figure A.3. Map of Mwea in Kirinyaga County.......................................................................... 126 


\section{General Introduction}

\subsection{Background}

Malnutrition in all its forms is one of the greatest challenges of the $21^{\text {st }}$ century. The main types of malnutrition include undernutrition, overnutrition and micronutrient deficiencies (FAO, 2013). The elimination of undernutrition has long been a major priority in development efforts. Worldwide, there has been remarkable progress in reducing this prevalence. Still, undernutrition remains a major public health problem especially in parts of South Asia and East and Central Africa (NCD Risk Factor Collaboration, 2016). It is estimated that approximately 800 million people are suffering from undernutrition, out of these, 156 million children under-five are currently stunted, meaning that they are too short for their age (FAO, 2015; IFPRI, 2016; UNICEF et al., 2015). While undernutrition is commonly associated with malnutrition, micronutrient deficiencies and overnutrition are increasingly posing a health threat. Recent studies estimate an approximate number of 2 billion people suffering from insufficient micronutrients and another 2 billion people being overweight and obese worldwide (FAO, 2013; NCD Risk Factor Collaboration, 2016; Ng et al., 2014). Globally, 39\% of adults are overweight and $13 \%$ are classified as obese. Although, the mean body mass index (BMI) in many developing countries is still lower than in high-income countries, the prevalence of a high BMI is rising rapidly also in low-income countries (NCD Risk Factor Collaboration, 2016). Together with these dietary shifts and an increasing sedentary lifestyle, overweight, obesity, and nutritionrelated non-communicable diseases (NR-NCDs), like diabetes, coronary heart diseases, and certain cancers are growing epidemically (NCD Risk Factor Collaboration, 2016; Ng et al., 2014; Rosin, 2008; 2015a, WHO, 2016a). By now, numbers for 2015 show that out of the worldwide total amount of approximately 57 million deaths, 40 million (70\%) were due to NCDs. Altogether, $78 \%$ of global NCD-related deaths occur in low- and middle-income countries (WHO, 2017). These problems are likely to grow further in the years and decades to come (Popkin, 2015; Popkin and Slining, 2013).

Being in an epidemiological and behavioral transition, many developing countries face a widespread coexistence of infectious and chronic diseases. Having people living in food insecurity and being undernourished, while people within the community or even in the same household suffer from obesity and NCDs, a double burden of malnutrition is acute in many of 
these countries (Sawaya et al., 2004; Steyn and Mchiza, 2014; Roemling and Qaim, 2013). Since changes in lifestyle, eating habits, and society are happening rapidly, prevention of new emerging health threats is even more difficult, especially as most developing countries are not aware of and do not have necessary experience in these fields (Dalal et al., 2011; Narayan et al., 2010; Okafor, 2012). Further, the double burden of malnutrition and related NCDs are also placing a substantial economic load on countries in terms of increased health care costs and reduced labor productivity (Bommer et al., 2017; Herman, 2013; World Economic Forum, 2011).

Causes for malnutrition and related health problems are complex and multidimensional. The availability of and access to sufficient, nutritious and safe food plus a balanced diet are key factors for fighting malnutrition in all its forms. Or put differently, consuming too little or too much energy or poor diets that are low in micronutrients and vitamins lead to undernutrition, overnutrition and micronutrient deficiencies (FAO, 2013). While in many developing countries especially the rural populations still consume a 'traditional' diet, high in locally available or ownproduced staples, nuts and vegetables, economic and social development are driving factors for transformation processes and fostering changes in diets. The so called 'nutrition transition' is a phenomenon describing different shifts in lifestyle, eating habits, and related diseases. Urbanization, technological changes for work, and an expansion of mass media cause an increased intake of processed foods, meat and dairy products, saturated and total fats, sugar and energy-dense beverages (Popkin and Ng, 2007; Popkin et al., 2012; Kennedy, 2013; Roemling and Qaim, 2013). While diets that are higher in energy content can be beneficial for people that suffer from having too little to eat, they foster overweight and obesity in others. The transformation in diets goes along with changes in the food systems in developing countries. The rapid diffusion of modern retails is often referred to as 'supermarket revolution' (T Reardon et al., 2012). This expansion of modern retail is mainly driven by a response to many interconnected forces, like increased incomes, urbanization, greater female labor participation and the desire to emulate Western culture (Traill et al., 2014). The influence of a growing number of supermarkets is not only associated with changes in purchasing location, shopping atmosphere, food prices, and types of foods but also in the way procurement systems are organized (Chege et al., 2015; T Reardon et al., 2012). Accordingly, the changes in supply chains do not only affect the retail systems and consumers but also farmers and their ways of production (Chege et al., 2015; Schipmann and Qaim, 2011). New technologies and new contractual arrangements between 
farmers and agribusiness firms cause a rising share of supermarkets in food retailing. In contrast to the supermarket expansion in developed countries, which already happened in the middle of the last century, the supermarket revolution in developing countries is happening at a much faster pace (Andersson et al., 2015; Chege et al., 2015; T Reardon et al., 2012; Timmer, 2009). These changes are often at the costs of traditional shops and daily markets (Reardon, 2011), but also constitute an alternative income source (Chege et al., 2015).

Although the diffusion of supermarkets happens in a rapid manner, the offer of fresh foods is rather slow. In comparison to traditional food retail formats, supermarkets tend to offer less fresh fruits and vegetables to the extent of a much wider variety of packed and (highly) processed foods (Rischke et al., 2015). The transformation in agri-food markets presents challenges and opportunities for farmers and consumers with profound implications for food consumption, nutrition, and health (Qaim, 2017). Possible influences on farmers are only one consequence of the modern retail formats. Other implications can be observed for the consumers. On the one hand, the way supermarket users decide on what they buy does highly influence the supply and organization in modern retails (Anand et al., 2015). Besides personal preferences, habitual and every-day shopping practices, customers' choices are also affected by changing lifestyles and society. On the other hand, as Hawkes (2008) and Traill et al. (2014) point out, not only the consumers' preferences shape the new retail outlets. Supermarkets and the way their business is organized also stimulate the consumers' food choices. Through pricing, advertising, positioning, and availability of different products they directly shape food preferences or create desires (Anand et al., 2015; Story et al., 2008).

Being confronted with the challenges of modern food systems, changing diets and the rising numbers of overweight and obesity, there is still an urgent need to tackle undernutrition. Facing undernutrition especially early in life can lead to delayed or impaired growth, triggering morbidity, mortality and a vicious circle since maternal undernutrition has adverse effects on pregnancy outcomes (Martins et al., 2011). It might seem illogical that societies are facing the problem of overnutrition, obesity and NCDs, while at the same time other members of the community or even the same family suffer from chronic energy and micronutrient deficiencies (Roemling and Qaim, 2013). But it is possible. While economic growth and increased affluence are potential drivers for changing dietary choices, overweight and obesity, they do not 
automatically lead to reductions in undernutrition (Vollmer et al., 2014). Remaining poverty, inequality as well as environmental and sociopolitical factors are responsible for causing and maintaining undernutrition in societies. Many interventions are trying to solve or cope with these underlying characteristics. Besides programs that provide food, cash, and nutrient supplements, enhancing maternal nutrition knowledge has been identified as one important channel to shape a healthy living environment for the whole household and to improve child nutrition (Hirvonen et al., 2016; Tabbakh and Freeland-Graves, 2016; World Bank, 2010). In this context, associations between maternal nutrition knowledge and young children's nutritional outcomes are well documented. What is much less understood, are the types of maternal nutrition knowledge that matter most, and that are possibly influencing older children and adolescents. Mainly there are two pathways and mechanisms through which maternal nutrition knowledge and nutritional outcomes are interrelated. First, assuming that mothers capitalize on their nutrition knowledge at any given level of household income and the food budget, household food availability, food choices, handling and sanitation practices are expected to change or to be maintained in a way that contributes to good nutritional outcomes (Variyam et al., 1999). Second, children and adolescents develop better, or maintain beneficial attitudes towards healthy dietary practices and lifestyles (Yabanc1 et al., 2014), something which can be influenced also by their peers and own (health) education. Enhanced nutritional attitudes are then expected to contribute to better dietary practices (Kigaru et al., 2015) and to improved long-term nutritional outcomes.

\subsection{Problem Statement}

Several papers deal with the linkage between supermarkets and farmers, their households' nutrition and income potentials when they are taking part in the supermarkets' procurement system (e.g. Andersson et al., 2015; Chege et al., 2015; Neven et al., 2009). While there seems to be a generally positive effect through the involvement of farmers in the supermarkets' procurement system, literature on supermarkets and the effects on consumers, their diets and nutritional outcomes show more diverse results. Regarding high-income countries the proximity to supermarkets and their wide range offer of diverse fresh and processed foods seem to be beneficial for the nutritional outcomes of consumers (Drewnowski et al., 2012; Laraia et al., 2004; Morland et al., 2006). However, there are some examples from developing countries which show different and controversial results. It is still not well understood how food choices are shaped and to what extent supermarkets play a role in the comprehensive dietary decision process 
where they are likely to influence nutritional outcomes. Given the few existing examples, the influences of supermarkets on consumers in developing countries cannot be regarded as necessarily positive or negative (Qaim, 2017). Based on linear estimations, one study from Tunis states positive associations with supermarket shopping and dietary quality of the modern retail users. By applying an instrumental variable (IV) approach on cross-sectional data, research from Guatemala and Kenya show negative relation in this context. Built on a large sample of urban and rural households, Asfaw (2008) finds supermarket shopping in Guatemala to increase caloric shares of partially and highly processed foods. With a sample of urban households in Kenya, Rischke et al. (2015) underline these findings. They depict that supermarket users have a greater caloric availability and higher food expenditure shares of highly and primary processed foods. Also for the impacts of supermarkets on nutritional outcomes the literature shows mixed results. After applying a Lewbel IV approach on data from urban adults in Indonesia, Umberger et al. (2015) do not find evidence for a link between supermarket shopping and higher BMI or the probability of being overweight or obese. Different to that and on top to the effects on diet, Asfaw (2008) derives positive effects of supermarket purchase on BMI and the probability of being overweight or obese. Comparably, and also on the basis of an IV approach, Kimenju et al. (2015) find urban supermarket users in Kenya to have higher BMI and a higher likelihood of being overweight or obese.

Almost all existing studies used cross-sectional data and IV techniques to draw causal inference about the effects of supermarket shopping on dietary choices and nutritional outcomes. We are not aware of any study that went beyond nutritional status and analyzed possible links between supermarkets and NR-NCDs. Here, we hypothesize that such a link exists, because overweight and obesity are known to increase the risk of NCDs (NCD Risk Factor Collaboration, 2016; Ng et al., 2014; Popkin, 2015). Better understanding possible health implications of the rapid spread of supermarkets could help in designing food and nutrition policies aimed at curbing the epidemic of NR-NCDs. Further, cross-section observational data have their limitations for robust impact assessment, because the causal inference relies on the validity of an instrument. Panel data are preferred for impact evaluation, because they help to reduce issues of unobserved heterogeneity with less restrictive assumptions. 
This dissertation comprises three essays. The first two essays directly address shortcomings in the existing literature about the effects of supermarkets on nutrition and health, building on data collected in urban Kenya. The first essay investigates the influence of supermarket purchase on NR-NCDs. The second essay focuses on the effects of supermarket shopping on nutritional outcomes and dietary choices using panel data. Both essays make use of a quasi-experimental setting, which allows us to compare households with easy supermarket access and households with no (or limited) supermarket access. The third essay focuses on the link between the type of maternal nutrition knowledge and child and adolescent nutritional outcomes.

While associations between maternal nutrition knowledge and young children's nutritional outcomes are well documented, it is much less understood, what type of maternal nutrition knowledge matters most, and which type possibly influences older children and adolescents. Examples from developing countries are mainly restricted to children under-five (e.g. Appoh and Krekling, 2005; Burchi, 2010; Webb and Block, 2004) as it is assumed that nutritional improvements are most beneficial for younger children (Black et al., 2013; Leroy et al., 2014; Ruel et al., 2008). Although a few studies found positive effects of different types of maternal nutritional knowledge on children above-five, the evidence is thin and limited to developed countries: based on a nationally representative sample of U.S. households, including children from 2 to 17 years, Variyam et al. (1999) built a maternal knowledge score out of questions on nutrient content and health awareness. They show positive effects of maternal knowledge on children's dietary quality. Similar to that and also based on an U.S. sample, Tabbakh and Freeland-Graves (2016) measure maternal nutritional knowledge based on combined knowledge about nutrient contents and recommendations. They found the nutritional knowledge of mothers to shape the home environment in such a way that it is positively associated with adolescents' dietary quality and negatively with adolescents' BMI. These studies base maternal nutrition knowledge on one or a maximum of two different components. In the third essay we aim at assessing more comprehensive types of maternal nutrition knowledge and their differentiated associations with nutritional outcomes of children above-five and adolescents. The analysis are based on a panel data set from urban Kenya. 


\subsection{Research Objectives}

The three essays in this dissertation focus on the links between supermarket shopping, dietary choices, nutritional outcomes and NR-NCDs, and the associations of maternal nutrition knowledge with child and adolescent nutritional outcomes. Specifically, the dissertation addresses the following research questions:

I. Does supermarket shopping increase the level of BMI and the probability of being overweight or obese?

II. Does supermarket shopping increase the outcomes of NR-NCDs?

III. Does supermarket shopping directly affect the nutrition transition in terms of dietary choices?

IV. Does maternal nutrition knowledge influence nutritional outcomes of children between 5 and 18 years?

V. Do different types of maternal nutrition knowledge result in differential results concerning child nutritional outcomes?

In order to address all research questions, Central Kenya is the chosen study region for all three essays in this dissertation. Kenya, which has one of the most prospering supermarket sectors in Sub-Saharan Africa, is of special interest for our analysis (Neven et al., 2009; Rischke et al., 2015). The share of national grocery sales through supermarkets is about $10 \%$ (Planet Retail, 2016). Further, Kenya provides an interesting study country given that malnutrition in all its forms is widespread. The share of adults being overweight or obese has risen to over $26 \%$ with steadily increasing NR-NCDs in recent years (Kenya National Bureau of Statistics, 2014; WHO, 2015a). The national prevalence of diabetes and hypertension is estimated at $2.5 \%$ and $35 \%$, respectively (International Diabetes Federation, 2015; WHO, 2015b). While the rates of overweight, obesity, and NCDs are growing, the prevalence of undernourished children underfive is still rather high. The share of Kenyan children being stunted is 35\%, 7\% are wasted, and 16\% are underweight (Matanda et al., 2014; Ministry of Public Health and Sanitation, 2012). As in most Kenyan regions, child undernutrition in Central Kenya has shown little or no improvement for over two decades after the year 1993 (Matanda et al., 2014). Given these multiple nutritional problems under a rapidly changing economy and society, Kenya represents a developing country like many African countries that urgently needs to account for these emerging 
nutritional challenges and improve the prevention of overweight, obesity and NCDs while also fighting hunger and undernutrition (IFPRI, 2016).

\subsubsection{Data}

Figure 1.1 shows a map of Kenya with the two Counties, Nyandarua and Kirinyaga, where the three towns $\mathrm{Ol} \mathrm{Kalou,} \mathrm{Njabini} \mathrm{and} \mathrm{Mwea} \mathrm{are} \mathrm{located} \mathrm{and} \mathrm{where} \mathrm{our} \mathrm{research} \mathrm{was} \mathrm{undertaken.}$

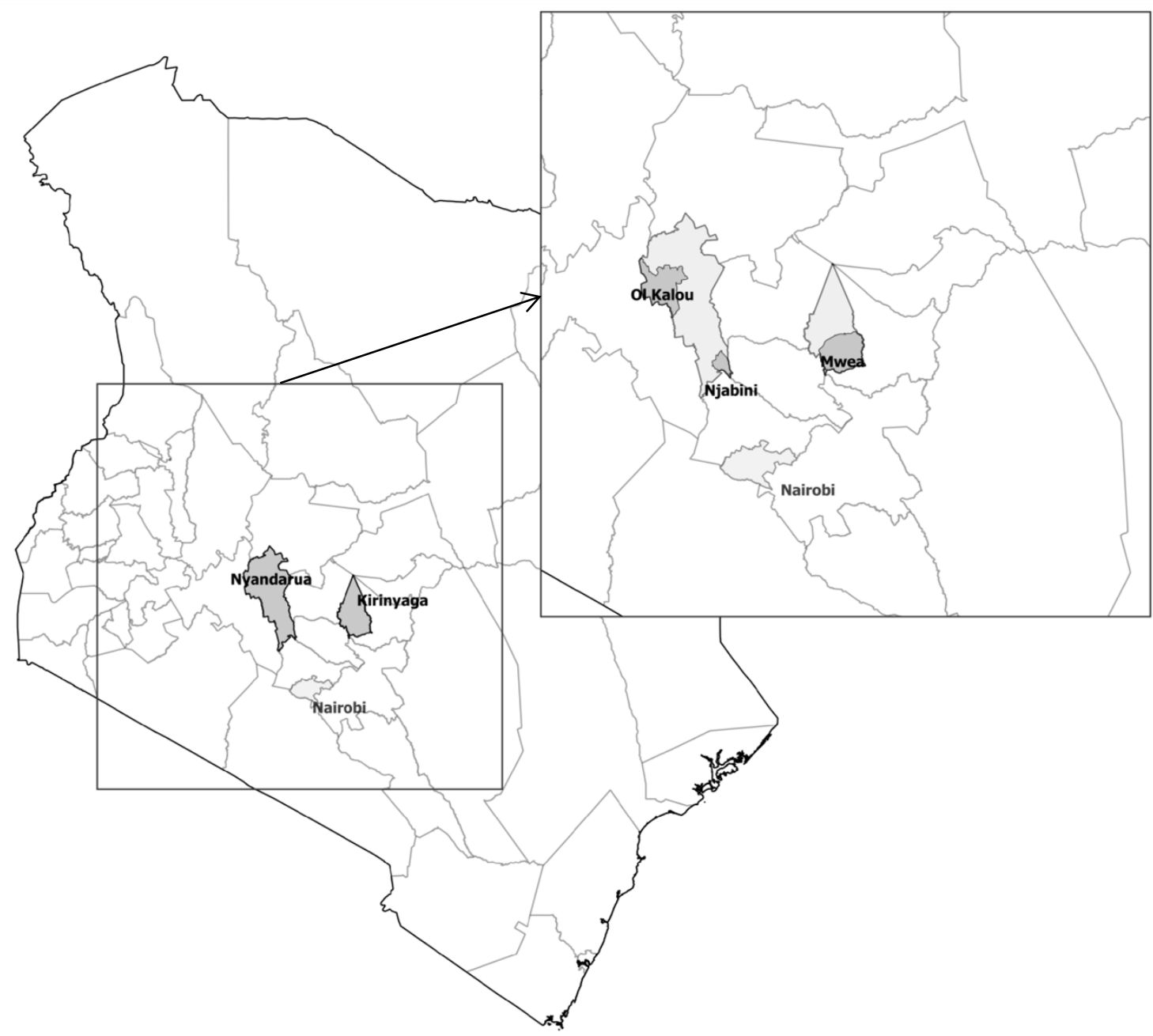

Figure 1.1. Map of Kenya with the study sites in the Counties Nyandarua and Kirinyaga. The zoomed in box shows the three towns Ol Kalou, Njabini and Mwea and their location in the two Counties. Map was created with QGIS (2015) based on data provided by Global Administrative Areas (2012).

All research questions are addressed by using data from the same three towns in urban Central Kenya in the years 2012 and 2015. In 2012, data collection was initiated, organized and implemented by Simon Kimenju and Ramona Rischke using systematic random sampling 
techniques in order to identify households and individuals. The team from 2012 kindly provided the collected data and allowed us to use it. ${ }^{1}$ The follow-up data collection in 2015 was planned and implemented by me. Here the same three towns and dwellings where followed up (see General Appendix, Maps of the Study Sides in Central Kenya). While comprehensive data on household and individual level, concerning socio demographic factors, food consumption, nutrition knowledge, and anthropometrics (de Haen et al., 2011) were collected in both rounds, measurements of bio-medical data (fasting blood glucose and blood pressure) were only performed in the year 2015 (see General Appendix, Household Survey 2015). In accordance with the ethical principles for research involving human subjects we obtained study approval from the Ethics-committee of the University Medical Center Goettingen, Germany (25/9/14), and the Kenyatta National Hospital Ethics and Research Committee (P192/04/2015) in Nairobi, Kenya. Permissions in the Kenyan Counties were obtained from Nyandarua (for the towns Ol Kalou and Njabini) and Kirinyaga (for Mwea) County Department of Health. Local authorizations were obtained from the County Commission and the respective deputy commissioner and chiefs in town. Leaders and elders were informed of the study. ${ }^{2}$

The essay in Chapter 2 is based on self-collected cross-sectional data from 2015 and includes all adults older than 18 years $(\mathrm{n}=550)$. The panel data set, containing data collected by Simon Kimenju and Ramona Rischke in 2012 and self-collected data from 2015 was the basis of the essays in Chapter 3 and 4. For the analysis in Chapter 3 all adults (> 18 years) from both years are included $(\mathrm{n}=1,199)$. The essay in Chapter 4 is based on the sample of children and adolescents between 5-18 years out of the panel data set $(n=426)$. Further details on the study design and the methodological approach can be found in the individual Chapters.

\footnotetext{
${ }^{1}$ Further details on the initiated data collection in 2012 can be found in Kimenju (2014) and Rischke (2014).

${ }^{2}$ In accordance with the Declaration of Helsinki (World Medical Association, 2013) all participants were asked of their written consent in order to participate in the study before interview and measurements (see General Appendix, Household Survey 2015, Declaration of Consent, p. 168). All results were reported for the study and copied for the participant's record. No human samples were kept. Follow-up care for detected clinical conditions was facilitated by referral to nearby district and county hospitals, respectively.
} 


\title{
2 Supermarket Purchase Contributes to Nutrition-Related Non- Communicable Diseases in Urban Kenya ${ }^{3}$
}

\begin{abstract}
While undernutrition and related infectious diseases are still pervasive in many developing countries, non-communicable diseases (NCD), typically associated with high body mass index (BMI), are rapidly on the rise. The fast spread of supermarkets and related shifts in diets were identified as possible factors contributing to overweight and obesity in developing countries. Potential effects of supermarkets on people's health have not been analyzed up till now. This study investigates the effects of purchasing food in supermarkets on people's BMI, as well as on health indicators such as fasting blood glucose (FBG), blood pressure (BP), and the metabolic syndrome. This study uses cross-section observational data from urban Kenya. Demographic, anthropometric, and bio-medical data were collected from 550 randomly selected adults. Purchasing food in supermarkets is defined as a binary variable that takes a value of one if any food was purchased in supermarkets during the last 30 days. In a robustness check, the share of food purchased in supermarkets is defined as a continuous variable. Instrumental variable regressions are applied to control for confounding factors and establish causality. Purchasing food in supermarkets contributes to higher BMI $\left(+1.8 \mathrm{~kg} / \mathrm{m}^{2}\right)(P<0.01)$ and an increased probability ( +20 percentage points) of being overweight or obese $(P<0.01)$. Purchasing food in supermarkets also contributes to higher levels of FBG $(+0.3 \mathrm{mmol} / \mathrm{L})(P<0.01)$ and a higher likelihood (+ 16 percentage points) of suffering from pre-diabetes $(P<0.01)$ and the metabolic syndrome $(+7$ percentage points $)(P<0.01)$. Effects on BP could not be observed. Supermarkets and their food sales strategies seem to have direct effects on people's health. In addition to increasing overweight and obesity, supermarkets contribute to nutrition-related NCDs. Effects of supermarkets on nutrition and health can mainly be ascribed to changes in the composition of people's food choices.
\end{abstract}

\footnotetext{
${ }^{3}$ This chapter is co-authored by Stephan Klasen, Jonathan M. Nzuma, and Matin Qaim. The authors' contributions are as follows: KMD, SK, and MQ designed the research. KMD collected, analyzed, and interpreted the data. JMN provided assistance in data collection. SK, JMN and MQ assisted in the analysis and interpretation of the results. KMD wrote the paper. All authors read and approved the final manuscript.
} 


\subsection{Introduction}

$\mathrm{W}$

hile undernutrition and related infectious diseases are still widespread problems in many developing countries (Food and Agriculture Organization of the United Nations (FAO), 2015), overweight, obesity, and nutrition-related noncommunicable diseases (NR-NCD) are growing epidemically (NCD Risk Factor Collaboration, 2016; Ng et al., 2014; World Health Organization (WHO), 2015c, 2016a). Seventy-five percent of all people with diabetes live in developing countries (International Diabetes Federation, 2015; World Health Organization (WHO), 2006a). Africa has the world's highest prevalence of hypertension (World Health Organization (WHO), 2013). Almost three-quarters of all worldwide NCD-related deaths occur in low-income and middle-income countries (World Health Organization (WHO), 2016a). These problems will likely grow further in the years and decades to come (Popkin, 2015; Popkin and Slining, 2013), also because most developing countries have little experience with diagnosing, treating, and preventing NCDs (Dalal et al., 2011; Narayan et al., 2010; Okafor, 2012). NCDs are placing a substantial economic and social burden on countries in terms of human suffering, increased health care costs, and reduced labor productivity (Herman, 2013; World Economic Forum, 2011).

It is widely known that "unhealthy" diets and physical inactivity contribute to overweight and obesity and hence higher prevalences of NR-NCDs (Institute of Medicine (U.S.), 2005). Depending on the stage of transition in a given society, changes in lifestyle and eating habits lead to an increased intake of processed foods, saturated and total fats, salt, sugar, and caloric beverages (Popkin and Ng, 2007; Popkin et al., 2012; Roemling and Qaim, 2013; Traill et al., 2014). The globalization of agri-food systems, with its rapid spread of supermarkets in developing countries, may contribute to the observed nutrition transition and thus also to overweight, obesity, and related NR-NCDs (Hawkes, 2008; Popkin, 2014; Qaim, 2017; Tilman et al., 2011). In this study, we analyze possible links between the spread of supermarkets, people's body mass index (BMI), and several other indicators of NR-NCDs.

What type of diets people consume and where they buy their food depends on their income, education, lifestyles, and various other socioeconomic factors. However, the food retail environment and the accessibility to different types of markets and shops can also play important roles (Qaim, 2017; Timmer, 2009). Modernization in the food retail sector is typically associated 
with changes in the types of foods offered, prices, packaging sizes, and shopping atmosphere. Especially in urban areas of developing countries, consumers increasingly buy their food in supermarkets instead of wet markets or other traditional retail outlets (Chege et al., 2015; Thomas Reardon et al., 2012; T Reardon et al., 2012; Timmer, 2009). Except for a few large supermarket stores in big cities, where fresh foods are also offered, many supermarket chains in developing countries primarily concentrate on selling processed foods, especially when they open up new stores in smaller towns (Minot et al., 2015; Rischke et al., 2015).

Recent research revealed significant associations between supermarket purchase and dietary shifts in different developing countries (Asfaw, 2008; Kimenju et al., 2015; Rischke et al., 2015; Tessier et al., 2008; Toiba et al., 2015; Umberger et al., 2015). While the concrete results differ and depend on the particular context, several studies showed that people buying in supermarkets tend to consume more energy and a higher share of processed foods (Asfaw, 2008; Rischke et al., 2015; Toiba et al., 2015; Traill et al., 2014). The consumption of highly processed food is often associated with higher overweight and obesity (Asfaw, 2011; Zhou et al., 2015). Studies carried out in Guatemala and Kenya suggested indeed that purchasing food in supermarkets tends to increase BMI and the likelihood of overweight and obesity, even after controlling for income and other possible confounding factors (Asfaw, 2008; Kimenju et al., 2015). We are not aware of any study that went beyond nutritional status and analyzed possible links between supermarkets and NR-NCDs. Better understanding possible health implications of the rapid spread of supermarkets could help in designing food and nutrition policies aimed at curbing the epidemic of NR-NCDs.

We contribute to the literature by investigating the effects of purchasing food in supermarkets on nutrition and health in Kenya. Kenya has experienced a rapid growth of supermarkets in recent years (Rischke et al., 2015). The share of national grocery sales through supermarkets in Kenya is about $10 \%$; when only focusing on larger cities the share is already much higher (Planet Retail, 2016). Kenya is still struggling with relatively high rates of child undernutrition. At the same time, NR-NCDs are growing problems. More than 26\% of all adults in Kenya are either overweight or obese (World Health Organization (WHO), 2015a). The national prevalence of diabetes and hypertension is estimated at $2.5 \%$ and $35 \%$, respectively (International Diabetes Federation, 2015; World Health Organization (WHO), 2015b). For this study, we collected data on food purchase and consumption behavior, other socioeconomic characteristics, nutrition, and 
health from randomly selected adults in urban areas of Central Kenya. We use regression models to estimate the effects of supermarket purchase on BMI, blood glucose, pre-diabetes, blood pressure, pre-hypertension, and the metabolic syndrome. Since BMI and the prevalence of NCDs can also be influenced by factors other than supermarket purchase, it is important to control for such confounding factors in the statistical analysis. We employ an instrumental variable (IV) approach, which helps to reduce endogeneity bias and establish causality with observational data.

\subsection{Materials and Methods}

\subsubsection{Ethics Statement}

This study was approved by the Ethics Commission of the University Medical Center Goettingen (http://www.ethikkommission.med.uni-goettingen.de/; study ID 25/9/14) and the Ethics and Research Committee of the Kenyatta National Hospital in Nairobi (http://erc.uonbi.ac.ke; study ID P192/04/2015). Written consent was obtained from each study participant.

\subsubsection{Study Design}

This study uses cross-sectional data collected in 2015 from households and individual household members in three small towns in Central Kenya. A focus on small towns was chosen because some of these towns already have a supermarket, while others have not. The three towns, Ol Kalou and Njabini in Nyandarua County and Mwea in Kirinyaga County, where purposively selected due to their supermarket characteristics. In Kenya, as in other developing countries, supermarket chains started their business in the big cities, now they are also expanding to smaller towns (Rischke et al., 2015). Ol Kalou has had a supermarket already since 2002 and Mwea since 2011. Njabini did not yet have a supermarket in 2015, although there were concrete plans to open one in the near future and the building was already constructed. Beyond having or not having a supermarket, the three towns are similar in terms of size, ethnic structure of the population, infrastructure conditions, and financial and social institutions (Kenya National Bureau of Statistics, 2010). This setup provides a quasi-experimental setting, allowing the comparison of consumers with varying degrees of supermarket exposure.

The sampling strategy for this study builds on an earlier household survey that was conducted in the same three towns in 2012 (Demmler et al., 2017; Kimenju et al., 2015; Rischke et al., 2015). In each town, households for inclusion were selected using systematic random sampling. Since 
recent census data were not available, population statistics and the help of local administrators were used. First, all neighborhoods (residential estates) were listed in each town. Then, for each neighborhood, household lists were compiled, from which households were selected randomly. To obtain a representative sample at town level and avoid clustering, households were selected from all neighborhoods. The 2012 data were collected to analyze the effects of supermarkets on consumers' diets and nutrition. Health indicators to analyze effects on NR-NCDs were not collected in 2012, but were added to the survey in 2015 .

The 2015 data, which are used in this study, were collected between May and July 2015. The survey comprised 433 randomly selected households. In these households, interviews were conducted and measurements were taken from 550 male and female adult household members above 18 years of age. The interviews were conducted in local languages (Kikuyu, Kiswahili, and English). All measurements, including weight, height, waist- and hip circumference, blood pressure, and fasting blood glucose, were taken by experienced local nurses, which were trained according to standards of anthropometric measurements by the Centers for Disease Control and Prevention (Centers for Disease Control and Prevention, 2007).

Interviews and measurements took place in participants' homes. Each household was visited twice. During the first visit, the interviews were conducted and appointments made for the second visit, during which measurements were taken. The second visits took place a few days later during early morning hours, as participants had to be fasting for the blood glucose measurements. In some cases, it was not possible to take fasting measurements. For the analysis of fasting blood glucose, pre-diabetes, and the metabolic syndrome only 496 adults from 400 households could be used, as non-fasting measurements had to be dropped. The means of key variables between the full sample and the smaller subsample were compared, without finding significant differences. About $5 \%$ of the randomly selected women were pregnant. We carried out all analyses with and without including pregnant women. As results were very similar in terms of directions and magnitudes, we decided to keep pregnant women in the sample, as the larger number of observations adds to statistical efficiency.

Power calculations showed that the sample with 550 observations, observed effect sizes, and a significance criterion of $95 \%$, yields statistical power ranging between 0.88 and 0.97 for the different nutrition and health indicators, thus exceeding common standards for adequacy. 


\subsubsection{Data}

Body weight measurements were taken from all adult individuals with an accuracy of $0.1 \mathrm{~kg}$ in minimum clothing and without shoes on a digital scale (range: 10-150 kg). Height was measured with portable stadiometers (SECA; range: 20-205 cm) with accuracy of $0.7 \mathrm{~cm}$ while standing upright, barefoot, and without headgear according to international standards (Centers for Disease Control and Prevention, 2007; de Onis et al., 2004). BMI was calculated from the body weight and height (BMI = body weight in $\mathrm{kg} /$ body height in meters squared) and classified according to WHO criteria (World Health Organization (WHO), 2014).

Fasting blood glucose $(\mathrm{FBG})$, which is an indicator of diabetes, was determined through one capillary blood drop using the finger prick procedure. Diabetes and pre-diabetes were defined according to criteria by the American Diabetes Association: a person was classified as being diabetic or pre-diabetic if his/her FBG exceeded $7.0 \mathrm{mmol} / \mathrm{L}$ or $5.6 \mathrm{mmol} / \mathrm{L}$, respectively (American Diabetes Association, 2006). Systolic blood pressure (SBP) and diastolic blood pressure (DBP) were determined by using a digital auscultatory blood pressure cuff. A SBP $\geq$ $140 \mathrm{mmHg}$ or a DBP $\geq 90 \mathrm{mmHg}$ were defined as hypertensive state; a SBP $\geq 120 \mathrm{mmHg}$ and a DBP $\geq 80 \mathrm{mmHg}$ were defined as pre-hypertensive state (World Health Organization (WHO), 2013). The metabolic syndrome (MetS) was defined according to the classifications of the International Diabetes Federation (International Diabetes Federation, 2006). As triglyceride levels and high-density-lipoprotein cholesterols were not measured, a person was classified as suffering from MetS when the following three conditions were all fulfilled: central obesity (waist circumference males $\geq 94 \mathrm{~cm}$; females $\geq 80 \mathrm{~cm})$, raised FBG $(\geq 5.6 \mathrm{mmol} / \mathrm{L})$, and raised blood pressure (SBP $\geq 130 \mathrm{mmHg} ; \mathrm{DBP} \geq 85 \mathrm{mmHg}$ ).

Food purchase and consumption decisions were captured through a 30-day food consumption recall at the household level. The person responsible for food purchases and food preparation was asked which of the 176 foods and drinks listed in the questionnaire had been consumed by any household member during the 30 days prior to the interview. Respondents were also asked to specify the quantities consumed of each food item, the source (supermarket, wet market, small shop, own production etc.), and the price. Household expenditures for non-food goods and services were also captured during the interviews. Total per capita consumption expenditures for food and non-food goods and services were used to measure household living standards. In the 
development economics literature, consumption expenditures are generally considered a more reliable indicator of living standards than income (Rischke et al., 2015).

\subsubsection{Statistical Methods}

All statistical analyses were conducted using Stata version 13 (StataCorp, College Station, Texas). The unit of analysis is the individual adult. At first, mean values of the nutrition and health outcome variables of interest are compared between individuals in households that did and did not buy food items in supermarkets. Buying in supermarkets means that at least some of the food items consumed during the 30 days prior to the survey were obtained from a supermarket. Not buying in supermarkets means that all of the food items consumed were obtained from traditional retail outlets or other sources. The nutrition and health outcomes considered for individual $i\left(\mathrm{NH}_{i}\right)$ are BMI $\left(\mathrm{kg} / \mathrm{m}^{2}\right)$, FBG $(\mathrm{mmol} / \mathrm{L}), \mathrm{SBP}(\mathrm{mmHg})$, and DBP $(\mathrm{mmHg})$, all measured as continuous variables. In addition, being classified as overweight/obese, pre-diabetic (including pre-diabetes and diabetes), pre-hypertensive (including pre-hypertension and hypertension), and suffering from MetS is captured through binary outcome variables.

Simple comparisons between households with and without supermarket purchase can provide a first impression of possible nutrition and health effects, but they should not be overinterpreted because observed differences in outcomes may also be caused by other factors. To control for possible confounding factors and estimate net effects of purchasing in supermarkets, regression models of the following type are estimated:

$$
N H_{i}=\beta_{0}+\beta_{1} S_{j}+\beta_{2} X_{i j}+u_{i j}
$$

where $S_{j}$ is the binary "treatment" variable defined as 1 if household $j$ (in which individual $i$ lives) purchased food items in a supermarket and 0 otherwise. $\boldsymbol{X}_{i j}$ is a vector of individual and household characteristics, including age, education, sex, living standard, and levels of physical activity, among others. $u_{i j}$ is a random error term.

As individuals and households decide themselves whether or not they purchase food in supermarkets, $S_{j}$ is likely endogenous. In particular, $S_{j}$ may be correlated with unobserved characteristics that could themselves have an effect on nutrition and health outcomes. Such a correlation could lead to selection bias (or omitted variable bias) in the estimation of the treatment effect, $\beta_{1}$. For instance, unobserved lifestyle factors could potentially cause such bias. 
To reduce selection bias and other possible problems of endogeneity, an instrumental variable approach is applied (Hill et al., 2008; Wooldridge, 2003).

\section{Instrumental Variable Approach}

The interpretation of causal effects with cross-section, observational data is possible when using an instrumental variable (IV) approach (Deaton, 2010). The IV approach helps to overcome problems of endogeneity with the treatment variable by replacing the potentially endogenous variable with predicted values, using one or more valid instruments in a two-stage estimation procedure. IV models are widely used in applied economics (Angrist and Krueger, 2001; Duflo, 2001; Gruber, 2000), but also in the nutrition and public health literature (Kimenju et al., 2015; Leigh and Schembri, 2004; Vellakkal et al., 2015). An instrument is valid if it is exogenous, correlated with the treatment variable, and uncorrelated with all outcome variables (Wooldridge, 2003). Previous studies that analyzed the effect of supermarket purchase on food choices and nutrition had used distance to the nearest supermarket as an instrument (Asfaw, 2008; Kimenju et al., 2015; Rischke et al., 2015). The same instrument is also employed here. Distance to the nearest supermarket from each individual home was measured through Global Positioning System (GPS) coordinates.

While the placement of supermarkets is not a random process, the decision is made by supermarket owners based on criteria that cannot be influenced by individual consumers. Both towns with a supermarket (Ol Kalou and Mwea) only had one supermarket, which was located in the town center, where many other shops were also found. Hence, the location of supermarkets was exogenously determined and not linked to socioeconomic characteristics of a particular neighborhood within the town. In order to double-check this assumption we used data from Njabini, the town where no supermarket had opened until 2015, and computed the correlation between supermarket purchase (some households in Njabini use supermarkets in other towns) and distance to the town center of Njabini (exactly the point where the building for the new supermarket was constructed). The correlation was insignificant $(r=0.03 ; P>0.10)$.

Distance to the nearest supermarket is closely correlated with supermarket purchase $(r=0.67)$. Table A2.1 in the Appendix A2 also confirms that distance to the nearest supermarket is highly significant in the first stage regression of the IV model, passing the test for a strong instrument. To examine whether distance to supermarket is correlated with any of the nutrition and health 
outcomes through mechanisms other than supermarket purchase, we used a simple test by additionally including the instrument in the set of models described in equation (2.1). While not being a standard overidentification test, this approach is widely used in the literature to evaluate the plausibility of the exclusion restriction when only one instrument is available (Andersson et al., 2015; Di Falco et al., 2011). Test results are shown in Tables A2.2 and A2.3 in the Appendix A2. Supermarket distance was not statistically significant in any of these models $(P>0.10)$. Hence, distance to supermarket seems to fulfill all requirements for a valid instrument.

The IV models are specified as follows:

$$
\begin{aligned}
& S_{j}=\propto_{0}+\propto_{1} D_{j}+\propto_{2} \boldsymbol{X}_{i j}+\varepsilon_{i j} \\
& N H_{i}=\delta_{0}+\delta_{1} \hat{S}_{j}+\delta_{2} \boldsymbol{X}_{i j}+\omega_{i j}
\end{aligned}
$$

Equation (2.2) is the first stage selection equation, whereas equation (2.3) is the outcome equation. $D_{j}$ is the instrument, distance to the nearest supermarket measured in $\mathrm{km} . \hat{S}_{j}$ is the instrumented treatment variable resulting from predictions based on the selection equation. Thus, $\delta_{1}$ can be interpreted as the unbiased treatment effect. $\varepsilon_{i j}$ and $\omega_{i j}$ are random error terms. The other variables are defined as above. These models were estimated with Stata IV estimators. For the binary outcome variables, a linear probability IV specification was used. For comparison, ordinary least-squares (OLS) estimators without instrumental variable were also employed. In all models, standard errors are cluster-corrected at town level to avoid problems of heteroskedasticity.

\section{Robustness Checks}

Several tests are used to check how robust the estimation results are to variations in model specifications or changes in some of the other underlying assumptions. A first test relates to the models with binary outcome variables. Instead of the linear probability specifications that we use in the main part of the analysis, we re-run the models with standard probit and IV probit specifications, in order to see whether the estimated effects change.

A second test relates to the definition of purchasing food in supermarkets as treatment variable. In the main analysis, we use a binary treatment variable that takes a value of 1 if the household purchased any food in a supermarket during the last 30 days and 0 otherwise. However, 
supermarket users typically also use traditional retail outlets, meaning that they only purchase parts of their total food in supermarkets. If supermarkets affect people's diets, nutrition, and health, we would expect that the effects increase with higher shares of food purchased in supermarkets. Such a dose dependency is tested by using a continuous treatment variable "share of supermarket purchase", defined as the percentage share of supermarket food expenditures in total household food expenditures during the last 30 days.

A third test relates to the assumptions in the IV modeling approach. IV models are a common statistical tool to reduce endogeneity bias and establish causality in impact evaluations with observational data. However, the reliability of results depends on the validity of the instrument, which is hard to prove beyond any possible doubt. An alternative approach to reduce issues of endogeneity without the need for an instrument is to use a statistical differencing technique with individual fixed effects (Wooldridge, 2003). This requires panel data. While we do not have panel data for the health outcomes of interest, we do have panel data for the socioeconomic and nutrition variables by combining the 2015 survey with the data collected in 2012 in the same three towns (Kimenju et al., 2015; Rischke et al., 2015). The sample in 2012 and 2015 was not identical, but there was a significant overlap in households and individuals, so that panel data models can be estimated. We use a panel data model for BMI with fixed effects and random effects specifications to check the robustness of the IV results. The advantage of the fixed effects specification is that any time-invariant heterogeneity at individual, household, or town level, whether observed or unobserved, is properly controlled for.

\subsection{Results}

Out of all 550 study participants, more than half (292) lived in households that purchased food in supermarkets; the rest (258) lived in households that did not buy any food in supermarkets during the 30 days prior to the survey. Descriptive statistics and definitions for the nutrition and health outcomes and the explanatory variables used in the analysis are shown in Table 2.1. 
Table 2.1. Descriptive statistics for adults in households that buy and do not buy food in supermarkets

\begin{tabular}{|c|c|c|c|c|}
\hline Variable & Definition & All & Does not buy in SM & Buys in SM \\
\hline Body mass index & Body mass index in $\mathrm{kg} / \mathrm{m}^{2}$ & $25.99(5.23)$ & $25.15(4.92)$ & $26.74 * * *(5.38)$ \\
\hline Underweight & $=1$ if BMI $\left(\right.$ in $\left.\mathrm{kg} / \mathrm{m}^{2}\right)<18.5$ & $0.04(0.20)$ & $0.04(0.20)$ & $0.04(0.19)$ \\
\hline Overweight & $=1$ if BMI (in $\left.\mathrm{kg} / \mathrm{m}^{2}\right) \geq 25.0$ and $<30.0$ & $0.32(0.47)$ & $0.26(0.44)$ & $0.36 * *(0.48)$ \\
\hline Obese & $=1$ if BMI $\left(\right.$ in $\left.\mathrm{kg} / \mathrm{m}^{2}\right) \geq 30.0$ & $0.22(0.41)$ & $0.18(0.39)$ & $0.25^{*}(0.43)$ \\
\hline Overweight/obese & $=1$ if BMI $\left(\right.$ in $\left.\mathrm{kg} / \mathrm{m}^{2}\right) \geq 25.0$ & $0.53(0.50)$ & $0.45(0.50)$ & $0.61 * * *(0.49)$ \\
\hline Fasting blood glucose a & Fasting blood glucose in $\mathrm{mmol} / \mathrm{L}$ & $5.04(1.37)$ & $4.99(1.54)$ & $5.07(1.20)$ \\
\hline Pre-diabetic ${ }^{\text {a }}$ & $=1$ if $\mathrm{FBG}($ in $\mathrm{mmol} / \mathrm{L}) \geq 5.6$ & $0.15(0.36)$ & $0.10(0.30)$ & $0.20 * * *(0.40)$ \\
\hline Diabetic $^{\text {a }}$ & $=1$ if $\mathrm{FBG}($ in $\mathrm{mmol} / \mathrm{L}) \geq 7.0$ & $0.03(0.18)$ & $0.03(0.18)$ & $0.03(0.18)$ \\
\hline Systolic blood pressure & Systolic blood pressure in $\mathrm{mmHg}$ & $132.42(21.57)$ & $134.54(23.69)$ & $130.54 * *(19.35)$ \\
\hline Diastolic blood pressure & Diastolic blood pressure in $\mathrm{mmHg}$ & $86.65(13.06)$ & $87.48(14.02)$ & $85.91(12.13)$ \\
\hline Pre-hypertensive & $=1$ if SBP/DBP (in mmHg) $\geq 120 / \geq 80$ & $0.82(0.38)$ & $0.83(0.38)$ & $0.82(0.39)$ \\
\hline Hypertensive & $=1$ if SBP/DBP (in $\mathrm{mmHg}$ ) $\geq 140 / \geq 90$ & $0.41(0.49)$ & $0.43(0.50)$ & $0.39(0.49)$ \\
\hline Metabolic syndrome $^{a}$ & $\begin{array}{l}=1 \text { if all } 3 \text { of the following criteria are fulfilled: waist circumference (in cm) } \\
\quad \text { for F/M }>80 />94 ; \mathrm{SBP} / \mathrm{DBP}(\text { in } \mathrm{mmHg}) \geq 130 / \geq 85 ; \mathrm{FBG}(\text { in } \mathrm{mmol} / \mathrm{L} \text { ) } \\
\quad \geq 5.6\end{array}$ & $0.07(0.26)$ & $0.06(0.23)$ & $0.08(0.28)$ \\
\hline $\begin{array}{l}\text { Share of supermarket } \\
\text { purchase }(\%)\end{array}$ & $\begin{array}{l}\text { Share of total household food expenditures from food purchases in } \\
\text { supermarkets within the last 30d }\end{array}$ & $7.25(11.01)$ & $0.00(0.00)$ & $13.65 * * *(11.88)$ \\
\hline Expenditure per capita & $\begin{array}{l}\text { Total (food and non-food) expenditures per capita of the last } 30 \mathrm{~d} \text { in } 1000 \\
\text { Kenyan shilling }\end{array}$ & $14.16(9.34)$ & $11.70(7.36)$ & $16.33 * * *(10.32)$ \\
\hline Education & School education in years of attendance & $9.67(3.49)$ & $8.72(3.61)$ & $10.52 * * *(3.14)$ \\
\hline Intensive work & $\begin{array}{l}\text { Physical effort demanded for work within the last } 7 \mathrm{~d} \text { (self-estimated on a } \\
\text { scale } 1-4 \text { ) multiplied by typical amount of work (considering occupational } \\
\text { activities within the last } 6 \mathrm{mo} \text { ) in } \mathrm{h} / \mathrm{wk}\end{array}$ & $123.02(77.35)$ & $124.47(85.32)$ & $121.74(69.68)$ \\
\hline Physical activity & $\begin{array}{l}\text { All leisure time physical activity (including walking) within the last } 30 \mathrm{~d} \text { in } \\
\mathrm{h} / \mathrm{wk}\end{array}$ & $15.98(11.06)$ & $16.85(11.24)$ & $15.21 *(10.86)$ \\
\hline Distance to hospital & Distance to nearest district hospital from home ${ }^{\mathrm{b}}$, in $\mathrm{km}$ & $10.57(7.09)$ & $12.82(3.92)$ & $8.57 * * *(8.53)$ \\
\hline Age & Age in y & $38.10(12.29)$ & 40.18 (14.09) & $36.26 * * *(10.11)$ \\
\hline Female & $=1$ if being female & $0.75(0.43)$ & $0.71(0.46)$ & $0.79 * *(0.41)$ \\
\hline Married & $=1$ if being married & $0.75(0.43)$ & $0.73(0.45)$ & $0.76(0.43)$ \\
\hline Household size & $\begin{array}{l}\text { Count of all household members that were either household head or } \geq 180 \mathrm{~d} \\
\text { present in the household within the last } 365 \mathrm{~d}\end{array}$ & 4.45 (1.97) & $4.79(2.29)$ & $4.15 * * *(1.58)$ \\
\hline History diabetes & $\begin{array}{l}=1 \text { if either mother, father, grandparents or siblings suffer(ed) from diabetes } \\
\text { type } 2\end{array}$ & $0.21(0.41)$ & $0.20(0.40)$ & $0.22(0.42)$ \\
\hline
\end{tabular}

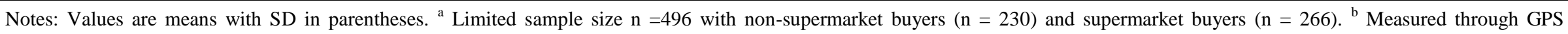

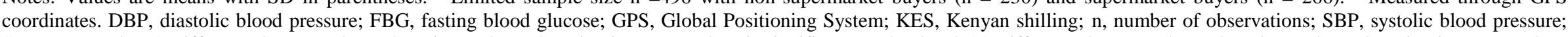

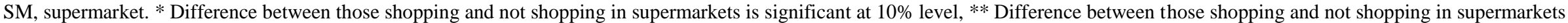
is significant at 5\% level; *** Difference between those shopping and not shopping in supermarkets is significant at $1 \%$ level. 
Mean BMI is significantly higher among those that purchased food in supermarkets. Similarly, prevalences of overweight and obesity are also significantly higher among individuals that purchased food in supermarkets. For the health variables, the comparison is more mixed. While supermarket buyers are more likely to be pre-diabetic, they have lower mean blood pressure levels than non-supermarket buyers. For the other health indicators, no significant differences between the two groups can be observed.

\subsubsection{Supermarket Effects on Nutrition and Health}

Tables 2.2 and 2.3 provide results of the IV model estimates for the continuous and binary nutrition and health outcome variables. Looking at Table 2.2, statistically significant effects of purchasing food in supermarkets on BMI and FBG can be seen. After controlling for confounding factors, purchasing food in supermarkets increases BMI by $1.82 \mathrm{~kg} / \mathrm{m}^{2}$ and FBG by $0.30 \mathrm{mmol} / \mathrm{L}$.

Table 2.2. Regression results forthe effects of supermarkets on BMI, fasting blood glucose, systolic and diastolic blood pressure

\begin{tabular}{|c|c|c|c|c|}
\hline & $\operatorname{BMI}\left(\mathrm{kg} / \mathrm{m}^{2}\right)$ & $\mathrm{FBG}(\mathrm{mmol} / \mathrm{L})$ & $\mathrm{SBP}(\mathrm{mmHg})$ & DBP (mmHg) \\
\hline Buys in supermarket & $1.82 * * *(0.24)$ & $0.30 * * *(0.06)$ & $1.98(1.33)$ & $1.23(0.86)$ \\
\hline Expenditure per capita, $1000 \mathrm{KES}$ & $0.11 * * *(0.02)$ & $0.01 * * *(0.00)$ & $-0.03(0.05)$ & $0.03(0.04)$ \\
\hline Education, y & $-0.00(0.10)$ & $-0.01(0.01)$ & $-0.42 * * *(0.14)$ & $-0.21 * *(0.10)$ \\
\hline Intensive work, $\mathrm{h} / \mathrm{wk}$ & $0.01 * *(0.00)$ & $0.00(0.00)$ & $0.00(0.01)$ & $-0.00(0.00)$ \\
\hline Physical activity, h/wk & $-0.02 * *(0.01)$ & $0.00(0.00)$ & $-0.01(0.02)$ & $-0.01(0.01)$ \\
\hline Age, y & $0.11 * * *(0.03)$ & $0.02 * * *(0.00)$ & $0.88 * * *(0.02)$ & $0.41 * * *(0.02)$ \\
\hline Distance to hospital, $\mathrm{km}$ & $0.05^{* * *}(0.00)$ & $0.02 * * *(0.00)$ & $-0.09(0.10)$ & $0.01(0.07)$ \\
\hline Female & $3.59 * * *(0.28)$ & $0.20 * *(0.09)$ & $-4.84 * *(2.31)$ & $-2.81 * *(1.39)$ \\
\hline Married & $1.01 * *(0.45)$ & $-0.11(0.13)$ & $-0.04(1.41)$ & $0.56(0.51)$ \\
\hline Household size & $-0.12 * * *(0.04)$ & $-0.01(0.04)$ & $-1.21 * * *(0.25)$ & $-0.54 * * *(0.09)$ \\
\hline Smoking & $-2.14 * * *(0.65)$ & $-0.17(0.14)$ & $-12.57 * * *(1.40)$ & $-7.30 * * *(1.78)$ \\
\hline History diabetes & & $0.26 *(0.14)$ & & \\
\hline History heart attack & & & $-0.08(0.36)$ & $-0.49(1.94)$ \\
\hline Constant & $15.31 * * *(2.15)$ & $3.46^{* * *}(0.19)$ & $112.80 * * *(5.62)$ & $76.73 * * *(2.92)$ \\
\hline R-squared & 0.23 & 0.07 & 0.28 & 0.17 \\
\hline Number of observations & 550 & 496 & 550 & 550 \\
\hline
\end{tabular}

Notes: Coefficient estimates of instrumental variable (IV) models are shown with standard errors in parentheses. Standard errors are cluster-corrected at town level. "Distance to nearest supermarket" was used as instrument for "buys in supermarket". BMI, body mass index; DBP, diastolic blood pressure; FBG, fasting blood glucose; SBP, systolic blood pressure. * Significant at $10 \%$ level; ** Significant at $5 \%$ level; *** Significant at $1 \%$ level. 
These effects are further underlined by the results in Table 2.3, showing that purchasing food in supermarkets increases the prevalence of overweight and obesity, pre-diabetes, and MetS. Buying food in a supermarket increases the likelihood of overweight/obesity by 20 percentage points, the likelihood of being pre-diabetic by 16 percentage points, and the likelihood of suffering from MetS by 7 percentage points, holding all other factors constant. For comparison, OLS estimates of the same models are shown in Tables A2.4 and A2.5 in the Appendix A2.

Table 2.3. Regression results for the effects of supermarkets on the probability of being overweight/obese, pre-diabetic, pre-hypertensive, and suffering from metabolic syndrome

\begin{tabular}{|c|c|c|c|c|}
\hline & Overweight/obese & Pre-diabetic & Pre-hypertensive & MetS \\
\hline Buys in supermarket & $0.204 * * *(0.02)$ & $0.164 * * *(0.01)$ & $-0.014(0.02)$ & $0.068 * * *(0.01)$ \\
\hline Expenditure per capita, $1000 \mathrm{KES}$ & $0.008 * * *(0.00)$ & $0.001(0.00)$ & $-0.000(0.00)$ & $0.000(0.00)$ \\
\hline Education, y & $0.014 *(0.01)$ & $-0.001(0.00)$ & $-0.001(0.00)$ & $-0.006^{* *}(0.00)$ \\
\hline Intensive work, h/wk & $0.001 * *(0.00)$ & $0.000(0.00)$ & $-0.000(0.00)$ & $0.000(0.00)$ \\
\hline Physical activity, h/wk & $-0.001(0.00)$ & $0.001(0.00)$ & $0.001(0.00)$ & $0.000(0.00)$ \\
\hline Age, y & $0.010 * * *(0.00)$ & $0.006^{* * *}(0.00)$ & $0.006 * * *(0.00)$ & $0.005^{* * *}(0.00)$ \\
\hline Distance to hospital, km & $0.005 * * *(0.00)$ & $0.001 *(0.00)$ & $-0.003 * * *(0.00)$ & $0.001 * * *(0.00)$ \\
\hline Female & $0.258 * * *(0.04)$ & $0.008(0.01)$ & $-0.050 * * *(0.02)$ & $0.017(0.02)$ \\
\hline Married & $0.077(0.05)$ & $0.021 * * *(0.01)$ & $-0.034 * *(0.02)$ & $0.041(0.03)$ \\
\hline Household size & $-0.005(0.01)$ & $0.004(0.01)$ & $-0.013(0.01)$ & $-0.001(0.00)$ \\
\hline Smoking & $-0.204 * * *(0.03)$ & $0.034 * * *(0.01)$ & $-0.002(0.03)$ & $\begin{array}{c}-0.050^{* * *} \\
(0.02)\end{array}$ \\
\hline History diabetes & & $0.096 * *(0.04)$ & & \\
\hline History heart attack & & & $0.105 * * *(0.03)$ & \\
\hline History diabetes/heart attack & & & & $0.071 * * *(0.01)$ \\
\hline Constant & $-0.537 * * *(0.16)$ & $-0.289 * *(0.12)$ & $0.776 * * *(0.04)$ & $\begin{array}{c}-0.172 * * * \\
(0.03)\end{array}$ \\
\hline R-squared & 0.18 & 0.07 & 0.05 & 0.08 \\
\hline Number of observations & 550 & 496 & 550 & 496 \\
\hline
\end{tabular}

Notes: Coefficient estimates of instrumental variable (IV) linear probability models are shown with standard errors in parentheses. Standard errors are cluster-corrected at town level. "Distance to nearest supermarket" was used as instrument for "buys in supermarket". Overweight/obese: BMI $\geq 25 \mathrm{~kg} / \mathrm{m}^{2}$; Pre-diabetic: FBG (in $\mathrm{mmol} / \mathrm{L}$ ) $\geq 5.6$ (also includes diabetic with FBG $\geq 7.0$ ); Pre-hypertensive: SBP/DBP (in $\mathrm{mmHg}$ ) $\geq 120 / 80$ (also includes hypertensive with SBP/DBP $\geq 140 / 90$ ); Metabolic syndrome (MetS): defined through three parameters: waist circumference (in $\mathrm{cm}$ ) $\mathrm{F} / \mathrm{M}>80 / 94 \mathrm{plus} \mathrm{SBP} / \mathrm{DBP}$ (in $\mathrm{mmHg}$ ) $\geq$ $130 / 85$ and FBG (in $\mathrm{mmol} / \mathrm{L}$ ) $\geq 5$.6. DBP, diastolic blood pressure; FBG, fasting blood glucose; MetS, metabolic syndrome; SBP, systolic blood pressure * Significant at $10 \%$ level; ** Significant at 5\% level; *** Significant at $1 \%$ level.

\subsubsection{Other Factors influencing Nutrition and Health Outcomes}

Looking at the socioeconomic control variables in Tables 2.2 and 2.3, it can be seen that household per capita expenditure, which is used to measure living standards, has a significantly positive effect on BMI, as well as on the likelihood of being overweight or obese. Similarly, 
positive effects on BMI and overweight/obesity are found for being female and being married. Holding other factors constant, female adults have a $3.6 \mathrm{~kg} / \mathrm{m}^{2}$ higher BMI and are 26 percentage points more likely to be overweight/obese than male adults. Being female is also positively related with FBG, but negatively related with blood pressure. Smoking is negatively related with BMI and overweight/obesity, but also with blood pressure, which is rather unexpected as smoking was identified as one of the major contributors to any coronary heart diseases (World Health Organization (WHO), 2013). It should be mentioned that the number of self-reported smokers in our sample is very small; the negative association of smoking with blood pressure may possibly be due to measurement error and/or unobserved lifestyle factors. Family histories of diabetes and heart attack are positively associated with the likelihood of suffering from prediabetes, pre-hypertension, and MetS. Age is positively associated with all nutrition and health outcomes, implying that older people are more likely to be overweight/obese and to suffer from NR-NCDs.

\subsubsection{Robustness Checks}

Standard probit and IV probit specifications for the models with binary outcome variables are shown in Table A2.6 in the Appendix A2. These alternative estimates lead to similar results as the linear probability models in Table 2.3.

The results with the continuous treatment variable "share of supermarket purchase" are summarized in Tables 2.4 and 2.5 (full results are shown in Tables A2.7 and A2.8). These alternative estimates confirm the general findings obtained with the binary treatment variable: the signs and significance levels of the treatment effects are identical to those in Tables 2.2 and 2.3. A one percentage point increase in the share of food purchased in supermarkets leads to a 0.15 $\mathrm{kg} / \mathrm{m}^{2}$ higher BMI and a $0.02 \mathrm{mmol} / \mathrm{L}$ increase in fasting blood glucose (Table 2.4). Similarly, a one percentage point increase in the share of food purchased in supermarkets raises the probability of being overweight/obese by 1.6 percentage points, the probability of being prediabetic by 1.3 percentage points, and the probability of suffering from MetS by 0.5 percentage points (Table 2.5). It should be stressed that for many households in the sample the share of supermarket purchase is still quite low (14\% on average). The continuous treatment effects are point estimates, which should not be extrapolated linearly over wide variations of the treatment variable. Nevertheless, the estimates clearly suggest that there is a dose dependency. We also 
estimated alternative models with the continuous treatment variable, but only using the subsample of supermarket users. These alternative models yielded results that are very similar to the full-sample results in Tables 2.4 and 2.5 .

Table 2.4. Regression results for the effects of supermarket purchase (\%) on BMI, fasting blood glucose, systolic and diastolic blood pressure

\begin{tabular}{lcccc}
\hline \hline & $\mathrm{BMI}\left(\mathrm{kg} / \mathrm{m}^{2}\right)$ & FBG $(\mathrm{mmol} / \mathrm{L})$ & $\mathrm{SBP}(\mathrm{mmHg})$ & $\mathrm{DBP}(\mathrm{mmHg})$ \\
\hline Share of supermarket & $0.15^{* * *}(0.02)$ & $0.02^{* * *}(0.00)$ & $0.16(0.11)$ & $0.10(0.07)$ \\
purchase, $\%$ & $14.22 * * *(2.18)$ & $3.30^{* * *}(0.21)$ & $111.61 * * *(6.34)$ & $75.99 * * *(3.32)$ \\
Constant & 550 & 496 & 550 & 550 \\
Number of observations & & &
\end{tabular}

Notes: Coefficient estimates of instrumental variable (IV) models are shown with standard errors in parentheses. Standard errors are cluster-corrected at town level. "Distance to nearest supermarket" was used as instrument for "share of supermarket purchase". Control variables are not shown for brevity. Full results are provided in Table A2.7. BMI, body mass index; DBP, diastolic blood pressure; FBG, fasting blood glucose; SBP, systolic blood pressure. * Significant at $10 \%$ level; ** Significant at $5 \%$ level; *** Significant at $1 \%$ level.

Table 2.5. Regression results for the effects of supermarket purchase (\%) on the probability of being overweight/obese, pre-diabetic, pre-hypertensive, and suffering from metabolic syndrome

\begin{tabular}{lcccc}
\hline \hline & Overweight/Obese & Pre-diabetic & Pre-hypertensive & MetS \\
\hline Share of supermarket & $0.016^{* * *}(0.00)$ & $0.013^{* * *}(0.00)$ & $-0.001(0.00)$ & $0.005^{* * *}(0.00)$ \\
purchase, $\%$ & $-0.660^{* * *}(0.16)$ & $-0.379^{* * *}(0.13)$ & $0.784 * * *(0.05)$ & $-0.209 * * *(0.03)$ \\
Constant & 550 & 496 & 550 & 496 \\
Number of observations & 550 & .
\end{tabular}

Notes: Coefficient estimates of instrumental variable (IV) linear probability models are shown with standard errors in parentheses. Standard errors are cluster-corrected at town level. "Distance to nearest supermarket" was used as instrument for "share of supermarket purchase". Control variables are not shown for brevity. Full results are provided in Table A2.8. MetS, metabolic syndrome. * Significant at $10 \%$ level; ** Significant at $5 \%$ level; *** Significant at $1 \%$ level.

As explained, in a final robustness check we used a panel data model for BMI to estimate the effect of supermarket purchase without the need for an instrument. Fixed effects and random effects specifications of this panel data model confirm a positive and significant effect of supermarket purchase on BMI (Table A2.9). These robustness checks suggest that the general findings are not driven by a particular type of model specification, by the definition of the treatment variables, the choice of instrument, or unobserved lifestyle factors. 


\subsection{Discussion}

\subsubsection{Study Limitations}

We have analyzed the effects of purchasing food in supermarkets on NR-NCDs among urban adults in Kenya. The methodological approach used has a few limitations. First, the observational data are cross-section in nature, which complicates the identification of causal effects. We used an IV modeling approach to control for confounding factors and reduce possible issues of endogeneity. For BMI, the effects were also confirmed with a panel data model, but for the health outcomes no panel data were available. Repeated collection of data for all relevant outcome variables through additional survey rounds would help to further test the robustness of the estimation results. Second, and related to the previous point, classifying health status based on single measurements can be imprecise, especially for health outcomes such as diabetes or hypertension. Employing well-trained and experienced nurses, using reliable clinical instruments, and taking all measurements at the same time of the day, as done in this study, can reduce sources of imprecision, but not completely. Third, due to budget constraints we were only able to collect certain health indicators and not others that could have been useful as well. For instance, the classification of MetS here was based on only three factors, instead of five that are commonly used (Alberti et al., 2006). Only considering three factors may lead to an underestimation of the true number of people suffering from MetS. Fourth, data were only collected in three towns. While these three towns are typical for medium-sized urban municipalities in Central Kenya, the sample is not representative for the country as a whole.

\subsubsection{Rising Rates of Nutrition-Related Non-Communicable Diseases}

In spite of the mentioned limitations, the results contribute to the literature because this is the first study that has attempted to analyze the effects of the spread of supermarkets on NR-NCDs in developing countries. In Kenya, as in many other developing countries, rapidly rising prevalence rates of obesity and NR-NCDs are observed, so that a better understanding of causes and contributing factors is important from public health and policy perspectives. In the study region in Central Kenya, mean BMI among adults was $26.0 \mathrm{~kg} / \mathrm{m}^{2}$ during the survey in 2015 . The 2012 data collected in the same three towns showed a mean BMI of $24.9 \mathrm{~kg} / \mathrm{m}^{2}$ (Kimenju et al., 2015). Hence, mean BMI increased considerably within a period of only three years. Similarly, between 
2012 and 2015 the prevalence of overweight has increased from $27 \%$ to $32 \%$, and the prevalence of obesity from $14 \%$ to $22 \%$.

A study with data collected in 2010 in Nairobi reported a prevalence of hypertension of $23 \%$ (Joshi et al., 2014), compared to a prevalence of hypertension of $41 \%$ in the 2015 sample used here. Furthermore, $15 \%$ of the individuals in the sample used here suffered from pre-diabetes and 7\% from MetS in 2015. Our estimated prevalence of pre-diabetes is higher than other available estimates for Kenya: according to the 2015 estimates of the International Diabetes Federation (IDF), the national prevalence of pre-diabetes in Kenya is 9.5\% (International Diabetes Federation, 2015). While we do not claim to have nationally representative data, our higher prevalence of $15 \%$ may still be more realistic. For most developing countries, IDF statistics are based on estimates and extrapolations using doctors' records rather than data from representative samples (Bommer et al., 2017; International Diabetes Federation, 2015). Doctors' records may underestimate the prevalence of NR-NCDs, because many people in developing countries do not see a doctor on a regular basis.

\subsubsection{Summary of Supermarket Effects}

The regression results suggest that the spread of supermarkets contributes to rising body weight. Buying food in supermarkets instead of (or in addition to) traditional retail outlets was shown to increase BMI by $1.82 \mathrm{~kg} / \mathrm{m}^{2}$, after controlling for confounding factors. Relatedly, supermarket purchase increases the likelihood of being overweight or obese by 20 percentage points. The directions and the magnitudes of these results are consistent with earlier studies carried out in Kenya and Guatemala (Asfaw, 2008; Kimenju et al., 2015). The analysis also revealed that buying food in supermarkets increases FBG by $0.30 \mathrm{mmol} / \mathrm{L}$ and the likelihood of being prediabetic and suffering from MetS by 16 and 7 percentage points, respectively. The general findings were also confirmed in a robustness check using the share of supermarket food purchases as a continuous treatment variable. We found no evidence that buying in supermarkets increases BP or the likelihood of suffering from pre-hypertension. The insignificant effect on hypertension might be due to the multifactorial character of this medical condition, which is not yet well examined, especially not in Africa.

Even though our results are consistent with the literature, the estimated effects in our study (for nutrition and health outcomes) as well as in previous studies (confined to nutrition outcomes) are 
relatively large in magnitude. Since all the results derive from cross-sectional data, one should be careful not to over-interpret the precision of the estimates. However, regardless of the exact magnitude of effects, the estimates and robustness checks depict a clear tendency, namely that supermarkets influence consumers' nutrition and health, also after controlling for other relevant socioeconomic and lifestyle factors.

\subsubsection{Expected Mechanisms of Supermarket Effects}

The observed effects of supermarkets on nutrition and health can be explained by changing food offers and shopping environments that influence consumer choices and diets. Supermarkets in developing countries tend to offer different types of foods than wet markets and other traditional retail outlets. Levels of processing, packaging sizes, and prices are often different as well. Previous research has shown that people who buy in supermarkets consume more calories and a higher share of processed foods (Asfaw, 2008; Hawkes, 2008; Kimenju et al., 2015; Qaim, 2017; Rischke et al., 2015; Toiba et al., 2015). And energy-dense, processed foods and beverages are known to contribute to overweight and obesity (Popkin and Ng, 2007; Popkin et al., 2012; Popkin and Slining, 2013).

These general relationships are also true in Kenya. Figure 2.1 shows differences in dietary patterns between households that buy and do not buy food in supermarkets. The observed differences in the consumption of various food groups are not very large, which is due to the fact that most of the households so far only buy part of their total foods consumed in supermarkets. Nevertheless, many of the differences are statistically significant. Households that purchase food in supermarkets consume higher quantities of processed snacks, fats and oils, soft drinks, meat and fish, and processed grains. On the other hand, they consume significantly lower quantities of vegetables and unprocessed grains. These differences in diets may contribute to increased overweight and obesity among supermarket buyers and thus also to a higher prevalence of NRNCDs. 


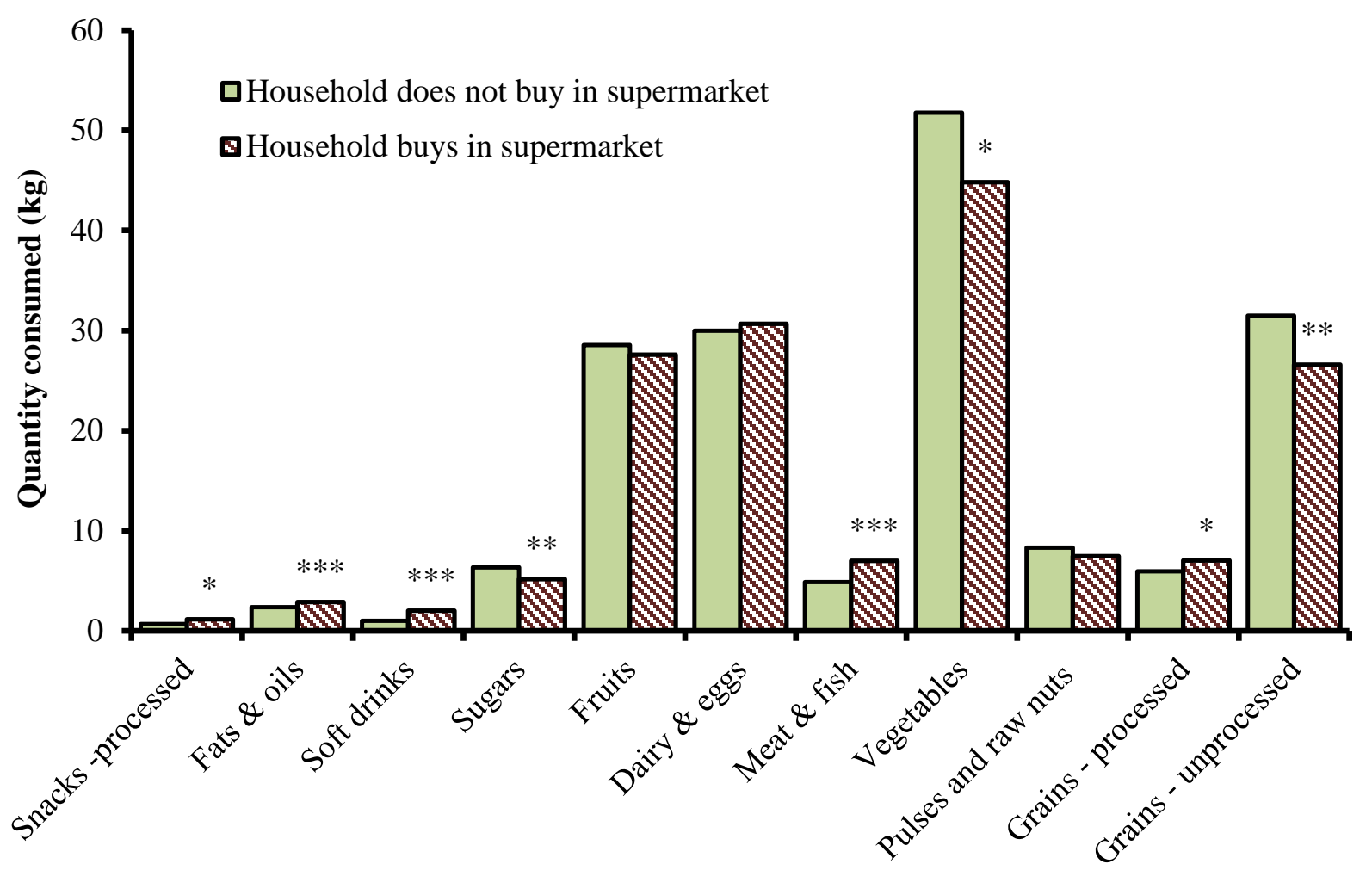

Figure 2.1. Comparison of mean food consumption within last 30d in households that buy and do not buy food in supermarkets $(\mathbf{n}=\mathbf{4 3 3})$. * Mean is different at $P<0.10$; ** Mean is different at $P<0.05 ; * * *$ Mean is different at $P<0.01$.

That such differences in diets are likely caused by supermarkets and their particular food offers was shown in another recent study with data from Kenya (Demmler et al., 2017). Demmler et al. (Demmler et al., 2017) confirmed that supermarkets contribute to increased consumption of highly processed foods, meats, dairy, and vegetable oils. They also showed that supermarkets decreased the amounts of energy obtained from unprocessed food items such as fresh vegetables and grains. While traditional retailers also sell processed foods, the processed food items purchased in supermarkets seem to be of additional nature. That is, supermarket users purchase additional quantities of processed foods without necessarily reducing processed food purchases from traditional shops. This may possibly be explained by supermarkets selling popular brands or larger packaging sizes that are not available in traditional shops. Also pricing and advertising strategies and the self-service character of supermarkets may incentivize consumers to use supermarkets and buy additional quantities (Demmler et al., 2017). 
We expect that most of the effects of supermarkets on NR-NCDs are channeled through higher BMI. However, there are also other possible mechanisms. One other possible mechanism is the reduced amount of bioactive compounds in "supermarket" diets that contain lower quantities of vegetables and unprocessed foods. There is evidence that bioactive compounds - including phytochemicals, vitamins, minerals, and fibers - can reduce the risk of diabetes and other chronic diseases even after controlling for BMI (Liu, 2013).

\subsubsection{Policy Implications}

Results of this study suggest that the rapid spread of supermarkets contributes to the nutrition transition and the rising epidemic of NR-NCDs in developing countries. However, this does not mean that supermarkets should be prohibited, as they may also have positive effects for public health and development. Compared to traditional food markets in developing countries, supermarket supply chains are often more efficient, which can make food more accessible for poor population segments (Kimenju et al., 2015; Qaim, 2017; Timmer, 2009). Recent studies showed that supermarkets can contribute to reduced rates of child undernutrition in some situations (Kimenju et al., 2015; Kimenju and Qaim, 2016). Food quality, food diversity, and food safety may also be higher in supermarkets than in traditional markets (Mergenthaler et al., 2009; Minot et al., 2015; Tessier et al., 2008). Finally, studies have shown that small-scale farmers in developing countries may benefit from participating in newly emerging supermarket supply chains (Chege et al., 2015; T Reardon et al., 2012). Against this background, it will be important for policymakers to strengthen the positive aspects of supermarket growth, while reducing negative implications to the extent possible. A critical aspect is to shape food environments that allow and instigate consumers to make more healthy food choices. This may require broader awareness building and education towards healthy nutrition, as well as appropriate regulation. For instance, outside of the big cities, supermarkets in developing countries often only sell processed foods. Requiring or supporting supermarkets to also offer fresh fruits and vegetables, and to position such a fresh produce section in a key place within the store, could be one possible route for nutrition-sensitive policymaking.

\subsection{Conclusion}

This study suggests that buying food in supermarkets increases BMI, fasting blood glucose, and the probability of being overweight/obese, pre-diabetic, and suffering from the metabolic 
syndrome. Since supermarket users consume larger quantities of highly processed and energydense foods, we reckon that the nutrition and health effects are mainly driven by supermarkets influencing people's dietary choices. This would mean that the rapid spread of supermarkets in developing countries directly contributes to the nutrition transition. However, premature judgements should be avoided, as supermarkets can also have positive effects for public health and development. We have highlighted new aspects and dimensions of the effects of supermarkets on nutrition and health in developing countries. This is a new research direction where the available evidence is still relatively thin. Given the rapidly rising prevalence of NRNCDs in many developing countries, more research on the role of changing food environments and appropriate policy responses that account for the complexity of effects will be needed. 


\subsection{Appendix A2}

\section{Table A2.1. First stage results of instrumental variable model}

\begin{tabular}{lc}
\hline \hline & Buys in supermarket \\
\hline Distance to supermarket, $\mathrm{km}$ & $-0.014^{* * *}(0.001)$ \\
Expenditure per capita & $0.009^{* *}(0.004)$ \\
Education, y & $0.011^{* * *}(0.001)$ \\
Intensive work, h/wk & $-0.000^{* * *}(0.000)$ \\
Physical activity, h/wk & $0.000(0.001)$ \\
Age, y & $-0.002(0.001)$ \\
Distance to hospital, km & $-0.009^{* *}(0.004)$ \\
Female & $0.040^{* * *}(0.005)$ \\
Married & $0.047(0.054)$ \\
Household size & $0.002(0.005)$ \\
Smoking & $0.004(0.033)$ \\
Constant & $0.656^{* * *}(0.108)$ \\
R-squared & 0.52 \\
F-statistic & 123.51 \\
Number of observations & 550 \\
\hline
\end{tabular}

Notes: First stage of instrumental variable estimation (selection equation), where "distance to nearest supermarket" is used as an instrument for "buys in supermarket". Coefficient estimates are shown with robust standard errors in parentheses. * Significant at $10 \%$ level; ** Significant at $5 \%$ level; *** Significant at $1 \%$ level. 
Table A2.2. Validity test of instrument in models for continuous nutrition and health outcomes

\begin{tabular}{lcccc}
\hline \hline & BMI $\left(\mathrm{kg} / \mathrm{m}^{2}\right)$ & $\mathrm{FBG}(\mathrm{mmol} / \mathrm{L})$ & $\mathrm{SBP}(\mathrm{mmHg})$ & $\mathrm{DBP}(\mathrm{mmHg})$ \\
\hline Buys in supermarket & $0.71(0.57)$ & $0.07(0.22)$ & $-3.28(2.44)$ & $-1.19(1.58)$ \\
Distance to supermarket, $\mathrm{km}$ & $-0.02(0.01)$ & $-0.00(0.00)$ & $-0.07(0.05)$ & $-0.03(0.04)$ \\
Constant & $16.04 * * *(1.39)$ & $3.60 * * *(0.30)$ & $116.22 * * *(6.04)$ & $78.30 * * *(3.85)$ \\
R-squared & 0.23 & 0.08 & 0.28 & 0.18 \\
Number of observations & 550 & 496 & 550 & 550 \\
\hline
\end{tabular}

Notes: Coefficients are shown with robust standard errors in parentheses. Not all control variables are shown for brevity. Included control variables are the same as in all other models: expenditure, education, intensive work, physical activity, age, distance to hospital, being female, being married, household size, smoking, history of diabetes, and history of heart attack. DBP, diastolic blood pressure; FBG, fasting blood glucose; SBP, systolic blood pressure. * Significant at $10 \%$ level; ** Significant at $5 \%$ level; *** Significant at $1 \%$ level.

Table A2.3. Validity test of instrument in models for binary nutrition and health outcomes

\begin{tabular}{lcccc}
\hline \hline & Overweight/obese & Pre-diabetic & Pre-hypertensive & MetS \\
\hline Buys in supermarket & $0.062(0.06)$ & $0.068(0.04)$ & $0.024(0.06)$ & $0.035(0.03)$ \\
Distance to supermarket, $\mathrm{km}$ & $-0.002(0.00)$ & $-0.001(0.00)$ & $0.001(0.00)$ & $-0.000(0.00)$ \\
Constant & $-0.444 * * *(0.14)$ & $-0.228 *(0.12)$ & $0.470 * * *(0.16)$ & $-0.152(0.09)$ \\
R-squared & 0.19 & 0.08 & 0.05 & 0.08 \\
Number of observations & 550 & 496 & 550 & 496 \\
\hline
\end{tabular}

Notes: Coefficients of linear probability models are shown with robust standard errors in parentheses. Overweight/obese: BMI $\geq 25 \mathrm{~kg} / \mathrm{m}^{2}$; Pre-diabetic: FBG (in mmol/L) $\geq 5.6$; Pre-hypertensive: SBP/DBP (in $\mathrm{mmHg}$ ) $\geq 120 / 80$; Metabolic syndrome (MetS): defined through three parameters: waist circumference (in $\mathrm{cm}$ ) F/M $>80 / 94$ plus SBP/DBP (in $\mathrm{mmHg}$ ) $\geq 130 / \geq 85$ and FBG (in $\mathrm{mmol} / \mathrm{L}$ ) $\geq 5.6$. Not all control variables are shown for brevity. Included control variables are the same as in all other models: expenditure, education, intensive work, physical activity, age, distance to hospital, being female, being married, household size, smoking, history of diabetes, and history of heart attack. DBP, diastolic blood pressure; FBG, fasting blood glucose; MetS, metabolic syndrome; SBP, systolic blood pressure * Significant at $10 \%$ level; ** Significant at 5\% level; *** Significant at $1 \%$ level. 
Table A2.4. Regression results for the effects of supermarkets on BMI, fasting blood glucose, systolic and diastolic blood pressure comparing OLS and IV estimations

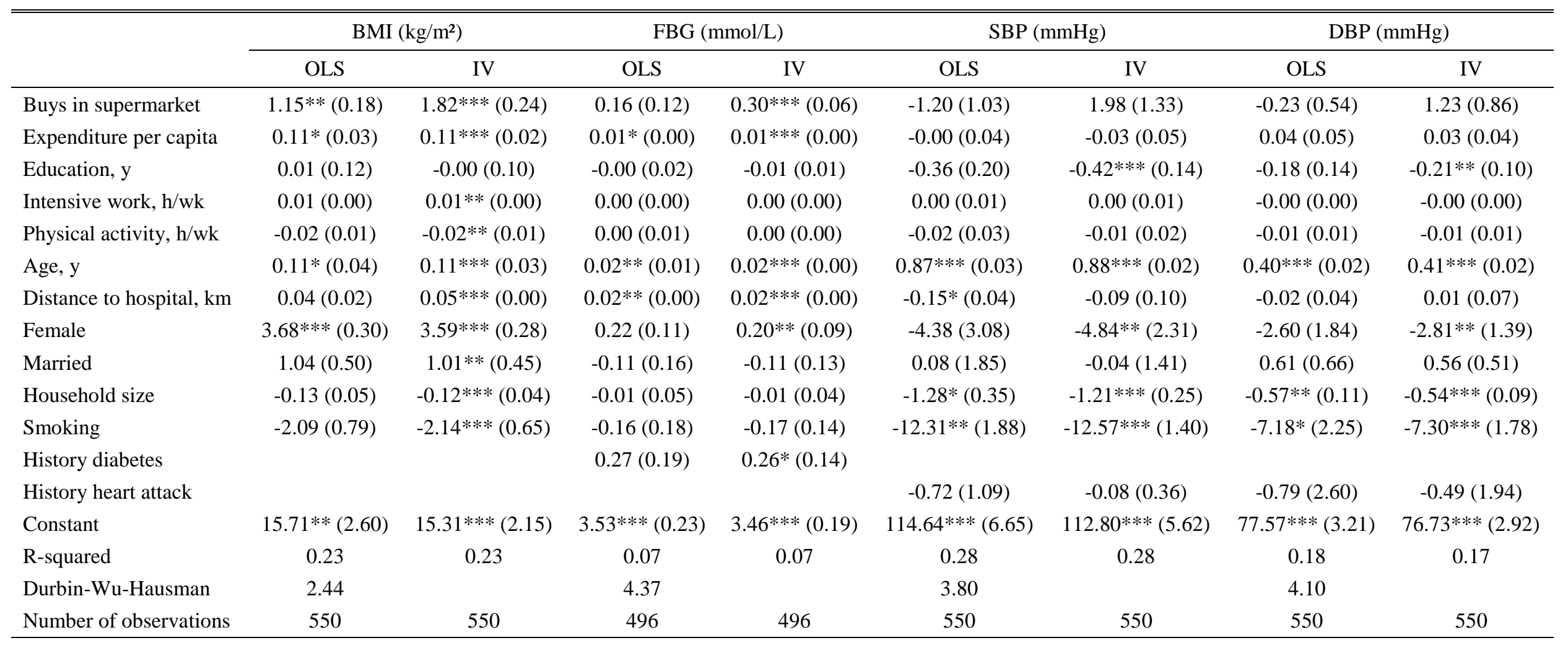

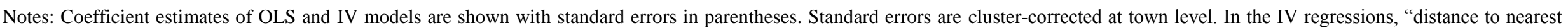

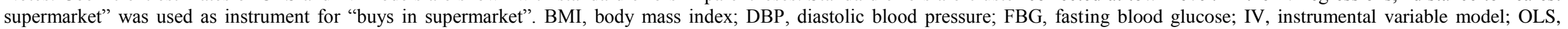
ordinary least squares; SBP, systolic blood pressure. * Significant at 10\% level; ** Significant at 5\% level; *** Significant at $1 \%$ level. 
Table A2.5. Regression results for the effects of supermarkets on the probability of being overweight/obese, pre-diabetic, prehypertensive, and suffering from metabolic syndrome comparing OLS and IV estimations

\begin{tabular}{|c|c|c|c|c|c|c|c|c|}
\hline & \multicolumn{2}{|c|}{ Overweight/Obese } & \multicolumn{2}{|c|}{ Pre-diabetic } & \multicolumn{2}{|c|}{ Pre-hypertensive } & \multicolumn{2}{|c|}{ MetS } \\
\hline & OLS & IV & OLS & IV & OLS & IV & OLS & IV \\
\hline Buys in supermarket & $0.119 *(0.03)$ & $0.204 * * *(0.02)$ & $0.108 * *(0.02)$ & $0.164 * * *(0.01)$ & $0.006(0.04)$ & $-0.014(0.02)$ & $0.048 * *(0.01)$ & $0.068 * * *(0.01)$ \\
\hline Expenditure per capita & $0.008(0.00)$ & $0.008 * * *(0.00)$ & $0.002(0.00)$ & $0.001(0.00)$ & $-0.001(0.00)$ & $-0.000(0.00)$ & $0.000(0.00)$ & $0.000(0.00)$ \\
\hline Education, y & $0.015(0.01)$ & $0.014 *(0.01)$ & $0.000(0.00)$ & $-0.001(0.00)$ & $-0.002(0.01)$ & $-0.001(0.00)$ & $-0.005(0.00)$ & $-0.006 * *(0.00)$ \\
\hline Intensive work, $\mathrm{h} / \mathrm{wk}$ & $0.001(0.00)$ & $0.001 * *(0.00)$ & $0.000(0.00)$ & $0.000(0.00)$ & $-0.000(0.00)$ & $-0.000(0.00)$ & $0.000(0.00)$ & $0.000(0.00)$ \\
\hline Physical activity, h/wk & $-0.002(0.00)$ & $-0.001(0.00)$ & $0.001(0.00)$ & $0.001(0.00)$ & $0.001(0.00)$ & $0.001(0.00)$ & $0.000(0.00)$ & $0.000(0.00)$ \\
\hline Age, $y$ & $0.010 *(0.00)$ & $0.010 * * *(0.00)$ & $0.006 * *(0.00)$ & $0.006 * * *(0.00)$ & $0.006 *(0.00)$ & $0.006 * * *(0.00)$ & $0.005^{* *}(0.00)$ & $0.005^{* * *}(0.00)$ \\
\hline Distance to hospital, $\mathrm{km}$ & $0.004(0.00)$ & $0.005 * * *(0.00)$ & $-0.000(0.00)$ & $0.001 *(0.00)$ & $-0.003(0.00)$ & $-0.003 * * *(0.00)$ & $0.000(0.00)$ & $0.001 * * *(0.00)$ \\
\hline Female & $0.270 * *(0.05)$ & $0.258 * * *(0.04)$ & $0.014(0.02)$ & $0.008(0.01)$ & $-0.053(0.03)$ & $-0.050 * * *(0.02)$ & $0.019(0.02)$ & $0.017(0.02)$ \\
\hline Married & $0.080(0.06)$ & $0.077(0.05)$ & $0.025 * *(0.00)$ & $0.021 * * *(0.01)$ & $-0.035(0.02)$ & $-0.034 * *(0.02)$ & $0.042(0.04)$ & $0.041(0.03)$ \\
\hline Household size & $-0.007(0.01)$ & $-0.005(0.01)$ & $0.003(0.01)$ & $0.004(0.01)$ & $-0.012(0.01)$ & $-0.013(0.01)$ & $-0.002(0.00)$ & $-0.001(0.00)$ \\
\hline Smoking & $-0.197 * *(0.03)$ & $-0.204 * * *(0.03)$ & $0.038(0.02)$ & $0.034 * * *(0.01)$ & $-0.004(0.03)$ & $-0.002(0.03)$ & $-0.048(0.02)$ & $-0.050 * * *(0.02)$ \\
\hline History diabetes & & & $0.097(0.05)$ & $0.096 * *(0.04)$ & & & & \\
\hline History heart attack & & & & & $0.109 *(0.03)$ & $0.105 * * *(0.03)$ & & \\
\hline History diabetes/heart attack & & & & & & & $0.070 * * *(0.01)$ & $0.071 * * *(0.01)$ \\
\hline Constant & $-0.487(0.20)$ & $-0.537 * * *(0.16)$ & $-0.258(0.14)$ & $-0.289 * *(0.12)$ & $0.764 * * *(0.04)$ & $0.776 * * *(0.04)$ & $-0.162 *(0.04)$ & $-0.172 * * *(0.03)$ \\
\hline R-squared & 0.18 & 0.18 & 0.08 & 0.07 & 0.05 & 0.05 & 0.08 & 0.08 \\
\hline Durbin-Wu-Hausman & 2.42 & & $9.48 *$ & & 0.12 & & 1.13 & \\
\hline Number of observations & 550 & 550 & 496 & 496 & 550 & 550 & 496 & 496 \\
\hline
\end{tabular}

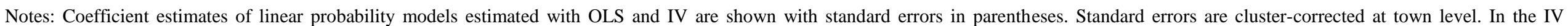

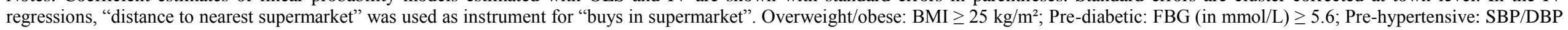

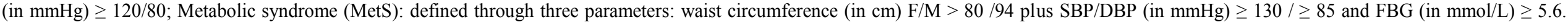

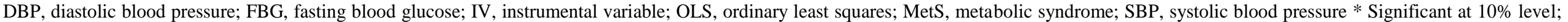
** Significant at $5 \%$ level; *** Significant at $1 \%$ level. 
Table A2.6. Regression results for the effects of supermarkets on the probability of being overweight/obese, pre-diabetic, prehypertensive, and suffering from metabolic syndrome comparing probit and IV probit estimations

\begin{tabular}{|c|c|c|c|c|c|c|c|c|}
\hline & \multicolumn{2}{|c|}{ Overweight/obese } & \multicolumn{2}{|c|}{ Pre-diabetic } & \multicolumn{2}{|c|}{ Pre-hypertensive } & \multicolumn{2}{|c|}{ MetS } \\
\hline & Probit & IV probit & Probit & IV probit & Probit & IV probit & Probit & IV probit \\
\hline Buys in supermarket & $0.114 * * *(0.03)$ & $0.112 * * *(0.02)$ & $0.116 * * *(0.03)$ & $0.138 * * *(0.01)$ & $0.003(0.03)$ & $-0.085 * * *(0.03)$ & $0.061 * * *(0.01)$ & $0.055 * * *(0.02)$ \\
\hline Expenditure per capita & $0.010 * * *(0.00)$ & $0.009 * * *(0.00)$ & $0.002(0.00)$ & $0.001 * * *(0.00)$ & $-0.001(0.00)$ & $0.000(0.00)$ & $0.000(0.00)$ & $-0.000(0.00)$ \\
\hline Education, y & $0.013 *(0.01)$ & $0.012(0.01)$ & $0.000(0.00)$ & $-0.001(0.00)$ & $-0.003(0.01)$ & $0.000(0.01)$ & $-0.005 *(0.00)$ & $-0.004(0.00)$ \\
\hline Intensive work, $\mathrm{h} / \mathrm{wk}$ & $0.001 *(0.00)$ & $0.001 *(0.00)$ & $0.000(0.00)$ & $0.000(0.00)$ & $-0.000 *(0.00)$ & $-0.000 * *(0.00)$ & $0.000(0.00)$ & $0.000(0.00)$ \\
\hline Physical activity, h/wk & $-0.002(0.00)$ & $-0.002(0.00)$ & $0.001(0.00)$ & $0.001(0.00)$ & $0.000(0.00)$ & $0.000(0.00)$ & $0.000(0.00)$ & $0.000(0.00)$ \\
\hline Age, y & $0.010 * * *(0.00)$ & $0.010 * * *(0.00)$ & $0.006 * * *(0.00)$ & $0.006 * * *(0.00)$ & $0.008 * * *(0.00)$ & $0.008 * * *(0.00)$ & $0.005 * * *(0.00)$ & $0.005 * * *(0.00)$ \\
\hline Distance to hospital, $\mathrm{km}$ & $0.003(0.00)$ & $0.004 * *(0.00)$ & $0.000(0.00)$ & $0.002 * * *(0.00)$ & $-0.003 * * *(0.00)$ & $-0.006 * * *(0.00)$ & $0.001 * * *(0.00)$ & $0.001 * * *(0.00)$ \\
\hline Female & $0.275 * * *(0.04)$ & $0.273 * * *(0.05)$ & $0.017(0.02)$ & $0.011(0.02)$ & $-0.051 * *(0.02)$ & $-0.037 * * *(0.01)$ & $0.031(0.03)$ & $0.034(0.03)$ \\
\hline Married & $0.087(0.06)$ & $0.076(0.07)$ & $0.032 * * *(0.01)$ & $0.020(0.02)$ & $-0.045^{*}(0.02)$ & $-0.033(0.02)$ & $0.067 *(0.03)$ & $0.062 * *(0.03)$ \\
\hline Household size & $-0.006(0.01)$ & $-0.007(0.01)$ & $0.001(0.01)$ & $0.002(0.01)$ & $-0.018 *(0.01)$ & $-0.020 *(0.01)$ & $-0.002(0.00)$ & $-0.001(0.00)$ \\
\hline Smoking & $-0.200 * * *(0.02)$ & $-0.204 * * *(0.02)$ & $0.027(0.02)$ & $0.035(0.03)$ & $-0.002(0.04)$ & $-0.003(0.04)$ & $-0.052 *(0.03)$ & $-0.051 * *(0.02)$ \\
\hline History diabetes & & & $0.083 * *(0.03)$ & $0.083 * *(0.03)$ & & & & \\
\hline History heart attack & & & & & $0.159 *(0.08)$ & $0.137(0.10)$ & & \\
\hline History diabetes/heart attack & & & & & & & $0.062 * * *(0.01)$ & $0.062 * * *(0.00)$ \\
\hline Pseudo R² & 0.15 & & 0.09 & & 0.07 & & 0.18 & \\
\hline Wald statistics & $4.36 * *$ & & $4.07 * *$ & & 0.34 & & 1.86 & \\
\hline Number of observations & 550 & 550 & 496 & 496 & 550 & 550 & 496 & 496 \\
\hline
\end{tabular}

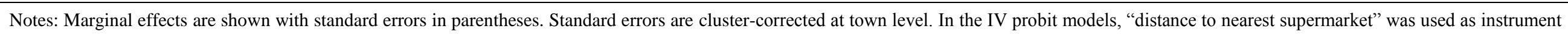

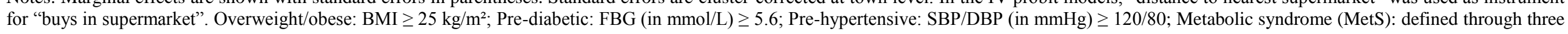

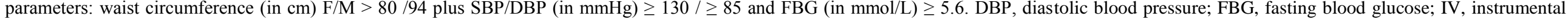
variable; MetS, metabolic syndrome; SBP, systolic blood pressure * Significant at $10 \%$ level; ** Significant at 5\% level; *** Significant at $1 \%$ level. 
Table A2.7. Full regression results for the effects of supermarket purchase (\%) on BMI, fasting blood glucose, systolic and diastolic blood pressure

\begin{tabular}{|c|c|c|c|c|}
\hline & $\operatorname{BMI}\left(\mathrm{kg} / \mathrm{m}^{2}\right)$ & $\mathrm{FBG}(\mathrm{mmol} / \mathrm{L})$ & $\mathrm{SBP}(\mathrm{mmHg})$ & $\mathrm{DBP}(\mathrm{mmHg})$ \\
\hline Share of supermarket purchase, $\%$ & $0.15 * * *(0.02)$ & $0.02 * * *(0.00)$ & $0.16(0.11)$ & $0.10(0.07)$ \\
\hline Expenditure per capita & $0.09 *(0.04)$ & $0.01(0.00)$ & $-0.05(0.05)$ & $0.02(0.04)$ \\
\hline Education, y & $-0.00(0.11)$ & $-0.01(0.01)$ & $-0.43^{* *}(0.15)$ & $-0.21(0.11)$ \\
\hline Intensive work, $\mathrm{h} / \mathrm{wk}$ & $0.01 *(0.00)$ & $0.00(0.00)$ & $0.00(0.01)$ & $-0.00(0.00)$ \\
\hline Physical activity, h/wk & $-0.03 *(0.01)$ & $-0.00(0.00)$ & $-0.02(0.03)$ & $-0.01 * * *(0.00)$ \\
\hline Age, y & $0.12 * * *(0.03)$ & $0.03 * * *(0.00)$ & $0.89 * * *(0.02)$ & $0.41 * * *(0.02)$ \\
\hline Distance to hospital, $\mathrm{km}$ & $0.12 * * *(0.01)$ & $0.03 * * *(0.01)$ & $-0.02(0.15)$ & $0.05(0.10)$ \\
\hline Female & $3.80 * * *(0.37)$ & $0.24 * * *(0.06)$ & $-4.61(2.41)$ & $-2.67(1.45)$ \\
\hline Married & $0.95 *(0.47)$ & $-0.12(0.12)$ & $-0.10(1.43)$ & $0.52(0.50)$ \\
\hline Household size & $-0.08(0.07)$ & $-0.00(0.04)$ & $-1.17 * * *(0.28)$ & $-0.51 * * *(0.11)$ \\
\hline Smoking & $-2.07 * * *(0.60)$ & $-0.15(0.12)$ & $-12.49^{* * *}(1.37)$ & $-7.25 * * *(1.78)$ \\
\hline History diabetes & & $0.29(0.18)$ & & \\
\hline History heart attack & & & $-0.05(0.62)$ & $-0.47(2.03)$ \\
\hline Constant & $14.22 * * *(2.18)$ & $3.30 * * *(0.21)$ & $111.61 * * *(6.34)$ & $75.99 * * *(3.32)$ \\
\hline Number of observations & 550 & 496 & 550 & 550 \\
\hline
\end{tabular}

Notes: Coefficient estimates of instrumental variable models are shown with standard errors in parentheses. Standard errors are clustercorrected at town level. "Distance to nearest supermarket" was used as instrument for "supermarket purchase". DBP, diastolic blood pressure; FBG, fasting blood glucose; SBP, systolic blood pressure. * Significant at $10 \%$ level; ** Significant at 5\% level; *** Significant at $1 \%$ level. 
Table A2.8. Full regression results for the effects of supermarket purchase (\%) on the probability of being overweight/obese, pre-diabetic, pre-hypertensive, and suffering from metabolic syndrome

\begin{tabular}{lcccc}
\hline \hline & Overweight/ Obese & Pre-diabetic & Pre-hypertensive & MetS \\
\hline Share of supermarket purchase, $\%$ & $0.016^{* * *}(0.00)$ & $0.013^{* * *}(0.00)$ & $-0.001(0.00)$ & $0.005^{* * *}(0.00)$ \\
Expenditure per capita & $0.006(0.00)$ & $-0.000(0.00)$ & $-0.000(0.00)$ & $-0.000(0.00)$ \\
Education, y & $0.013^{*}(0.01)$ & $-0.001(0.00)$ & $-0.001(0.00)$ & $-0.006^{* *}(0.00)$ \\
Intensive work, h/wk & $0.001^{* *}(0.00)$ & $0.000(0.00)$ & $-0.000(0.00)$ & $0.000(0.00)$ \\
Physical activity, h/wk & $-0.003^{* * *}(0.00)$ & $0.000(0.00)$ & $0.001(0.00)$ & $-0.000(0.00)$ \\
Age, y & $0.011^{* * *}(0.00)$ & $0.007^{* * *}(0.00)$ & $0.006^{* * *}(0.00)$ & $0.005^{* * *}(0.00)$ \\
Distance to hospital, km & $0.013^{* * *}(0.00)$ & $0.007^{* * *}(0.00)$ & $-0.004 * *(0.00)$ & $0.003^{* * *}(0.00)$ \\
Female & $0.282^{* * *}(0.05)$ & $0.026(0.02)$ & $-0.051^{* * *}(0.02)$ & $0.024(0.02)$ \\
Married & $0.070(0.05)$ & $0.020^{* * *}(0.01)$ & $-0.034^{* *}(0.02)$ & $0.041(0.03)$ \\
Household size & $-0.001(0.01)$ & $0.007(0.01)$ & $-0.013(0.01)$ & $-0.000(0.00)$ \\
Smoking & $-0.195^{* * *}(0.04)$ & $0.045^{* *}(0.02)$ & $-0.003(0.03)$ & $-0.045^{* * *}(0.01)$ \\
History diabetes & & $0.113^{* *}(0.05)$ & & \\
History heart attack & & & $0.104 * * *(0.03)$ & \\
History diabetes/heart attack & $-0.660^{* * *}(0.16)$ & $-0.379 * * *(0.13)$ & $0.784 * *(0.05)$ & $-0.209^{* * *}(0.03)$ \\
Constant & 550 & 496 & 550 & 496 \\
Number of observations & & & & \\
\hline
\end{tabular}

Notes: Coefficient estimates of instrumental variable linear probability models are shown with standard errors in parentheses. Standard errors are cluster-corrected at town level. "Distance to nearest supermarket" was used as instrument for "supermarket purchase". MetS, metabolic syndrome. * Significant at 10\% level; ** Significant at 5\% level; *** Significant at $1 \%$ level. 
Table A2.9. Regression results for the effects of supermarkets on BMI with panel data model

\begin{tabular}{lcc}
\hline & \multicolumn{2}{c}{ BMI $\left(\mathrm{kg} / \mathrm{m}^{2}\right)$} \\
\cline { 2 - 3 } & Fixed effects & Random effects \\
\hline Buys in supermarket & $0.59^{*}(0.34)$ & $0.63^{* *}(0.28)$ \\
Expenditure per capita, deflated ${ }^{\mathrm{a}}$ & $-0.02(0.02)$ & $0.06^{* * *}(0.01)$ \\
Physical activity, h/wk & $-0.03^{* * *}(0.01)$ & $-0.02^{* * *}(0.01)$ \\
Age, $\mathrm{y}$ & $-0.02(0.04)$ & $0.10^{* * *}(0.01)$ \\
Female & & $3.40^{* * *}(0.33)$ \\
Married & $1.02^{* *}(0.51)$ & $1.00^{* * *}(0.29)$ \\
Ol Kalou & & $-0.75^{* *}(0.38)$ \\
Njabini & & $-0.78^{*}(0.42)$ \\
Year 2015 & $0.37^{* *}(0.19)$ & $-0.04(0.13)$ \\
Constant & $25.51^{* * *}(1.50)$ & $18.37 * * *(0.69)$ \\
Wald-chi2 & & $224.91 * * *$ \\
F-value & $3.58^{* * *}$ & \\
Hausman test & $54.47^{* * *}$ & 1161 \\
Number of observations & 1161 & \\
\hline
\end{tabular}

Notes: Coefficient estimates of fixed effects and random effects panel data models are shown with standard errors in parentheses. Hausman test was performed in order to see significant differences between fixed and random effects. Total number of observations for the unbalanced panel data set is 1161 adults (>18 y), including 611 from 2012 and 550 from 2015 . ${ }^{\text {a }} 2015$ expenditures were adjusted for inflation using official consumer price indices. * Significant at $10 \%$ level; ** Significant at $5 \%$ level; *** Significant at $1 \%$ level. 


\title{
3 Supermarket Shopping and Nutritional Outcomes: A Panel Data Analysis for Urban Kenya ${ }^{4}$
}

\begin{abstract}
Overweight and obesity are growing health problems in many developing countries. Rising obesity rates are the result of changes in people's diets and lifestyles. Income growth and urbanization are factors that contribute to these changes. Modernizing food retail environments may also play a certain role. For instance, the rapid spread of supermarkets in many developing countries could affect consumer food choices and thus nutritional outcomes. However, concrete evidence about the effects of supermarkets on consumer diets and nutrition is thin. A few existing studies have analyzed related linkages with cross-sectional survey data. We add to this literature by using panel data from households and individuals in urban Kenya. Employing panel regression models with individual fixed effects and controlling for other factors we show that shopping in supermarkets significantly increases body mass index (BMI). We also analyze impact pathways. Shopping in supermarkets contributes to higher consumption of processed and highly processed foods and lower consumption of unprocessed foods. These results confirm that the retail environment affects people's food choices and nutrition. However, the effects depend on the types of foods offered. Rather than thwarting modernization in the retail sector, policies that incentivize the sale of more healthy foods - such as fruits and vegetables - in supermarkets may be more promising to promote desirable nutritional outcomes.
\end{abstract}

\footnotetext{
${ }^{4}$ This paper is accepted for publication in Word Development. http://dx.doi.org/10.1016/j.worlddev.2017.07.018. It is co-authored by Olivier Ecker and Matin Qaim. The authors' contributions are as follows: KMD, OE, and MQ designed the research. KMD collected, analyzed, and interpreted the data. OE and MQ assisted in the analysis and interpretation of the results. KMD wrote the paper. All authors read and approved the final manuscript.
} 


\subsection{Introduction}

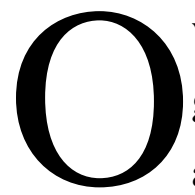

verweight and obesity are growing health problems worldwide. During 1980-2013, the global proportion of overweight or obese adults increased from $29 \%$ to $37 \%$ in men, and from $30 \%$ to $38 \%$ in women ( $\mathrm{Ng}$ et al., 2014). Developing countries are also increasingly affected. The rapid rise in people's body mass index (BMI) strongly contributes to various non-communicable diseases (NCDs), such as diabetes, hypertension, and some forms of cancer (NCD Risk Factor Collaboration, 2016). Obesity and NCDs are associated with morbidity and mortality, lost labor productivity, and high healthcare costs (Bommer et al., 2017; Herman, 2013; IFPRI, 2016; Withrow and Alter, 2011; World Economic Forum, 2011).

Rising rates of obesity are caused by income growth, urbanization, and related changes in people's lifestyles and diets. The 'nutrition transition' is particularly characterized by higher consumption of processed foods that are dense in sugar, fat, and salt (Popkin et al., 2012). Changes in the food retail environment may also play a role. In many developing countries, modern supermarkets are spreading rapidly (Reardon et al., 2003). As supermarkets sometimes offer different types of products than traditional markets and shops, such modernization of the retail sector could possibly contribute to negative nutrition and health outcomes (Hawkes, 2008; Popkin, 2014; Qaim, 2017).

Concrete evidence about the effects of supermarket shopping on people's diets in developing countries is thin. Very few studies analyzed related linkages, with mixed results. Tessier et al. (2008) showed that supermarket shopping is associated with improved dietary quality in Tunis, Tunisia. However, average living standards in Tunisia are higher than in most other African countries. Moreover, data from a large city, such as Tunis, may not be representative for other regions. Studies with data from Kenya and Guatemala revealed that supermarkets contribute to higher overall energy consumption and a larger share of energy from processed foods (Asfaw, 2008; Kimenju et al., 2015; Rischke et al., 2015). The same studies for Kenya and Guatemala also suggested that supermarket shopping increases adult BMI and the likelihood of being overweight or obese. A study with data from Indonesia found no significant association between supermarket shopping and BMI (Umberger et al., 2015). These existing studies used crosssectional survey data, partly employing instrumental variable (IV) approaches to draw causal inference. However, finding a valid instrument that is correlated with supermarket shopping but 
uncorrelated with diets and nutrition is very difficult. Hence, causal inferences based on crosssection observational data remain tentative (Bound et al., 1995).

We contribute to this research direction by using panel data and panel regression models for more robust causal inference. The main aim is to get a better understanding of the effects that the spread of supermarkets in developing countries has on consumers' diets and nutrition. In particular, we use data collected in urban Kenya in 2012 and 2015 to analyze the effects of supermarket shopping on adult BMI and dietary composition. Kenya has one of the most prospering supermarket sectors in sub-Saharan Africa (Neven et al., 2009; Rischke et al., 2015).

The share of grocery sales through supermarkets is about $10 \%$ at national level, but already much higher in large urban centers (Planet Retail, 2016). A rapid growth of supermarkets is also expected in other parts of Africa. Better understanding the nutrition effects of modernizing retail environments can help to design policies aimed at reducing negative health externalities.

\subsection{Food Environment and Dietary Choices}

Food choices are determined by various biological, socioeconomic, and psychological factors (Nestle et al., 1998). Food availability, price, type of display, quality, personal income, attitudes, taste, time constraints, and several other factors play a role when people decide on what to eat (Dover and Lambert, 2016; Ventura and Worobey, 2013). Economic development is typically associated with profound changes in people's diets. Income growth, urbanization, technological change, advances in food preservation, and advertising through mass media, all contribute to higher consumption of relatively energy-dense processed foods and beverages. These dietary shifts are often referred to as the 'nutrition transition' (Popkin, 2014; Popkin et al., 2012). In most developed countries, this nutrition transition already occurred several decades ago. In many developing countries, it is now happening at a relatively fast pace.

The nutrition transition can contribute to increases in body weight in two ways. First, consuming energy-dense foods will likely lead to higher overall energy intakes. Second, nutrient composition and processing levels play important roles for the human body's energy usage during food digestion and storage. On average, the human body's energy use for food digestion and storage makes up around 15\% of total daily energy expenditures (Barr and Wright, 2010). However, this value varies with dietary composition. For instance, the body requires more energy for digesting proteins than for carbohydrates and fats (Westerterp, 2004). Also, the digestion of 
fresh and whole foods with higher fiber contents requires more energy than the digestion of processed foods (Barr and Wright, 2010). Higher energy intakes and lower body energy expenditures may have positive nutrition effects in situations where people suffer from energy deficiency. However, for people with sufficient energy consumption, the nutrition transition contributes to overweight and obesity (Popkin et al., 2012).

Changing retail environments may possibly speed up the nutrition transition. In developing countries, supermarkets and other modern retail outlets are spreading rapidly, partly crowding out more traditional markets and small shops (Reardon et al., 2003). Supermarkets tend to be larger than traditional outlets, and they usually offer a bigger range of products under one roof. Another major difference is that supermarkets have self-service character, providing greater freedom of choice for customers. Supermarkets respond to changing consumer preferences and lifestyles, offering the types of foods that customers with rising incomes and appeal for modernity demand. However, it is likely that supermarkets do not only react to changing consumer preferences but, in turn, also shape these preferences to some extent. Influence on consumer food choices can occur through locational factors, the range of products offered, the positioning of items in the shelves, packaging sizes, promotional campaigns, and general shopping atmosphere (Battersby and Peyton, 2014; Hawkes, 2008; Timmer, 2009).

Compared to small traditional shops, supermarkets can better exploit economies-of-scale. Hence, certain foods can be offered at lower prices (Drewnowski et al., 2012; Rischke et al., 2015). This is especially relevant for non-perishable processed food items. In fact, outside of bigger cities, supermarkets in developing countries often concentrate primarily on the sale of processed foods. ${ }^{5}$ Cheaper access to processed foods can improve food security and nutrition for very poor population segments (Kimenju and Qaim, 2016; Reardon et al., 2003). However, heavy reliance on processed foods does not necessarily improve dietary quality and can intensify the obesity pandemic. Hence, the spread of supermarkets in developing countries can have both positive and negative nutrition and health effects.

\footnotetext{
${ }^{5}$ In big cities, many supermarkets and hypermarkets also have large fresh fruit and vegetable sections, but in smaller cities and towns this is rare up till now, at least in low-income countries of Asia and Africa (Rischke et al. 2015).
} 


\subsection{Materials and Methods}

\subsubsection{Data}

We use data from a survey of households and individuals carried out in two rounds in Central Kenya. The first round was carried out in 2012, the second in 2015. The survey concentrated on small towns ( $<70$ thousand inhabitants), because this is the typical size of towns that supermarket chains currently enter in Kenya. All larger cities in the nation already have one or more supermarkets, whereas in rural areas supermarkets are not yet observed. In 2012, we purposively selected three towns in Central Kenya with differences in the availability of supermarkets. ${ }^{6}$ The three towns are $\mathrm{Ol}$ Kalou and Njabini in Nyandarua County, and Mwea in Kirinyaga County. Ol Kalou has had a supermarket since 2002. In Mwea, a supermarket was opened in 2011. Njabini had no supermarket, neither in 2012 nor in 2015. This provides a quasi-experimental setting for the analysis of supermarket impacts on diets and nutrition. ${ }^{7}$ Except for these differences, the three towns are similar in terms of infrastructure and other economic development indicators (Kenya National Bureau of Statistics, 2010).

Systematic random sampling was used to select households for interview within the urban and peri-urban areas of the three towns. Since recent census data did not exist, we used available population statistics and the help of local administrators. At first, all neighborhoods (residential estates) in each town were listed. Then, household lists were compiled for each neighborhood, from which we randomly selected the required number of households. We selected households from all neighborhoods, in order to avoid clustering and obtain a representative sample at town level.

In each selected household, whenever available one male and one female adult ( $>18$ years) were included in the study for interviews and anthropometric measurements. In 2012, we included 432 randomly selected households and 601 adults. In 2015, we tried to reach the same households and individuals, but were only able to track 219 households and 286 adult individuals of those that were also included in 2012. Unlike in rural areas, where extended families often live in the same

\footnotetext{
${ }^{6}$ The cross-sectional data collected in 2012 was also used by Kimenju et al. (2015) and Rischke et al. (2015). This study builds up on this earlier research with panel data.

${ }^{7}$ Living in a town with supermarket is not perfectly correlated with supermarket use. Not all households in Ol Kalou and Mwea use supermarkets to buy food, and a few households in Njabini occasionally buy food in supermarkets elsewhere. However, this deliberate choice of towns provides exogenous variation in supermarket use that is very useful for the impact evaluation.
} 
place for several generations, in urban areas households are often much smaller and relocate more frequently. Hence, higher attrition rates in urban panels are commonplace. Attrition households were replaced with other randomly selected ones in the same towns and neighborhoods. In total, in 2015 we collected data from 430 households and 598 adult individuals. Thus, the total sample includes 1,199 individual adult observations.

Table 3.1 in the Appendix A3 compares key variables for individuals that were included in both survey rounds (balanced panel) and those that had to be excluded and newly included in 2015 due to attrition. While small differences occur for age and gender, no significant differences are found for consumption expenditures and other indicators of living standard. Against this background, we use the unbalanced panel in the further analysis, even though we test key results for possible attrition bias.

\subsubsection{Statistical Methods}

Our main objective is to analyze the effects of supermarket shopping on adult nutritional outcomes. For this purpose, we estimate panel data regression models of the following type:

$$
N_{i t}=\beta_{0}+\beta_{1} S_{i t}+\beta_{2} \boldsymbol{X}_{i t}+\varepsilon_{i t}
$$

where $N_{i t}$ is the nutritional outcome variable for individual $i$ at time $t$, such as BMI or being overweight or obese. The main explanatory variable of interest is $S_{i t}$, a dummy variable that indicates whether or not the individual (or the household in which individual $i$ lives) purchased any food in supermarkets (see below for details of variable definitions). $\boldsymbol{X}_{\boldsymbol{i t}}$ is a vector of control variables, and $\varepsilon_{i t}$ is a random error term. We are particularly interested in the coefficient estimate for $\beta_{1}$. A positive and significant estimate for $\beta_{1}$ would indicate that shopping in supermarkets has a net-increasing effect on BMI, or on the likelihood of being overweight or obese.

One important question is what type of control variables to include in the vector $\boldsymbol{X}_{\boldsymbol{i t}}$. Especially relevant are variables that may be jointly correlated with $N_{i t}$ and $S_{i t}$, as omitting such variables could lead to biased estimates for $\beta_{1}$. We include a range of factors, such as individual age, gender, marital status, and physical activity levels, as well as household living standard (economic status). In developing countries, living standard is often positively correlated with BMI (Popkin et al., 2012). At the same time, richer households are more likely to buy food in supermarkets, because they can afford a wider range of processed and convenience foods. 
Moreover, consumers in developing countries often associate supermarkets with western brands and modern lifestyles (Batra et al., 2000). Hence, not controlling for living standard would likely lead to an overestimated coefficient $\beta_{1}$. Similarly, physical activity levels may also be jointly correlated with supermarket shopping and nutritional outcomes. Finally, we include a time trend as part of vector $\boldsymbol{X}_{\boldsymbol{i t}}$, and town dummy variables to control for possible regional differences.

In addition to equation (3.1) with nutritional outcomes as dependent variables, we estimate models with diet-related dependent variables as follows:

$$
D_{i t}=\gamma_{0}+\gamma_{1} S_{i t}+\gamma_{2} \boldsymbol{X}_{i t}+\varepsilon_{i t}
$$

where $D_{i t}$ is a dietary indicator of individual $i$ at time $t$, such as the share of energy consumed from highly processed foods, or the energy consumed from specific food groups. The coefficient $\gamma_{1}$ characterizes the net effects of supermarket shopping on dietary choices and thus helps to better understand the mechanisms for nutritional outcomes.

The models in equations (3.1) and (3.2) can be estimated with random effects (RE) panel estimators. However, one potential issue is that the individual decision where to buy food is not random and may be influenced by unobserved factors. If such unobserved factors are also correlated with the nutritional outcomes or the dietary dependent variables, the estimated supermarket effects would be biased. This type of bias due to unobserved heterogeneity is also the main reason why IV approaches are commonly employed in impact evaluations with crosssectional data. When panel data are available, as in our case, estimators with individual fixed effects (FE) can alternatively be used. FE estimators use differencing techniques, so that timeinvariant heterogeneity is cancelled out, even if unobserved (Wooldridge, 2010). Time-variant heterogeneity may still bias the results, which is why we control for living standards and levels of physical activity that can change over time. Much more difficult to capture are individual lifestyle factors and attitudes that may also influence the decision where to buy food. However, such unobserved factors are not expected to change within three years (the period in-between our two survey rounds), so that they can be considered as time-invariant in this analysis. Hence, we argue that FE estimators properly control for unobserved heterogeneity in our context without the need for instruments. 
FE panel estimators require data variability within individuals over time. Hence, while unbalanced panel data can be used, the FE specifications rely on those individuals that were included in both survey rounds. We run all models with both FE and RE estimators and compare results using the Hausman test (Hausman, 1978). A significant Hausman test statistic means that there is unobserved heterogeneity, so that the FE specification is preferred. For all model estimations, we use standard errors that are cluster-corrected at the household level, which is important because in most households we observed more than one individual. All statistical analyses are conducted using Stata version 13.

\subsubsection{Supermarket Dummy Variable}

The main explanatory variable of interest in the regression models is the supermarket dummy variable $\left(S_{i t}\right)$, which takes a value of one if any food consumed in the household of individual $i$ during the 30 days prior to the survey was purchased in a supermarket, and zero if all the food consumed was obtained from traditional sources. Traditional sources include traditional retailers, such as daily markets, small shops, and kiosks, as well as food from own production or obtained through gifts. Table 3.2 in the Appendix A3 shows characteristics of the different sources of food (retail outlets), including typical food groups obtained from these sources.

Information on food consumption was obtained at the household level through a 30-day recall covering 168 food items. The recall interviews were conducted with the household member that was mainly responsible for food purchases and food preparation. In addition to the quantities consumed, information on sources and monetary expenditures was collected separately for each food item.

In the total sample with 1,199 observations, 668 individuals had consumed food purchased in supermarkets, whereas the other 531 had not. The proportion of supermarket shoppers varies by town. As one could expect, most non-supermarket shoppers live in Njabini, where no supermarket had been opened until 2015. A certain proportion of non-supermarket shoppers is also found in the other two towns, Mwea and Njabini. There is also variation in supermarket shopping over time, which is important for efficient FE estimations. As mentioned, in Mwea a supermarket was only established in 2011, shortly before the first survey round was conducted in 2012. As people first have to get used to this new retail format, some of the households in Mwea that had not yet used the supermarket in 2012 had started to use it by 2015. Some variation in 
supermarket shopping over time was also observed in the other two towns. Out of those individuals that were included in both survey rounds ( $\mathrm{n}=286), 44(15 \%)$ had switched their supermarket shopping status during 2012-15.

\subsubsection{Nutritional Outcomes and Dietary Variables}

We use the body mass index (BMI) as the main indicator of nutritional outcomes for adults. BMI is the most common indicator to classify overweight and obesity (Nelms et al., 2011). Anthropometric measurements of individual weight and height were obtained during both rounds of the survey according to international standards (Centers for Disease Control and Prevention, 2007). Using these measurements, we calculated BMI (BMI = body weight in $\mathrm{kg} /$ body height in meters squared) for each individual. Using common international thresholds for BMI, we also classified individuals according to their nutritional status (WHO, 2014). Adults with a BMI $\geq 25$ $\mathrm{kg} / \mathrm{m}^{2}$ and $<30 \mathrm{~kg} / \mathrm{m}^{2}$ are defined as overweight. With a BMI $\geq 30 \mathrm{~kg} / \mathrm{m}^{2}$ individuals are defined as obese. We club the two categories and define individuals with BMI $\geq 25 \mathrm{~kg} / \mathrm{m}^{2}$ as overweight/obese.

For the dietary analysis, we used the food consumption data from the 30-day recall. Quantities of each food item consumed by the household were converted to amounts of energy using national food composition tables for Kenya and other countries in Africa (2012, FAO, 2010; Sehmi, 1993). Energy consumption from each food item at the household level was divided by 30 to obtain daily values and then converted to individual levels with the help of adult equivalent scales. Adult equivalents (AE) were calculated based on average energy requirements, taking individual age, sex, and body height into account (FAO, 2004).

In addition to total energy consumption per person (expressed in kcal/AE/day), we also look at energy consumption from specific food groups that may be affected by supermarket shopping. As supermarkets in small towns offer very few fresh and unprocessed foods, we are particularly interested in effects on energy from unprocessed staples (grains, pulses, roots, and tubers) and fruits and vegetables. These groups are generally considered as 'healthy' foods, because they are high in dietary fiber. Fruits and vegetables are also rich in vitamins and minerals. Other food groups, such as meats and fish, dairy and eggs, and vegetable oils, are more energy-dense and often further processed. High consumption of such energy-dense foods can more easily contribute to overweight and obesity (Swinburn et al., 2004). Furthermore, we look at the share of highly 
processed foods (see Table A3.3 in the Appendix A3) in total daily energy consumption, as this may also be influenced by supermarket shopping.

\subsubsection{Control Variables}

In the individual-level regression models to explain nutritional outcomes and diets we control for typical sociodemographic factors such as age, sex, and marital status. In addition, we include a year dummy variable for observations in 2015 and town variables for Ol Kalou and Njabini (Mwea is the reference category). It should be noted that all time-invariant variables drop out in the FE specifications. In all models, we also control for household living standard, measured in terms of per capita consumption expenditures in Kenyan Shillings (KES). These expenditures comprise the value of all food and non-food goods and services consumed over a period of 30 days, including home-produced foods. To make monetary values comparable between survey years, expenditures in 2015 were deflated to 2012 using official consumer price indices (Kenya National Bureau of Statistics, 2016).

Finally, we control for individual physical activity, as this can also influence food consumption and nutritional outcomes. In the survey, respondents were asked for the number of hours of physical activity during leisure time. These data were used to calculate leisure time physical activity ratios (PAR). ${ }^{8}$ PAR is a continuous variable taking values larger than 1 . Bigger values indicate higher levels of physical activity.

\subsection{Results}

\subsubsection{Descriptive Statistics}

Descriptive statistics for key variables used in this analysis are shown in Table 3.1, for the total sample and also disaggregated for supermarket shoppers and non-shoppers. The upper part of the table shows the nutrition and dietary indicators.

\footnotetext{
${ }^{8}$ PAR is defined as a multiple of the basal metabolic rate. In the nutritional sciences, PAR is often used to calculate physical activity levels (PAL), which are one ingredient in determining individual energy requirements (FAO, 2004).
} 


\section{Table 3.1. Sample descriptive statistics}

\begin{tabular}{|c|c|c|c|}
\hline Variable & Total & $\begin{array}{l}\text { Shopping in } \\
\text { supermarkets }\end{array}$ & $\begin{array}{l}\text { Not shopping in } \\
\text { supermarkets }\end{array}$ \\
\hline Body mass index $\left(\mathrm{kg} / \mathrm{m}^{2}\right)$ & $\begin{array}{l}25.33 \\
(5.07)\end{array}$ & $\begin{array}{c}25.80 * * * \\
(5.08)\end{array}$ & $\begin{array}{l}24.73 \\
(5.00)\end{array}$ \\
\hline Overweight/obese $(1,0)$ & $\begin{array}{c}0.47 \\
(0.50)\end{array}$ & $\begin{array}{c}0.52^{* * * *} \\
(0.50)\end{array}$ & $\begin{array}{c}0.40 \\
(0.49)\end{array}$ \\
\hline Energy consumption (kcal/AE/day) & $\begin{array}{c}3164.61 \\
(1439.11)\end{array}$ & $\begin{array}{c}3300.71 * * * \\
(1388.74)\end{array}$ & $\begin{array}{c}2993.41 \\
(1483.75)\end{array}$ \\
\hline Energy from unprocessed staples (kcal/AE/day) & $\begin{array}{c}408.66 \\
(386.15)\end{array}$ & $\begin{array}{c}387.46^{* *} \\
(421.46)\end{array}$ & $\begin{array}{c}435.34 \\
(335.01)\end{array}$ \\
\hline Energy from fruits and vegetables (kcal/AE/day) & $\begin{array}{c}375.32 \\
(250.35)\end{array}$ & $\begin{array}{c}392.05 * * * \\
(245.02)\end{array}$ & $\begin{array}{c}354.26 \\
(255.58)\end{array}$ \\
\hline Energy from meats and fish (kcal/AE/day) & $\begin{array}{c}121.84 \\
(112.00)\end{array}$ & $\begin{array}{c}148.28 * * * \\
(123.06)\end{array}$ & $\begin{array}{c}88.59 \\
(85.49)\end{array}$ \\
\hline Energy from dairy and egg (kcal/AE/day) & $\begin{array}{c}39.75 \\
(45.90)\end{array}$ & $\begin{array}{c}47.60 * * * \\
(51.67)\end{array}$ & $\begin{array}{c}29.89 \\
(35.02)\end{array}$ \\
\hline Energy from oils (kcal/AE/day) & $\begin{array}{c}133.26 \\
(190.58)\end{array}$ & $\begin{array}{c}187.68 * * * \\
(208.80)\end{array}$ & $\begin{array}{c}64.79 \\
(137.12)\end{array}$ \\
\hline Share of energy from highly processed foods (\%) & $\begin{array}{c}7.60 \\
(5.59)\end{array}$ & $\begin{array}{c}8.57 * * * \\
(5.25)\end{array}$ & $\begin{array}{c}6.37 \\
(5.76)\end{array}$ \\
\hline Expenditure per capita (1000 KES) & $\begin{array}{l}11.90 \\
(9.19)\end{array}$ & $\begin{array}{c}14.02 * * * \\
(10.67)\end{array}$ & $\begin{array}{c}9.24 \\
(5.88)\end{array}$ \\
\hline Age (years) & $\begin{array}{c}36.54 \\
(12.20)\end{array}$ & $\begin{array}{c}34.60 * * * \\
(9.92)\end{array}$ & $\begin{array}{c}38.99 \\
(14.21)\end{array}$ \\
\hline Female $(1,0)$ & $\begin{array}{c}0.65 \\
(0.48)\end{array}$ & $\begin{array}{c}0.67 \\
(0.47)\end{array}$ & $\begin{array}{c}0.63 \\
(0.48)\end{array}$ \\
\hline Married $(1,0)$ & $\begin{array}{c}0.74 \\
(0.44)\end{array}$ & $\begin{array}{l}0.76 * * \\
(0.43)\end{array}$ & $\begin{array}{c}0.70 \\
(0.46)\end{array}$ \\
\hline Physical activity ratio (PAR) & $\begin{array}{c}2.23 \\
(0.49)\end{array}$ & $\begin{array}{l}2.21 * * \\
(0.47)\end{array}$ & $\begin{array}{c}2.27 \\
(0.51)\end{array}$ \\
\hline Ol Kalou $(1,0)$ & $\begin{array}{c}0.32 \\
(0.47)\end{array}$ & $\begin{array}{c}0.50^{* * * *} \\
(0.50)\end{array}$ & $\begin{array}{c}0.09 \\
(0.29)\end{array}$ \\
\hline Mwea $(1,0)$ & $\begin{array}{c}0.29 \\
(0.46)\end{array}$ & $\begin{array}{c}0.41 * * * \\
(0.49)\end{array}$ & $\begin{array}{c}0.14 \\
(0.35)\end{array}$ \\
\hline Njabini $(1,0)$ & $\begin{array}{c}0.39 \\
(0.49)\end{array}$ & $\begin{array}{c}0.08^{* * * *} \\
(0.28)\end{array}$ & $\begin{array}{c}0.77 \\
(0.42)\end{array}$ \\
\hline Share of supermarket purchase (\%) & $\begin{array}{c}8.39 \\
(11.24)\end{array}$ & $\begin{array}{c}15.06 * * * \\
(11.25)\end{array}$ & $\begin{array}{c}0.00 \\
(0.00)\end{array}$ \\
\hline Number of observations & 1199 & 668 & 531 \\
\hline
\end{tabular}

Notes: Mean values are shown with standard deviations in parentheses. ** Difference between those shopping and not shopping in supermarkets is significant at $5 \%$ level; *** Difference between those shopping and not shopping in supermarkets is significant at $1 \%$ level.

Even though Kenya is still facing problems of undernutrition and child stunting, rates of adult overweight and obesity are high. In our sample, $47 \%$ of the adults were overweight or obese. This is higher than the average of $26 \%$ found in recent statistics for Kenya (IFPRI, 2016; Kenya National Bureau of Statistics, 2014; WHO, 2015a). However, these national statistics refer to all of the country's regions, including poor rural areas where undernutrition is still more widespread. 
Regionally disaggregated official statistics are only available for women. For Central Kenya, where the three towns included in this study are located, the prevalence of overweight/obesity among female adults was estimated at 47\% in 2014 (Kenya National Bureau of Statistics, 2014). Hence, the nutritional outcomes measured in our survey seem to be reasonable for urban areas in Central Kenya.

Looking at the disaggregated groups in Table 3.1, we see that those shopping in supermarkets have a significantly higher mean BMI and are also more likely to be overweight or obese than those not shopping in supermarkets. Figure 3.1 breaks these comparisons down by survey year. During 2012-15, BMI of both groups increased considerably, but the increase was more pronounced for those shopping in supermarkets. ${ }^{9}$ The data in Table 3.1 also show that supermarket shoppers have significantly higher total energy consumption than non-supermarket shoppers and a larger share of this energy comes from animal products and highly processed foods. However, these comparisons do not control for other factors that may also influence diets and nutrition. As can be seen in the lower part of Table 3.1, there are also significant differences in living standard and other sociodemographic variables. Below, we control for such differences through estimation of panel regression models.

\footnotetext{
${ }^{9}$ While the growth rates in BMI and in the prevalence of overweight/obesity during 2012-15 are higher for supermarket shoppers, the growth rate differences between the two groups are not statistically significant.
} 

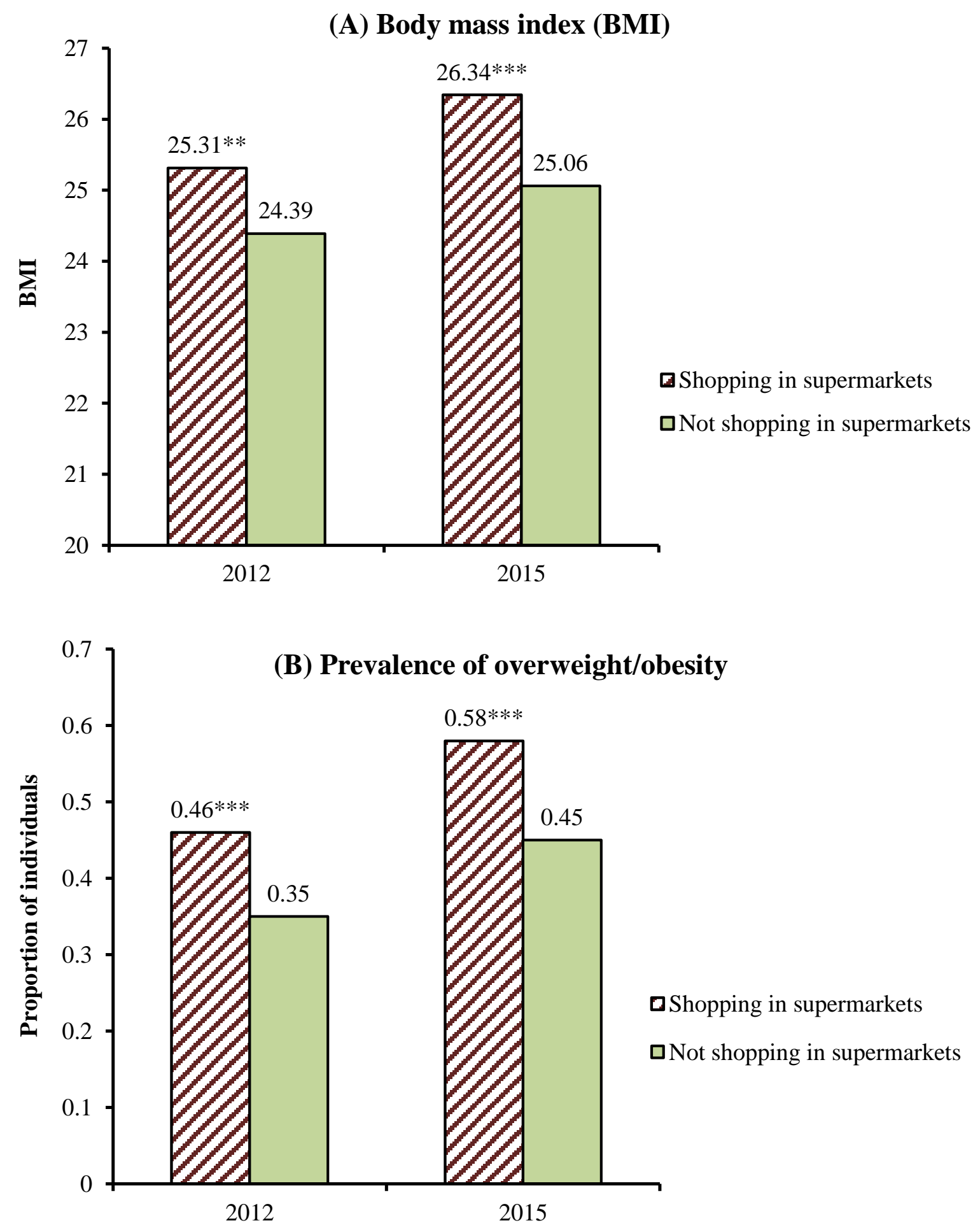

Figure 3.1. Differences in nutritional outcomes between individuals shopping and not shopping in supermarkets. $* *$ Difference between those shopping and not shopping in supermarkets is significant at 5\% level; *** Difference between those shopping and not shopping in supermarkets is significant at $1 \%$ level. 


\subsubsection{Supermarket Effects on BMI}

Table 3.2 shows results of panel regression models with BMI as dependent variable. Model (1) refers to the unbalanced panel with all observations included. Two versions are shown, one with FE and the other with RE specifications. The Hausman test statistic, which is shown in the lower part of the table, suggests that the FE specification is preferred. Shopping in supermarkets increases individual BMI by $0.64 \mathrm{~kg} / \mathrm{m}^{2}$. The finding of a net-increasing effect of supermarkets on BMI is consistent with Asfaw (2008) and Kimenju et al. (2015), who had used cross-sectional data. However, our estimate is smaller in magnitude. For instance, Kimenju et al. (2015), who used the same data from Central Kenya collected in 2012, estimated that supermarket shopping increases BMI by $1.69 \mathrm{~kg} / \mathrm{m}^{2}$. As argued above, the FE panel estimator used here is more reliable because it does not depend on assumptions about the validity of an instrument. However, in spite of the smaller effect found here, we confirm the hypothesis that supermarkets contribute to BMI increases, even after controlling for unobserved heterogeneity and other confounding factors.

The other results of model (1) in Table 3.2 show that being married also contributes to higher BMI. Furthermore, the RE specification, which includes the time-invariant characteristics that drop out from the FE specification, suggests that females have a much higher BMI than males. This is consistent with existing statistics from Kenya and elsewhere (Kenya National Bureau of Statistics, 2014; Ng et al., 2014). BMI is also positively associated with age and living standard, as one would expect. Looking at the town variables, we see that people living in Ol Kalou have a higher BMI than those living in Mwea, which is the reference town in this model. As mentioned, Ol Kalou is the town where a supermarket had already opened in 2002. On the other hand, people in Njabini, where no supermarket had been opened until 2015, have a significantly lower BMI. This correlation between the town variables and nutritional status is likely the result of our sampling strategy where we deliberately chose towns with differences in supermarket access. It implies that the town variables may possibly capture some of the effects of supermarket shopping. Indeed, when excluding the town variables from the RE specification of model (1), the supermarket effect on BMI increases to 0.72 . 
Table 3.2. Effects of supermarket shopping on body mass index

\begin{tabular}{|c|c|c|c|c|}
\hline & \multicolumn{4}{|c|}{ Body mass index $\left(\mathrm{kg} / \mathrm{m}^{2}\right)$} \\
\hline & \multicolumn{2}{|c|}{ (1) } & \multicolumn{2}{|c|}{ (2) } \\
\hline & $\mathrm{FE}$ & $\mathrm{RE}$ & $\mathrm{FE}$ & $\mathrm{RE}$ \\
\hline Shopping in supermarkets $(1,0)$ & $0.64 *(0.38)$ & $0.61 * *(0.29)$ & $0.64 *(0.38)$ & $0.70 * *(0.36)$ \\
\hline Married $(1,0)$ & $1.07 *(0.56)$ & $1.06^{* * *}(0.30)$ & $1.07 *(0.56)$ & $0.93 * *(0.44)$ \\
\hline Physical activity ratio & $-0.22(0.18)$ & $-0.25(0.16)$ & $-0.22(0.18)$ & $-0.27(0.17)$ \\
\hline Female $(1,0)$ & & $3.29 * * *(0.28)$ & & $3.29 * * *(0.49)$ \\
\hline Age (years) & $-0.02(0.04)$ & $0.10^{* * *}(0.02)$ & $-0.02(0.04)$ & $0.08 * * *(0.02)$ \\
\hline Expenditure per capita (1000 KES) & $-0.01(0.02)$ & $0.06^{* * *}(0.02)$ & $-0.01(0.02)$ & $0.03(0.02)$ \\
\hline Ol Kalou $(1,0)$ & & $-0.84 * *(0.39)$ & & $-0.46(0.75)$ \\
\hline Njabini $(1,0)$ & & $-0.82 *(0.43)$ & & $-1.01(0.76)$ \\
\hline Year 2015 & $0.38 * *(0.17)$ & $-0.00(0.13)$ & $0.38 * *(0.17)$ & $0.03(0.14)$ \\
\hline Constant & $25.26 * * *(1.50)$ & $18.63 * * *(0.74)$ & $25.89 * * *(1.62)$ & $20.30 * * *(1.15)$ \\
\hline Wald $\chi^{2}$ & & $236.38 * * *$ & & $75.25 * * *$ \\
\hline$F$-value & $2.50 * *$ & & $2.48 * *$ & \\
\hline Hausman test $\chi^{2}$ & $58.43 * * *$ & & $48.39 * * *$ & \\
\hline Number of observations & 1199 & 1199 & 572 & 572 \\
\hline
\end{tabular}

Notes: Coefficient estimates are shown with standard errors cluster-corrected at household level in parentheses. Model (1) uses the unbalanced panel with all observations. Model (2) only uses observations from the balanced panel. FE, fixed effects; RE, random effects. * Significant at $10 \%$ level; ** Significant at $5 \%$ level; *** Significant at $1 \%$ level.

We carry out a few additional tests to check the robustness of the results. A first test relates to the possible effects of sample attrition. Model (2) in Table 3.2 shows FE and RE specifications of the BMI model with only the observations from the balanced panel included. Except for the constant term, the FE results are identical to those in model (1), which is not surprising. Although all observations were included in model (1), FE estimation of the treatment effect only considers individuals that were included in both survey rounds, as the FE estimator exploits the variation within individuals over time. But also for the RE specifications, results of models (1) and (2) are quite similar, which we take as evidence that sample attrition does not lead to systematic bias.

A second test relates to the relatively small number of supermarket switchers. As mentioned in section 3, there are only 44 individuals in the sample who were included in both survey rounds and switched their supermarket shopping status during 2012-15 (88 observations). The FE estimates rely on these switchers, so it is important to know how representative they are for the rest of the sample. Table A3.4 in the Appendix A3 compares key socioeconomic characteristics of these switchers with the total sample. The switchers are more likely to be female. In terms of 
the other variables, including household living standards, no significant differences are observed. Of course, a larger number of switching observations could lead to more efficient FE estimates. But the similarity of the switchers with the rest of the sample suggests at least that the FE estimates do not suffer from significant selection bias.

A third test relates to the possible role of traditional retail outlets, which are not uniform. As shown in Table A3.2 in the Appendix A3, traditional retailers include daily markets, kiosks, and small shops. In terms of some characteristics, small shops are similar to supermarkets: while supermarkets are larger and offer a wider variety of processed foods, some small shops also have a self-service option. To analyze the possible role of small shops, we include an additional dummy variable for shopping in these small shops in the BMI models. Results are shown in Table A3.5 in the Appendix A3. Shopping in small shops does not seem to affect individual BMI, neither in the FE nor in the RE specification. At the same time, the supermarket effects remain significant and similar in magnitude to those in Table 3.2.

\subsubsection{Supermarket Effects on the Prevalence of Overweight/Obesity}

Table 3.3 shows results of model estimates where being overweight/obese is used as a dummy dependent variable. We use linear probability models for these estimates. ${ }^{10}$ The FE and RE specifications of model (1) show positive coefficients for supermarket shopping, but these are not statistically significant. This is surprising because Figure 3.1 shows that supermarket shoppers are significantly more likely to be overweight/obese than individuals who obtained all of their food from traditional sources. Interesting to see in Table 3.3, however, is that people in Njabini are significantly less likely to be overweight/obese than people in Mwea, even after controlling for other factors. Njabini is the town where no supermarket had opened until 2015. In model (2) of Table 3.3, we exclude the town variables and suddenly see a significant positive coefficient for supermarket shopping. According to this model, shopping in supermarkets increases the probability of being overweight/obese by 7 percentage points. ${ }^{11}$

We admit that the evidence of an overweight/obesity increasing net effect of supermarket shopping in our data is not very strong, also because the RE specifications do not control for

\footnotetext{
${ }^{10}$ Alternatively, one could have estimated probit models. The reason why we prefer linear probability models is that these also allow fixed effects specifications, which is not possible with probit models in most software packages.

${ }^{11}$ This is in line with findings by Asfaw (2008) and Kimenju et al. (2015), even though the estimated effects in these earlier cross-sectional studies were larger. For instance, Kimenju et al. (2015) estimated that supermarket shopping increases the probability of being overweight/obese by 13 percentage points.
} 
unobserved heterogeneity. That the supermarket effect is not showing up more clearly is due to the fact that many adults have a BMI around $25 \mathrm{~kg} / \mathrm{m}^{2}$. Of course, supermarkets are not the only factors contributing to BMI increases, so that crossing the overweight/obesity threshold occurs in both groups, supermarket shoppers and non-shoppers (Figure 3.1). However, the finding that supermarket shopping significantly increases BMI as such already implies that this will also contribute to more overweight/obesity. We presume that this would be more visible with a larger number of switching observations in the balanced panel.

\section{Table 3.3. Effects of supermarket shopping on the probability of being overweight/obese}

\begin{tabular}{|c|c|c|c|}
\hline & \multicolumn{3}{|c|}{ Being overweight/obese $(1,0)$} \\
\hline & \multicolumn{2}{|c|}{ (1) } & \multirow{2}{*}{$\begin{array}{l}\text { (2) } \\
\mathrm{RE}\end{array}$} \\
\hline & $\mathrm{FE}$ & $\mathrm{RE}$ & \\
\hline Shopping in supermarkets $(1,0)$ & $0.01(0.04)$ & $0.03(0.03)$ & $0.07 * *(0.03)$ \\
\hline Married $(1,0)$ & $0.07(0.05)$ & $0.09 * * *(0.03)$ & $0.09 * * *(0.03)$ \\
\hline Physical activity ratio & $-0.04(0.03)$ & $-0.04 * *(0.02)$ & $-0.04 * *(0.02)$ \\
\hline Female $(1,0)$ & & $0.25^{* * *}(0.03)$ & $0.26 * * *(0.03)$ \\
\hline Age (years) & $-0.01(0.01)$ & $0.01 * * *(0.00)$ & $0.01 * * *(0.00)$ \\
\hline Expenditure per capita (1000 KES) & $-0.00(0.00)$ & $0.01 * * *(0.00)$ & $0.01 * * *(0.00)$ \\
\hline Ol Kalou $(1,0)$ & & $-0.06(0.04)$ & \\
\hline Njabini $(1,0)$ & & $-0.10 * *(0.04)$ & \\
\hline Year 2015 & $0.09^{* * *}(0.03)$ & $0.04 * *(0.02)$ & $0.05 * *(0.02)$ \\
\hline Constant & $0.80 * * *(0.30)$ & $-0.07(0.08)$ & $-0.15 *(0.08)$ \\
\hline Wald $\chi^{2}$ & & $215.99 * * *$ & $201.00 * * *$ \\
\hline$F$-value & $2.17 * *$ & & \\
\hline Hausman test $\chi^{2}$ & $26.32 * * *$ & & \\
\hline Number of observations & 1199 & 1199 & 1199 \\
\hline
\end{tabular}

Notes: Coefficient estimates of linear probability models are shown with standard errors cluster-corrected at household level in parentheses. Being overweight/obese includes individuals with BMI $>25 \mathrm{~kg} / \mathrm{m}^{2}$. FE, fixed effects; RE, random effects. * Significant at $10 \%$ level; ** Significant at $5 \%$ level; *** Significant at $1 \%$ level.

\subsubsection{Supermarket Effects on Dietary Choices}

To better understand how supermarkets contribute to rising BMI, we analyze effects on consumers' dietary choices. Several studies had used cross-sectional data to show that supermarket shopping contributes to higher total energy consumption (Asfaw, 2008; Kimenju et al., 2015; Rischke et al., 2015; Toiba et al., 2015). Rischke et al. (2015) showed that the average price of calories purchased in supermarkets is lower than the price per calorie purchased in traditional outlets. This could explain some of the calorie consumption effects. Our descriptive 
statistics confirm that supermarket shoppers consume significantly more calories than people who obtain all of their food from traditional sources (Table 3.1). However, panel model estimates that we tried revealed that these differences in total energy consumption cannot be interpreted as a net effect of supermarket shopping. After controlling for other factors, supermarket shopping does not increase total energy consumption significantly.

However, beyond total energy consumption we find significant effects of supermarkets on dietary composition. The FE specification in Table 3.4 shows that shopping in supermarkets increases the share of energy from highly processed foods in total energy consumption by about 3 percentage points. This increase is plausible given that supermarkets in the small towns considered here primarily sell processed and highly processed foods. Higher consumption of highly processed foods with more sugar, fat, and lower fiber content can contribute to rising BMI even without significant effects on total energy consumption.

A tendency of supermarkets to contribute to dietary shifts toward more processed foods was also found by Asfaw (2008), Kimenju et al. (2015), and Rischke et al. (2015). Coefficient estimates are not directly comparable across studies, because of differences in the exact specification of the dependent variables and functional forms. Yet, in general, the earlier studies with cross-sectional data suggested larger effects on dietary composition, underlining again the importance of panel data for identifying reliable net impacts of supermarket shopping.

Table 3.5 analyzes further details of supermarket effects on people's diets beyond highly processed foods. The models shown have absolute energy consumption from different food groups as dependent variables. In all models, the supermarket dummy variable has significant coefficients, either in the FE or RE specifications. The FE specifications suggest that supermarket shopping reduces energy consumption from unprocessed staples by $112 \mathrm{kcal} / \mathrm{AE} / \mathrm{day}$, and from fresh fruits and vegetables by $124 \mathrm{kcal} / \mathrm{AE} / \mathrm{day}$. These are substantial effects, accounting for more than one-third of total average energy consumption from these two food groups. 
Table 3.4. Effects of supermarket shopping on the share of energy consumed from highly processed foods

\begin{tabular}{lcc}
\hline \hline & \multicolumn{2}{c}{ Share of energy from highly processed foods $(\%)$} \\
\cline { 2 - 3 } & FE & RE \\
\hline Shopping in supermarkets $(1,0)$ & $3.07^{* * *}(1.13)$ & $0.45(0.87)$ \\
Married $(1,0)$ & $-3.08(2.62)$ & $-1.61^{* *}(0.78)$ \\
Physical activity ratio & $0.65(0.57)$ & $-0.20(0.48)$ \\
Female $(1,0)$ & & $-1.46^{* *}(0.59)$ \\
Age (years) & $0.11(0.13)$ & $-0.23^{* * *}(0.02)$ \\
Expenditure per capita (1000 KES) & $0.06(0.06)$ & $0.18^{* * *}(0.04)$ \\
Ol Kalou $(1,0)$ & & $-0.68(0.80)$ \\
Njabini $(1,0)$ & & $-1.90^{*}(1.07)$ \\
Year 2015 & $2.33^{* * *}(0.60)$ & $2.76^{* * *}(0.45)$ \\
Constant & $4.71(4.95)$ & $19.77^{* * *}(2.09)$ \\
Wald $\chi^{2}$ & & $177.89^{* * *}$ \\
$F$-value & $5.96^{* * *}$ & \\
Hausman test $\chi^{2}$ & $23.10^{* * *}$ & 1199 \\
Number of observations & 1199 & \\
\hline
\end{tabular}

Notes: Coefficient estimates are shown with standard errors cluster-corrected at household level in parentheses. FE, fixed effects; RE, random effects. * Significant at $10 \%$ level; ** Significant at $5 \%$ level; *** Significant at $1 \%$ level.

For the other food groups in Table 3.5, the supermarket dummy variable is only significant in the RE specifications. Yet the Hausman test statistics suggest that unobserved heterogeneity is not an issue in these models, so that the RE estimator produces unbiased estimates. 


\section{Table 3.5. Effects of supermarket shopping on energy consumption from different food groups}

\begin{tabular}{|c|c|c|c|c|c|c|c|c|c|c|}
\hline & \multicolumn{10}{|c|}{ Energy consumption from different food groups (kcal/AE/day) } \\
\hline & \multicolumn{2}{|c|}{ Unprocessed staples } & \multicolumn{2}{|c|}{ Fruits and vegetables } & \multicolumn{2}{|c|}{ Meats and fish } & \multicolumn{2}{|c|}{ Dairy and egg } & \multicolumn{2}{|c|}{ Vegetable oils } \\
\hline & $\mathrm{FE}$ & RE & $\mathrm{FE}$ & RE & $\mathrm{FE}$ & RE & $\mathrm{FE}$ & RE & $\mathrm{FE}$ & RE \\
\hline Shopping in supermarkets $(1,0)$ & $\begin{array}{l}-111.61 * \\
(59.27)\end{array}$ & $\begin{array}{l}-22.43 \\
(30.58)\end{array}$ & $\begin{array}{c}-124.30 * * \\
(56.82)\end{array}$ & $\begin{array}{l}-16.53 \\
(21.34)\end{array}$ & $\begin{array}{c}5.70 \\
(11.28)\end{array}$ & $\begin{array}{c}24.17 * * * \\
(7.30)\end{array}$ & $\begin{array}{c}7.88 \\
(6.16)\end{array}$ & $\begin{array}{c}8.94 * * * \\
(3.45)\end{array}$ & $\begin{array}{c}9.03 \\
(27.39)\end{array}$ & $\begin{array}{c}59.81 * * * \\
(15.31)\end{array}$ \\
\hline Married $(1,0)$ & $\begin{array}{c}-56.69 \\
(154.93)\end{array}$ & $\begin{array}{l}-47.46 * \\
(27.56)\end{array}$ & $\begin{array}{l}-97.29 \\
(93.22)\end{array}$ & $\begin{array}{l}-28.78 * \\
(16.81)\end{array}$ & $\begin{array}{c}41.23 \\
(32.21)\end{array}$ & $\begin{array}{l}-5.02 \\
(8.01)\end{array}$ & $\begin{array}{c}-20.66 \\
(17.11)\end{array}$ & $\begin{array}{l}-5.34 \\
(4.10)\end{array}$ & $\begin{array}{l}-37.27 \\
(63.46)\end{array}$ & $\begin{array}{c}-27.66^{* * *} \\
(13.26)\end{array}$ \\
\hline Physical activity ratio & $\begin{array}{c}21.69 \\
(41.86)\end{array}$ & $\begin{array}{c}8.07 \\
(17.65)\end{array}$ & $\begin{array}{c}13.04 \\
(24.79)\end{array}$ & $\begin{array}{l}31.96^{* *} \\
(13.06)\end{array}$ & $\begin{array}{l}-10.54 \\
(10.84)\end{array}$ & $\begin{array}{l}-3.80 \\
(6.43)\end{array}$ & $\begin{array}{c}1.99 \\
(4.17)\end{array}$ & $\begin{array}{l}-0.86 \\
(3.21)\end{array}$ & $\begin{array}{c}-5.80 \\
(19.16)\end{array}$ & $\begin{array}{c}2.82 \\
(11.25)\end{array}$ \\
\hline Female $(1,0)$ & & $\begin{array}{c}49.31 * * * \\
(15.59)\end{array}$ & & $\begin{array}{c}24.12 * * \\
(9.74)\end{array}$ & & $\begin{array}{c}1.13 \\
(4.94)\end{array}$ & & $\begin{array}{l}-3.63 \\
(2.33)\end{array}$ & & $\begin{array}{c}21.06 * * * \\
(7.39)\end{array}$ \\
\hline Age (years) & $\begin{array}{c}3.04 \\
(9.48)\end{array}$ & $\begin{array}{c}2.83 * * * \\
(1.04)\end{array}$ & $\begin{array}{l}-2.99 \\
(4.60)\end{array}$ & $\begin{array}{l}1.40 * * \\
(0.62)\end{array}$ & $\begin{array}{c}0.04 \\
(1.14)\end{array}$ & $\begin{array}{l}-0.35 \\
(0.26)\end{array}$ & $\begin{array}{c}0.17 \\
(0.44)\end{array}$ & $\begin{array}{c}-0.26 * * \\
(0.13)\end{array}$ & $\begin{array}{l}-1.16 \\
(2.00)\end{array}$ & $\begin{array}{c}1.24 * * * \\
(0.46)\end{array}$ \\
\hline Expenditure p.c. (1000 KES) & $\begin{array}{c}15.13 * * * \\
(5.00)\end{array}$ & $\begin{array}{c}7.92 * * * \\
(2.05)\end{array}$ & $\begin{array}{c}18.92 * * * \\
(3.07)\end{array}$ & $\begin{array}{c}11.26 * * * \\
(1.76)\end{array}$ & $\begin{array}{c}6.12 * * * \\
(1.25)\end{array}$ & $\begin{array}{c}6.23 * * * \\
(1.48)\end{array}$ & $\begin{array}{c}1.55^{* * * *} \\
(0.55)\end{array}$ & $\begin{array}{c}1.69 * * * \\
(0.42)\end{array}$ & $\begin{array}{c}9.70 * * * \\
(2.42)\end{array}$ & $\begin{array}{c}7.75^{* * * *} \\
(1.38)\end{array}$ \\
\hline O1 Kalou $(1,0)$ & & $\begin{array}{l}80.82 * * \\
(34.40)\end{array}$ & & $\begin{array}{c}-86.66 * * * \\
(21.44)\end{array}$ & & $\begin{array}{l}14.06 \\
(9.23)\end{array}$ & & $\begin{array}{l}8.71 * \\
(4.60)\end{array}$ & & $\begin{array}{c}-118.73 * * * \\
(16.97)\end{array}$ \\
\hline Njabini $(1,0)$ & & $\begin{array}{c}130.68 * * * \\
(35.16)\end{array}$ & & $\begin{array}{c}-68.36 * * * \\
(24.85)\end{array}$ & & $\begin{array}{c}3.87 \\
(10.21)\end{array}$ & & $\begin{array}{c}6.20 \\
(3.90)\end{array}$ & & $\begin{array}{c}-112.32 * * * \\
(17.71)\end{array}$ \\
\hline Year 2015 & $\begin{array}{c}-199.37 * * * \\
(53.87)\end{array}$ & $\begin{array}{c}-170.79 * * * \\
(24.16)\end{array}$ & $\begin{array}{c}78.92 * * * \\
(23.63)\end{array}$ & $\begin{array}{c}72.35 * * * \\
(15.38)\end{array}$ & $\begin{array}{c}5.13 \\
(7.63)\end{array}$ & $\begin{array}{c}9.10 \\
(5.77)\end{array}$ & $\begin{array}{c}6.26^{* * *} \\
(2.93)\end{array}$ & $\begin{array}{c}6.26 * * * \\
(2.37)\end{array}$ & $\begin{array}{c}34.11 * * \\
(14.10)\end{array}$ & $\begin{array}{c}35.76 * * * \\
(9.67)\end{array}$ \\
\hline Constant & $\begin{array}{c}272.37 \\
(379.24)\end{array}$ & $\begin{array}{c}217.03 * * * \\
(66.29)\end{array}$ & $\begin{array}{l}331.75^{*} \\
(169.25)\end{array}$ & $\begin{array}{c}151.57 * * * \\
(51.71)\end{array}$ & $\begin{array}{c}34.82 \\
(57.97)\end{array}$ & $\begin{array}{l}47.73^{*} \\
(28.89)\end{array}$ & $\begin{array}{c}18.44 \\
(23.67)\end{array}$ & $\begin{array}{c}24.18^{* *} \\
(11.35)\end{array}$ & $\begin{array}{c}78.65 \\
(117.63)\end{array}$ & $\begin{array}{c}25.26 \\
(40.36)\end{array}$ \\
\hline Wald- $\chi^{2}$ & & $109.05 * * *$ & & $119.49 * * *$ & & $94.13 * * *$ & & $51.21 * * *$ & & $248.89 * * *$ \\
\hline$F$-value & $5.40 * * *$ & & $9.42 * * *$ & & $5.81 * * *$ & & $3.25 * * *$ & & $54.99 * * *$ & \\
\hline Hausman test $\chi^{2}$ & 4.23 & & $21.42 * * *$ & & 6.41 & & 5.75 & & 8.43 & \\
\hline Number of observations & 1199 & 1199 & 1199 & 1199 & 1199 & 1199 & 1199 & 1199 & 1199 & 1199 \\
\hline
\end{tabular}

Notes: Coefficient estimates are shown with standard errors cluster-corrected at household level in parentheses. AE, adult equivalent; FE, fixed effects; RE, random effects. * Significant at $10 \%$ level; ** Significant at $5 \%$ level; *** Significant at $1 \%$ level. 
Supermarket shopping increases the consumption of meats and fish by $24 \mathrm{kcal} / \mathrm{AE} / \mathrm{day}$, of dairy and eggs by $9 \mathrm{kcal} / \mathrm{AE} / \mathrm{day}$, and of vegetable oils by $60 \mathrm{kcal} / \mathrm{AE} / \mathrm{day}$. Together with highly processed foods, these are also the food groups that supermarket shoppers actually purchase most in supermarkets (Figure 3.2). Table 3.5 and Figure 3.2 also reveal a few other interesting phenomena.

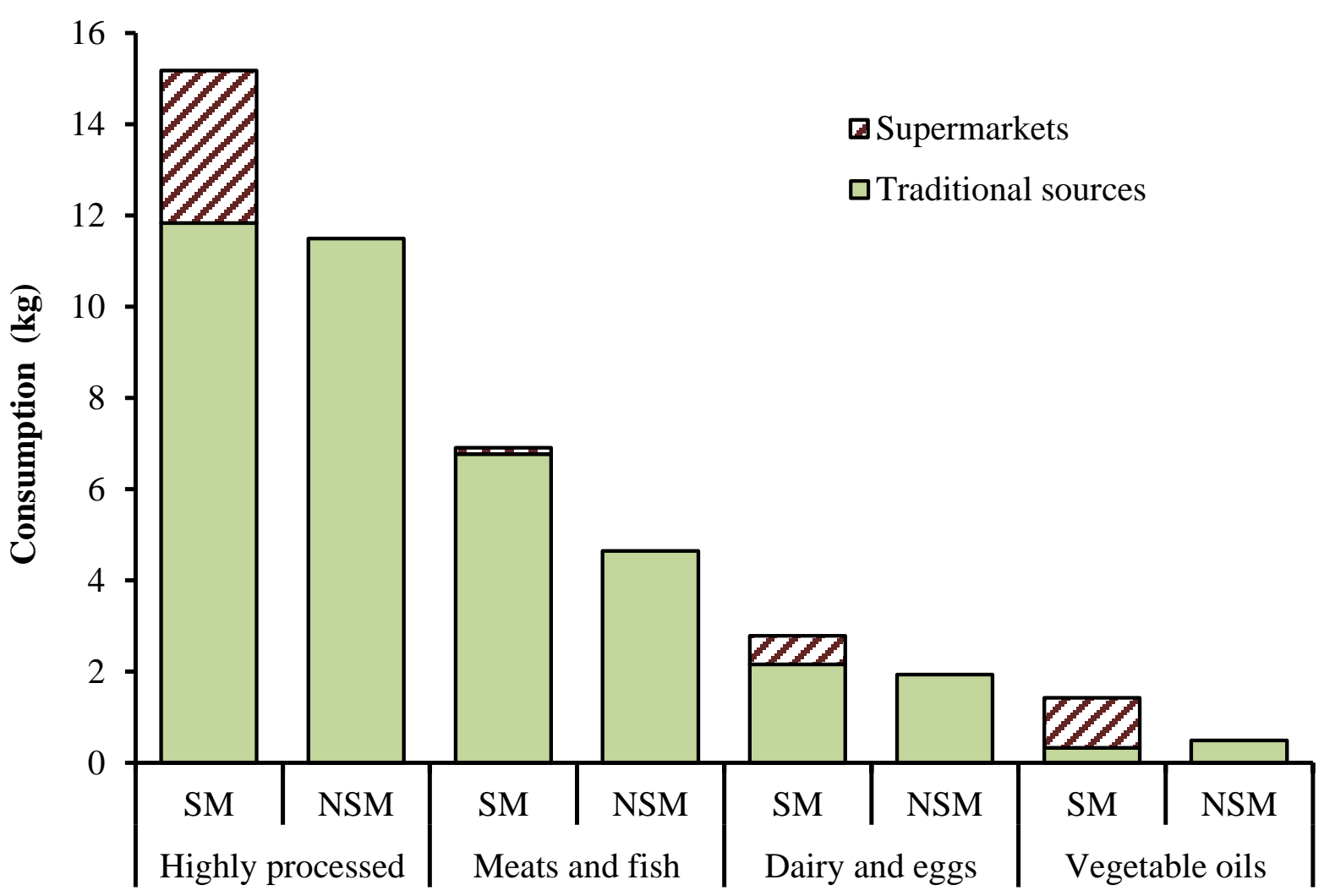

Figure 3.2. Quantity of food consumed from different food groups and food sources.

Notes: Quantities refer to consumption at the household level over a 30-day period. Total quantity consumed per household is split up by quantity purchased in supermarkets and quantity obtained from traditional sources. SM, refers to individuals who purchased some of their food in supermarkets; NSM, refers to individuals who did not use supermarkets at all. Pooled data for 2012 and 2015.

Households that use supermarkets purchase only some of their food in supermarkets. Of course, certain foods that are hardly sold in supermarkets but that people still want to consume have to be obtained from traditional sources. Cases in point are unprocessed staples and fresh fruits and vegetables. Results in Table 3.5 show that supermarket shoppers reduce the consumption of these 
groups, but they do not abandon them completely. But even for the types of foods that are sold in supermarkets, traditional sources continue to play an important role for all consumers. Interestingly, the quantities of highly processed foods, dairy, and vegetable oils consumed from traditional sources are more or less the same for those shopping and not shopping in supermarkets. Only that supermarket shoppers consume extra quantities of these foods that they purchase in supermarkets (Figure 3.2). Hence, the quantities of these foods obtained from supermarkets seem to be of additional nature. This may possibly be explained by supermarkets selling popular brands that are not available in traditional outlets. Larger packaging sizes, product placement, pricing, advertising, and the self-service character of supermarkets may also incentivize customers to buy additional quantities.

The establishment of supermarkets in small towns of Kenya is a relatively recent development, and the range of products offered in these supermarkets is still limited, at least when compared to much larger stores in big cities. Our data do not allow us to analyze how dietary behavior of small-town consumers may change when the number of supermarkets, as well as store sizes, continue to grow. However, even at this early stage, the results clearly support the hypothesis that supermarkets contribute to the nutrition transition, rather than only reacting to shifting consumer preferences.

\subsection{Conclusion}

Many developing countries currently experience profound transformations in the food retail sector, with modern supermarkets massively gaining in importance. While developments are already more advanced in some parts of Asia and Latin America, the share of supermarkets in food retailing is still relatively low in most sub-Saharan African countries, even though it is increasing rapidly. Possible dietary and nutrition implications are not yet sufficiently understood. We have analyzed effects on food consumers in Kenya, which is among the countries with the fastest growth of supermarkets in Africa. Using panel data from small towns in Central Kenya, we have shown that supermarkets significantly affect nutritional outcomes. After controlling for other relevant factors, our results suggest that shopping food in supermarkets increases adult BMI by $0.64 \mathrm{~kg} / \mathrm{m}^{2}$. That supermarkets tend to increase consumer BMI in developing countries was also shown in a few previous studies (Asfaw, 2008; Kimenju et al., 2015). These previous studies had even suggested larger effects, but they built on cross-section observational data where 
controlling for possible bias due to unobserved heterogeneity is more difficult. We argue that our estimates with panel data models are more realistic and reliable. However, regardless of the exact magnitude of effects, results confirm that the growth of supermarkets contributes to the nutrition transition in Africa.

To better understand the underlying mechanisms, we have also analyzed effects of supermarkets on consumer dietary choices. Unlike a few previous studies (Asfaw, 2008; Rischke et al., 2015, Toiba, Umberger, \& Minot, 2015), we did not find that supermarkets contribute to net increases in total calorie consumption. However, our panel data models revealed significant shifts in dietary composition. Supermarket shopping contributes to a sizeable decrease in energy consumption from unprocessed staples and from fresh fruits and vegetables. These food groups are hardly sold in the small-town supermarkets in Central Kenya that primarily concentrate on processed foods. Accordingly, we found significant increases of supermarket shopping on energy consumption from dairy, vegetable oil, processed meat products (sausages etc.), and highly processed foods (bread, pasta, snacks, soft drinks etc.). These shifts toward processed and highly processed foods lead to less healthy diets, with higher sugar, fat, and salt contents, and probably lower amounts of micronutrients and dietary fibers. Some of the effects are still relatively small in magnitude, but they may increase with supermarkets further gaining in importance. The observed changes in dietary composition can also explain the increasing effect on BMI, even without a rise in total calorie consumption. The reason is that the human body requires less energy for the digestion of processed and highly processed foods.

These results are alarming from a nutrition and health perspective. Even though we failed to establish a clear effect of supermarket shopping on the likelihood of being overweight or obese, rising BMI will inevitably aggravate nutrition status in situations where many people are already near or above the BMI threshold of $25 \mathrm{~kg} / \mathrm{m}^{2}$, as is the case for adults in Central Kenya. Overweight and obesity are responsible for various non-communicable diseases that cause high economic costs, human suffering, and lost quality of life.

It would be wrong to attribute the obesity pandemic in developing countries to the expansion of supermarkets alone. There are many factors that contribute to the nutrition transition. However, our results suggest that supermarkets are not only a symptom of this transition, but they influence dietary habits to a significant extent. Nevertheless, a modernizing retail sector should not be 
condemned, because - if properly managed - it can also have important positive nutrition effects. For instance, in a recent study in Kenya, Chege, Andersson, \& Qaim (2015) showed that smallholder farmers benefit from marketing contracts with supermarkets in terms of higher incomes that also contribute to better quality diets in these farm households. Depending on initial nutrition status and access to food diversity, the establishment of new supermarkets can also improve the nutrition of consumers. A few studies showed that better access to supermarkets is associated with healthier diets in some regions in the US (Drewnowski et al., 2012; Laraia et al., 2004; Morland et al., 2006). In these situations, supermarkets offer fresh foods that are otherwise more difficult to access, especially for lower income consumers living in so-called 'food desert' neighborhoods (Michimi and Wimberly, 2010). This is different from typical situations in Africa, but these examples underline that modern retail is not inevitably associated with negative nutrition and health implications.

The expansion of supermarkets in Africa and other parts of the developing world will likely continue. Hence, from a food policy perspective it is important to understand the diet and nutrition implications and intervene where necessary to avoid undesirable outcomes. Intervening does not imply banning supermarkets. But certain types of regulations and economic incentives may be appropriate in some situations. For instance, supermarkets in small African towns so far hardly sell fresh fruits and vegetables, because this does not yet seem to be profitable. Regulations that incentivize supermarket stores to also offer certain fresh products at reasonable prices could be a possible policy intervention. Alternatively, traditional fruit and vegetable vendors could be encouraged to set up stalls near the supermarket entrances, possibly through contractual arrangements. Other measures to promote dietary diversity and nutrition-sensitive food environments are also worth considering. Apart from regulations, this may also include consumer awareness building for the importance of fruits and vegetables in healthy diets.

Finally, we would like to point out a few limitations of our study. First, while the use of panel data has clear advantages over cross-sectional data, our panel suffered from significant attrition. While we tested for attrition bias to the extent possible, a balanced panel with a larger number of observations would be beneficial to analyze further details. Especially a sample with a larger number of individuals switching their supermarket shopping behavior over time would be useful for more robust causal inference with fixed effects estimators. Second, the geographic range of 
our data is limited and the time period considered relatively short. More comprehensive and longer term data may help to better understand impact heterogeneity and dynamics. Third, the 30day food consumption recall at the household level that we used has certain drawbacks in terms of data accuracy (Schoeller, 1995). We chose this relatively long recall period because some of the more durable food items are only purchased once a month. However, shorter and repeated recalls at individual level are preferable when the focus is on analyzing actual food and nutrient intakes (Shim et al., 2014). Hence, there is clearly scope for follow-up research to better understand the nutrition and health effects of the modernizing retail sector in various developingcountry situations. 


\subsection{Appendix A3}

Table A3.1. Comparison of balanced panel with excluded and newly included observations in 2015

(1)

\begin{tabular}{lcccc} 
& Total sample & Balanced panel & $\begin{array}{c}\text { Excluded and } \\
\text { newly included in } \\
2015\end{array}$ & $\begin{array}{c}\text { Difference } \\
\text { between }(2) \text { and } \\
(3)\end{array}$ \\
\hline Female $(1,0)$ & $0.65(0.48)$ & $0.68(0.47)$ & $0.63(0.48)$ & $-0.06^{* *}(0.03)$ \\
Age, y & $36.54(12.20)$ & $39.44(12.77)$ & $33.89(11.02)$ & $-5.55^{* * *}(0.69)$ \\
Married (1,0) & $0.74(0.44)$ & $0.76(0.43)$ & $0.72(0.45)$ & $-0.04^{*}(0.03)$ \\
Physical activity ratio & $2.23(0.49)$ & $2.25(0.50)$ & $2.22(0.48)$ & $-0.02(0.03)$ \\
$\begin{array}{l}\text { Energy availability } \\
\text { kcal/AE/day) }\end{array}$ & $3164.61(1439.11)$ & $3205.28(1513.14)$ & $3127.51(1368.26)$ & $-77.77(83.60)$ \\
Expenditure per capita (1000 & $11.90(9.19)$ & $12.04(8.28)$ & $11.78(9.94)$ & $-0.26(0.53)$ \\
KES) & $11.08(5.01)$ & $11.08(5.26)$ & $11.07(4.78)$ & $-0.01(0.29)$ \\
Education (school years) & 1199 & 572 & 627 & 1199 \\
Number of observations & & & & \\
\hline
\end{tabular}

Notes: Mean values are shown with standard deviations in parentheses. * Significant at $10 \%$ level; ** Significant at 5\% level; *** Significant at $1 \%$ level. 
Table A3.2. Different sources of food and their characteristics

\begin{tabular}{|c|c|c|c|c|}
\hline Source of food & Characteristics & $\begin{array}{l}\text { Main food } \\
\text { groups obtained } \\
\text { from this source }\end{array}$ & $\begin{array}{l}\text { Average share of } \\
\text { total energy } \\
\text { consumption (\%) }\end{array}$ & $\begin{array}{l}\text { Number of } \\
\text { observations } \\
\text { using source }\end{array}$ \\
\hline $\begin{array}{l}\text { Supermarket } \\
\text { (modern retail) }\end{array}$ & $\begin{array}{l}\text { Self-service; } \\
\text { Large variety of foods and brands; } \\
\text { Highly processed foods; } \\
\text { Refrigerated and frozen food; } \\
\text { Limited offer of fresh foods; } \\
\text { Non-food products; } \\
\text { No credit possibility }\end{array}$ & $\begin{array}{l}\text { Bread, pasta, } \\
\text { cereals, instant } \\
\text { noodles, snacks, } \\
\text { fats, oils, dairy } \\
\text { products, sugar }\end{array}$ & 12.7 & 668 \\
\hline $\begin{array}{l}\text { Small shop } \\
\text { (traditional retail) }\end{array}$ & $\begin{array}{l}\text { Semi self-service; } \\
\text { Limited variety of foods and brands; } \\
\text { Some refrigerated foods; } \\
\text { Sometimes credit possibility }\end{array}$ & $\begin{array}{l}\text { Rice, flour, } \\
\text { sugar, fats }\end{array}$ & 5.4 & 485 \\
\hline $\begin{array}{l}\text { Market/kiosk } \\
\text { (traditional retail) }\end{array}$ & $\begin{array}{l}\text { Over the counter service; } \\
\text { Very limited variety of brands; } \\
\text { Fresh fruits and vegetables; } \\
\text { Unprocessed staples; } \\
\text { Credit possibility }\end{array}$ & $\begin{array}{l}\text { Maize, other } \\
\text { staple foods, } \\
\text { fruits, } \\
\text { vegetables, } \\
\text { meat, milk }\end{array}$ & 65.7 & 1199 \\
\hline $\begin{array}{l}\text { Own } \\
\text { production/gift }\end{array}$ & $\begin{array}{l}\text { Own plot or garden; } \\
\text { In a few cases own farms; } \\
\text { Gifts from friends }\end{array}$ & $\begin{array}{l}\text { Maize, potatoes, } \\
\text { poultry, eggs, } \\
\text { milk }\end{array}$ & 16.3 & 1014 \\
\hline
\end{tabular}




\section{Table A3.3. Food groups by level of processing}

\begin{tabular}{ll}
\hline \hline Food groups & Examples \\
\hline Unprocessed & \\
Eggs \& milk & Eggs, fresh whole milk, natural yoghurt \\
Fruits \& vegetables & Mango, orange, green leafy vegetables, tomatoes, onions \\
Meats & Beef, pork meat, fresh chicken, fresh fish \\
Pulses & Lentils, black beans, cowpea etc. \\
Roots, tuber, plantain & Arrow roots, cassava, yams, potato, cooking bananas \\
Traditional staples & Amaranth, sorghum, green maize \\
Medium processed & \\
Fats \& oils & Butter, margarine, vegetable oils \\
Meats & Frozen fish, frozen chicken, dried fish \\
Staples & Rice, maize flour, wheat flour, oats \\
Sugars & Sugar, jaggery \\
Highly processed & \\
Bread \& pasta & Bread, cornflakes, pasta \\
Dairy & Flavored yoghurt/milk, tinned baby milk \\
Fats \& oils & Peanut butter \\
Meats & Sausages, bacon, ham \\
Miscellaneous & Mandazi, samosa, ketchup \\
Sugars & Glucose powder \\
Sweet drinks and snacks & Chips, soft drinks, cake, popcorn \\
\hline
\end{tabular}

Note: The food items mentioned are only examples. In total, 168 food items were included in the survey. All of them were classified by level of processing following the same principle. 
Table A3.4. Comparison of total sample with supermarket switchers

\begin{tabular}{lccc}
\hline \hline Variable & Total sample & $\begin{array}{c}\text { Supermarket } \\
\text { switchers }\end{array}$ & Difference \\
\hline Female $(1,0)$ & $0.65(0.48)$ & $0.77(0.42)$ & $-0.13^{* * *}(0.05)$ \\
Age, y & $36.54(12.20)$ & $36.99(11.02)$ & $-0.48(1.23)$ \\
Married $(1,0)$ & $0.74(0.44)$ & $0.75(0.44)$ & $-0.01(0.05)$ \\
Physical activity ratio & $2.23(0.49)$ & $2.24(0.45)$ & $-0.01(0.05)$ \\
Expenditure per capita (1000 KES) & $11.90(9.19)$ & $12.63(6.02)$ & $-0.78(0.70)$ \\
Number of observations & 1199 & 88 & \\
\hline
\end{tabular}

Notes: Mean values are shown with standard deviations in parentheses (standard errors in the last column). Supermarket switchers are those who changed their supermarket shopping status during $2012-15$. *** Difference significant at $1 \%$ level. 
Table A3.5. Effects of supermarket shopping on body mass index with additional controls

\begin{tabular}{lcc}
\hline \hline & \multicolumn{2}{c}{ Body mass index $\left(\mathrm{kg} / \mathrm{m}^{2}\right)$} \\
\cline { 2 - 3 } & $\mathrm{FE}$ & $\mathrm{RE}$ \\
\hline Shopping in supermarkets $(1,0)$ & $0.65^{*}(0.38)$ & $0.61^{* *}(0.29)$ \\
Shopping in small shops $(1,0)$ & $-0.14(0.20)$ & $0.03(0.19)$ \\
Married $(1,0)$ & $1.07^{*}(0.56)$ & $1.06^{* * *}(0.30)$ \\
Physical activity ratio & $-0.22(0.18)$ & $-0.25(0.16)$ \\
Female $(1,0)$ & & $3.29^{* * *}(0.28)$ \\
Age (years) & $-0.02(0.04)$ & $0.10^{* * *}(0.02)$ \\
Expenditure per capita (1000 KES) & $-0.01(0.02)$ & $0.06^{* * *}(0.02)$ \\
Ol Kalou (1,0) & & $-0.85^{* *}(0.40)$ \\
Njabini $(1,0)$ & & $-0.83^{*}(0.44)$ \\
Year 2015 & $0.38^{* *}(0.17)$ & $-0.01(0.14)$ \\
Constant & $25.34^{* * *}(1.53)$ & $18.63^{* * *}(0.74)$ \\
Wald $\chi^{2}$ & & $247.67^{* * *}$ \\
$F$-value & $2.17^{* *}$ & \\
Hausman test $\chi^{2}$ & $59.85^{* * *}$ & 1199 \\
Number of observations & 1199 & \\
\hline
\end{tabular}

Notes: Coefficient estimates are shown with standard errors cluster-corrected at household level in parentheses. FE, fixed effects; RE, random effects. * Significant at $10 \%$ level; ** Significant at $5 \%$ level; *** Significant at $1 \%$ level. 


\title{
4 Maternal Nutrition Knowledge and Child Nutritional Outcomes in Urban Kenya $^{12}$
}

\begin{abstract}
We examine the link between maternal nutrition knowledge and nutritional outcomes of children and adolescents (5-18 years) measured in terms of height-for-age Z-scores (HAZ). One particular focus is on the role of different types of nutrition knowledge. The analysis builds on householdlevel and individual-level data collected in urban Kenya in 2012 and 2015. Various regression models are developed and estimated. Results show that maternal nutrition knowledge - measured through an aggregate knowledge score - is positively associated with child HAZ, even after controlling for other influencing factors such as household living standard and general maternal education. However, disaggregation by type of knowledge reveals important differences. Maternal knowledge about food ingredients only has a weak positive association with child HAZ. For maternal knowledge about specific dietary recommendations, no significant association is detected. The strongest positive association with child HAZ is found for maternal knowledge about the health consequences of not following recommended dietary practices. These findings have direct relevance for nutrition and health policies, especially for designing the contents of educational campaigns and training programs.
\end{abstract}

\footnotetext{
${ }^{12}$ This paper is published in Appetite; 116:518-526. https://doi.org/10.1016/j.appet.2017.05.042. It is co-authored by Bethelhem Legesse Debela, Ramona Rischke, and Matin Qaim. The authors' contributions are as follows: BLD, KMD, RR, and MQ designed the research. KMD and RR collected the data. BLD organized the data and performed the analysis. BLD, KMD, RR, and MQ wrote the paper.
} 


\subsection{Introduction}

This study analyzes the link between maternal nutrition knowledge and child nutritional outcomes in urban households in Kenya. Malnutrition in all its forms affects one out of three individuals worldwide (IFPRI, 2016). While overnutrition rates are rising, undernutrition remains a major concern in many countries. It is estimated that $25 \%$ of all children in developing countries are stunted, an indication of sustained episodes of energy and micronutrient deficiencies. In spite of the progress made elsewhere, in Africa the number of stunted children continues to increase (IFPRI, 2016; UNICEF et al., 2015).

Various interventions are commonly implemented to improve child nutrition and promote healthy living environments for poor households. Among others, these interventions include food and cash transfers, supplementary feeding programs, and nutrition education campaigns (Hirvonen et al., 2016; Tabbakh and Freeland-Graves, 2016; World Bank, 2010). While the evidence for the effect of transfer programs on child health outcomes is mixed (Burchi et al., 2016; de Groot et al., 2017), there is a potential for an increased impact on child nutrition if conditional cash transfer programs are combined with nutrition education programs (Burchi et al., 2016). Positive associations between maternal nutrition knowledge and child nutritional outcomes are well documented for young children (Appoh and Krekling, 2005; Burchi, 2010; Webb and Block, 2004). For older children and adolescents, the effects have hardly been analyzed. Moreover, existing studies typically do not differentiate by type of nutrition knowledge, which would be useful to better understand how nutrition education programs should be designed to make them most effective.

Studies on the effects of maternal nutrition knowledge in developing countries are mainly restricted to children under five years of age (e.g. Appoh and Krekling, 2005; Burchi, 2010; Webb and Block, 2004). It is assumed that nutritional improvements are most beneficial for young children (Black et al., 2013; Leroy et al., 2014; Ruel et al., 2008). Appoh and Krekling (2005), for instance, used data from Ghana to illustrate positive associations between mothers' nutritional knowledge and the nutritional status of children under three. In that study on Ghana, maternal nutrition knowledge was measured with a composite knowledge score, calculated using answers to questions on breastfeeding, complementary feeding, and causes of Kwashiorkor. Burchi (2010) found positive effects of maternal knowledge on preschool children based on 
nationally representative data from Mozambique. Burchi (2010) constructed a nutrition and health knowledge variable by considering respondents' awareness of vitamin A, HIV/AIDS, oral rehydration, and family planning.

A few studies identified positive links between maternal nutrition knowledge and child nutrition also for older children, but this evidence is limited to developed countries. Variyam et al. (1999) used data from the US and showed that maternal health awareness and knowledge about nutrient contents of foods had positive effects on dietary quality of children between 2 and 17 years of age. Also using data from households in the US, Tabbakh and Freeland-Graves (2016) measured maternal nutrition knowledge based on awareness of nutrient contents and dietary recommendations, finding a positive association with adolescents' dietary quality and a negative association with adolescents' body mass index.

Here, we contribute to this literature by analyzing associations between different types of maternal nutrition knowledge and older children's nutritional status in a developing country. We use primary survey data collected in urban Kenya in 2012 and 2015. Specifically, we aim to answer the following two research questions: (1) Is maternal nutrition knowledge positively associated with height-for-age Z-score (HAZ) of children and adolescents? (2) Do different types of maternal nutrition knowledge produce dissimilar results?

Kenya is an interesting example for this type of research because malnutrition in all its forms is prevalent. Especially in urban areas, traditional diets are increasingly shifting towards more processed foods, which was shown to contribute to overweight and obesity among adults (Rischke et al., 2015; Kimenju et al., 2015). At the same time, rates of stunting remain relatively high among children and adolescents. The coexistence of different forms of malnutrition in the same setting and the same households is common also in other parts of Africa. In such situations, it is especially important to better understand the role of nutrition knowledge. This can help to design more effective food and nutrition policies.

\subsection{Materials and Methods}

\subsubsection{Conceptual Framework}

Theoretical and empirical research suggests that maternal nutrition knowledge is necessary but not sufficient for healthy child nutrition and for inducing related behavioral change (e.g. 
Contento, 2008; Hawkes et al., 2015). Mothers are particularly important for nutritional outcomes of children and other household members, because in most situations mothers are primarily responsible for dietary choices and food preparation.

There are two main pathways how children can be affected by the nutrition knowledge of their mother. First, the quantity, quality, and diversity of the food prepared in the household, as well as the sanitary practices, influence child nutritional outcomes directly (Campbell et al., 2014; Variyam et al., 1999). Second, the dietary and sanitary practices observed and experienced during childhood can also have an indirect effect through forming attitudes towards nutrition and health (Hoddinott et al., 2016; Vereecken and Maes, 2010; Yabanc1 et al., 2014). Attitudes developed during childhood are known to affect own dietary practices in later life (Kigaru et al., 2015). This already starts with older children and adolescents making their own choices for food consumed away from home. Against this background it is very plausible that different types of maternal nutrition knowledge can have different effects on child nutrition.

Household and contextual variables - such as living standard and food environment - can influence maternal nutrition knowledge and also child nutritional outcomes (Hawkes et al., 2015). In our empirical analysis, we control for such factors through including appropriate covariates in regression models. The main nutritional outcome of interest is child HAZ, which measures long-term nutritional outcomes. Maternal nutrition knowledge is expected to influence the nutrition of children and adolescents in the long run.

\subsubsection{Study Context and Data}

The data for this study were collected in two rounds of a household survey conducted in Kenya in 2012 and 2015. Kenya's child undernutrition rates are high, with 35\% of all children being stunted, 7\% wasted, and $16 \%$ underweight (Matanda et al., 2014; Ministry of Public Health and Sanitation, 2012). Our research was conducted in Central Kenya, where child undernutrition has seen only moderate improvement over the last two decades (Matanda et al., 2014).

We concentrated on urban and peri-urban areas and used a two-stage sampling procedure. At the first stage, we purposively selected three towns in Central Kenya, namely Ol Kalou, Njabini, and Mwea. These three towns have similar characteristics in terms of the size of the urban center, infrastructure conditions, and availability of social institutions (hospitals etc.). Yet some variation in terms of the type of available food retail outlets was observed (Kimenju et al., 2015; Rischke 
et al., 2015). At the second stage, around 150 households were randomly selected in each of the three towns. In 2012, the total sample comprised 453 households. In 2015, the sample included 450 households. For the 2015 survey round, about half of the 2012 households were revisited, the other half were newly selected, again using random sampling.

In both survey rounds, a structured questionnaire was used to collect data on various socioeconomic characteristics, including household composition, income sources, food and nonfood consumption expenditures, the health of household members, and access to various types of services. In addition to the household-level data we took anthropometric measures from one randomly selected child (aged 5-18) in each household and his/her mother or caretaker. ${ }^{13}$ Body measurements were taken according to international standards (Centers for Disease Control and Prevention, 2007) with an accuracy of $0.1 \mathrm{~kg}$ for body weight and $0.7 \mathrm{~cm}$ for height (de Onis et al., 2004). Maternal nutrition knowledge was captured through a series of diet and nutrition related questions, as explained in more detail below.

Not all sample households had children between 5 and 18 years of age. In a few cases, there were children in the households but we were unable to trace them, even after repeated visits. For the analysis, we pool the sample from the two survey rounds and construct a child-level data set. Sixty-four children were observed during both survey rounds (128 observations), while 298 children were observed only in 2012 or in 2015 . In total, we have 426 observations from children and adolescents (aged 5-18) with complete data for all relevant variables.

\subsubsection{Measuring Child Nutritional Outcomes}

We used the WHO growth references for school-aged children and adolescents (de Onis, 2007) to generate height-for-age Z-scores (HAZ) for all children and adolescents in our sample. HAZ refers to the standard deviation from the median height of a child or adolescent of the same age and sex in a reference population. A child or adolescent is considered stunted (extremely stunted; mildly stunted) if the Z-score is below the cutoff of $-2(-3 ;-1)$ standard deviations below the reference population (O'Donnell et al., 2008; WHO, 2006b). A low HAZ reflects a status of suboptimal growth due to long-term adverse nutrition and health conditions (WHO, 2016b, WHO, 1995). While child growth largely depends on nutrition and health during early childhood,

\footnotetext{
${ }^{13}$ In cases where the child's mother was unavailable, data from another female caretaker in the same household were taken. This happened in $12 \%$ of the sample households.
} 
conditions during later childhood and adolescence also matter, and some catch-up growth is possible (Adair, 1999; Darnton-Hill et al., 2004; Prentice et al., 2013; Stein et al., 2010).

In our sample, we only consider children above 5 years of age, without assuming that the association between mothers' nutrition knowledge and HAZ is directly transferable to younger children. As mentioned, however, a positive association for younger children has been shown in previous studies (e.g. Appoh and Krekling, 2005; Burchi, 2010; Webb and Block, 2004).

\subsubsection{Measuring Maternal Nutrition Knowledge}

In the survey, we asked the children's mothers various questions concerning nutrition knowledge. Building on the 'stages of change' model (Glanz et al., 1994), which illustrates that changes in dietary behavior have different types of information needs, our knowledge questions were subdivided into three categories: (a) knowledge about food ingredients (particularly focusing on sugar, fat, and salt), (b) knowledge about specific dietary recommendations (focusing on the consumption of fresh fruits and vegetables and on breastfeeding), and (c) knowledge about the health consequences of not following recommended dietary practices. Details of the questions asked are shown in Table 4.1 .

Responses to each question were classified as correct or incorrect. Based on the number of correct responses, we generated different types of nutrition knowledge scores. First, for each respondent we used the sum of correct responses for the different questions belonging to the same knowledge category. This sum was then divided by the number of correct responses at the 95\% distribution of correct responses among all individuals. To standardize values in a range between 0 and 1, we replaced any value greater than one with the value 1 . This procedure results in an individual nutrition knowledge score for each category (a), (b), and (c), which we use in order to analyze the role of each type of nutrition knowledge. Second, for each respondent we calculate an aggregated nutrition knowledge score as the arithmetic mean of the knowledge scores for all three categories.

\subsubsection{Statistical Analysis}

We use non-parametric and parametric statistical approaches to analyze the data. Non-parametric approaches that we use include local polynomial regression and kernel density plots to visualize the association between maternal nutrition knowledge and child HAZ. A local polynomial regression smooths a scatter plot of the two variables by using a polynomial fit. The analysis 
applies a weighted least squares regression with greater weights given to data points closer to the polynomial fit (Cleveland, 1979).

Kernel density plots smooth kernel density functions of each data point, whereby the kernel estimates vary depending on the number of observations in the neighborhood of each data point (Silverman, 1986; Wand and Jones, 1995). In our density plot, we use a univariate kernel density estimation of HAZ for households with different levels of nutrition knowledge. For this purpose, we take the arithmetic mean of the aggregated maternal nutrition knowledge score and split the sample into two: households with a high (above average) and households with a low (below average) nutrition knowledge score. We also use a modified threshold in a robustness check.

For the parametric statistical analysis, we use ordinary least squares (OLS) regression models of the following form:

$$
H A Z_{i t}=\beta_{0}+\beta_{1} N_{h t}+\beta_{2}^{\prime} Z_{i t}+\beta_{3}^{\prime} X_{h t}+\beta_{4}^{\prime} E_{h t}+\beta_{4} T+\varepsilon_{i}
$$

where subscript $i$ denotes child-level and subscript $h$ household-level variables, measured at time t. $H A Z_{i t}$ is the height-for-age Z-score of children and adolescents. $N_{h t}$ is the maternal nutrition knowledge score. $\boldsymbol{Z}_{i t}$ is a vector of child characteristics such as age, sex, and the incidence of infectious diseases during the month prior to each survey round. $\boldsymbol{X}_{h t}$ is a vector of household characteristics such as age and sex of the household head and height of the mother. $\boldsymbol{E}_{h t}$ is a vector of human capital and living standard variables, where we specifically include maternal education and household consumption expenditures ${ }^{14}$. Maternal education refers to the schooling years of the mother and is therefore different from the more specific maternal nutrition knowledge score. $T$ is a time dummy representing the survey year and taking a value of 1 for 2015. $\varepsilon_{i}$ is a random error term with mean zero.

We are particularly interested in the estimate for $\beta_{1}$ and hypothesize a positive association between maternal nutrition knowledge and child HAZ. To test for the role of different types of nutrition knowledge, we run the model in four different versions. In model (1), $N_{h t}$ is the aggregate nutrition knowledge score, whereas in models (2), (3), and (4) we use the

\footnotetext{
${ }^{14}$ Household consumption expenditures include expenditures for all food and non-food items consumed by the household over a period of one month. To make values comparable across households of different size, we express consumption expenditures per adult equivalent. Monetary values for 2015 were deflated to 2012 using the consumer price index.
} 
disaggregated scores for the three knowledge categories explained above. Furthermore, variants of each model are estimated, with and without including $\boldsymbol{E}_{h t}$. Maternal education and household consumption expenditures are important control variables, but due to their expected correlation with $N_{h t}$ they may capture some of the maternal knowledge effects. Comparing the estimates with and without $E_{h t}$ allows us to examine whether maternal nutrition knowledge has a significant association with child HAZ even after controlling for maternal education and household living standard.

We estimate model (1) in four variants. Model (1A) presents the base model without $\boldsymbol{E}_{h t}$ included. Models (1B) and (1C) respectively include maternal education and consumption expenditures, whereas Model (1D) includes both these variables together. For brevity, Models (2) to (4) are only presented in two variants, namely with and without both variables in $\boldsymbol{E}_{h t}$ included.

Although one may expect the nutrition knowledge variable to be endogenous, we control for relevant confounding factors in estimating HAZ of children and adolescents. Note that we do not claim causality but seek to explore associations. To control for heteroscedasticity, we use robust standard errors based on White's heteroscedasticity correction (White, 1980). We are looking at current maternal nutrition knowledge, which has likely formed over a longer period of time, and relate this to current child nutritional outcomes, which are also the result of a longer-term process. The implicit assumption is that maternal nutrition knowledge and child nutritional outcomes have similar time horizons.

\subsection{Results}

\subsubsection{Descriptive Results}

Table 4.1 shows the questions that were asked in the survey to calculate the maternal nutrition knowledge scores, as well as the share of respondents giving correct answers. The highest average share of correct responses is observed for knowledge about the health consequences of not following dietary recommendations (79\%). For the other two categories of nutrition knowledge, the average shares of correct responses are lower. Comparing between the two survey years, the share of correct responses on food ingredients and on dietary recommendations was somewhat lower in 2015 than in 2012, while the share of correct responses on health 
consequences was higher in 2015. Hence, it is not possible to establish a clear time trend for maternal nutrition knowledge.

Table 4.1. Nutrition knowledge questions and percentages of correct answers

\begin{tabular}{|c|c|c|c|c|}
\hline & \multicolumn{3}{|c|}{ Percentage correct } & \multirow{2}{*}{$\begin{array}{l}\text { Correct } \\
\text { answer }\end{array}$} \\
\hline & All years & 2012 & 2015 & \\
\hline Knowledge about food ingredients & 35 & 37 & 30 & \\
\hline \multicolumn{5}{|c|}{ Do you think these food products are high, medium or low in added sugar? } \\
\hline Natural yoghurt & 29 & 37 & 21 & Low \\
\hline Flavored yoghurt & 26 & 28 & 25 & High \\
\hline Fresh juice & 24 & 33 & 14 & Low \\
\hline White bread & 47 & 50 & 43 & Low \\
\hline Tomato ketchup & 16 & 20 & 12 & High \\
\hline \multicolumn{5}{|l|}{ Do you think these food products are high, medium or low in fat? } \\
\hline Chips & 79 & 88 & 70 & High \\
\hline Margarine & 62 & 68 & 56 & High \\
\hline Crisps & 30 & 29 & 31 & High \\
\hline Fried beef sausage & 46 & 46 & 46 & High \\
\hline Honey & 53 & 70 & 36 & Low \\
\hline Raw nuts & 12 & 12 & 13 & High \\
\hline White bread & 64 & 70 & 58 & Low \\
\hline Cake & 27 & 36 & 19 & High \\
\hline \multicolumn{5}{|l|}{ Do you think these food products are high, medium or low in salt? } \\
\hline Sausages & 22 & 19 & 25 & High \\
\hline Brown bread & 6 & 4 & 8 & High \\
\hline Popcorn & 26 & 28 & 25 & High \\
\hline Tomato ketchup & 15 & 16 & 14 & High \\
\hline Instant noodles & 14 & 13 & 15 & High \\
\hline Knowledge about dietary recommendations & 52 & 56 & 49 & \\
\hline $\begin{array}{l}\text { How many servings of fruits and vegetables together do you } \\
\text { think experts advise people to eat every day? }\end{array}$ & 8 & 16 & 1 & $4-6$ \\
\hline $\begin{array}{l}\text { What do you think is the recommended period of exclusively } \\
\text { breastfeeding infants? }\end{array}$ & 96 & 96 & 96 & 6 months \\
\hline $\begin{array}{l}\text { Knowledge about the health consequences of not } \\
\text { following dietary recommendations }\end{array}$ & 79 & 72 & 86 & \\
\hline $\begin{array}{l}\text { Are you aware of any health problems associated with } \\
\text { eating none or too little fresh fruits and vegetables? }\end{array}$ & 78 & 74 & 82 & \\
\hline $\begin{array}{l}\text { Are you aware of any health problems or diseases } \\
\text { associated with excess body weight? }\end{array}$ & 92 & 88 & 96 & \\
\hline $\begin{array}{l}\text { Which health problems or diseases do you think are } \\
\text { associated with not exclusively breastfeeding infants? }\end{array}$ & 67 & 54 & 81 & \\
\hline Observations $^{\mathrm{a}}$ & 399 & 200 & 199 & \\
\hline
\end{tabular}

Notes: ${ }^{\mathrm{a}}$ The number of observations refers to the number of unique households. 
The average number of correct responses for the three categories and the calculated nutrition knowledge scores are presented in Table 4.2. The average aggregate nutrition knowledge score is 0.59 , which means that the average respondent had $59 \%$ of the knowledge of the best-performing individuals $\left(95^{\text {th }}\right.$ percentile of correct answers) in the sample.

Table 4.2. Number of correct responses and maternal nutrition knowledge scores

\begin{tabular}{|c|c|c|c|}
\hline & All years & 2012 & 2015 \\
\hline \multicolumn{4}{|l|}{ Number of correct responses } \\
\hline Knowing food ingredients ${ }^{a}$ & $5.96(2.94)$ & $6.63(2.81)$ & $5.30(2.92)$ \\
\hline Knowing dietary recommendations ${ }^{\mathrm{b}}$ & $1.05(0.34)$ & $1.12(0.43)$ & $0.97(0.21)$ \\
\hline Knowing health consequences ${ }^{c}$ & $2.37(0.81)$ & $2.15(0.87)$ & $2.60(0.67)$ \\
\hline \multicolumn{4}{|l|}{ Standardized knowledge scores } \\
\hline Knowing food ingredients & $0.46(0.22)$ & $0.47(0.20)$ & $0.44(0.24)$ \\
\hline Knowing dietary recommendations & $0.52(0.17)$ & $0.56(0.21)$ & $0.49(0.11)$ \\
\hline Knowing health consequences & $0.79(0.27)$ & $0.72(0.29)$ & $0.87(0.22)$ \\
\hline Aggregate nutrition knowledge score & $0.59(0.13)$ & $0.58(0.15)$ & $0.60(0.12)$ \\
\hline
\end{tabular}

Notes: Values are means with SD in parentheses. ${ }^{a}$ The total number of questions in this category was $18 .{ }^{\mathrm{b}}$ The total number of questions in this category was $2{ }^{\mathrm{c}}$ The total number of questions in this category was 3.

Table 4.3 shows descriptive statistics for the other variables used in the empirical analysis. The average height-for-age Z-score of children and adolescents in our sample is -0.85 , with lower values in 2012 (-1.05) than in 2015 (-0.66). HAZ of boys (-0.92) is lower than of girls (-0.78), which is consistent with other studies in Africa and Asia (Christiaensen and Alderman, 2004; Debela et al., 2015; Webb and Block, 2004). 
Table 4.3. Descriptive statistics

\begin{tabular}{|c|c|c|c|c|c|c|}
\hline \multirow[b]{2}{*}{ Variables } & \multirow[b]{2}{*}{ All } & \multicolumn{2}{|c|}{ Year } & \multicolumn{3}{|c|}{ By maternal nutrition knowledge ${ }^{c}$} \\
\hline & & 2012 & 2015 & $\begin{array}{l}\text { High nutrition } \\
\text { knowledge }\end{array}$ & $\begin{array}{c}\text { Low nutrition } \\
\text { knowledge }\end{array}$ & Difference \\
\hline Height-for-age Z-scores & $-0.85(1.20)$ & $-1.05(1.30)$ & $-0.66(1.19)$ & $-0.69(1.07)$ & $-1.01(1.31)$ & $0.31 * * *$ \\
\hline Height-for-age Z-scores, boys & $-0.92(1.22)$ & $-1.15(1.21)$ & $-0.66(1.18)$ & $-0.74(1.13)$ & $-1.09(1.29)$ & $0.35 * *$ \\
\hline Height-for-age Z-scores, girls & $-0.78(1.26)$ & $-0.94(1.38)$ & $-0.66(1.01)$ & $-0.65(1.02)$ & $-0.92(1.33)$ & $0.27 *$ \\
\hline Prevalence of stunting (\%) ${ }^{a}$ & 16 & 21 & 12 & 13 & 19 & $-0.06 *$ \\
\hline Prevalence of mildly stunting $(\%)^{\mathrm{a}}$ & 43 & 50 & 36 & 37 & 49 & $-0.12 * *$ \\
\hline Prevalence of extreme stunting $(\%)^{a}$ & 4 & 7 & 2 & 1 & 7 & $-0.06 * * *$ \\
\hline Age of child in months & $120(41.13)$ & $117(42.44)$ & $123(39.78)$ & $120(41.93)$ & $120(40.37)$ & -0.78 \\
\hline Sex of child ( $1=$ female $)$ & $0.52(0.50)$ & $0.48(0.50)$ & $0.56(0.50)$ & $0.53(0.50)$ & $0.51(0.50)$ & 0.03 \\
\hline Infection during past month $(1 / 0)$ & $0.08(0.26)$ & $0.09(0.29)$ & $0.06(0.24)$ & $0.10(0.30)$ & $0.05(0.22)$ & $0.04 *$ \\
\hline Sex of household head ( $1=$ female $)$ & $0.28(0.45)$ & $0.29(0.45)$ & $0.27(0.44)$ & $0.23(0.42)$ & $0.33(0.47)$ & $-0.10 * *$ \\
\hline Age of household head (years) & $41(10.55)$ & $40(10.57)$ & $41(10.53)$ & $40(9.69)$ & $41(11.42)$ & -0.58 \\
\hline Height of mother $(\mathrm{cm})$ & $159(5.81)$ & $158(5.81)$ & $159(5.78)$ & $159(5.35)$ & $158(6.26)$ & 0.70 \\
\hline Education of mother (schooling years) & $9.63(4.62)$ & $9.81(4.96)$ & $9.47(4.30)$ & $10.49(4.88)$ & $8.72(4.15)$ & $1.77 * * *$ \\
\hline Consumption expenditure (KES/month/AE) ${ }^{b}$ & $6770(3945)$ & $7031(4595)$ & $6540(3258)$ & $7230(4447)$ & $6284(3274)$ & $947 * *$ \\
\hline Ol Kalou & $0.34(0.47)$ & $0.36(0.48)$ & $0.32(0.47)$ & $0.33(0.47)$ & $0.34(0.47)$ & -0.00 \\
\hline Mwea & $0.28(0.45)$ & $0.23(0.42)$ & $0.32(0.47)$ & $0.31(0.46)$ & $0.25(0.43)$ & 0.06 \\
\hline Njabini & $0.39(0.49)$ & $0.42(0.49)$ & $0.35(0.48)$ & $0.36(0.48)$ & $0.42(0.49)$ & -0.05 \\
\hline Number of observations & 426 & 200 & 226 & 219 & 207 & \\
\hline
\end{tabular}

Notes: Values are means with SD in parentheses. ${ }^{a}$ Stunting is defined as HAZ<-2; mild stunting as HAZ<-1; extreme stunting as HAZ<-3. ${ }^{\mathrm{b}} 1$ US dollar $=95$ Kenyan Shilling (KES); average official exchange rate in 2015. Consumption expenditure value for 2015 has been deflated to 2012 values using World Bank's Consumer Price Index $(2010=100) .{ }^{c}$ Using the aggregate maternal nutrition knowledge score, households were subdivided into those with above and those with below average scores. $\mathrm{AE}$, adult equivalent; HAZ, height-for-age Z-score; KES, Kenyan Shilling. $* P<0.10$, ** $P<0.05$, *** $P<0.01$. 
In the right-hand part of Table 4.3, we subdivide the sample into households with high and low maternal nutrition knowledge using the average aggregate nutrition score as the cutoff point. Children and adolescents with mothers that have high nutrition knowledge have a significantly larger HAZ $(p<0.01)$ than children and adolescents with mothers that have low nutrition knowledge. We also observe significant differences between the two groups for some of the other child and household characteristics, such as the incidence of infectious diseases, sex of the household head, and household consumption expenditures. These are variables that we control for in the parametric regressions.

\subsubsection{Non-Parametric Estimation Results}

The graphical illustration of the non-parametric analysis shows a positive link between maternal nutrition knowledge and HAZ of children and adolescents (Figure 4.1). Panel (A) depicts the local polynomial regression plot. It can clearly be seen that maternal nutrition knowledge has a positive association with HAZ. Panel (B) shows the distribution of HAZ in households with high and low maternal nutrition knowledge. In households with high nutrition knowledge, the HAZ distribution is shifted to the right, which further underlines the positive association. The subsequent analysis investigates this relationship after controlling for confounding factors. 

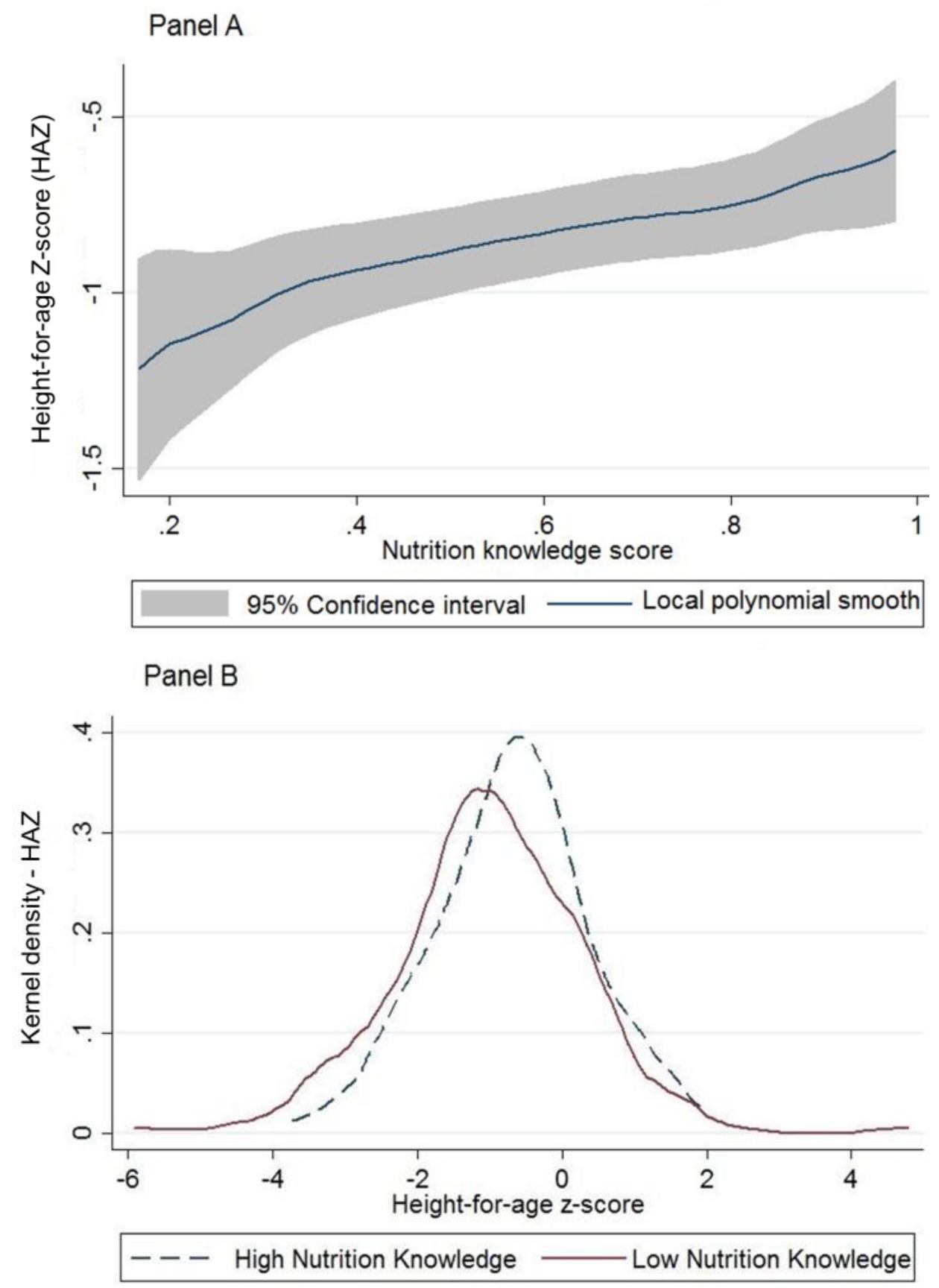

Figure 4.1. Relationship between maternal nutrition knowledge and child HAZ. Panel (A) shows a local polynomial regression with $\mathrm{N}=426$ observations of children and adolescents (aged 518). Panel (B) shows kernel density plots of child and adolescent HAZ in households with high maternal nutrition knowledge score $(\mathrm{N}=219)$ and in households with low maternal nutrition knowledge score $(\mathrm{N}=207)$. 


\subsubsection{Parametric Estimation Results}

Table 4.4 shows estimation results of the HAZ models using the aggregate maternal nutrition knowledge score, next to a set of child and household level covariates as explanatory variables. Model (1A) does not control for maternal education and household consumption expenditures. The estimates show that maternal nutrition knowledge is positively and significantly associated with HAZ of children and adolescents $(p<0.01)$. The estimation coefficient of 1.25 implies that an increase in the knowledge score from 0 to 1 would increase child HAZ by 1.25. This is an extreme interpretation, however, because most of the observed knowledge scores are in a narrower range. As shown in Table 4.2, the aggregate nutrition knowledge score has a mean value of 0.59 and a standard deviation of 0.13 . Using the 1.25 estimate from model (1A), an increase in the knowledge score by one standard deviation is associated with a 0.16 increase in HAZ.

Model (1B) in Table 4.4 additionally controls for maternal education. Results show that education of the mother positively affects HAZ of children and adolescents. In line with previous research by Burchi (2010) for younger children, we find that maternal nutrition knowledge remains positive and significant $(\mathrm{p}<0.01)$, even after accounting for maternal education. The coefficient magnitude for nutrition knowledge declines somewhat, implying that maternal nutrition knowledge and maternal education are positively correlated, as one would expect. However, the results also clearly suggest that formal school education is not the only pathway through which nutrition knowledge is acquired.

Model (1C) in Table 4.4 excludes maternal education and controls for household consumption expenditures instead. Consumption expenditures have a significantly positive effect on HAZ of children and adolescents, as one would expect. At the same time, the coefficient for maternal nutrition knowledge shrinks, but remains positive and statistically significant $(p<0.05)$. This suggests that maternal nutrition knowledge plays an important role for child nutritional outcomes, even after controlling for household living standard. ${ }^{15}$

\footnotetext{
${ }^{15}$ This result of a strong positive association between maternal nutrition knowledge and HAZ of children and adolescents also holds when we use alternative indicators of nutrition knowledge. In Table A4.1 in the Appendix A4, we show results where we used the total number of correct answers to the nutrition questions instead of the standardized aggregate knowledge score.
} 
Table 4.4. Association between aggregate maternal nutrition knowledge and child HAZ

\begin{tabular}{|c|c|c|c|c|}
\hline & Model (1A) & Model (1B) & Model (1C) & Model (1D) \\
\hline Aggregate nutrition knowledge score & $\begin{array}{c}1.25^{* * *} \\
(0.35)\end{array}$ & $\begin{array}{c}1.01 * * * \\
(0.36)\end{array}$ & $\begin{array}{c}0.90 * * \\
(0.35)\end{array}$ & $\begin{array}{l}0.85^{* *} \\
(0.35)\end{array}$ \\
\hline Age of child in months & $\begin{array}{c}-0.01 * * * \\
(0.00)\end{array}$ & $\begin{array}{c}-0.01 * * * \\
(0.00)\end{array}$ & $\begin{array}{c}-0.01 * * * \\
(0.00)\end{array}$ & $\begin{array}{c}-0.01 * * * \\
(0.00)\end{array}$ \\
\hline Sex of child $(1=$ female $)$ & $\begin{array}{c}0.15 \\
(0.11)\end{array}$ & $\begin{array}{c}0.16 \\
(0.11)\end{array}$ & $\begin{array}{c}0.17 \\
(0.11)\end{array}$ & $\begin{array}{c}0.17 \\
(0.11)\end{array}$ \\
\hline Infection during past month(1/0) & $\begin{array}{c}-0.39 * * \\
(0.20)\end{array}$ & $\begin{array}{c}-0.40 * * \\
(0.19)\end{array}$ & $\begin{array}{c}-0.42^{* *} \\
(0.18)\end{array}$ & $\begin{array}{c}-0.42 * * \\
(0.18)\end{array}$ \\
\hline Sex of household head $(1=$ female $)$ & $\begin{array}{l}-0.08 \\
(0.12)\end{array}$ & $\begin{array}{l}-0.04 \\
(0.12)\end{array}$ & $\begin{array}{l}-0.04 \\
(0.12)\end{array}$ & $\begin{array}{l}-0.03 \\
(0.12)\end{array}$ \\
\hline Age of household head(years) & $\begin{array}{c}0.00 \\
(0.01)\end{array}$ & $\begin{array}{c}0.01 \\
(0.01)\end{array}$ & $\begin{array}{c}0.01 \\
(0.01)\end{array}$ & $\begin{array}{c}0.01 \\
(0.01)\end{array}$ \\
\hline Height of mother $(\mathrm{cm})$ & $\begin{array}{c}0.05^{* * *} \\
(0.01)\end{array}$ & $\begin{array}{c}0.05^{* * *} \\
(0.01)\end{array}$ & $\begin{array}{c}0.04 * * * \\
(0.01)\end{array}$ & $\begin{array}{c}0.04 * * * \\
(0.01)\end{array}$ \\
\hline Year dummy(1=2015) & $\begin{array}{c}0.33^{* * *} \\
(0.11)\end{array}$ & $\begin{array}{c}0.35^{* * *} \\
(0.11)\end{array}$ & $\begin{array}{c}0.35^{* * * *} \\
(0.11)\end{array}$ & $\begin{array}{c}0.35 * * * \\
(0.11)\end{array}$ \\
\hline Education of mother (years) & & $\begin{array}{c}0.03 * * \\
(0.01)\end{array}$ & & $\begin{array}{c}0.01 \\
(0.02)\end{array}$ \\
\hline Consumption expenditures $(\log )$ & & & $\begin{array}{c}0.46 * * * \\
(0.11)\end{array}$ & $\begin{array}{c}0.43 * * * \\
(0.12)\end{array}$ \\
\hline Town dummies & Yes & Yes & Yes & Yes \\
\hline Constant & $\begin{array}{c}-8.47 * * * \\
(1.72)\end{array}$ & $\begin{array}{c}-8.61 * * * \\
(1.72)\end{array}$ & $\begin{array}{c}-12.11^{* * *} \\
(1.79)\end{array}$ & $\begin{array}{c}-11.88 * * * \\
(1.89)\end{array}$ \\
\hline R-squared & 0.18 & 0.20 & 0.23 & 0.23 \\
\hline Number of obs. & 426 & 426 & 426 & 426 \\
\hline
\end{tabular}

Notes: Coefficient estimates are shown with standard errors in parentheses. The dependent variable in all models is height-for-age Zscores (HAZ) of children and adolescents (aged 5-18). * $P<0.10, * * P<0.05$, *** $P<0.01$.

In Model (1D) of Table 4.4 we control for both maternal education and consumption expenditures. Once consumption expenditures are controlled for, mother's education no longer affects HAZ of children and adolescents. This is due to the close correlation between maternal education and household consumption expenditures. As maternal education is an important determinant of household income, and income determines consumption expenditures, this close correlation between the variables should not surprise. The coefficient of the maternal nutrition knowledge score remains significant also in this model specification. 
The coefficient estimates of the other control variables in Table 4.4 also reveal some interesting patterns. The age of the child is negatively associated with HAZ $(p<0.01)$, which underlines the importance of including older children and adolescents in the analysis. Children who suffered from an infectious disease during the month prior to the survey have significantly lower HAZ $(p<0.05)$. In children, infectious diseases often have immediate implications for body weight, which is not reflected in HAZ. However, the infectious disease dummy is probably also a proxy of health and sanitation conditions in the household more generally, so that the negative association with HAZ is not surprising. The positive and significant association between the mother's height and the child's HAZ $(p<0.01)$ is also as expected. Finally, the year dummy indicates that the nutritional status of children and adolescents generally improved between 2012 and 2015 .

Table 4.5 shows estimation results of the HAZ models with the disaggregated nutrition knowledge scores (for the three knowledge categories) as explanatory variables. Model (2) reveals that maternal knowledge about food ingredients is associated with a higher HAZ of children and adolescents, even though the association is relatively weak $(p<0.10)$. Model (3) suggests that maternal knowledge about dietary recommendations has no significant association with HAZ of children and adolescents.

The largest and strongest positive association with HAZ is found for maternal knowledge about the health consequences of not following dietary recommendations. Given that the observed standard deviation for the knowledge score on health consequences is 0.27 (Table 4.2), the coefficient estimate of 0.54 in model (4A) implies that an increase in knowledge of this type by one standard deviation is associated with a 0.15 increase in child HAZ. This association remains weakly significant $(p<0.1)$ also after controlling for maternal education and household consumption expenditures.

An important implication of comparing coefficients for the different types of knowledge in Table 4.5 is that knowledge about the negative health consequences of not following dietary recommendations seems to play a more important role than knowledge about the dietary recommendations as such. 
Table 4.5. Association between different types of maternal nutrition knowledge and child HAZ

\begin{tabular}{|c|c|c|c|c|c|c|}
\hline & \multicolumn{2}{|c|}{ Model (2) } & \multicolumn{2}{|c|}{ Model (3) } & \multicolumn{2}{|c|}{ Model (4) } \\
\hline & $(2 \mathrm{~A})$ & $(2 \mathrm{~B})$ & $(3 \mathrm{~A})$ & (3B) & $(4 \mathrm{~A})$ & (4B) \\
\hline Knowledge about food ingredients & $0.41 *(0.22)$ & $0.32(0.22)$ & & & & \\
\hline Knowledge about dietary recommendations & & & $0.42(0.35)$ & $0.17(0.34)$ & & \\
\hline Knowledge about health consequences & & & & & $0.54 * * *(0.20)$ & $0.35 *(0.20)$ \\
\hline Age of child in months & $-0.01 * * *(0.00)$ & $-0.01 * * *(0.00)$ & $-0.01 * * *(0.00)$ & $-0.01 * * *(0.00)$ & $-0.01 * * *(0.00)$ & $-0.01 * * *(0.00)$ \\
\hline Sex of child ( $1=$ female $)$ & $0.17(0.11)$ & $0.19 *(0.11)$ & $0.15(0.11)$ & $0.18 *(0.11)$ & $0.15(0.11)$ & $0.18 *(0.11)$ \\
\hline Infection during past month (1/0) & $-0.34 *(0.20)$ & $-0.39 * *(0.18)$ & $-0.34 *(0.19)$ & $-0.39 * *(0.18)$ & $-0.38 *(0.20)$ & $-0.41 * *(0.19)$ \\
\hline Sex of household head ( $1=$ female) & $-0.11(0.12)$ & $-0.04(0.12)$ & $-0.13(0.12)$ & $-0.05(0.12)$ & $-0.09(0.12)$ & $-0.03(0.12)$ \\
\hline Age of household head (years) & $0.00(0.01)$ & $0.01(0.01)$ & $0.00(0.01)$ & $0.01(0.01)$ & $0.00(0.01)$ & $0.01(0.01)$ \\
\hline Height of mother $(\mathrm{cm})$ & $0.05^{* * *}(0.01)$ & $0.04 * * *(0.01)$ & $0.05 * * *(0.01)$ & $0.04 * * *(0.01)$ & $0.05^{* * *}(0.01)$ & $0.04 * * *(0.01)$ \\
\hline Year dummy $(1=2015)$ & $0.37 * * *(0.11)$ & $0.38 * * *(0.11)$ & $0.38 * * *(0.11)$ & $0.38 * * *(0.11)$ & $0.27 * *(0.11)$ & $0.31 * * *(0.11)$ \\
\hline Education of mother (schooling years) & & $0.01(0.02)$ & & $0.02(0.02)$ & & $0.01(0.02)$ \\
\hline Consumption expenditures (log) & & $0.45 * * *(0.12)$ & & $0.44 * * *(0.12)$ & & $0.43 * * *(0.12)$ \\
\hline Town dummies & Yes & Yes & Yes & Yes & Yes & Yes \\
\hline Constant & $-7.91 * * *(1.72)$ & $-11.73 * * *(1.89)$ & $-7.97 * * *(1.73)$ & $-11.65^{* * *}(1.90)$ & $-8.21 * * *(1.73)$ & $-11.76^{* * *}(1.89)$ \\
\hline R-squared & 0.17 & 0.22 & 0.17 & 0.22 & 0.18 & 0.22 \\
\hline Number of observations & 426 & 426 & 426 & 426 & 426 & 426 \\
\hline
\end{tabular}

Notes: Coefficient estimates are shown with standard errors in parentheses. The dependent variable in all models is height-for-age Z-scores (HAZ) of children and adolescents (aged 5 -18). * $P<$ $0.10, * * P<0.05, * * * P<0.01$. 


\subsubsection{Robustness Checks}

In the descriptive analysis and for some of the non-parametric estimations, we subdivided the sample into households with high and low maternal nutrition knowledge, using the average aggregate nutrition score as the cutoff point. This cutoff was chosen for convenience. To check whether the results change when using a different cutoff, we classified those that correctly responded to more (less) than $50 \%$ of the nutrition questions as having high (low) nutrition knowledge. The results do not change much (see Table A4.2 and Figure A4.1, Appendix A4), underlining the robustness of the findings to changes in the cutoff point.

Another aspect that is worth some further analysis is the fact that our sample is characterized by a high attrition rate. Many children that were included in the first survey round could not be included again in the second round and were replaced by other children in the same locations. In order to check whether there is any systematic difference between the children that were included in both survey rounds and those that were only included in one of the rounds, we regressed an attrition dummy on the set of socioeconomic explanatory variables, using a probit specification (see Table A4.3, Appendix A4). Most of the socioeconomic variables are statically insignificant in this probit model, except for height and education of the mother. We do not find systematic differences for the child's own characteristics. The probit model was also used to calculate an inverse mills ratio that we included as an additional explanatory variable in model (1) to explain HAZ. This is a common approach to test and control for possible attrition bias. The inverse mills ratio in this HAZ model is statistically insignificant (see Table A4.3), so we conclude that our results are not affected by attrition bias.

\subsubsection{Limitations}

Two limitations of the study should be mentioned here. First, while international growth standards exist for infants and preschool children (WHO, 2006b), for children above 5 years of age the available growth references still have certain shortcomings (de Onis, 2007). Although the references for school-age children and adolescents were reconstructed recently ${ }^{16}$, an international growth standard for this age group, designed with multi-ethnic sampling strategies, does not exist. This means that levels of optimal growth for children between 5-19 years cannot be derived

\footnotetext{
${ }^{16}$ The reconstructed growth references for children between 5-19 years make use of the 1977 NCHS/WHO growth reference (Hamill et al., 1977) supplemented with data from the WHO child growth standards (WHO, 2006b) and apply the state-of-the-art statistical methods (de Onis, 2007).
} 
very accurately (Butte et al., 2007; Wells, 2014). We do not expect that this inaccuracy would affect the general relationship between maternal nutrition knowledge and child growth.

Second, the number of survey questions for each of the nutrition knowledge categories in our study was not equally distributed. In the calculation of the aggregate knowledge score, we took this into account by first calculating a score for each category separately before constructing the composite knowledge indicator. This ensures that none of the categories is under- or overrepresented in the aggregate score. Nevertheless, more questions in some of the categories could have further added to our understanding of the role of different types of nutrition knowledge. In future research, it would be particularly interesting to increase the number and the variety of questions related to dietary recommendations and to the health consequences of not following such recommendations.

\subsection{Discussion}

It has long been established that raising awareness of balanced nutrition and nutrition-related health issues is one important avenue of reducing child undernutrition in developing countries. However, the extent to which different types of nutrition knowledge affect child nutritional outcomes is not yet sufficiently understood. We have contributed to this research direction by using survey data from Central Kenya. Results show that maternal nutrition knowledge is positively and significantly associated with HAZ of children and adolescents. This positive association is consistent with previous findings using data from younger children (e.g. Christiaensen and Alderman, 2004; Variyam et al., 1999; Webb and Block, 2004).

In addition, we have analyzed the role of different types of nutrition knowledge, which has rarely been done in previous studies. Indeed, our results differ by knowledge type. Maternal knowledge about food ingredients only has a weak positive association with HAZ of children and adolescents. For maternal knowledge about specific dietary recommendations, no significant association was detected. The strongest positive association with HAZ was found for maternal knowledge about the health consequences of not following recommended dietary practices.

These findings imply that building broader awareness of the health risks of unsuitable dietary practices among mothers and caretakers is important for improving nutrition and health of children and adolescents. Put differently, knowledge about adverse health consequences seems to be more effective in shaping dietary behavioral responses than knowledge about food ingredients 
and dietary recommendations per se. Of course, nutrition education programs will always have to take into account the concrete nutritional needs and challenges in a particular setting. But our conclusion that effective nutrition education and training programs should always link dietary recommendations to concrete health consequences probably holds beyond the concrete setting. 


\subsection{Appendix A4}

\section{Table A4. 1. Association between maternal nutrition knowledge and child HAZ (alternative knowledge indicator)}

\begin{tabular}{lcc}
\hline \hline & \multicolumn{2}{c}{ Height-for-age Z-score } \\
\cline { 2 - 3 } & Model (A4.1-1) & Model (A4.1-2) \\
\hline Maternal knowledge (number of correct answers) & $0.04^{* * *}(0.02)$ & $0.03^{* *}(0.02)$ \\
Age of child in months & $-0.01^{* * *}(0.00)$ & $-0.01^{* * *}(0.00)$ \\
Sex of child $(1=$ female) & $0.16(0.11)$ & $0.19^{*}(0.11)$ \\
Infection during past month (1/0) & $-0.35^{*}(0.20)$ & $-0.40^{* *}(0.18)$ \\
Sex of household head (1=female) & $-0.09(0.12)$ & $-0.05(0.12)$ \\
Age of household head (years) & $0.00(0.01)$ & $0.01(0.01)$ \\
Height of mother $(\mathrm{cm})$ & $0.05^{* * *}(0.01)$ & $0.04^{* * *}(0.01)$ \\
Year dummy $(1=2015)$ & $0.40^{* * *}(0.11)$ & $0.40^{* * *}(0.11)$ \\
Consumption expenditure (log) & & $0.48^{* * *}(0.11)$ \\
Town dummies & Yes & Yes \\
Constant & $-8.15^{* * *}(1.72)$ & $-12.06^{* * *}(1.78)$ \\
R-squared & 0.18 & 0.22 \\
Number of observations & 426 & 426 \\
\hline Nos Coffir
\end{tabular}

Notes: Coefficient estimates are shown with standard errors in parentheses. The dependent variable in all models is height-forage Z-scores (HAZ) of children and adolescents (aged 5-18). * $P<0.1$; ** $P<0.05$; *** $P<0.01$. 
Table A4.2. Descriptive statistics by maternal nutrition knowledge (alternative cutoff point for high and low nutrition knowledge)

\begin{tabular}{lcccc}
\hline \hline Variables & \multirow{2}{*}{ All } & \multicolumn{2}{c}{ By maternal nutrition knowledge ${ }^{\text {a }}$} \\
\cline { 3 - 5 } & & $\begin{array}{c}\text { High nutrition } \\
\text { knowledge }\end{array}$ & $\begin{array}{c}\text { Low nutrition } \\
\text { knowledge }\end{array}$ & Difference \\
\hline HAZ & $-0.85(1.20)$ & $-0.61(0.98)$ & $-0.92(1.26)$ & $0.31^{* *}$ \\
HAZ, boys & $-0.92(1.22)$ & $-0.52(0.91)$ & $-1.05(1.29)$ & $0.53^{* * *}$ \\
HAZ, girls & $-0.78(1.26)$ & $-0.71(1.04)$ & $-0.80(1.23)$ & 0.09 \\
Prevalence of stunting $^{\text {b }}$ & 0.16 & 0.09 & 0.18 & $-0.08^{* *}$ \\
Prevalence of mild stunting $^{\text {b }}$ & 0.43 & 0.32 & 0.46 & $-0.14^{* *}$ \\
Prevalence of extreme stunting $^{\text {b }}$ & 0.04 & 0.00 & 0.06 & $-0.06^{* *}$ \\
Number of observations & 426 & 106 & 320 & \\
\hline
\end{tabular}

Notes: Mean values are shown with standard deviations in parentheses. ${ }^{a}$ Using the total number correct answers to nutrition knowledge questions, households were subdivided into those who correctly answered more than $50 \%$ of the questions (high nutrition knowledge) and those who correctly answered less than $50 \%$ of the questions (low nutrition knowledge). ${ }^{\mathrm{b}}$ Stunting is defined as HAZ<-2; mild stunting as HAZ $<-1$; extreme stunting as HAZ<-3. * $P<0.1$; ** $P<0.05$; *** $P<0.01$. 


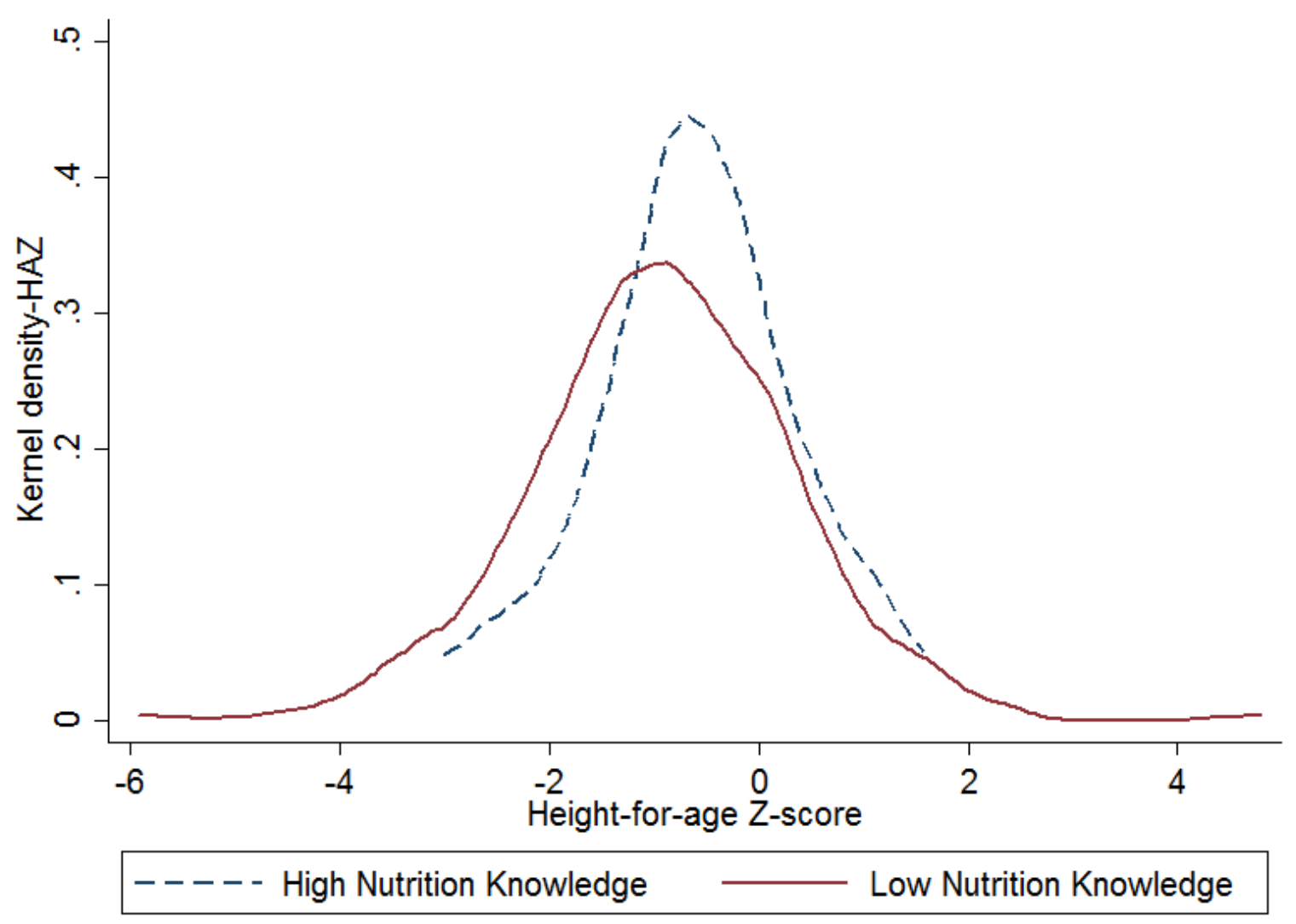

Figure A4.1. Kernel density of $\mathrm{HAZ}$ by alternative definition of nutrition knowledge threshold. Households with high nutrition knowledge score $(\mathrm{N}=106)$ correctly answered more than $50 \%$ of the questions; those with low nutrition knowledge score $(\mathrm{N}=320)$ correctly answered less than $50 \%$ of the questions. 


\section{Table A4.3. Attrition probit model and HAZ regression after controlling for possible attrition bias}

\begin{tabular}{|c|c|c|}
\hline & Attrition probit ${ }^{\mathrm{a}}$ & $\mathrm{HAZ}^{\mathrm{b}}$ \\
\hline Aggregate nutrition knowledge score & & $0.88 * *(0.35)$ \\
\hline Age in months & $0.00(0.00)$ & $-0.01 * * *(0.00)$ \\
\hline Sex of child(1=Female $)$ & $0.08(0.13)$ & $0.16(0.12)$ \\
\hline Infection during past month(1/0) & $-0.02(0.24)$ & $-0.41 * *(0.18)$ \\
\hline Sex of household head(1=Female) & $0.16(0.14)$ & $-0.06(0.13)$ \\
\hline Age of household head(years) & $0.00(0.01)$ & $0.01(0.01)$ \\
\hline Height of mother $(\mathrm{cm})$ & $-0.02 *(0.01)$ & $0.05^{* * *}(0.01)$ \\
\hline Year dummy(1=2015) & $0.13(0.13)$ & $0.33 * * *(0.12)$ \\
\hline Ol Kalou (town with SM since 2004) & $0.05(0.16)$ & $0.19(0.12)$ \\
\hline Mwea (town with SM since 2011) & $-0.05(0.17)$ & $0.03(0.14)$ \\
\hline Education of mother (schooling years) ${ }^{c}$ & $0.04 * *(0.02)$ & \\
\hline Consumption expenditure (log) & $0.12(0.13)$ & $0.43^{* * *}(0.16)$ \\
\hline Inverse mills ratio ${ }^{\mathrm{d}}$ & & $-0.28(0.87)$ \\
\hline Town dummies & Yes & Yes \\
\hline Constant & $2.03(2.11)$ & $-12.09 * * *(1.93)$ \\
\hline Chi2 & 14.84 & \\
\hline P-value & 0.19 & 0.00 \\
\hline R-squared & & 0.23 \\
\hline Number of observations & 426 & 426 \\
\hline
\end{tabular}

Notes: Coefficient estimates are shown with robust standard errors in parentheses. ${ }^{\mathrm{a}}$ The dependent variable is 1 if the child was excluded or newly included in the second round, and 0 if the child was included in both survey rounds. ${ }^{b}$ The dependent variable is height-for-age Z-scores (HAZ) of children and adolescents (aged 5-18). Coefficient estimates are shown with bootstrapped standard errors (400 replications) in parentheses. ${ }^{\mathrm{c}}$ Maternal education in the HAZ model had to be dropped because of multicollinearity problems. ${ }^{\mathrm{d}}$ The inverse mills ratio was calculated based on predictions from the attrition probit. $* P<0.1 ; * * P<0.05 ; * * * P<0.01$. 


\section{General Conclusion}

\subsection{Main Findings}

In Kenya, as in many developing countries, dietary choices are shifting from traditional foods towards energy dense and highly processed foods. This nutrition transition does not only provoke a dietary shift but also a transformation in health outcomes. Kenyan official national statistics report an increase in the share of men and women being overweight or obese between 1998 and 2014 by approximately 5 and 12 percentage points, respectively (NCD Risk Factor Collaboration, 2016). At the same time, the share of children under five being stunted in Kenya remained almost unchanged within the last 20 years (IFPRI, 2016). Besides contributing to morbidity and mortality, this double burden of malnutrition places a substantial economic constraint on the country and makes Kenya an extreme example of a country in transition. It is therefore of immense importance to understand different influencing factors to fight malnutrition in all its forms.

The spread of supermarkets was identified as one potential driving force for the nutrition transition in many developing countries. Through modern retails, a broad variety of food products and brands with different degrees of processing are available and promoted in strategic ways. Literature examples are limited to the nexus between supermarket shopping and dietary choices, as well as between supermarket shopping and nutritional outcomes. The few examples that exist are all based on cross-sectional data and show conflicting results. With this dissertation, we have contributed to the existing and respective literature in two respects. First, we have broadened the analysis of linkages between supermarket shopping and nutritional outcomes towards health (see Chapter 2). In detail, we have analyzed effects of supermarket shopping on BMI, overweight/obesity, as well as on fasting blood glucose, pre-diabetes, systolic blood pressure, diastolic blood pressure, pre-hypertension, and the metabolic syndrome. Based on a cross-sectional data set from 2015 and by using an IV approach, we show that supermarket purchase increases adult's BMI and the probability of being overweight/obese. Supermarket purchase is also associated with $0.3 \mathrm{mmol} / \mathrm{L}$ higher levels of fasting blood glucose and a higher likelihood of suffering from pre-diabetes and the metabolic syndrome, by 16 percentage points and 7 percentage points, respectively. Effects on blood pressure could not be detected. 
Second, with the use of panel data and fixed effects regression models (Chapter 3), we have established robust causality between supermarket use, nutritional outcomes, and dietary choices. The nutritional outcomes we looked at are BMI and being overweight/obese. As dietary choices, we have used the share of energy from highly processed foods and energy consumption of unprocessed staples, fruits/vegetables, meats/fish, dairy/eggs, and vegetable oils. This approach is unique as the linkages have never been analyzed with a panel data set before. Our findings showed that supermarket shopping increased the BMI of individuals by $0.64 \mathrm{~kg} / \mathrm{m}^{2}$ and the share of energy from highly processed foods by 3.1 percentage points. Further, supermarket shopping lowered the energy consumption of unprocessed staples by $112 \mathrm{kcal} / \mathrm{AE} / \mathrm{day}$, of fresh fruits and vegetables by $124 \mathrm{kcal} / \mathrm{AE} / \mathrm{day}$, and increased the consumption of meats and fish by 24 $\mathrm{kcal} / \mathrm{AE} / \mathrm{day}$, of dairy and eggs by $9 \mathrm{kcal} / \mathrm{AE} / \mathrm{day}$, and of vegetable oils by $60 \mathrm{kcal} / \mathrm{AE} / \mathrm{day}$. Since we did not find significant effects of supermarket shopping on total energy consumption, the increasing effects on BMI were probably driven by changes in the dietary compositions, with medium and highly processed foods gaining in relative importance.

Nutritional knowledge and education are key factors in establishing a healthy nutrition environment. It is widely known that especially maternal nutrition knowledge plays a major role for the nutritional outcomes of children. Many examples from developing countries show that especially for children under-five the mother's nutritional knowledge is an important factor for their nutritional outcomes. Only a few studies identify positive links between maternal nutrition knowledge and child nutrition for older children, and this evidence is limited to developed countries. With our third essay (see Chapter 4) we have contributed to this gap in the literature by using a panel data set from 2012 and 2015 from urban Kenya to analyze the associations between maternal nutrition knowledge and height-for-age Z-scores of children between 5 and 18 years. We find that the aggregated maternal nutrition knowledge score is positively associated with child HAZ (+ 1.25). Further, we have used different types of maternal nutrition knowledge in our analysis in order to understand dissimilar results in children and adolescents nutritional outcomes. We have subdivided the maternal knowledge into three categories: (a) knowledge about food ingredients, (b) knowledge about specific dietary recommendations, and (c) knowledge about the health consequences of not following recommended dietary practices. We find that maternal nutrition knowledge about health consequences of not following dietary recommendations has the largest and strongest positive association with HAZ (+ 0.54). 
Overall, and valid for all essays in Chapters 2, 3 and 4, we are adding empirical findings from an African country, where so far only little evidence in the respective research questions is available.

\subsection{Policy Implications}

In Chapters 2 and 3 we have shown that the rapid spread of supermarkets has direct effects on nutrition and health and contributes to the nutrition transition in Kenya. Since many other factors are also driving these nutritional and dietary outcomes we consider supermarket shopping as an important external factor in the overall discussion about dietary choices, nutrition and health. For policy makers it will be of immense importance to understand these linkages in order to be able to intervene properly. Intervening in this sense does not imply banning supermarkets. We like to avoid the view that supermarkets should be seen as something negative, as they may have clear positive effects for public health and development. Compared to traditional food markets in developing countries, supermarket supply chains are often more efficient, which can make food more accessible for poor population segments and increase food security (Kimenju et al., 2015; Qaim, 2017; Timmer, 2009). The levels of food quality and food safety may also be higher in supermarkets than in traditional markets (Mergenthaler et al., 2009; Minot et al., 2015). Further, studies show that farmers in developing countries could benefit from participating in newly emerging supermarket supply chains (Chege et al., 2015; T Reardon et al., 2012).

However, our results demonstrated that the influence of supermarkets on consumers in small urban centers in Kenya could also be challenging in terms of 'unhealthier' food choices and higher levels of BMI and NR-NCDs. Therefore, certain types of regulations and economic incentives may be appropriate in some situations. It will be important for policymakers to strengthen the positive aspects of supermarket growth, while reducing negative implications to the extent possible. A critical aspect will be to create food environments that allow and instigate consumers to make more healthy food choices (Minos et al., 2016). This may require broader awareness building and education towards healthy nutrition, as well as appropriate regulations. Examples from high-income countries show that the access to supermarkets is associated with healthier diets and greater access to fresh products (Drewnowski et al., 2012; Laraia et al., 2004; Morland et al., 2006). In our Kenyan example, and also in other developing countries, outside of the big cities, supermarkets often only sell processed foods, because the offer of fresh fruits and vegetables does not seem to be profitable yet. Requiring supermarkets to offer more fresh fruits 
and vegetables, and to position such a fresh produce section in a key place within the store, could be one possible route of tightened regulation. Besides fresh products also other measures to promote healthy diets and nutrition-sensitive food environments, like food products lower in sugar, salt and fat are worth considering. Policy interventions should help to improve people's diets and prevent overweight and obesity without discouraging modernization processes in the food and retail sector.

In Chapter 4 we showed that maternal nutrition knowledge, especially the type of knowledge about health consequences of not following recommended dietary practices, positively influenced child and adolescent nutritional outcomes. Hence, we imply that building broader awareness of the health risks of unsuitable dietary practices among mothers and caretakers plays an important role for improving nutrition and health of children and adolescents. Or seen from another angle, nutritional knowledge about adverse health consequences seems to be more effective in causing dietary behavioral responses than knowledge about food ingredients and dietary recommendations per se. Of course, nutrition education programs will always have to take into account the respective nutritional needs and challenges in a particular setting. But our conclusion, that effective nutrition education and training programs should always link dietary recommendations to precise health consequences holds beyond this specific setting.

\subsection{Limitations}

A few limitations of the study shall be summarized here. First, we could show significant effects of supermarket shopping on nutritional outcomes in the cross-sectional data and in the panel data set. For the health outcomes, neither panel data nor repeated measurements were available. Repeated collection of comprehensive data for all health outcomes through additional survey rounds or repeated measurements would help to further test the robustness of the estimation results. Further, having additional measurements on different health outcomes would increase the available factors to build other and more robust health indicators like the metabolic syndrome, which is normally based on five instead of three indicators. Second, besides having a clear methodological advantage by using panel data, one also needs to consider the challenges that arise from repeated data collection. The attrition rate that we were facing in our study is rather high. While we tested this bias to the extent possible, balanced panel data sets for longer time periods and with a larger number of observations would be beneficial in this regard. Third, while 
we found positive associations between different types of maternal nutrition knowledge and child/adolescent nutritional outcomes, we are aware that the distribution of questions to build the different knowledge score was not equal. We took this into account in the calculation of the aggregated knowledge score. Nevertheless, more questions in some of the categories could have been added to the understanding of the role of different types of nutrition knowledge. In future research, it would be particularly interesting to increase the number and the variety of questions related to dietary recommendations and to the health consequences of not following such recommendations. Fourth, survey data always suffer a certain amount of imprecision. While selfreported (dietary) data face the problems of under- and over estimation, measurement errors in anthropometry are easy to influence the entire outcome of nutritional assessments. Misestimations and mis-measurements happen in all social settings and locations, and regardless of the individual body size. We tried to account for these challenges by well-trained enumerators, constant refresher on measurement accuracy, a precise data cleaning and management. Besides these general shortcomings of dietary assessments and anthropometric measurements, we are aware that a 30-day food consumption recall at household level has its limitations in terms of explanatory power for the individual (Deaton and Zaidi, 2002). This relatively long recall period was chosen as some of the more durable food items are only purchased once a month. However, a higher precision of dietary assessment at individual level could be obtained by combining different assessment methods like several non-consecutive 24-hour dietary recalls or methods on bio-maker levels (Shim et al., 2014). Fifth, all our essays were based on the same three towns which are typical for medium-sized urban municipalities in Central Kenya. In comparing the survey characteristics of our study to national statistics we observe that there are similarities especially for the Central Region. However, the amount of towns included in our study is small and our sample is not representative for the country as a whole, which mitigates the external validity of our estimations.

Besides given examples here, one should not forget that dietary choices, nutrition and health are highly interlinked and influenced by many different internal and external factors. Supermarket shopping and maternal nutritional knowledge are only two components in a large set of a comprehensive connection. Of course other factors, like overall health behavior, physical activity, education, media and policy regulations need to be discussed and considered as well in order to fight malnutrition in all its forms. 


\section{References}

Adair, L. S. (1999). Filipino children exhibit catch-up growth from age 2 to 12 years. The Journal of Nutrition, 129(6), 1140-1148.

Alberti, K. G. M. M., Zimmet, P., \& Shaw, J. (2006). Metabolic syndrome-a new world-wide definition. A consensus statement from the International Diabetes Federation. Diabetic Medicine, 23(5), 469-480. http://doi.org/10.1111/j.1464-5491.2006.01858.x

American Diabetes Association. (2006). Standards of medical care in diabetes. Diabetes Care, 29 (Suppl. 1), s4-s42.

Anand, S. S., Hawkes, C., de Souza, R. J., Mente, A., Dehghan, M., Nugent, R., .. Popkin, B. M. (2015). Food consumption and its impact on cardiovascular disease. Importance of solutions focused on the globalized food system. Journal of the American College of Cardiology, 66(14), 1590-1614. http://doi.org/10.1016/j.jacc.2015.07.050

Andersson, C. I. M., Chege, C. G. K., Rao, E. J. O., \& Qaim, M. (2015). Following up on smallholder farmers and supermarkets in Kenya. American Journal of Agricultural Economics, 97(4), 1247-1266. http://doi.org/10.1093/ajae/aav006

Angrist, J. D., Krueger, A. B. (2001). Instrumental variables and the search for identification: from supply and demand to natural experiments. Journal of Economic Perspectives, 15(4), 69-85. http://doi.org/10.1257/jep.15.4.69

Appoh, L. Y., \& Krekling, S. (2005). Maternal nutritional knowledge and child nutritional status in the Volta Region of Ghana. Maternal \& Child Nutrition, 1(2), 100-110. http://doi.org/10.1111/j.1740-8709.2005.00016.x

Asfaw, A. (2008). Does supermarket purchase affect the dietary practices of households? Some empirical evidence from Guatemala. Development Policy Review, 26(2), 227-243. http://doi.org/10.1111/j.1467-7679.2008.00407.x

Asfaw, A. (2011). Does consumption of processed foods explain disparities in the body weight of individuals? The case of Guatemala. Health Economics, 20(2), 184-195. http://doi.org/10.1002/hec.1579

Barr, S. B., \& Wright, J. C. (2010). Postprandial energy expenditure in whole-food and processed-food meals: implications for daily energy expenditure. Food \& Nutrition Research, 54(1): 5144. http://doi.org/10.3402/fnr.v54i0.5144 
Batra, R., Ramaswamy, V., Alden, D. L., Steenkamp, J.-B. E. M., \& Ramachander, S. (2000). Effects of Brand Local and Nonlocal Origin on Consumer Attitudes in Developing Countries. Journal of Consumer Psychology, 9(2), 83-95. http://doi.org/10.1207/S15327663JCP0902_3

Battersby, J., \& Peyton, S. (2014). The geography of supermarkets in Cape Town: supermarket expansion and food access. Urban Forum, 25(2), 153-164. http://doi.org/10.1007/s12132014-9217-5

Bing Maps Aerial (2015). Kenya (Satellite Image). Microsoft. Retrieved February 15, 2015, from http://www.bing.com/maps?v=2\&app=60526

Black, R. E., Victora, C. G., Walker, S. P., Bhutta, Z. A., Christian, P., de Onis, M., ... Uauy, R. (2013). Maternal and child undernutrition and overweight in low-income and middleincome countries. The Lancet, 382(9890), 427-451. http://doi.org/10.1016/S01406736(13)60937-X

Bommer, C., Heesemann, E., Sagalova, V., Manne-Goehler, J., Atun, R., Bärnighausen, T., \& Vollmer, S. (2017). The global economic burden of diabetes in adults aged 20 to 79: a costof-illness study. The Lancet Diabetes \& Endocrinology. 5(6), 423-430. http://doi.org/10.1016/S2213-8587(17)30097-9

Bound, J., Jaeger, D. A., \& Baker, R. M. (1995). Problems with instrumental variables estimation when the correlation between the instruments and the endogenous explanatory variable is weak. Journal of the American Statistical Association, 90(430), 443-450. http://doi.org/10.1080/01621459.1995.10476536

Burchi, F. (2010). Child nutrition in Mozambique in 2003: the role of mother's schooling and nutrition knowledge. Economics \& Human Biology, 8(3), 331-345. http://doi.org/10.1016/j.ehb.2010.05.010

Burchi, F., Scarlato, M., \& d'Agostino, G. (2016). Addressing food insecurity in sub-Saharan Africa: the role of cash transfers. DIE Discussion Paper, 17/2016. Retrieved June 14, 2017 , from http://www.die-gdi.de/uploads/media/DP_17.2016.pdf

Butte, N. F., Garza, C., \& de Onis, M. (2007). Evaluation of the feasibility of international growth standards for school-aged children and adolescents. The Journal of Nutrition, 137, 153-157. http://doi.org/10.1177/15648265060274s501

Campbell, K. J., Abbott, G., Spence, A. C., Crawford, D. A., McNaughton, S. A., \& Ball, K. (2013). Home food availability mediates associations between mothers' nutrition knowledge and child diet. Appetite, 71, 1-6. http://doi.org/10.1016/j.appet.2013.07.006 
Centers for Disease Control and Prevention. (2007). National Health and Nutrition Examination Survey (NHANES). Anthropometry Procedures Manual. Atlanta, GA: Centers for Disease Control and Prevention.

Chege, C. G. K., Andersson, C. I. M., \& Qaim, M. (2015). Impacts of supermarkets on farm household nutrition in Kenya. World Development, 72, 394-407. http://doi.org/10.1016/j.worlddev.2015.03.016

Christiaensen, L., \& Alderman, H. (2004). Child malnutrition in Ethiopia: can maternal knowledge augment the role of income? Economic Development and Cultural Change, 52(2), 287-312. http://doi.org/10.1086/380822

Cleveland, W. S. (1979). Robust locally weighted regression and smoothing scatterplots. Journal of the American Statistical Association, 74(368), 829-836.

Contento, I. R. (2008). Nutrition education: linking research, theory, and practice. Asia Pacific Journal of Clinical Nutrition, 17(1), 176-179.

Dalal, S., Beunza, J. J., Volmink, J., Adebamowo, C., Bajunirwe, F., Njelekela, M., ... Holmes, M. D. (2011). Non-communicable diseases in sub-Saharan Africa: what we know now. International Journal of Epidemiology, 40(4), 885-901. http://doi.org/10.1093/ije/dyr050

Darnton-Hill, I., Nishida, C., \& James, W. (2004). A life course approach to diet, nutrition and the prevention of chronic diseases. Public Health Nutrition, 7(1a), 101-121. http://doi.org/http://doi.org/10.1079/PHN2003584

de Groot, R., Palermo, T., Handa, S., Ragno, L. P. \& Peterman, A. (2017). Cash transfers and child nutrition: pathways and impacts. Development Policy Review, 1-23. http://doi.org/10.1111/dpr.12255

de Haen, H., Klasen, S., \& Qaim, M. (2011). What do we really know? Metrics for food insecurity and undernutrition. Food Policy, 36(6), 760-769. http://doi.org/10.1016/j.foodpol.2011.08.003

de Onis, M. (2007). Development of a WHO growth reference for school-aged children and adolescents. Bulletin of the World Health Organization, 85(9): 660-667. http://doi.org/10.2471/blt.07.043497

de Onis, M., Onyango, A., Van den Broeck, J., Chumlea, W. C., \& Martorell, R. (2004). Measurement and standardization protocols for anthropometry used in the construction of a new international growth reference. Food and Nutrition Bulletin, 25(1_Suppl 1), s27-s36.

Deaton, A. (2010). Instruments, randomization, and learning about development. Journal of Economic Literature, 48(2), 424-455. http://doi.org/10.1257/jel.48.2.424 
Deaton, A., \& Zaidi, S. (2002). Guidelines for Constructing Consumption Aggregates for Welfare Analysis. Living Standards Measurement Study (LSMS) Working Paper; No. LSM 135. The World Bank, Washington, DC. Retrieved November 24, 2016, from http://documents.worldbank.org/curated/en/206561468781153320/Guidelines-forconstructing-consumption-aggregates-for-welfare-analysis

Debela, B. L., Shively, G., \& Holden, S. T. (2015). Does Ethiopia's productive safety net program improve child nutrition? Food Security, 7(6), 1273-1289. http://doi.org/10.1007/s12571-015-0499-9

Demmler K. M., Ecker O., Qaim M. (2017). Supermarket shopping and nutritional outcomes: a panel data analysis for urban Kenya. World Development, Epub ahead of print: http://dx.doi.org/10.1016/j.worlddev.2017.07.018

Di Falco, S., Veronesi, M., Yesuf, M. (2011). Does adaptation to climate change provide food security? A micro-perspective from Ethiopia. American Journal of Agricultural Economics, 93(3), 829-846. http://doi.org/10.1093/ajae/aar006

Dover, R. V. H., \& Lambert, E. V. (2016). 'Choice Set' for health behavior in choice-constrained settings to frame research and inform policy: examples of food consumption, obesity and food security. International Journal for Equity in Health, 15(48), 1-8. http://doi.org/10.1186/s12939-016-0336-6

Drewnowski, A., Aggarwal, A., Hurvitz, P. M., Monsivais, P., \& Moudon, A. V. (2012). Obesity and supermarket access: proximity or price? American Journal of Public Health, 102(8), e74-e80. http://doi.org/10.2105/AJPH.2012.300660

Duflo, E., 2001. Schooling and labor market consequences of school construction in Indonesia: evidence from an unusual policy experiment. American Economic Review, 91(4), 795813. http://doi.org/:10.1257/aer.91.4.795

Food and Agriculture Organization of the United Nations (FAO). (2010). World Food Dietary Assessment System, Version 2.0. International Network of Food Data Systems of FAO. Rome, Italy: Food and Agriculture Organization of the United Nations.

Food and Agriculture Organization of the United Nations (FAO). (2012). West African Food Composition Table. Rome, Italy: Food and Agriculture Organization of the United Nations. Retrieved November 24, 2016, from http://www.fao.org/news/story/en/item/143840/icode/

Food and Agriculture Organization of the United Nations (FAO). (2013). The State of Food and Agriculture 2013. Food Systems for Better Nutrition. Rome, Italy: Food and Agriculture Organization of the United Nations. Retrieved March 7, 2017, from http://www.fao.org/docrep/018/i3300e/i3300e00.htm 
Food and Agriculture Organization of the United Nations (FAO). (2015). The State of Food Insecurity in the World. Meeting the 2015 International Hunger Target: Taking Stock of Uneven Progress. Rome, Italy: Food and Agriculture Organization of the United Nations. Retrieved April 14, 2016, from http://www.fao.org/hunger/en/

Food and Agriculture Organization of the United Nations (FAO), United Nations University (UNU), \& World Health Organization (WHO). (2004). Human Energy Requirements: Report of a Joint FAO/WHO/UNU Expert Consultation: Rome, 17-24 October 2001. Rome, Italy: Food and Agricultural Organization of the United Nations. Retrieved November 4, 2016, from http://www.fao.org/docrep/007/y5686e/y5686e00.htm

Glanz, K., Patterson, R. E., Kristal, A. R., DiClemente, C. C., Heimendinger, J., Linnan, L., \& McLerran, D. F. (1994). Stages of change in adopting healthy diets: fat, fiber, and correlates of nutrient intake. Health Education Quarterly, 21(4), 499-519. http://doi.org/10.1177/109019819402100412

Global Administrative Areas. (2012). GADM database of Global Administrative Areas (Version 2.0). Retrieved March 12, 2017, from http://www.gadm.org

Gruber, J. (2000). Disability insurance benefits and labor supply. Journal of Political Economy, 108(6), 1162-1183. http://doi.org/10.1086/317682

Hamill, P. V., Drizd, T. A., Johnson, C. L., Reed, R. B., \& Roche, A. F. (1977). NCHS growth curves for children birth-18 years. United States. Vital and Health Statistics, 11(165), i-iv, $1-74$.

Hausman, J. A. (1978). Specification tests in econometrics. Econometrica, 46(6), 1251-1271. http://doi.org/10.2307/1913827

Hawkes, C. (2008). Dietary implications of supermarket development: a global perspective. Development Policy Review, 26(6), 657-692. http://doi.org/10.1111/j.14677679.2008.00428.x

Hawkes, C., Smith, T. G., Jewell, J., Wardle, J., Hammond, R. A., Friel, S., ... Kain, J. (2015). Smart food policies for obesity prevention. The Lancet, 385(9985), 2410-2421. http://doi.org/10.1016/S0140-6736(14)61745-1

Herman, W. H. (2013). The economic costs of diabetes: is it time for a new treatment paradigm? Diabetes Care, 36(4), 775-776. http://doi.org/10.2337/dc13-0270

Hill, R. C., Griffiths, W. E., \& Lim, G. C. (2008). Principles of Econometrics (3rd ed.). Hoboken, NJ: Wiley. 
Hirvonen, K., Hoddinott, J. F., Minten, B., \& Stifel, D. (2016). Children's Diets, Nutrition Knowledge, and Access to Markets. ESSP II Working Paper No. 84. International Food Policy Research Institute (IFPRI) and Ethiopian Development Research Institute (EDRI), Washington, DC and Addis Ababa, Ethiopia. Retrieved September 16, 2016, from http://www.ifpri.org/publication/childrens-diets-nutrition-knowledge-and-access-markets

Hoddinott, J., Karachiwalla, N. I., Ledlie, N. A., \& Roy, S. (2016). Adolescent girls' infant and young child nutrition knowledge levels and sources differ among rural and urban samples in Bangladesh: adolescent girls' nutrition knowledge sources. Maternal \& Child Nutrition, 12(4), 885-897. http://doi.org/10.1111/mcn.12355

Institute of Medicine (U.S.). (2005). Dietary Reference Intakes for Energy, Carbohydrate, Fiber, Fat, Fatty Acids, Cholesterol, Protein, and Amino Acids (Macronutrients) (1st ed.). Washington, DC: National Academies Press.

International Diabetes Federation. (2006). The IDF Consensus Worldwide Definition of the Metabolic Syndrome. Brussels, Belgium: International Diabetes Federation. Retrieved July 30, 2014, from http://www.idf.org/metabolic-syndrome

International Diabetes Federation. (2015). Diabetes Atlas (7th ed.). Brussels, Belgium: International Diabetes Federation. Retrieved June 30, 2014, from http://www.diabetesatlas.org/

International Food Policy Research Institute (IFPRI). (2016). Global Nutrition Report 2016. From Promise to Impact Ending Malnutrition by 2030. Washington, DC: International Food Policy Research Institute. Retrieved September 6, 2016, from http://ebrary.ifpri.org/cdm/ref/collection/p15738coll2/id/130354

Joshi, M., Ayah, R., Njau, E., Wanjiru, R., Kayima, J., Njeru, E., \& Mutai, K. (2014). Prevalence of hypertension and associated cardiovascular risk factors in an urban slum in Nairobi, Kenya: a population-based survey. BMC Public Health, 14(1), 1177-1187. http://doi.org/10.1186/1471-2458-14-1177

Kennedy, E. (2013). Chapter 4: The obesity crisis. In M. Eggersdorfer (Ed.), The Road to Good Nutrition. Basel, Switzerland: Karger, pp.51-63

Kenya National Bureau of Statistics. (2010). Population Distribution by Administrative Units. Nairobi, Kenya: Kenya National Bureau of Statistics. Retrieved January 4, 2017 from http://www.knbs.or.ke/index.php?option=com_phocadownload\&view=category\&id=109:p ppopulati-and-housing-census-2009\&Itemid=599 
Kenya National Bureau of Statistics. (2014). Demographic and Health Survey 2014. Nairobi, Kenya: Kenya National Bureau of Statistics. Retrieved April 14, 2016, from http://www.knbs.or.ke/index.php?option=com_phocadownload\&view=category\&id=19:ke nya-demographic-health-survey-documents \&Itemid=599

Kenya National Bureau of Statistics. (2016). Consumer Price Indices (CPI). Kenya National Bureau of Statistics. Retrieved November 7, 2016, from http://www.knbs.or.ke/index.php

Kigaru, D. M. D., Loechl, C., Moleah, T., Macharia-Mutie, C. W., \& Ndungu, Z. W. (2015). Nutrition knowledge, attitude and practices among urban primary school children in Nairobi City, Kenya: a KAP study. BMC Nutrition, 1(1), 1-44. http://doi.org/10.1186/s40795-015-0040-8

Kimenju, S. C. (2014). The nutrition transition, supermarkets, and nutritional outcomes in developing countries. (Doctoral dissertation). University of Goettingen, Goettingen, Germany. Retrieved August 5, 2014, from http://hdl.handle.net/11858/00-1735-0000-00225 F36-F

Kimenju, S. C., \& Qaim, M. (2016). The nutrition transition and indicators of child malnutrition. Food Security, 8(3), 571-583. http://doi.org/10.1007/s12571-016-0566-x

Kimenju, S. C., Rischke, R., Klasen, S., \& Qaim, M. (2015). Do supermarkets contribute to the obesity pandemic in developing countries? Public Health Nutrition, 18(17), 3224-3233. http://doi.org/10.1017/S1368980015000919

Laraia, B. A., Siega-Riz, A. M., Kaufman, J. S., \& Jones, S. J. (2004). Proximity of supermarkets is positively associated with diet quality index for pregnancy. Preventive Medicine, 39(5), 869-875. http://doi.org/10.1016/j.ypmed.2004.03.018

Leigh, J. P., Schembri, M. (2004). Instrumental variables technique: cigarette price provided better estimate of effects of smoking on SF-12. Journal of Clinical Epidemiology, 57(3), 284-293. http://doi.org/10.1016/j.jclinepi.2003.08.006

Leroy, J. L., Ruel, M., Habicht, J.-P., \& Frongillo, E. A. (2014). Linear growth deficit continues to accumulate beyond the first 1000 days in low- and middle-income countries: global evidence from 51 national surveys. The Journal of Nutrition, 144(9), 1460-1466. http://doi.org/10.3945/jn.114.191981

Liu, R. H. (2013). Health-promoting components of fruits and vegetables in the diet. Advances in Nutrition: An International Review Journal, 4(3), S384-92. http://doi.org/10.3945/an.112.003517 
Martins, V. J. B., Toledo Florêncio, T. M. M., Grillo, L. P., Franco, M. do C. P., Martins, P. A., Clemente, A. P. G., ... Sawaya, A. L. (2011). Long-lasting effects of undernutrition. International Journal of Environmental Research and Public Health, 8(6), 1817-1846. http://doi.org/10.3390/ijerph8061817

Matanda, D. J., Mittelmark, M. B., \& Kigaru, D. M. D. (2014). Child undernutrition in Kenya: trend analyses from 1993 to 2008-09. BMC Pediatrics, 14(1), 1-13. http://doi.org/10.1186/1471-2431-14-5

Mergenthaler, M., Weinberger, K., \& Qaim, M. (2009). The food system transformation in developing countries: a disaggregate demand analysis for fruits and vegetables in Vietnam. Food Policy, 34(5), 426-436. http://doi.org/10.1016/j.foodpol.2009.03.009

Michimi, A., \& Wimberly, M. C. (2010). Associations of supermarket accessibility with obesity and fruit and vegetable consumption in the conterminous United States. International Journal of Health Geographics, 9, 49-63. http://doi.org/10.1186/1476-072X-9-49

Ministry of Public Health and Sanitation. (2012). National Nutrition Action Plan 2012-2017. Nairobi, Kenya: Republic of Kenya.

Minos, D., Butzlaff, I., Demmler, K. M., Rischke, R., (2016). Economic growth, climate change, and obesity. Current Obesity Reports, 5(4), 441-448. http://doi.org/10.1007/s13679-0160234-7

Minot, N., Stringer, R., Umberger, W. J., \& Maghraby, W. (2015). Urban shopping patterns in Indonesia and their implications for small farmers. Bulletin of Indonesian Economic Studies, 51(3), 375-388. http://doi.org/10.1080/00074918.2015.1104410

Morland, K., Diez Roux, A. V., \& Wing, S. (2006). Supermarkets, other food stores, and obesity: the atherosclerosis risk in communities study. American Journal of Preventive Medicine, 30(4), 333-339. http://doi.org/10.1016/j.amepre.2005.11.003

Narayan, K. V., Ali, M. K., \& Koplan, J. P. (2010). Global noncommunicable diseases-where worlds meet. New England Journal of Medicine, 363(13), 1196-1198. http://doi.org/10.1056/NEJMp1002024

NCD Risk Factor Collaboration. (2016). Trends in adult body-mass index in 200 countries from 1975 to 2014: a pooled analysis of 1698 population-based measurement studies with 19.2 million participants. The Lancet, 387(10026), 1377-1396. http://doi.org/10.1016/S01406736(16)30054-X

Nelms, M., Sucher, K., \& Lacey, K. (2011). Nutrition Therapy and Pathophysiology (2nd ed.). Belmont, CA: Wadsworth, Cengage Learning. 
Nestle, M., Wing, R., Birch, L., DiSogra, L., Drewnowski, A., Middleton, S., ... Economos, C. (1998). Behavioral and social influences on food choice. Nutrition Reviews, 56(5), 50-64. http://doi.org/10.1111/j.1753-4887.1998.tb01732.x

Neven, D., Odera, M. M., Reardon, T., \& Wang, H. (2009). Kenyan supermarkets, emerging middle-class horticultural farmers, and employment impacts on the rural poor. World Development, 37(11), 1802-1811. http://doi.org/10.1016/j.worlddev.2008.08.026

Ng, M., Fleming, T., Robinson, M., Thomson, B., Graetz, N., Bennett, D. A., ... Lopez, A. D. (2014). Global, regional, and national prevalence of overweight and obesity in children and adults during 1980-2013: a systematic analysis for the Global Burden of Disease Study 2013. The Lancet, 384(9945), 766-781. http://doi.org/10.1016/S0140-6736(14)60460-8

O’Donnell, O., van Doorslaer, E., Wagstaff, A., \& Lidelow, M. (2008). Analysing Health Equity using Household Survey Data: A Guide to Techniques and their Implementation. Washington, DC: World Bank. Retrieved January 19, 2017, from http://www.ncbi.nlm.nih.gov/pmc/articles/PMC2649524/

Okafor, C. (2012). The metabolic syndrome in Africa: current trends. Indian Journal of Endocrinology and Metabolism, 16(1), 56-66. http://doi.org/10.4103/2230-8210.91191

OpenStreetMap contributors. (2015). Kenya (Street Map). OpenStreetMap. Retrieved February 15, 2015, from http://www.openstreetmap.org/browse/node/633024977

Planet Retail. (2016). Country Report Kenya. Planet Retail. Retrieved February 28, 2016, from http://www.planetretail.net/Markets/Country/91

Popkin, B. M. (2014). Nutrition, agriculture and the global food system in low and middle income countries. Food Policy, 47, 91-96. http://doi.org/10.1016/j.foodpol.2014.05.001

Popkin, B. M. (2015). Nutrition transition and the global diabetes epidemic. Current Diabetes Reports, 15(9), 1-8. http://doi.org/10.1007/s11892-015-0631-4

Popkin, B. M., Adair, L. S., \& Ng, S. W. (2012). Global nutrition transition and the pandemic of obesity in developing countries. Nutrition Reviews, 70(1), 3-21. http://doi.org/10.1111/j.1753-4887.2011.00456.x

Popkin, B. M., \& Ng, S. W. (2007). The nutrition transition in high-and low-income countries: what are the policy lessons? Agricultural Economics, 37, 199-211. http://doi.org/10.1111/j.1574-0862.2007.00245.x

Popkin, B. M., \& Slining, M. M. (2013). New dynamics in global obesity facing low- and middle-income countries. Obesity Reviews, 14, 11-20. http://doi.org/10.1111/obr.12102 
Prentice, A. M., Ward, K. A., Goldberg, G. R., Jarjou, L. M., Moore, S. E., Fulford, A. J., \& Prentice, A. (2013). Critical windows for nutritional interventions against stunting. The American Journal of Clinical Nutrition, 97(5), 911-918. http://doi.org/10.3945/ajcn.112.052332

Qaim, M. (2017). Globalisation of agrifood systems and sustainable nutrition. Proceedings of the Nutrition Society, 76(1), 12-21. http://doi.org/10.1017/S0029665116000598

QGIS Development Team. (2015). QGIS Geographic Information System. Open Source Geospatial Foundation Project. Retrieved February 15, 2015, from http://www.qgis.org/

Reardon, T. (2011). The global rise and impact of supermarkets: an international perspective. Paper Presented at the Conference: Supermarket Revolution in Food: Good, Bad or Ugly for The World's Farmers, Consumers and Retailers? Canberra, Australia: Crawford Fund for International Agricultural Research, 14-16 August.

Reardon, T., Chen, K., Minten, B., \& Adriano, L. (2012). The Quiet Revolution in Staple Food Value Chains: Enter the Dragon, the Elephant and the Tiger (1st ed.). Manila, Philippines: Asian Development Bank. Retrieved June 26, 2016, from http://www.ifpri.org/publication/quiet-revolution-staple-food-value-chains

Reardon, T., Timmer, C. P., Barrett, C. B., \& Berdegué, J. (2003). The rise of supermarkets in Africa, Asia, and Latin America. American Journal of Agricultural Economics, 85(5), 1140-1146. http://doi.org/10.1111/j.0092-5853.2003.00520.x

Reardon, T., Timmer, C. P., \& Minten, B. (2012). Supermarket revolution in Asia and emerging development strategies to include small farmers. Proceedings of the National Academy of Sciences, 109(31), 12332-12337. http://doi.org/10.1073/pnas.1003160108

Rischke, R. (2014). Essays on Food Security and the Nutrition Transition in Developing Countrie. (Doctoral dissertation). University of Goettingen, Goettingen, Germany. Retrieved January 22, 2015, from http://hdl.handle.net/11858/00-1735-0000-0023-9973-7

Rischke, R., Kimenju, S. C., Klasen, S., \& Qaim, M. (2015). Supermarkets and food consumption patterns: the case of small towns in Kenya. Food Policy, 52, 9-21. http://doi.org/10.1016/j.foodpol.2015.02.001

Roemling, C., \& Qaim, M. (2013). Dual burden households and intra-household nutritional inequality in Indonesia. Economics \& Human Biology, 11(4), 563-573. http://doi.org/10.1016/j.ehb.2013.07.001

Rosin, O. (2008). The economic causes of obesity: a survey. Journal of Economic Surveys, 22(4), 617-647. http://doi.org/10.1111/j.1467-6419.2007.00544.x 
Ruel, M. T., Menon, P., Habicht, J.-P., Loechl, C., Bergeron, G., Pelto, G., .. Hankebo, B. (2008). Age-based preventive targeting of food assistance and behaviour change and communication for reduction of childhood undernutrition in Haiti: a cluster randomised trial. The Lancet, 371(9612), 588-595. http://doi.org/10.1016/S0140-6736(08)60271-8

Sawaya, A. L., Martins, P. A., Grillo, L. P., \& Florêncio, T. T. (2004). Long-term effects of early malnutrition on body weight regulation. Nutrition Reviews, 62(7), 127-133. http://doi.org/10.1301/nr.2004.jul.S127-S133

Schipmann, C., \& Qaim, M. (2011). Supply chain differentiation, contract agriculture, and farmers' marketing preferences: the case of sweet pepper in Thailand. Food Policy, 36(5), 667-677. http://doi.org/10.1016/j.foodpol.2011.07.004

Schoeller, D. A. (1995). Limitations in the assessment of dietary energy intake by self-report. Metabolism, 44, 18-22. http://doi.org/10.1016/0026-0495(95)90204-X

Sehmi, J. (1993). National Food Composition Tables and the Planning of Satisfactory Diets in Kenya. Nairobi, Kenya: Government Printers.

Shim, J.-S., Oh, K., \& Kim, H. C. (2014). Dietary assessment methods in epidemiologic studies. Epidemiology and Health, 36: e2014009. http://doi.org/10.4178/epih/e2014009

Silverman, B. W. (1986). Density Estimation for Statistics and Data Analysis. London, UK: Chapman \& Hall.

Stein, A. D., Wang, M., Martorell, R., Norris, S. A., Adair, L. S., Bas, I., ... Cohorts Group. (2010). Growth patterns in early childhood and final attained stature: data from five birth cohorts from low- and middle-income countries. American Journal of Human Biology: The Official Journal of the Human Biology Council, 22(3), 353-359. http://doi.org/10.1002/ajhb.20998

Steyn, N. P., \& Mchiza, Z. J. (2014). Obesity and the nutrition transition in Sub-Saharan Africa. Annals of the New York Academy of Sciences, 1311(1), 88-101. http://doi.org/10.1111/nyas.12433

Story, M., Kaphingst, K. M., Robinson-O’Brien, R., \& Glanz, K. (2008). Creating healthy food and eating environments: policy and environmental approaches. Annual Review of Public Health, 29(1), 253-272. http://doi.org/10.1146/annurev.publhealth.29.020907.090926

Swinburn, B., Caterson, I., Seidell, J., \& James, W. (2004). Diet, nutrition and the prevention of excess weight gain and obesity. Public Health Nutrition, 7(1a), 123-146. http://doi.org/10.1079/PHN2003585 
Tabbakh, T., \& Freeland-Graves, J. H. (2016). The home environment: a mediator of nutrition knowledge and diet quality in adolescents. Appetite, 105, 46-52. http://doi.org/10.1016/j.appet.2016.05.002

Tessier, S., Traissac, P., Maire, B., Bricas, N., Eymard-Duvernay, S., El Ati, J., \& Delpeuch, F. (2008). Regular users of supermarkets in Greater Tunis have a slightly improved diet quality. The Journal of Nutrition, 138(4), 768-774.

Tilman, D., Balzer, C., Hill, J., \& Befort, B. L. (2011). Global food demand and the sustainable intensification of agriculture. Proceedings of the National Academy of Sciences, 108(50), 20260-20264. http://doi.org/10.1073/pnas.1116437108

Timmer, C. P. (2009). Do supermarkets change the food policy agenda? World Development, 37(11), 1812-1819. http://doi.org/10.1016/j.worlddev.2008.08.022

Toiba, H., Umberger, W. J., \& Minot, N. (2015). Diet transition and supermarket shopping behaviour: is there a link? Bulletin of Indonesian Economic Studies, 51(3), 389-403. http://doi.org/10.1080/00074918.2015.1111997

Traill, W. B., Mazzocchi, M., Shankar, B., \& Hallam, D. (2014). Importance of government policies and other influences in transforming global diets. Nutrition Reviews, 72(9), 591604. http://doi.org/10.1111/nure.12134

Umberger, W. J., He, X., Minot, N., \& Toiba, H. (2015). Examining the relationship between the use of supermarkets and over-nutrition in Indonesia. American Journal of Agricultural Economics, 97(2), 510-525. http://doi.org/10.1093/ajae/aau111

United Nations Children's Fund (UNICEF), World Health Organization (WHO), \& World Bank Group. (2015). Joint Child Malnutrition Estimates 2016 Edition. New York, NY; Geneva, Switzerland and Washington, DC: United Nations Children's Fund, the World Health Organization and World Bank Group. Retrieved September 15, 2016, from http://www.who.int/nutgrowthdb/estimates2015/en/

Variyam, J. N., Blaylock, J., Lin, B.-H., Ralston, K., \& Smallwood, D. (1999). Mother's nutrition knowledge and children's dietary intakes. American Journal of Agricultural Economics, 81(2), 373-384. http://doi.org/10.2307/1244588

Vellakkal, S., Fledderjohann, J., Basu, S., Agrawal, S., Ebrahim, S., Campbell, O., Doyle, P., Stuckler, D. (2015). Food price spikes are associated with increased malnutrition among children in Andhra Pradesh, India. Journal of Nutrition, 145(8), 1942-1949. http://doi.org/10.3945/jn.115.211250

Ventura, A. K., \& Worobey, J. (2013). Early influences on the development of food preferences. Current Biology, 23(9), R401-R408. http://doi.org/10.1016/j.cub.2013.02.037 
Vereecken, C., \& Maes, L. (2010). Young children's dietary habits and associations with the mothers' nutritional knowledge and attitudes. Appetite, 54, 44-51. http://doi.org/10.1016/j.appet.2009.09.005

Vollmer, S., Harttgen, K., Subramanyam, M. A., Finlay, J., Klasen, S., \& Subramanian, S. V. (2014). Association between economic growth and early childhood undernutrition: evidence from 121 Demographic and Health Surveys from 36 low-income and middleincome countries. The Lancet Global Health, 2(4), e225-e234. http://doi.org/10.1016/S2214-109X(14)70025-7

Wand, M. P., \& Jones, M. C. (1995). Kernel Smoothing (1st ed.). London, UK; New York, NY: Chapman \& Hall.

Webb, P., \& Block, S. (2004). Nutrition information and formal schooling as inputs to child nutrition. Economic Development and Cultural Change, 52(4), 801-820. http://doi.org/10.1086/420901

Wells, J. C. K. (2014). Toward body composition reference data for infants, children, and adolescents. Advances in Nutrition: An International Review Journal, 5(3), 320S-329S. http://doi.org/10.3945/an.113.005371

Westerterp, K. R. (2004). Diet induced thermogenesis. Nutrition \& Metabolism, 1, 1-5. http://doi.org/10.1186/1743-7075-1-5

White, H. (1980). A heteroskedasticity-consistent covariance matrix estimator and a direct test for heteroskedasticity. Econometrica, 48(4), 817-838. http://doi.org/10.2307/1912934

Withrow, D., \& Alter, D. A. (2011). The economic burden of obesity worldwide: a systematic review of the direct costs of obesity. Obesity Reviews: An Official Journal of the International Association for the Study of Obesity, 12(2), 131-141. http://doi.org/10.1111/j.1467-789X.2009.00712.x

Wooldridge, J. M. (2003). Introductory Econometrics: A Modern Approach (2nd ed.). Mason, $\mathrm{OH}$ : South-Western Cengage Learning.

Wooldridge, J. M. (2010). Econometric Analysis of Cross Section and Panel Data (2nd ed.). Cambridge, MA; London, UK: The MIT Press.

World Bank. (2010). What Can We Learn From Nutrition Impact Evaluations? Lessons From a Review of Interventions to Reduce Child Malnutrition in Developing Countries. Washington, DC: World Bank. Retrieved January 4, 2017, from http://elibrary.worldbank.org/doi/abs/10.1596/978-0-8213-8406-0 
World Economic Forum. (2011). The Global Economic Burden of Non-Communicable Diseases. Geneva, Switzerland. Retrieved June 30, 2016, from http://www3.weforum.org/docs/WEF_Harvard_HE_GlobalEconomicBurdenNonCommu nicableDiseases_2011.pdf

World Health Organization (WHO). (1995). Physical Status: The Use and Interpretation of Anthropometry. Geneva, Switzerland: World Health Organization. Retrieved November 29, 2016, from http://www.who.int/childgrowth/publications/physical_status/en/

World Health Organization (WHO). (2006a). Definition and Diagnosis of Diabetes Mellitus and Intermediate Hyperglycemia. Geneva, Switzerland: World Health Organization. Retrieved July 28, 2014, from http://www.who.int/diabetes/publications/diagnosis_diabetes2006/en/

World Health Organization (WHO). (2006b). The WHO Child Growth Standards: Length/heightfor-age, weight-for-age, weight-for-length, weight-for-height and body mass index-for-age: Methods and development. Geneva, Switzerland: World Health Organization. Retrieved September 11, 2014, from http://www.who.int/childgrowth/standards/en/

World Health Organization (WHO). (2013). A Global Brief on Hypertension. Silent Killer, Global Public Health Crisis. Geneva, Switzerland: World Health Organization. Retrieved July 28, 2014, from http://apps.who.int/iris/bitstream/10665/79059/1/WHO_DCO_WHD_2013.2_eng.pdf?ua=1

World Health Organization (WHO). (2014). Nutrition - Body Mass Index [Web Page]. World Health Organization. Retrieved August 19, 2016, from http://www.euro.who.int/en/healthtopics/disease-prevention/nutrition/a-healthy-lifestyle/body-mass-index-bmi

World Health Organization (WHO). (2015a). Global Health Observatory Data Repository [Web Page]. World Health Organization. Retrieved October 26, 2016, from ttp://apps.who.int/gho/data/node.main.A897A?lang=en

World Health Organization (WHO). (2015b). Global Health Observatory Data - Kenya: WHO Statistical Profile [Web Page]. Retrieved April 16, 2016, from http://www.who.int/gho/countries/ken/country_profiles/en/

World Health Organization (WHO). (2015c). World Health Statistics 2015. Geneva, Switzerland: World Health Organization. Retrieved April 13, 2016 from http://www.who.int/gho/publications/world_health_statistics/2015/en/

World Health Organization (WHO). (2016a). Fact Sheet $N^{\circ} 311$ : Obesity and Overweight [Web Page]. World Health Organization. Retrieved February 23, 2017, from http://www.who.int/mediacentre/factsheets/fs311/en/ 
World Health Organization (WHO). (2016b). Global Database on Child Growth and Malnutrition. World Health Organization [Web Page]. Retrieved September 14, 2016, from http://www.who.int/nutgrowthdb/about/introduction/en/index2.html

World Health Organization (WHO). (2017). Fact Sheet $N^{\circ} 310$ : The Top 10 Causes of Death [Web Page]. World Health Organization. Retrieved February 23, 2017, from http://www.who.int/mediacentre/factsheets/fs310/en/

World Medical Association. (2013). WMA Declaration of Helsinki - Ethical Principles for Medical Research Involving Human Subjects. World Medical Association. Retrieved March 7, 2017, from http://www.wma.net/en/30publications/10policies/b3/

Yabanc1, N., Kısaç, İ., \& Karakuş, S. Ş. (2014). The effects of mother's nutritional knowledge on attitudes and behaviors of children about nutrition. Procedia - Social and Behavioral Sciences, 116, 4477-4481. http://doi.org/10.1016/j.sbspro.2014.01.970

Zhou, Y., Du, S., Su, C., Zhang, B., Wang, H., \& Popkin, B. M. (2015). The food retail revolution in China and its association with diet and health. Food Policy, 55, 92-100. http://doi.org/10.1016/j.foodpol.2015.07.001 


\section{General Appendix}

Maps of the Study Sites in Central Kenya

Household Survey 2015 


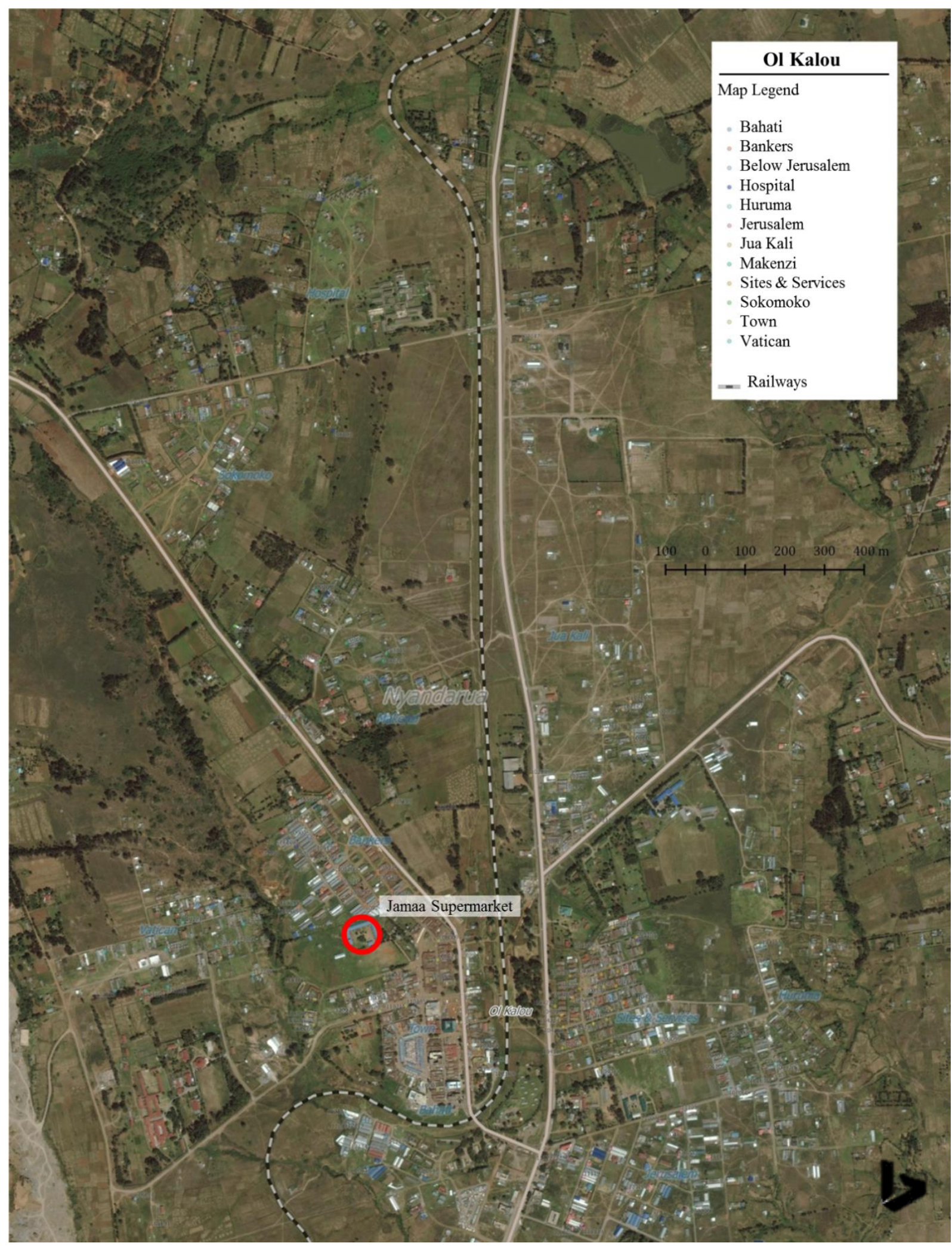

Figure A.1. Map of Ol Kalou in Nyandarua County. Created with QGIS (2015) based on data provided by OpenStreetMap Contributors (2015) and Bing Aerial (2015). 


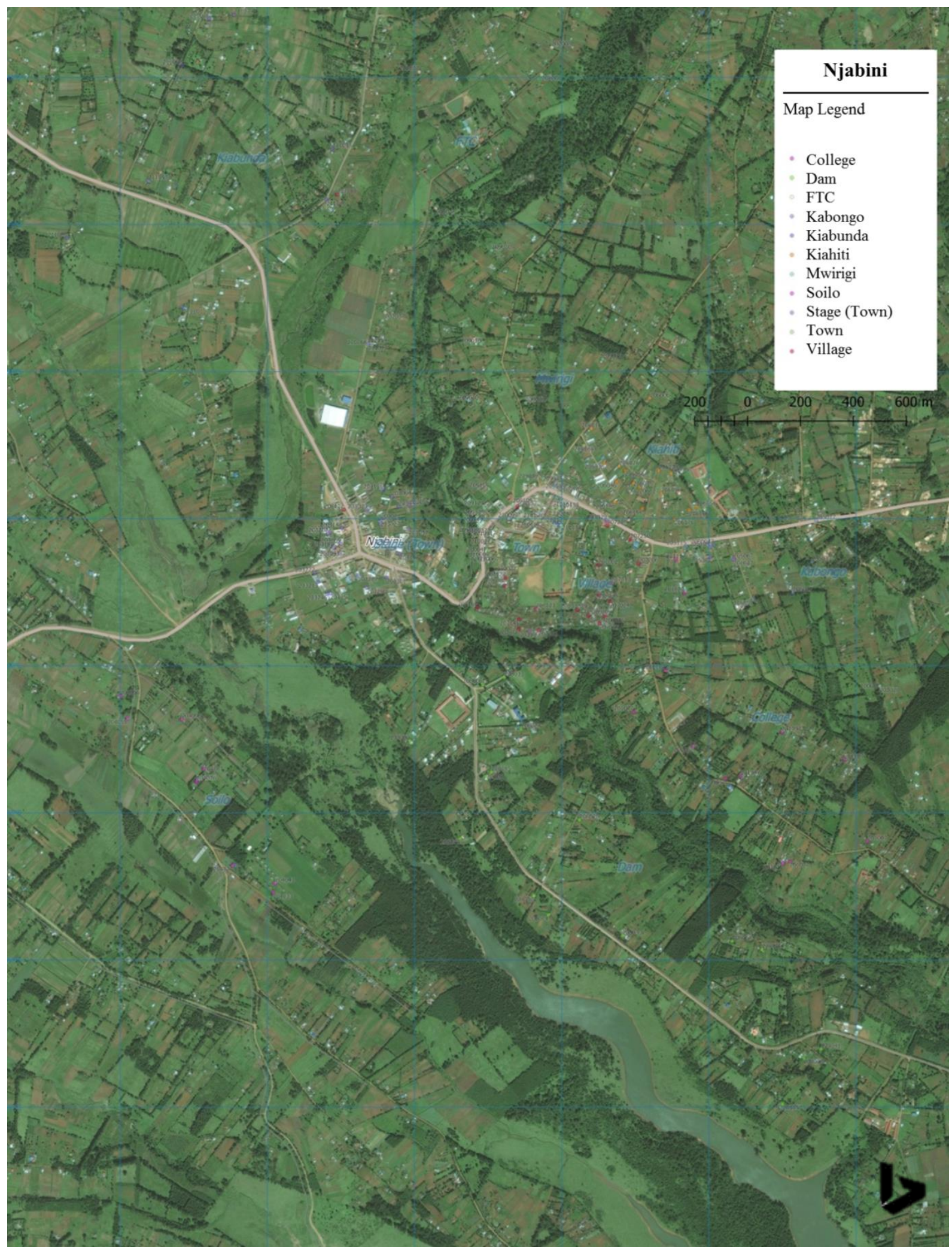

Figure A.2. Map of Njabini in Nyandarua County. Created with QGIS (2015) based on data provided by OpenStreetMap Contributors (2015) and Bing Aerial (2015). 


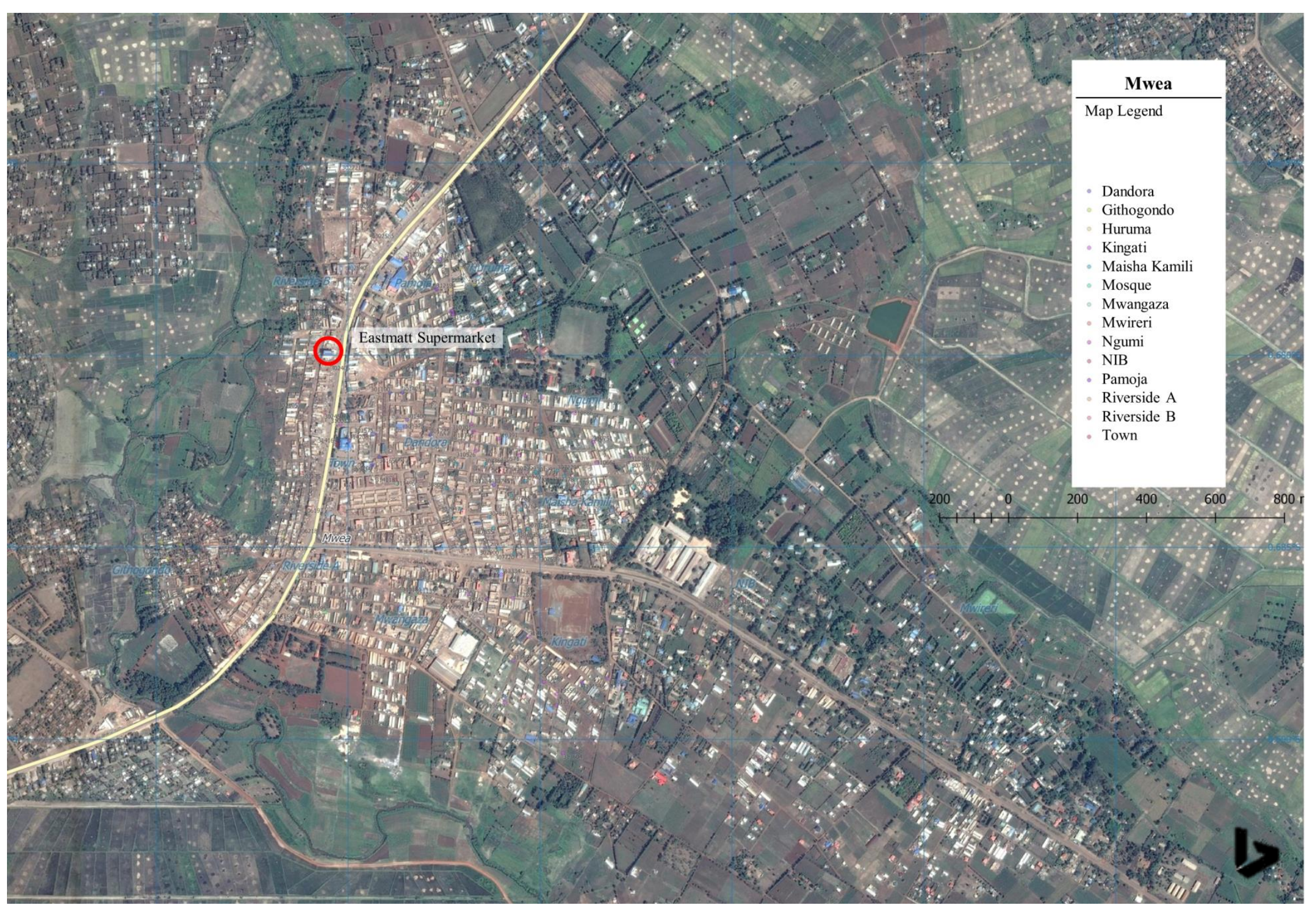

Figure A.3. Map of Mwea in Kirinyaga County. Created with QGIS (2015) based on data provided by OpenStreetMap Contributors (2015) and Bing Aerial (2015). 


\section{Household Survey 2015}

\section{UON}

University of Nairobi

\section{KENYA HOUSEHOLD CONSUMPTION SURVEY 2015}

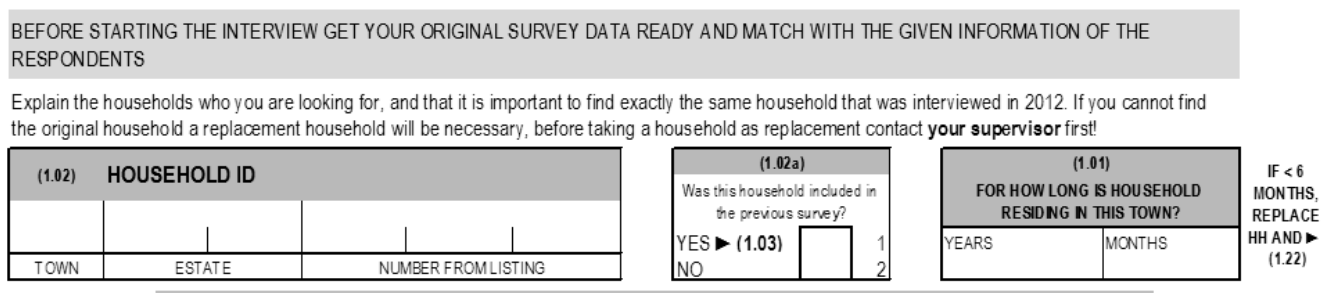

Match name of household head with original survey. If household head changed write down new household head, but do not change the order of the household members on FLAP

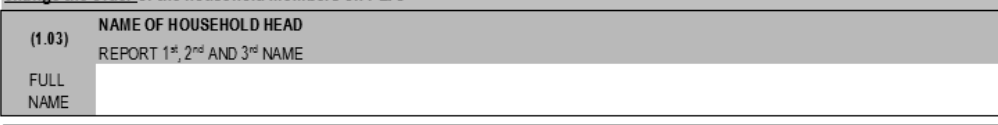

\begin{tabular}{|ll|}
\hline$(1.04)$ & ADDRESS \\
\hline$(1.04) \mathrm{a}$ & SUELOCATION: \\
\hline$(1.04) \mathrm{b} b$ & $\begin{array}{l}\text { ESTATE: } \\
\text { (NAME) }\end{array}$ \\
\hline \begin{tabular}{ll}
$(1.04) \mathrm{c}$ & FEATURES THAT HELPFINDING HOUSEHOLD AGAIN \\
\hline
\end{tabular} & \\
\hline
\end{tabular}

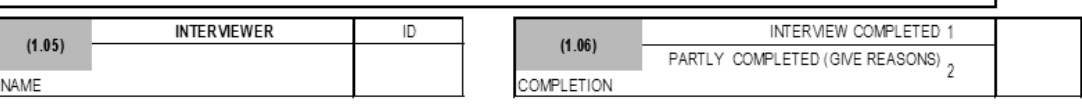

\begin{tabular}{|c|c|c|c|c|c|c|c|}
\hline \multicolumn{8}{|c|}{ VISIT 1 (ONE DAY) } \\
\hline \multicolumn{3}{|c|}{$(1.07) \mathrm{a}$} & \multirow{2}{*}{\multicolumn{2}{|c|}{$\frac{(1.07) \mathbf{b}}{\text { TIME STARTED }}$}} & \multirow{2}{*}{\multicolumn{2}{|c|}{$\begin{array}{l}\frac{(1.07) \mathbf{c}}{\text { TIMEENDED }} \\
\end{array}$}} & $(1.07) \mathrm{d}$ \\
\hline DAY & MONTH & YEAR & & & & & TOTAL BREAKS \\
\hline 1 & 1 & & HOURS & MINUTES & HOURS & MNUTES & MNUTES \\
\hline
\end{tabular}

\begin{tabular}{|c|c|c|c|c|c|c|c|}
\hline \multicolumn{8}{|c|}{ VISIT 2 (ONE DAY) } \\
\hline & $(1.0)$ & & & & $(1.08)$ & & $(1.08) \mathrm{d}$ \\
\hline DAY & MONTH & YEAR & & RTED & & NDED & TOTAL BREAKS \\
\hline 1 & | & | & HOURS & $\begin{array}{c}\text { MNUTES } \\
\text {. }\end{array}$ & HOURS & MNUTES & MNUTES \\
\hline
\end{tabular}

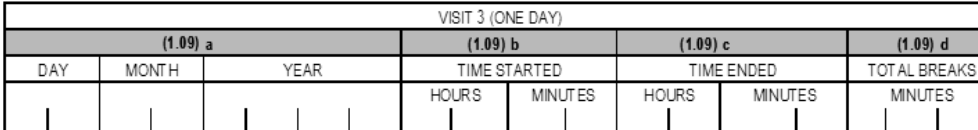

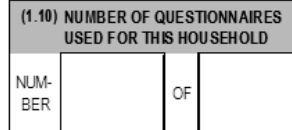

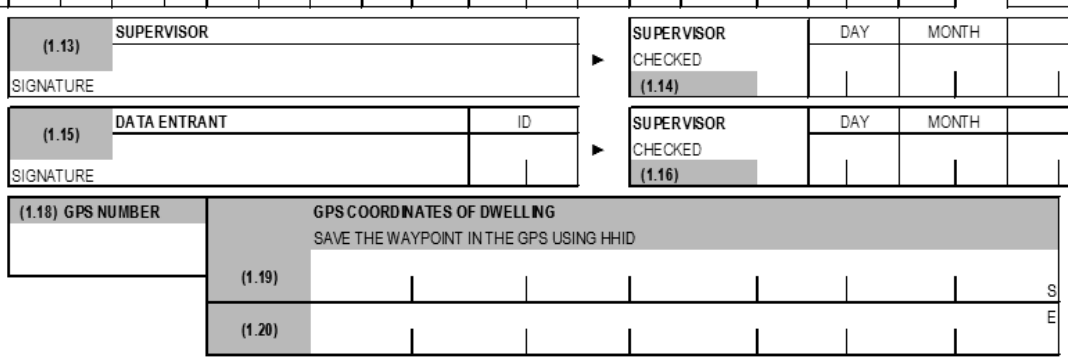

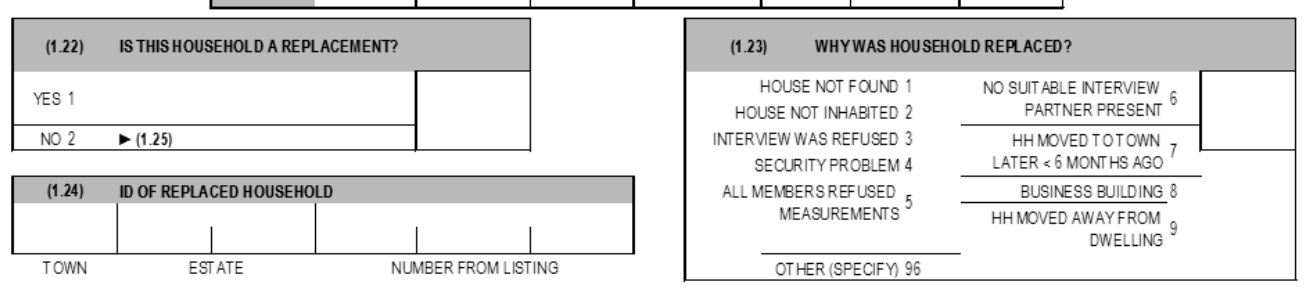




\begin{tabular}{lll|}
\hline LAST YEAR: & EVENING \\
LAST MONTH: & RESPONDENT ID 2012: & \\
\hline RESPONDENT ID 2015: & \\
\hline
\end{tabular}

I would now like to ask some information about the people who lived here when we visited in 2012 and about the ones living currently in this household

\begin{tabular}{|c|c|c|c|c|c|c|c|c|c|c|}
\hline Copy all names from & & $(1.25)$ & (1.26) & $(1.27)$ & (1.27a) & (1.27b) & $(1.2$ & 7c) & $(1.2)$ & \\
\hline $\begin{array}{l}\text { your info sheet in the } \\
\text { exact same order }\end{array}$ & & Could you please give me the & $\begin{array}{l}\text { How old is } \\
\text { [NAME]? }\end{array}$ & \begin{tabular}{|l|} 
What is \\
[NAMEI's
\end{tabular} & $\begin{array}{r}\text { THIS QUESTIONRES } \\
\text { IN } 2012\end{array}$ & $\begin{array}{l}\text { FERS TO THE MEMBE } \\
2 \text { AND WERE LISTED }\end{array}$ & $\begin{array}{l}\text { ERS THAT } \\
\text { BY THE EI }\end{array}$ & $\begin{array}{l}\text { ALREAD } \\
\text { NUMERA }\end{array}$ & $\begin{array}{l}\text { Y PARTICI } \\
\text { TOR }\end{array}$ & PATED \\
\hline $\begin{array}{l}\text { before you read out } \\
\text { and check together } \\
\text { with respondent if the } \\
\text { members are still part }\end{array}$ & & $\begin{array}{l}\text { names of all people currently living } \\
\text { in this household? }\end{array}$ & $\begin{array}{l}\text { IF BABY LESS THAN } \\
1 \text { YEAR ENTER ZERO } \\
\end{array}$ & gender? & $\begin{array}{c}\text { Was [NAME] part } \\
\text { of the household } \\
\text { last year? }\end{array}$ & $\begin{array}{c}\text { Why is [NAME] } \\
\text { no longer living } \\
\text { in this } \\
\text { household? }\end{array}$ & $\begin{array}{r}\text { Wher } \\
\text { [NAME] } \\
\text { out of } \\
\text { house }\end{array}$ & $\begin{array}{l}\text { did } \\
\text { move } \\
\text { this } \\
\text { hold? }\end{array}$ & $\begin{array}{l}\text { When } \\
\text { [NAME }\end{array}$ & $\begin{array}{l}\text { did } \\
\text { die? }\end{array}$ \\
\hline of the household. & $\begin{array}{l}0 \\
0 \\
0\end{array}$ & & $\begin{array}{l}\text { ELDERLY USING } \\
\text { THEIR CHILDREN'S } \\
\text { AGE OR AN EVENT }\end{array}$ & & YES & Moved & & & & \\
\hline $\begin{array}{l}\text { Include new members } \\
\text { underneath the "old" }\end{array}$ & & & $\begin{array}{l}\text { FOR CHILDREN }<5 \\
\text { ASKFOREXACT } \\
\text { AGE INYEARS AND }\end{array}$ & & $\begin{array}{lr}\text { NO } & 2 \\
\text { CROSS OUT AND } \\
\text { NEXT PERSON }\end{array}$ & $\begin{array}{l}\text { Set up own } \\
\text { household in } \\
\text { same dwelling }\end{array}$ & NEXT & PERSON & $\begin{array}{l}-N E \\
\text { PERS }\end{array}$ & \\
\hline from the original survey & & & & Male & & $\mid \begin{array}{ll}\text { Died } & 3 \\
-(1.27 \mathrm{~d}) & \end{array}$ & & & & \\
\hline & & & YEARSIMONTHS & Female & CODE & CODE & MONTH & YEAR & MONTH & YEAR \\
\hline & 1 & & & & & & & & & \\
\hline & 2 & & & & & & & & & \\
\hline & 3 & & & & & & & & & \\
\hline & 4 & & & & & & & & & \\
\hline & 5 & & & & & & & & & \\
\hline & 6 & & & & & & & & & \\
\hline & 7 & & & & & & & & & \\
\hline & 8 & & & & & & & & & \\
\hline & 9 & & & & & & & & & \\
\hline & 10 & & & & & & & & & \\
\hline & 11 & & & & & & & & & \\
\hline & 12 & & & & & & & & & \\
\hline & 13 & & & & & & & & & \\
\hline & 14 & & & & & & & & & \\
\hline & 15 & & & & & & & & & \\
\hline
\end{tabular}


SECTION 1: Household Composition (1/2)

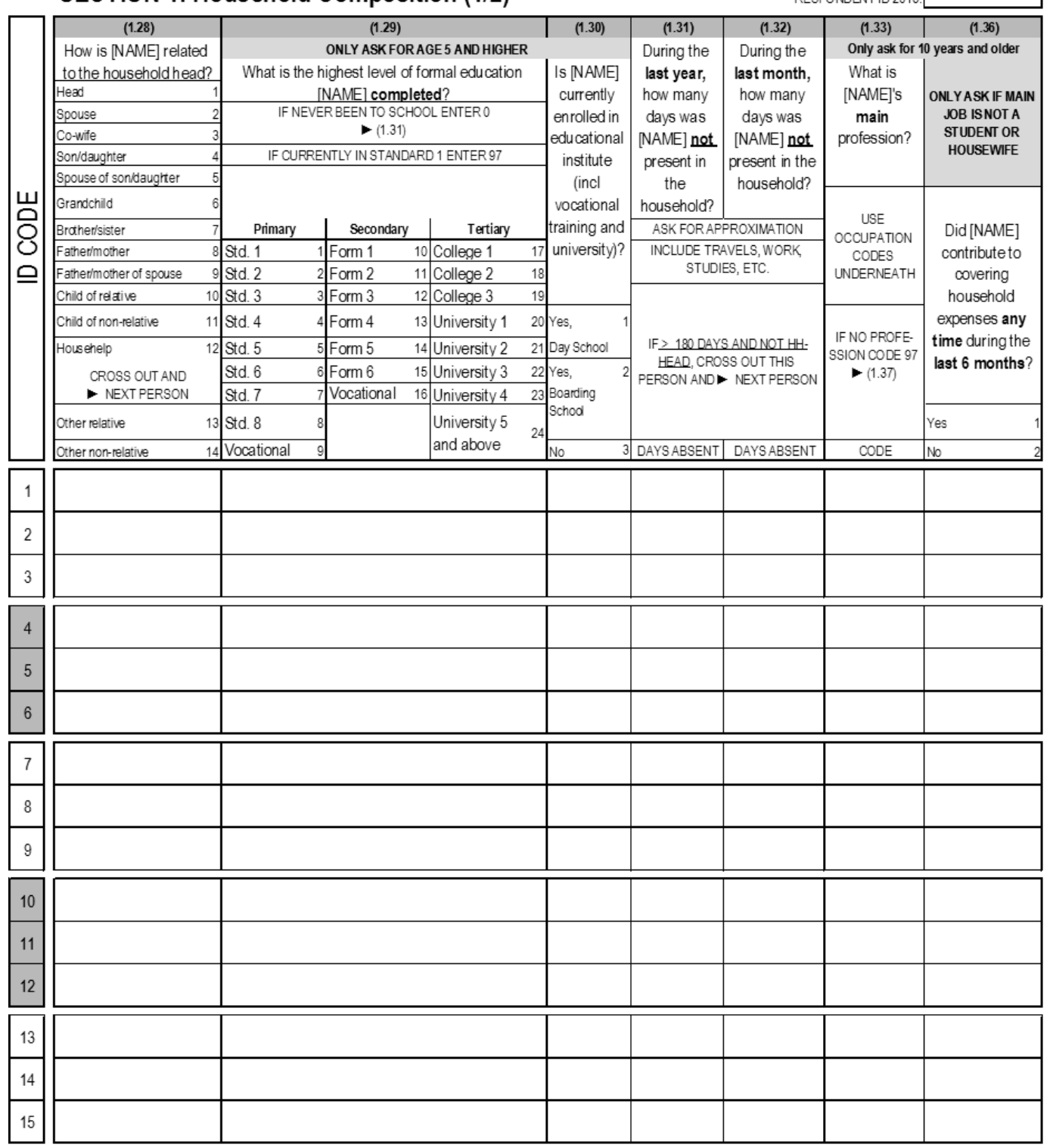




\section{SECTION 1: Household Composition (2/2)}

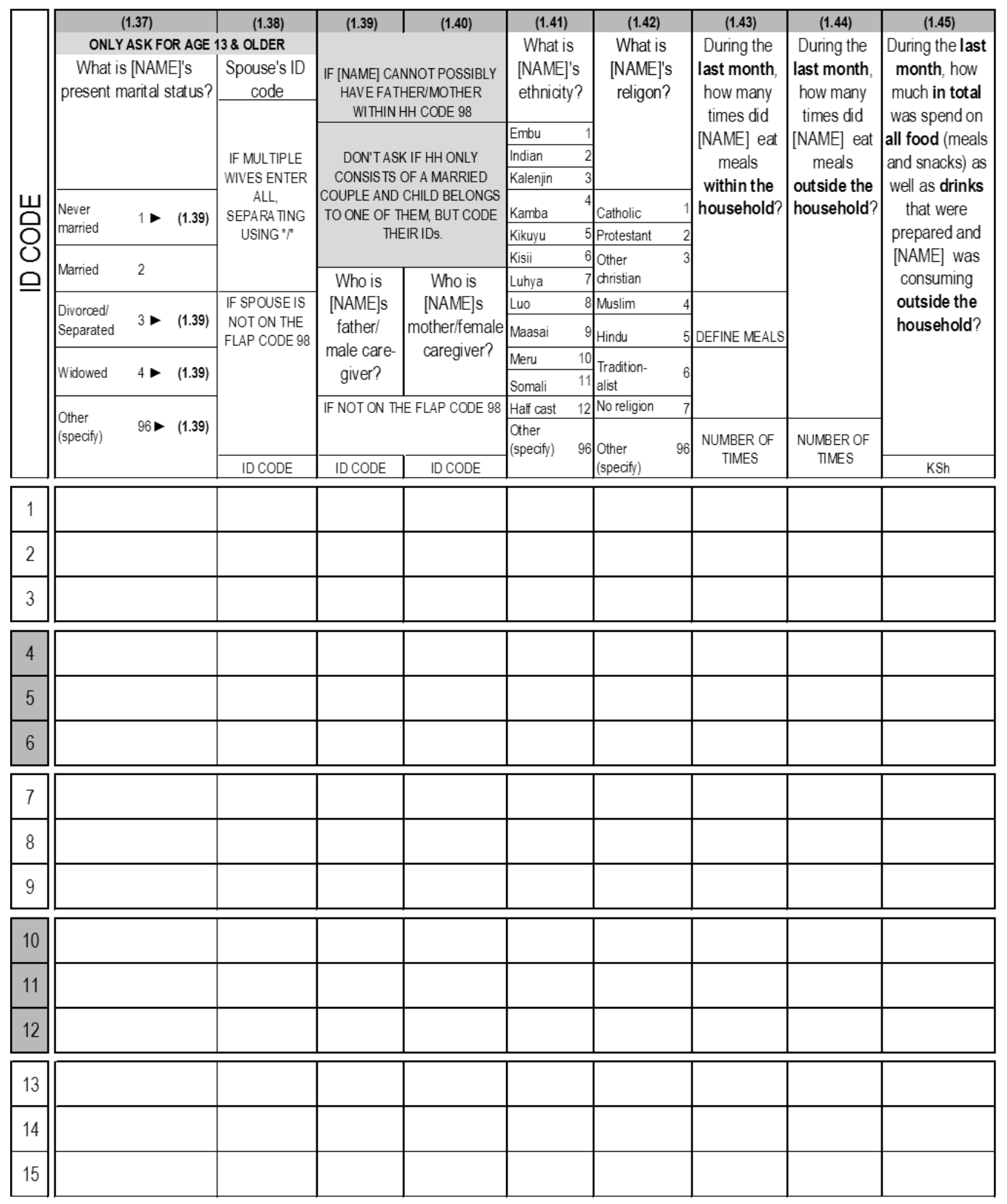




\section{Respondent Selection}

\begin{tabular}{l} 
SELECTION OF HOUSEHOLD MEMBERS FOR ANTHROPOMETRIC and BIOMEDICAL MEASUREMENT \\
\hline 1. Check your information on 2012, who were the selected respondents in 2012 and note them down \\
2. For each case (Male, Female, child1/adolecents) check if they are still part of the household (1.27 a-d) and if they are willing to participate \\
again \\
3. Explain and probe for consents to interview and to take the measurements of this household member later \\
4. If interviewing the former person is not possible, cross him/her out, report the reason and find a replacement within the household if possible- \\
check if the replacement was not crossed out before (1.28) or (1.31) \\
5. For CHILD2 in best case mother is also underneath the SPs. If not make sure mother is available for the interviews to help answering the \\
questions \\
>lf no CHILD2 can be found among the household, cross out completely \\
USE DECLARATION FORM \\
ALL ADOLESCENTS AND ADULTS (OLDER THAN 14 YEARS OF AGE) SIGN FOR THEMSELVES \\
FOR CHILDREN YOUNGER THAN 14 YEARS OF AGE AND LET THE LEGAL REPRESENTATIVE SIGN \\
\hline IF CONSENT IS GIVEN, LET THE SELECTED RESPONDENTS (LEGAL REPRESENTATIVES) SIGN AND PROCEED.
\end{tabular}

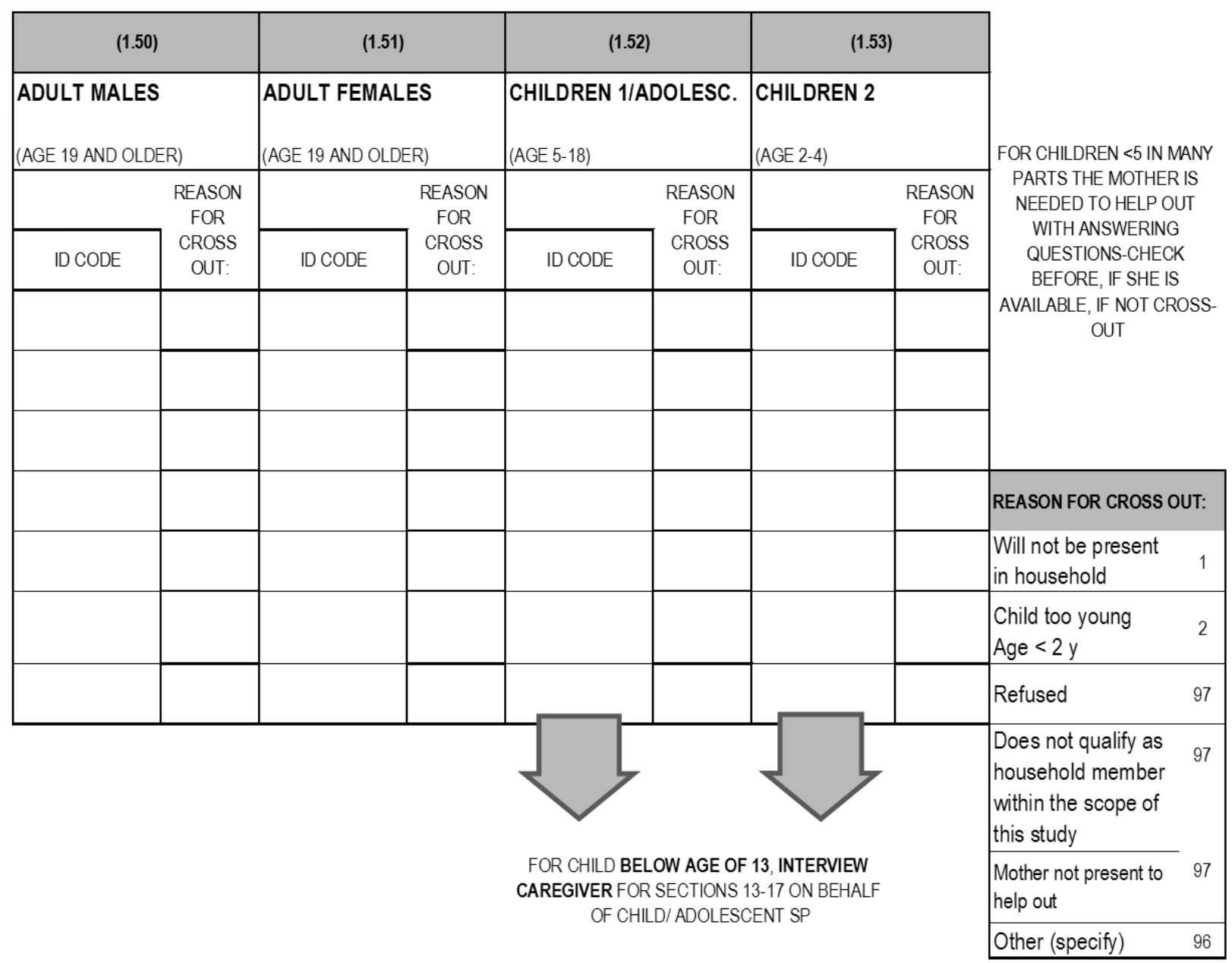




\section{SECTION 2: Food Consumption Within Household}

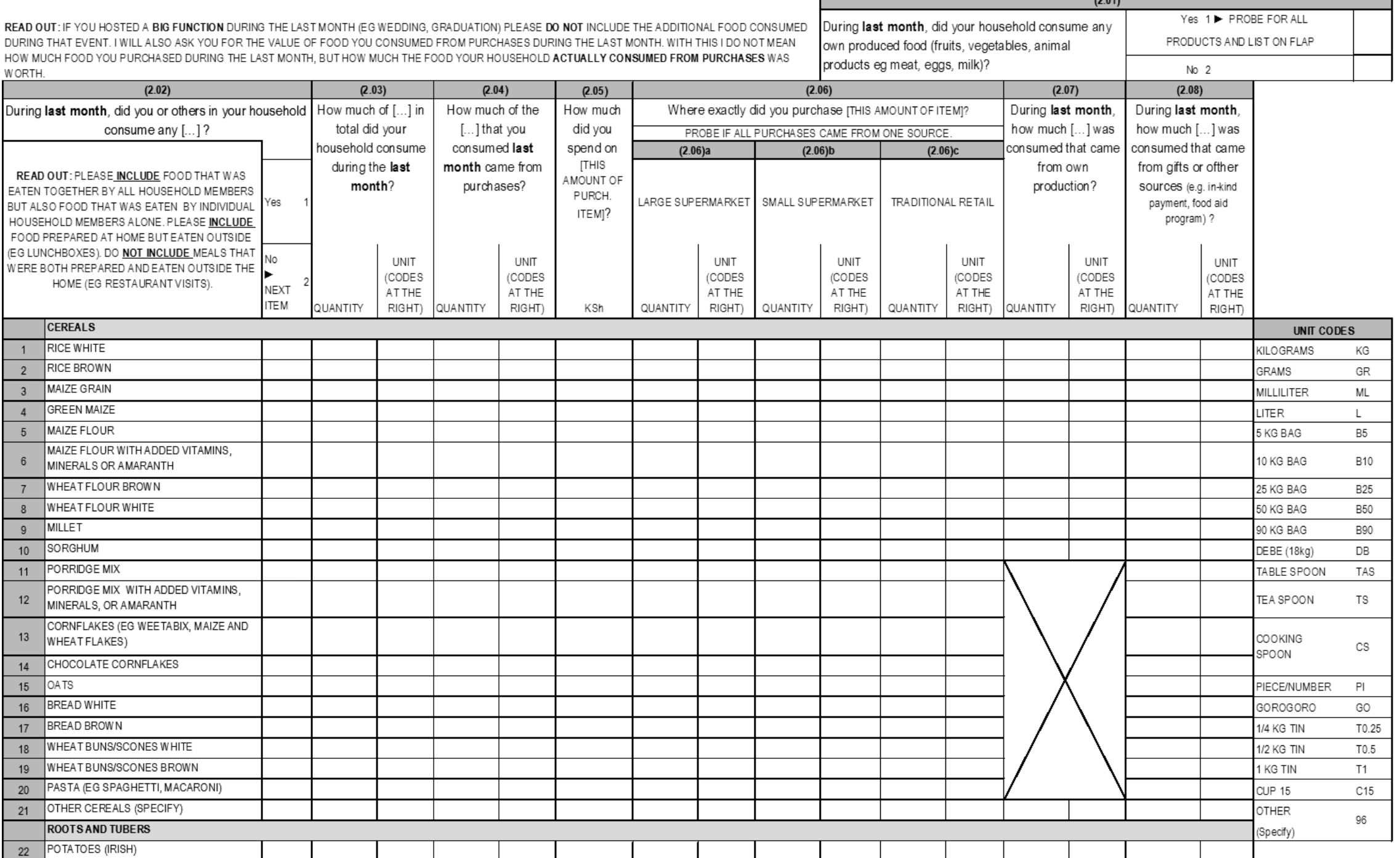




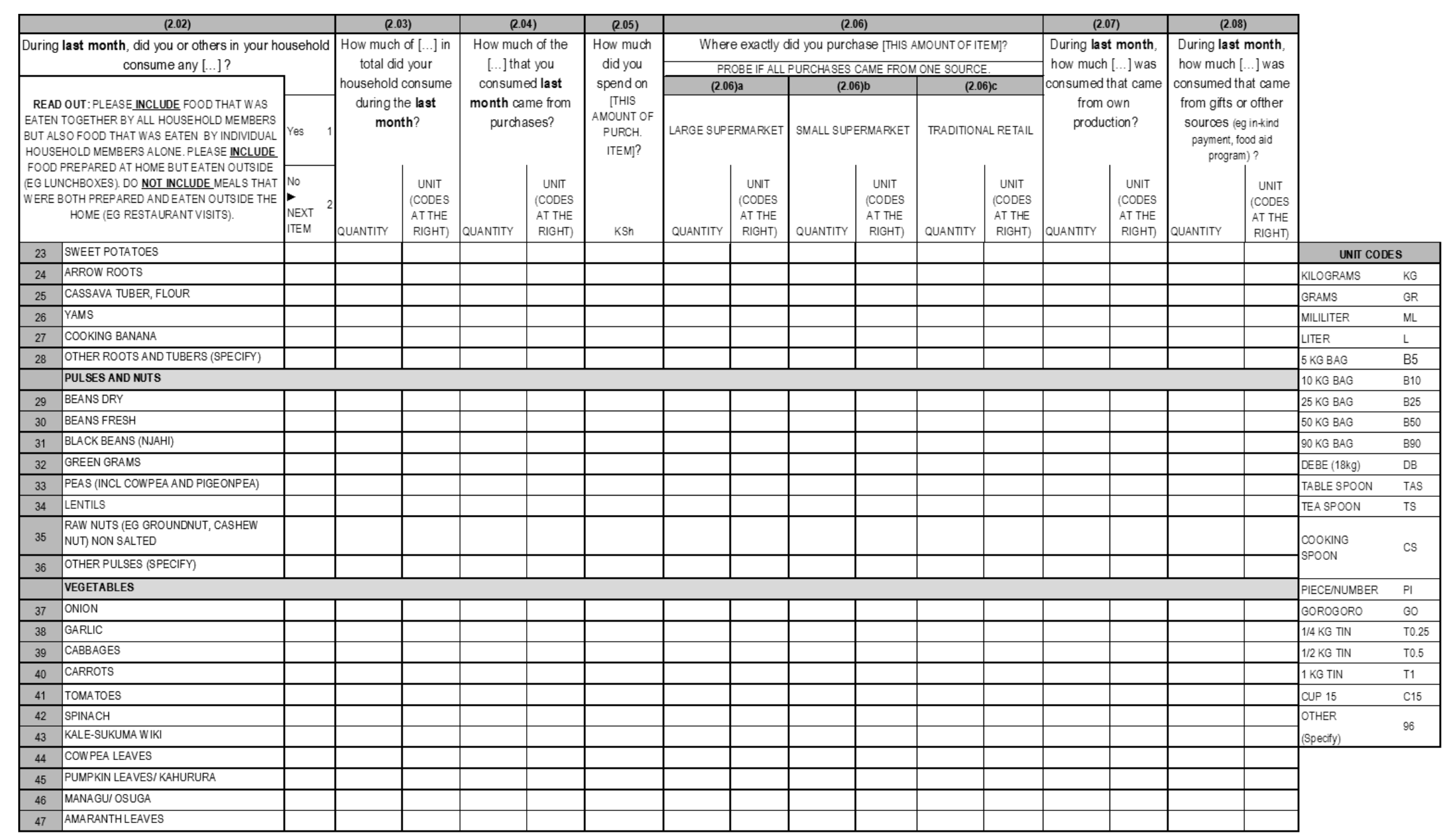




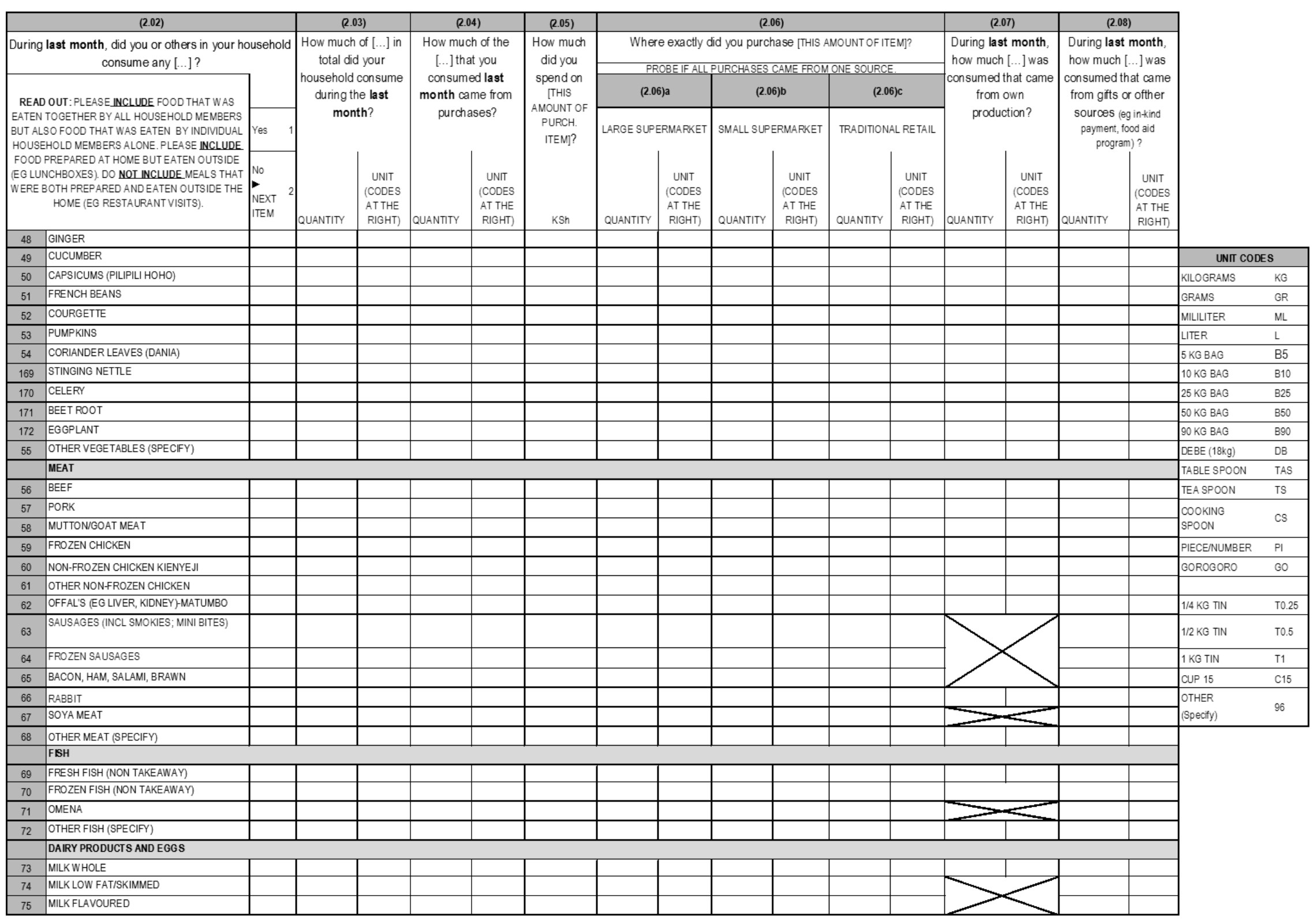




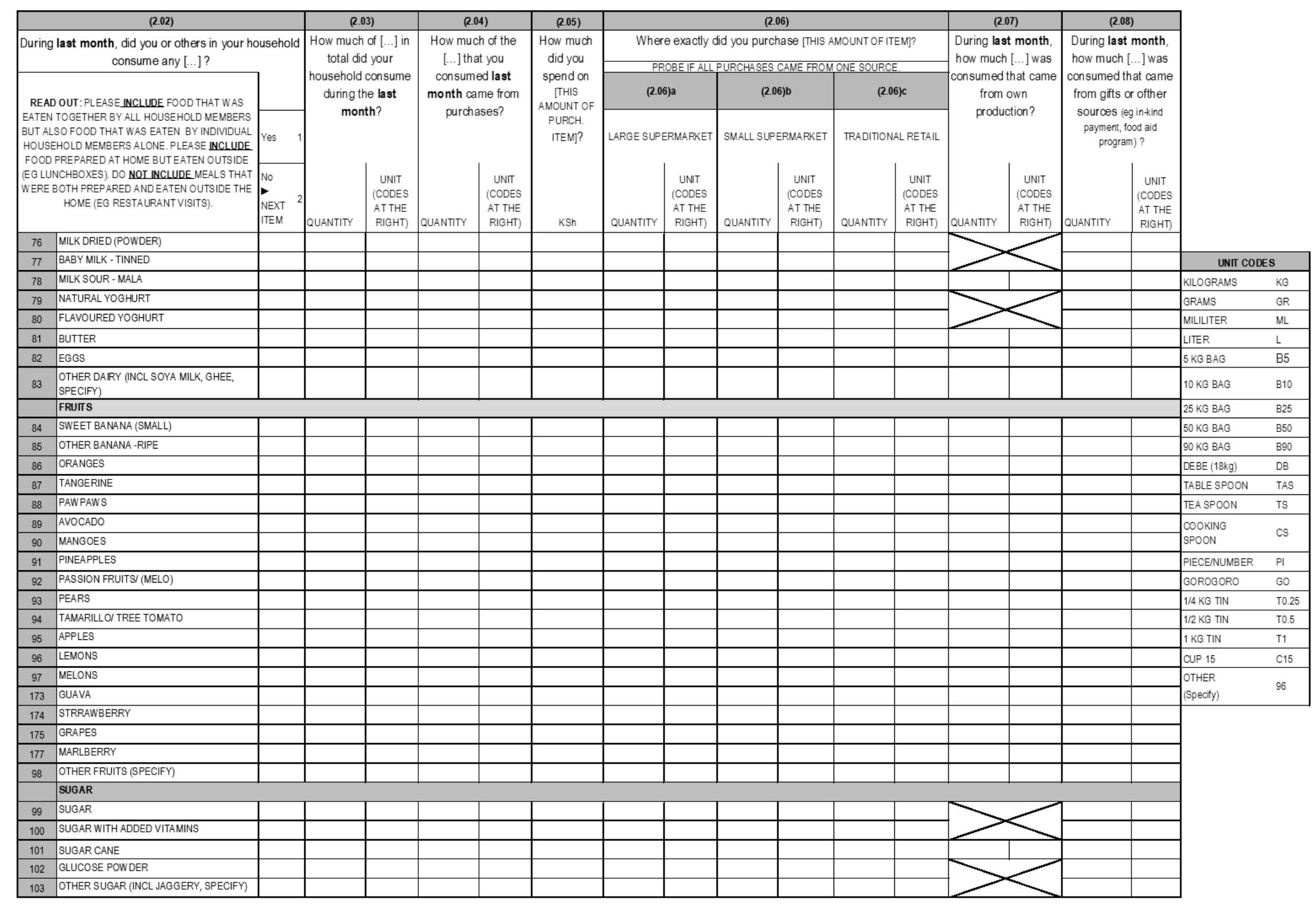




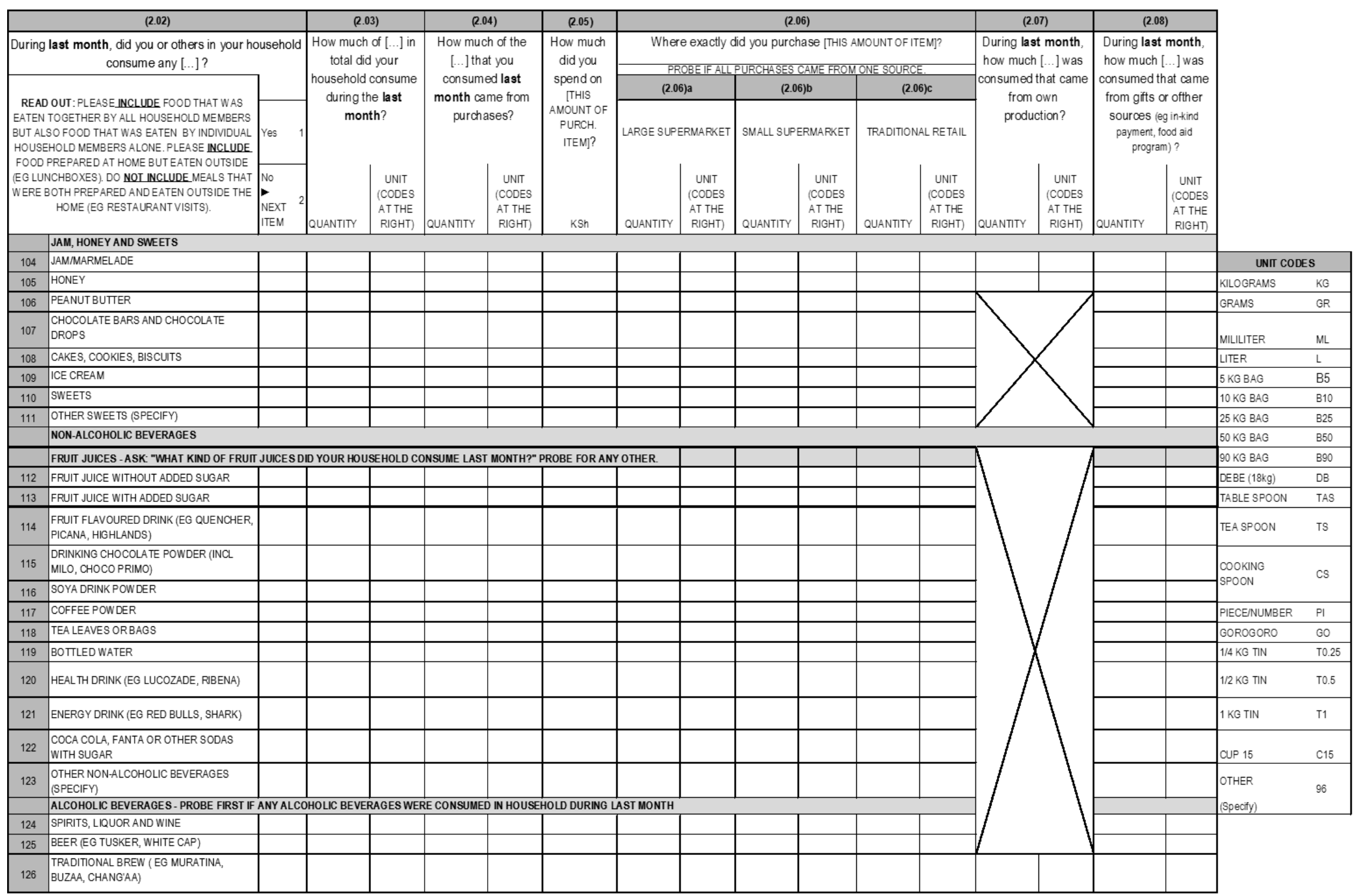




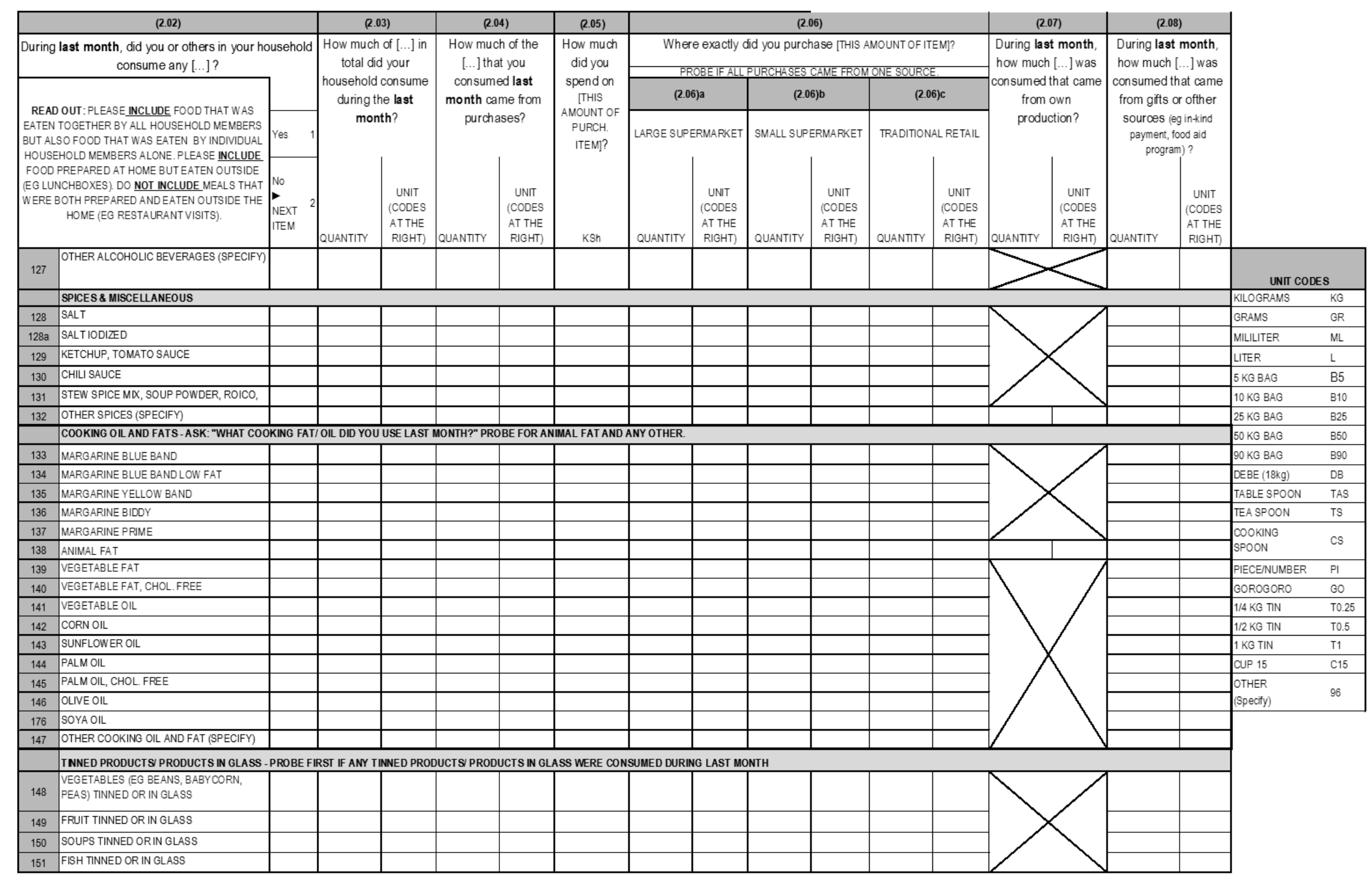




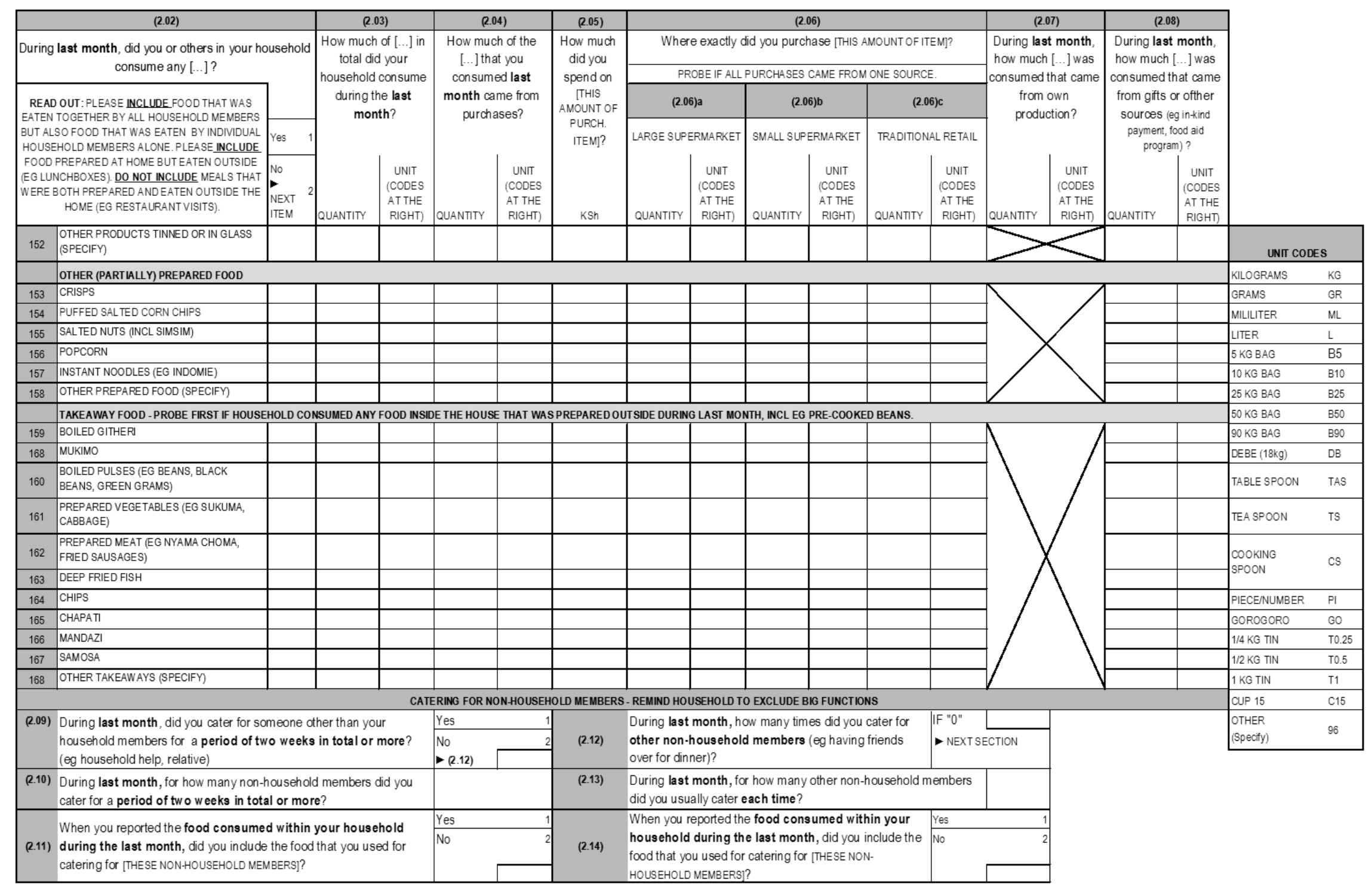




\section{SECTION 3: Shopping Behaviour and Attitudes (1/3)}

INTRODUCTION: DEFINE RETAIL OUTLETS

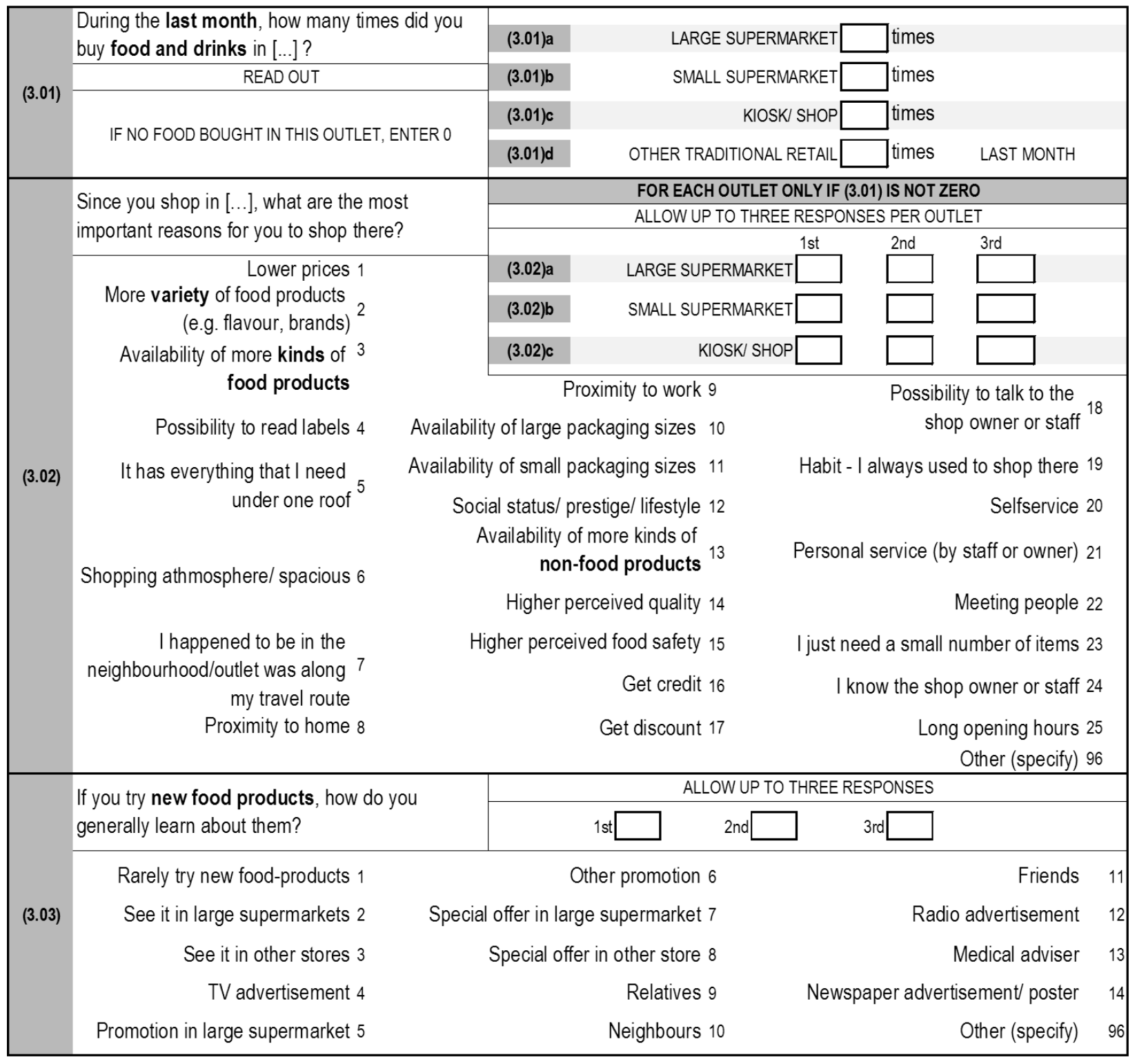


SECTION 3: Shopping Behaviour and Attitudes (2/3)

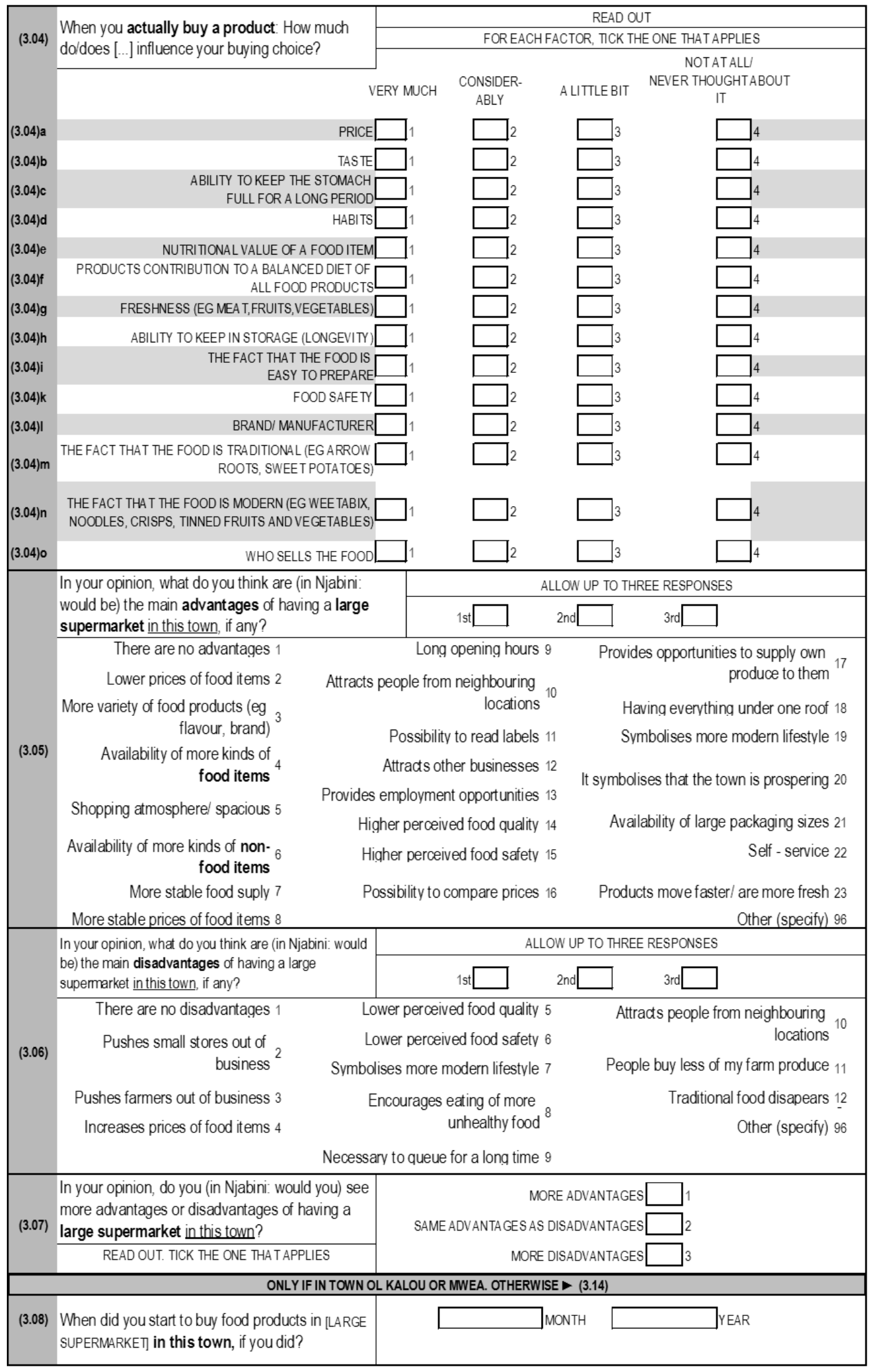




\section{SECTION 3: SHOPPING BEHAVIOUR AND ATTITUDES (3/3)}

USE OF FOOD LABELS - READ OUT: "A FOOD LABEL IS EVERY INFORMATION WRITTEN ON THE PACKAGE, EXCEPT THE PRICE"

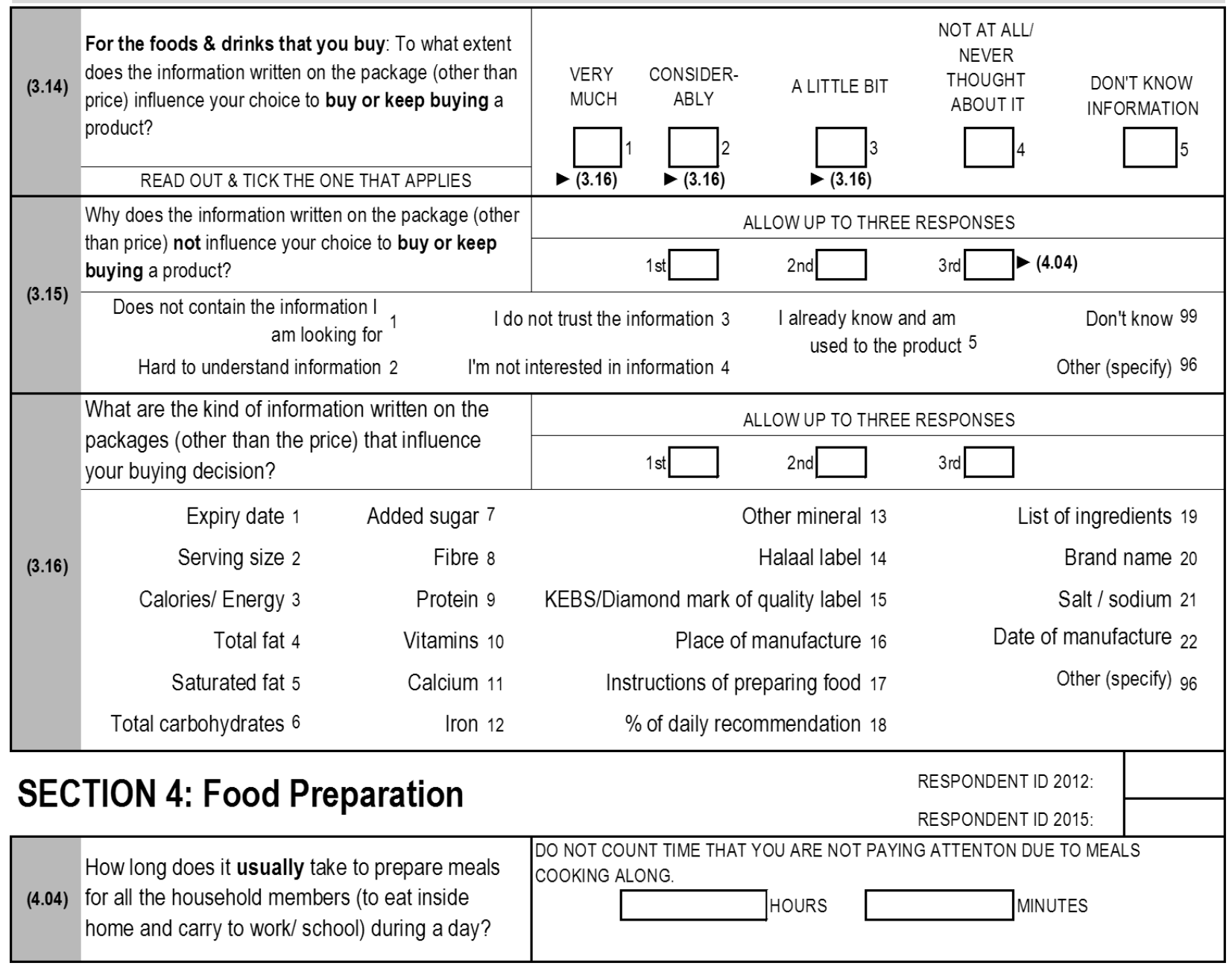




\section{SECTION 5: Food Accessibility (1/1)}

RESPONDENT ID 2012:

RESPONDENT ID 2105:

\begin{tabular}{|c|c|c|c|c|c|c|}
\hline \multicolumn{2}{|r|}{$\begin{array}{l}\text { READ OUT: NOW, I AM GOING TO ASK YOU A FEW } \\
\text { QUESTIONS ABOUT FOOD ACCESSIBILITY }\end{array}$} & $\begin{array}{l}\text { LARGE SUPER- } \\
\quad \text { MARKET }\end{array}$ & \begin{tabular}{c|c} 
SMALL & \\
SUPERMARKET
\end{tabular} & KIOSK & \begin{tabular}{|c|} 
PLACE FOR \\
FRESH FRUITS + \\
VEGETABLES \\
\end{tabular} & RESTAURANT \\
\hline \multirow{2}{*}{\multicolumn{2}{|c|}{$\begin{array}{c}\text { How long does it take you/ would it take } \\
\text { you to travel from here (one way) to } \\
\text { nearest [...]? }\end{array}$}} & (5.08)a & $(5.08) \mathrm{b}$ & $(5.08) \mathrm{c}$ & (5.08)d & $(5.08) \mathrm{e}$ \\
\hline & & & & & & \\
\hline \multirow{2}{*}{ (5.08) } & \multirow{2}{*}{$\begin{array}{l}\text { GIVE TIME IN MINUTES AND INCLUDE TIME } \\
\text { WAITING (EG FOR A BUS) }\end{array}$} & \multirow{2}{*}{$\square_{\min }$} & \multirow{2}{*}{$\square_{\text {min }}$} & \multirow{2}{*}{$\square_{\min }$} & \multirow{2}{*}{$\square$ min } & \multirow[t]{2}{*}{ ]min } \\
\hline & & & & & & \\
\hline \multirow{6}{*}{ (5.09) } & \multirow{2}{*}{$\begin{array}{l}\text { How do you usually get to/ would you } \\
\text { travel to nearest [...]? (one way) }\end{array}$} & $(5.09) \mathrm{a}$ & $(5.09) \mathrm{b}$ & $(5.09) \mathrm{c}$ & (5.09)d & $(5.09) \mathrm{e}$ \\
\hline & & & & & & \\
\hline & \multirow{4}{*}{\multicolumn{6}{|c|}{$\begin{array}{cr}\text { Bicycle 2 } & \text { (5.11) } \\
\text { Car 3 } & \text { Boda boda } 5 \\
& \text { Matatu } 6 \\
\text { Other (specify) } 96\end{array}$}} \\
\hline & & & & & & \\
\hline & & & & & & \\
\hline & & & & & & \\
\hline \multirow[b]{2}{*}{ (5.10) } & \multirow{2}{*}{$\begin{array}{l}\text { How much does it cost you/ would it cost } \\
\text { you to get to nearest [...] by [THIS MEANS } \\
\text { OF TRANSPORT]? (one way) }\end{array}$} & $(5.10) \mathrm{a}$ & $(5.10) \mathrm{b}$ & $(5.10) c$ & $(5.10) d$ & $(5.10) \mathrm{e}$ \\
\hline & & ]KSh & $\square$ KSh & KSh & KSh & $\square_{\text {KSh }}$ \\
\hline \multirow{5}{*}{ (5.11) } & \multirow{3}{*}{$\begin{array}{l}\text { Is most of the food for your household } \\
\text { that is bought in [...] usually done on the } \\
\text { way to work of some household member } \\
\text { or on the way from work back home? }\end{array}$} & (5.11)a & $(5.11) \mathrm{b}$ & $(5.11) \mathrm{c}$ & (5.11)d & (5.11)e \\
\hline & & \multicolumn{5}{|c|}{ FOR EACH CASE TICK THE ONE THAT APPLIES } \\
\hline & & & & Yes & Yes & es \\
\hline & & & $2 \square$ No & No & No & Nor \\
\hline & $\begin{array}{l}\text { IF NO FOOD IS BOUGHT IN [...] } \\
\text { CROSS OUT AND } \triangleright \text { NEXT OUTLET }\end{array}$ & NEXT OUTLET & NEXT OUTLET & NEXT OUTLET & NEXT OUTLET & NEXT SECTION \\
\hline & HELP FOR INTERVIEWER: & & & & & \\
\hline & FROM HOME TO WORK & & & & & \\
\hline & FROM WORK TO HOME & & & & & \\
\hline & How long would it take this household & (5.12)a & $(5.12) \mathrm{b}$ & $(5.12) \mathrm{c}$ & $(5.12) \mathrm{d}$ & (5.12)e \\
\hline (5.12) & $\begin{array}{l}\text { member to travel: } \\
\text { a) from home straight to work? } \\
\text { b) from work straight home? }\end{array}$ & min & min & \begin{tabular}{|l}
$\min$ \\
\end{tabular} & min & $\square \min$ \\
\hline & How long does it take this household & (5.13)a & $(5.13) \mathrm{b}$ & $(5.13) \mathrm{c}$ & (5.13)d & (5.13)e \\
\hline (5.13) & & & VE TIME IN MINUTE & $\begin{array}{l}\text { S AND INCLUDE T } \\
\text { LUDE TIME SPEN }\end{array}$ & $\begin{array}{l}\text { IME WAITING (EG F } \\
\text { T SHOPPING. }\end{array}$ & \\
\hline & b) from work to $[\ldots]$ and then home? & $\min$ & $\min$ & $\min$ & $\min$ & $\min$ \\
\hline & How does this houshold member usually & (5.14)a & $(5.14) \mathrm{b}$ & $(5.14) \mathrm{c}$ & $(5.14) \mathrm{d}$ & $(5.14) \mathrm{e}$ \\
\hline$(5,1)$ & $\begin{array}{l}\text { travel to [...] on the way } \\
\text { a) to work } \\
\text { b) from work? }\end{array}$ & WAY TO [... & WAY TO [. & WAY TO [. & WAY TO [.. & WAY TO [...] \\
\hline$(0.14)$ & Motorcycle 4 & WAY FROM & WAY FROM & WAY FROM & WAYFROM & WAYFROM \\
\hline & Boda boda 5 & {$[\ldots]$ TO } & {$[\ldots]$ TO } & {$[\ldots]$ TO } & {$[\ldots]$ TO } & {$[\ldots]$ TO } \\
\hline & $\begin{array}{c}\text { Matatu } 6 \\
\text { Other (specify) } 96\end{array}$ & a)/b) & a)/b) & a)/b) & a)/b) & a)/b) \\
\hline
\end{tabular}




\section{SECTION 6: Non-Food Expenditure (1/2)}

\begin{tabular}{|c|c|c|c|c|c|}
\hline & & & $(6.01)$ & $(6.02)$ & $(6.03)$ \\
\hline & & EXPENDITURE DURING LAST MONTH & \begin{tabular}{|c|} 
Did your \\
household
\end{tabular} & $\begin{array}{l}\text { How much did } \\
\text { your household }\end{array}$ & $\begin{array}{l}\text { How much of [ITEM]/SERVICE] } \\
\text { did your household receive }\end{array}$ \\
\hline & & $\begin{array}{c}\text { READ OUT: PLEASE EXCLUDE BUSINESS } \\
\text { EXPENDITURES. }\end{array}$ & $\begin{array}{c}\text { purchase or pay } \\
\text { for any }\end{array}$ & $\begin{array}{l}\text { spend on } \\
\text { [ITEM][SERVICE] }\end{array}$ & $\begin{array}{l}\text { without payment during the last } \\
\text { month (eg gifts, subsidies)? }\end{array}$ \\
\hline & & IN OTHER (SPECIFY) EXCLUDE VERY INFREQUENT & month? & & TOCKS \\
\hline & & $\begin{array}{l}\text { HIGH VALUE PURCHASES (EG PURCHASING A TV } \\
\text { SET) }\end{array}$ & Yes & & IF NONE CODE "0" \\
\hline & & & & & INCL OWN PRODUCTION \\
\hline & & ENTER 99 IF RESPONDENT DOESN'T KNOW & $\nabla(6.03)$ & VALUE IN KSh & VALUE IN KSh \\
\hline & $\overline{\text { READ }}$ & OUT: INCLUDE ONLY WHAT IS NOT ALREADY INCLUD & DED IN RENT & & \\
\hline & 1 & MAINTENANCE AND REPAIRS & & & \\
\hline & 2 & GARBAGE (SOLID WASTE) COLLECTION & & & \\
\hline$\stackrel{\Phi}{2}$ & 3 & ELECTRICITY & & & \\
\hline g & 4 & GAS & & & \\
\hline$\frac{\bar{c}}{\frac{1}{0}}$ & 5 & KEROSENE/ FUEL FOR COOKING/ LIGHT & & & \\
\hline$\overline{8}$ & 6 & FIREWOOD/ CHARCOAL & & & \\
\hline Oㅁ & 7 & WATER (EXCL. BOTTLED WATER) & & & \\
\hline 듀 & 8 & WATER FILTER AND OTHER TREATMENT & & & \\
\hline$\stackrel{\text { D }}{=}$ & 9 & BATTERIES, LIGHTBULBS, LIGHTERS & & & \\
\hline $\begin{array}{l}\overline{5} \\
\text { 오 }\end{array}$ & 10 & $\begin{array}{l}\text { HOUSEHOLD HELP (EG GARDNER, PERSON DOING } \\
\text { LAUNDRY, SECURITY GUARD) } \\
\end{array}$ & & & \\
\hline & 11 & OTHER HOUSING EXPENDITURE (EXCLUDE RENT) & & & \\
\hline & 12 & SOAP FOR WASHING HANDS AND BODY & & & \\
\hline & 13 & $\begin{array}{l}\text { CLEANING EQUIPMENT (INCL LAUNDRY } \\
\text { DETERGENT) }\end{array}$ & & & \\
\hline & 14 & TOOTHPASTE AND TOOTHBRUSHES & & & \\
\hline$\stackrel{\Phi}{\Phi}$ & 15 & BEAUTY PRODUCTS/ COSMETICS/ PERFUMES & & & \\
\hline $\bar{s}$ & 16 & TOILET PAPER AND OTHER TISSUES & & & \\
\hline & 17 & BABY DIAPERS & & & \\
\hline & 18 & INSECTICIDES/ MOSQUITO COILS & & & \\
\hline & 19 & CANDLES/ MATCHES/ INCENSE & & & \\
\hline & 20 & HAIR CUTS AND DRESSING & & & \\
\hline & 21 & OTHER HYGIENE EXPENDITURES & & & \\
\hline 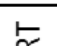 & 22 & FUEL LUBRICATION PERSONAL VEHICLE & & & \\
\hline 낭 & 23 & REPAIRS PERSONAL VEHICLE (EG CAR) & & & \\
\hline$\frac{1}{3}$ & 24 & BUS, MATATU, BODA BODA, TAXI & & & \\
\hline$\sum$ & 25 & PARKING FEES & & & \\
\hline 品 & 26 & OTHER TRANSPORTATION EXPENDITURE & & & \\
\hline & 27 & AIRTIME FOR MOBILE PHONES (INCL MPESA) & & & \\
\hline 음 & 28 & BILL FORLANDLINE PHONES & & & \\
\hline 㱛 & 29 & AIRTIME OR BILL FOR INTERNET & & & \\
\hline$\sum_{\bar{\Sigma}}^{\bar{z}}$ & 30 & $\begin{array}{l}\text { POSTAL EXPENSES (POSTBOX AND SENDING } \\
\text { LETTERS/ PARCEL) }\end{array}$ & & & \\
\hline రิ & 31 & DAILY OR WEEKLY NEWSPAPER & & & \\
\hline & 32 & OTHER COMMUNICATION EXPENDITURE & & & \\
\hline & 33 & TOBACCO (INCL SNUFF AND MIRAA(KHAT)) & & & \\
\hline
\end{tabular}


SECTION 6: Non-Food Expenditure (2/2)

\begin{tabular}{|c|c|c|c|c|c|}
\hline & & & $(6.01)$ & $(6.02)$ & $(6.03)$ \\
\hline & & LAST YEAR & \multirow{3}{*}{$\begin{array}{c}\text { Did your } \\
\text { household } \\
\text { purchase or pay } \\
\text { for any } \\
\text { [ITEM][SERVICE] } \\
\text { during the last } \\
\text { year? }\end{array}$} & \multirow{4}{*}{$\begin{array}{c}\text { How much did } \\
\text { your household } \\
\text { spend on } \\
\text { [TTEM][SERVICE] } \\
\text { during the last } \\
\text { year? }\end{array}$} & $\begin{array}{c}\text { How much of [ITEM]/[SERVICE] } \\
\text { did your household receive }\end{array}$ \\
\hline & & \multirow[t]{2}{*}{$\begin{array}{l}\text { READ OUT: PLEASE EXCLUDE BUSINESS } \\
\text { EXPENDITURES. }\end{array}$} & & & \\
\hline & & & & & $\begin{array}{l}\text { DO NOT INCLUDE STOCKS } \\
\text { IF NONE CODE "0" }\end{array}$ \\
\hline & & \multirow{2}{*}{ ENTER 99 IF RESPONDENT DOESN'T KNOW } & Yes & & INCL OWN PRODUCTION \\
\hline & & & No & VALUE IN KSh & VALUE IN KSh \\
\hline \multirow{5}{*}{$\begin{array}{l}\text { 을 } \\
\text { 응 } \\
\text { 뮴 }\end{array}$} & 34 & SCHOOL FEES & & & \\
\hline & 35 & SCHOOL TEXTBOOKS & & & \\
\hline & 36 & STATIONARY (EG PENCILS, NOTEBOOKS) & & & \\
\hline & 37 & SCHOOL UNIFORMS & & & \\
\hline & 38 & OTHER EDUCATION EXPENSES & & & \\
\hline \multirow{8}{*}{$\begin{array}{l}\text { 兲 } \\
\text { 焉 }\end{array}$} & 39 & MEDICATION (PURCHASED PRIVATELY) & & & \\
\hline & 40 & $\begin{array}{l}\text { NUTRIENT SUPPLEMENTS (EG IRON, VIT AMIN A } \\
\text { PILLS, NUTRITIOUS STONES) }\end{array}$ & & & \\
\hline & 41 & $\begin{array}{l}\text { FEES FOR DOCTORS/ CLINICAL OFFICER (INCL } \\
\text { REGISTRATION FEES) } \\
\end{array}$ & & & \\
\hline & 42 & FEES FOR MIDWIVES/ DELIVERY & & & \\
\hline & 43 & FEES FOR HOSPITAL STAYS (EXCL DELIVERIES) & & & \\
\hline & 44 & FEES FOR TRADITIONAL HEALERS & & & \\
\hline & 45 & $\begin{array}{l}\text { THERAPEUTIC APPLIANCES (EG GLASSES, } \\
\text { CRUTCHES) }\end{array}$ & & & \\
\hline & 46 & OTHER HEALTH EXPENSES & & & \\
\hline
\end{tabular}

\begin{tabular}{|c|c|c|c|}
\hline \multirow{5}{*}{ 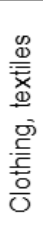 } & \multicolumn{3}{|c|}{ INCLUDE CLOTHING, SHOES, SHEETS, FABRIC, REPAIRS } \\
\hline & 47 & WOMEN'S CLOTHING & \\
\hline & 48 & $\begin{array}{l}\text { CHILDREN'S CLOTHING (NOT INCL CHILDREN } \\
\text { BORN LAST YEAR) }\end{array}$ & \\
\hline & 49 & MEN'S CLOTHING & \\
\hline & 50 & $\begin{array}{l}\text { OTHER TEXTILES (INCL DRYCLEANING, NOT INCL } \\
\text { CHILDREN BORN LAST YEAR) }\end{array}$ & \\
\hline
\end{tabular}

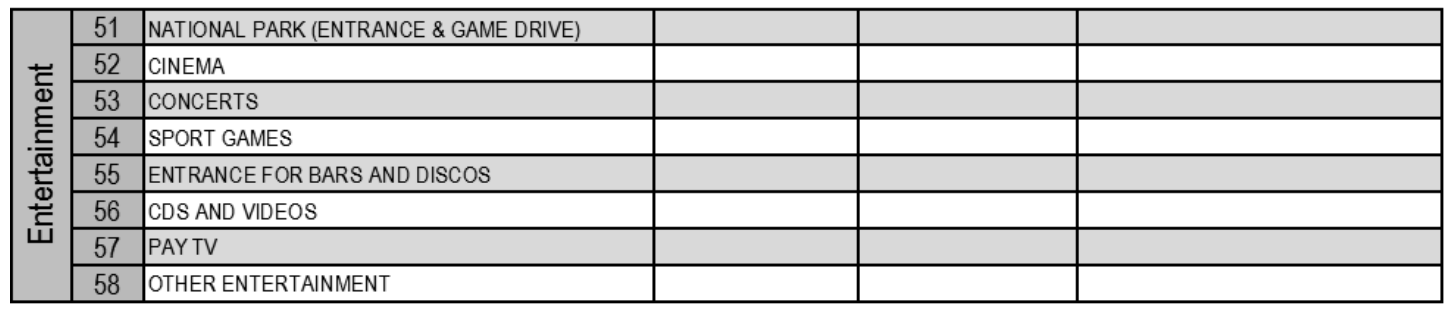

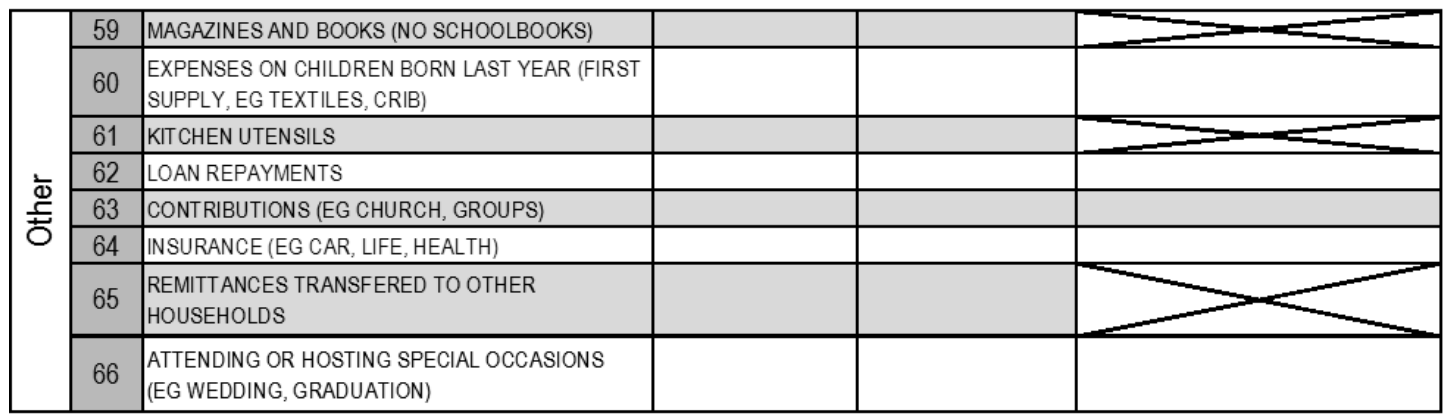

(6.04) Taken together, how much did your household approximately spend on last month's food consumption and non-food expenditure? 
SECTION 7:Livelihood (1/1)

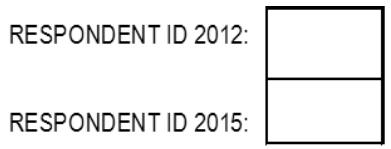

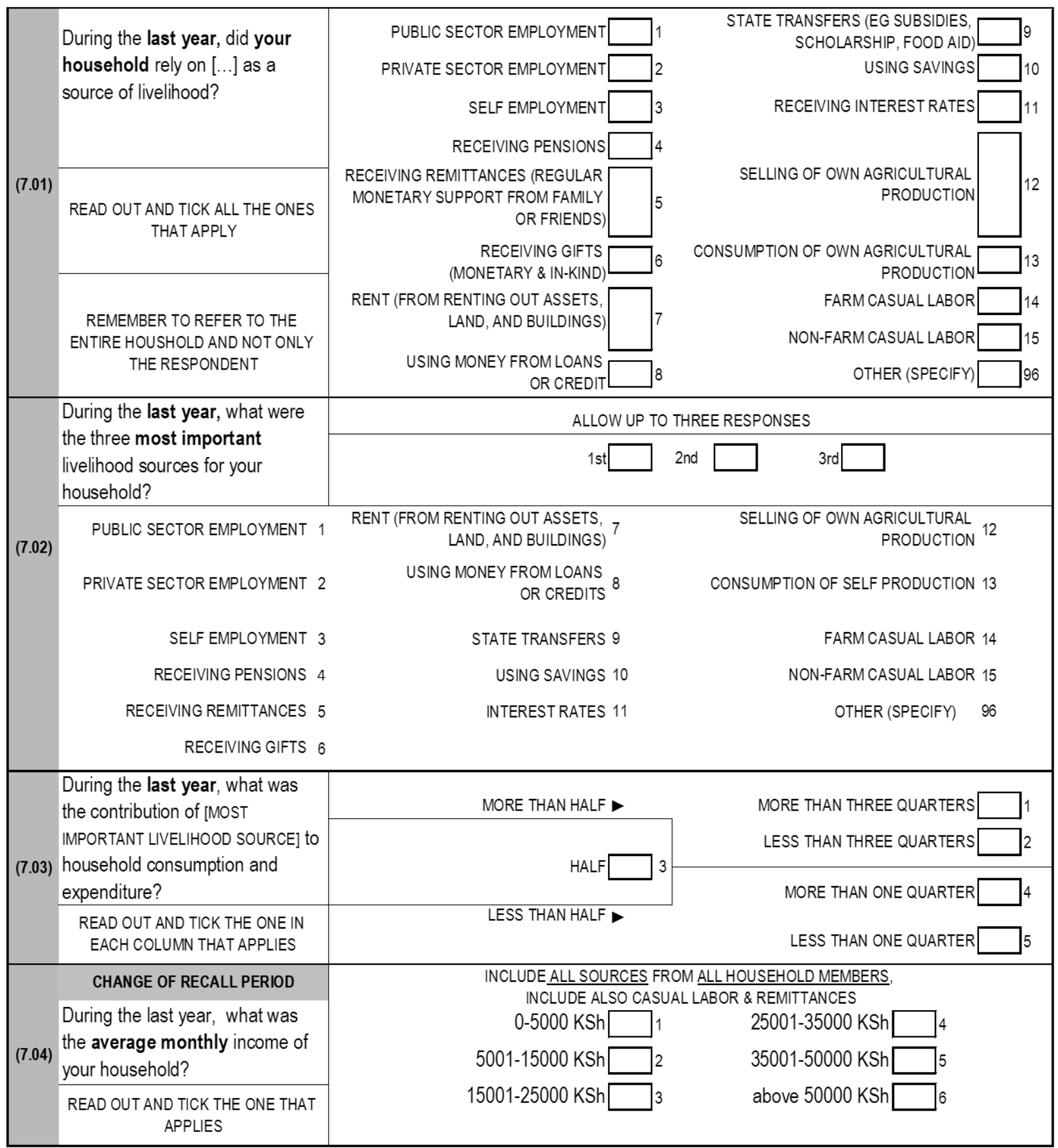




\section{SECTION 8: Health (1/3)}

\begin{tabular}{|c|c|c|c|c|c|}
\hline \multirow{14}{*}{$\begin{array}{l}\Psi \\
0 \\
0 \\
0\end{array}$} & $(8.01)$ & $(8.02)$ & $(8.03)$ & $(8.031)$ & $(8.04)$ \\
\hline & \multirow{3}{*}{$\begin{array}{c}\text { What chronic } \\
\text { illnesses/ } \\
\text { conditions has } \\
\text { [NAME] been } \\
\text { diagnosed } \\
\text { with and is } \\
\text { still suffering } \\
\text { from, if any? }\end{array}$} & \multirow{12}{*}{$\begin{array}{l}\text { For how } \\
\text { long has } \\
\text { [NAME] } \\
\text { been } \\
\text { diagnosed } \\
\text { with this } \\
\text { [CHRONIC } \\
\text { ILLNESS/ } \\
\text { CONDITION] } \\
?\end{array}$} & $\begin{array}{c}\text { Who told [NAME] that } \\
\text { he/she was suffering from } \\
\text { this [CHRONIC } \\
\text { ILLNESS/CONDITION]? }\end{array}$ & \multirow[t]{3}{*}{$\begin{array}{l}\text { What did [NAME] get as } \\
\text { treatment when he/she } \\
\text { was suffering from this } \\
\text { [CHRONIC } \\
\text { ILLNESS/CONDITION]? }\end{array}$} & \multirow{4}{*}{$\begin{array}{l}\text { Since the } \\
\text { diagnosis of this } \\
\text { [CHRONIC } \\
\text { ILLNESS/CONDITIO } \\
\mathrm{N} \text { ], what have } \\
\text { been the total } \\
\text { direct costs } \\
\text { associated with } \\
\text { diagnosis and } \\
\text { treatment? }\end{array}$} \\
\hline & & & \begin{tabular}{|l|} 
Medical Doctor/ \\
Clinical Officer
\end{tabular} & & \\
\hline & & & $\begin{array}{l}\text { Medical worker in } \\
\text { hospital }\end{array}$ & & \\
\hline & \multirow{3}{*}{$\begin{array}{l}\text { READ OUT } \\
\text { CHRONIC } \\
\text { DISEASES ON } \\
\text { THE RIGHT }\end{array}$} & & Medical worker at & & \\
\hline & & & \begin{tabular}{|l|} 
dispensary \\
Medical worker at non- \\
health facility \\
\end{tabular} & & \multirow{8}{*}{$\begin{array}{c}\text { READ OUT: } \\
\text { INCLUDE } \\
\text { TRANSPORTATION } \\
\text { DIAGNOSIS, } \\
\text { MEDICATION, } \\
\text { MEDICAL CARE. } \\
\text { DO NOT INCLUDE } \\
\text { INCOME LOSS } \\
\text { AND OTHER } \\
\text { OPPORTUNITY } \\
\text { COSTS }\end{array}$} \\
\hline & & & Pharmacist & No treatment & \\
\hline & \multirow{6}{*}{$\begin{array}{l}\text { IF NO ILLNESS } \\
\text { FILL IN } 97, \text { IF } \\
\text { DON'T KNOW, } \\
\text { FILL IN } 99 \text { AND } \\
\text { NEXT } \\
\text { PERSON }\end{array}$} & & Traditional healer & Aspirin & \\
\hline & & & $\begin{array}{l}\text { Community Health } \\
\text { Worker }\end{array}$ & \multirow[t]{2}{*}{$\begin{array}{l}\text { Other medicines, } \\
\text { tablets or pills }\end{array}$} & \\
\hline & & & \multirow{2}{*}{$\begin{array}{l}\text { Self diagnosis/ other } \\
\text { household members }\end{array}$} & & \\
\hline & & & & \begin{tabular}{|l|} 
Diet \\
Fxercise
\end{tabular} & \\
\hline & & & Other (Specify) & Other (Specify) & \\
\hline & & & Don't know & Don't know & \\
\hline & CODE & MONTHS & CODE & CODE & KSh \\
\hline \multirow{2}{*}{1} & $1 \mathrm{st}$ & $1 \mathrm{st}$ & $1 \mathrm{st}$ & $1 \mathrm{st}$ & $1 \mathrm{st}$ \\
\hline & 2nd & 2nd & 2nd & 2nd & 2nd \\
\hline \multirow{2}{*}{2} & 1st & $1 s t$ & 1st & $1 \mathrm{st}$ & 1st \\
\hline & 2nd & 2nd & 2nd & 2nd & 2nd \\
\hline \multirow{2}{*}{3} & $1 s t$ & $1 \mathrm{st}$ & $1 \mathrm{st}$ & $1 \mathrm{st}$ & $1 \mathrm{st}$ \\
\hline & 2nd & 2nd & 2nd & 2nd & 2nd \\
\hline \multirow{2}{*}{4} & 1 st & $1 \mathrm{st}$ & $1 \mathrm{st}$ & $1 \mathrm{st}$ & $1 \mathrm{st}$ \\
\hline & 2nd & 2nd & 2nd & 2nd & 2nd \\
\hline \multirow{2}{*}{5} & 1st & $1 \mathrm{st}$ & 1st & $1 \mathrm{st}$ & $1 \mathrm{st}$ \\
\hline & 2nd & 2nd & 2nd & 2nd & 2nd \\
\hline \multirow{2}{*}{6} & $1 \mathrm{st}$ & $1 s t$ & 1st & $1 \mathrm{st}$ & 1st \\
\hline & 2nd & 2nd & 2nd & 2nd & 2nd \\
\hline \multirow{2}{*}{7} & $1 \mathrm{st}$ & $1 \mathrm{st}$ & $1 \mathrm{st}$ & $1 \mathrm{st}$ & $1 \mathrm{st}$ \\
\hline & 2nd & 2nd & 2nd & 2nd & 2nd \\
\hline \multirow{2}{*}{8} & $1 \mathrm{st}$ & $1 \mathrm{st}$ & $1 \mathrm{st}$ & $1 \mathrm{st}$ & $1 \mathrm{st}$ \\
\hline & 2nd & 2nd & 2nd & 2nd & 2nd \\
\hline \multirow{2}{*}{9} & $1 \mathrm{st}$ & 1 st & $1 \mathrm{st}$ & $1 \mathrm{st}$ & $1 \mathrm{st}$ \\
\hline & 2nd & 2nd & 2nd & 2nd & 2nd \\
\hline \multirow{2}{*}{10} & 1st & $1 \mathrm{st}$ & $1 \mathrm{st}$ & $1 \mathrm{st}$ & 1st \\
\hline & 2nd & 2nd & 2nd & 2nd & 2nd \\
\hline \multirow{2}{*}{11} & $1 \mathrm{st}$ & 1 st & $1 \mathrm{st}$ & $1 \mathrm{st}$ & $1 \mathrm{st}$ \\
\hline & 2nd & 2nd & 2nd & 2nd & 2nd \\
\hline \multirow{2}{*}{12} & $1 \mathrm{st}$ & $1 s t$ & 1st & $1 \mathrm{st}$ & $1 \mathrm{st}$ \\
\hline & 2nd & 2nd & 2nd & 2nd & 2nd \\
\hline \multirow{2}{*}{13} & $1 \mathrm{st}$ & $1 \mathrm{st}$ & 1st & $1 \mathrm{st}$ & 1st \\
\hline & 2nd & 2nd & 2nd & 2nd & 2nd \\
\hline 14 & 1st & $1 s t$ & 1st & 1st & $1 \mathrm{st}$ \\
\hline & 2nd & 2nd & 2nd & 2nd & 2nd \\
\hline 15 & 1st & 1 st & 1st & 1st & $1 \mathrm{st}$ \\
\hline & 2nd & 2nd & 2nd & 2nd & 2nd \\
\hline
\end{tabular}

\begin{tabular}{|c|c|}
\hline \multicolumn{2}{|c|}{$\begin{array}{c}\text { RECORD UP TO TWO ILLNESSES PER } \\
\text { MEMBER }\end{array}$} \\
\hline \multirow{2}{*}{\multicolumn{2}{|c|}{$\begin{array}{l}\text { IF MORE THAN TWO ILLNESSES } \\
\text { RECORD THE TWO MOST SEVERE } \\
\text { CHRONIC ILLNESSES }\end{array}$}} \\
\hline & \\
\hline DIABETES & 1 \\
\hline HYPERTENSION & 2 \\
\hline $\begin{array}{l}\text { CARDIOVASCULAR/ } \\
\text { HEART DISEASE }\end{array}$ & 3 \\
\hline KWASHIORKOR & 4 \\
\hline CANCER (Specify) & 5 \\
\hline HIGH CHOLESTEROL & 6 \\
\hline ANAEMIA & 7 \\
\hline RICKETTS & 8 \\
\hline $\begin{array}{l}\text { IF NOT BY BIRTH: } \\
\text { BLINDNESS/LOSS OF } \\
\text { (NIGHT)VISION }\end{array}$ & 9 \\
\hline GOITER & 10 \\
\hline GOUT (Arthritis) & 11 \\
\hline BAD TEETH & 12 \\
\hline
\end{tabular}

\begin{tabular}{|lr|}
\hline \multicolumn{1}{|c|}{ NON-CHRONIC ILLNESSES } \\
\hline FEVER, MALARIA & 1 \\
\hline DIARRHEA & 2 \\
\hline STOMACH ACHE & 3 \\
\hline VOMITING & 4 \\
\hline FLU/COLD & 5 \\
\hline HEADACHE & 6 \\
\hline SKIN PROBLEM & 7 \\
\hline BAD TEETH (ACHE) & 8 \\
\hline EYE PROBLEM & 9 \\
\hline EAR/NOSE/THROAT & 10 \\
\hline PAIN WHEN PASSING & 11 \\
URIN & 12 \\
\hline TUBERCULOSIS & 13 \\
\hline KWASHIORKOR & 14 \\
\hline TYPHOID & 15 \\
\hline PNEUMONIA & 16 \\
\hline FAINTING & 17 \\
\hline INTESTINAL WORMS & 96 \\
\hline OTHER (SPECIFY) & \\
\hline
\end{tabular}




\section{SECTION 8: Health $(2 / 3)$}

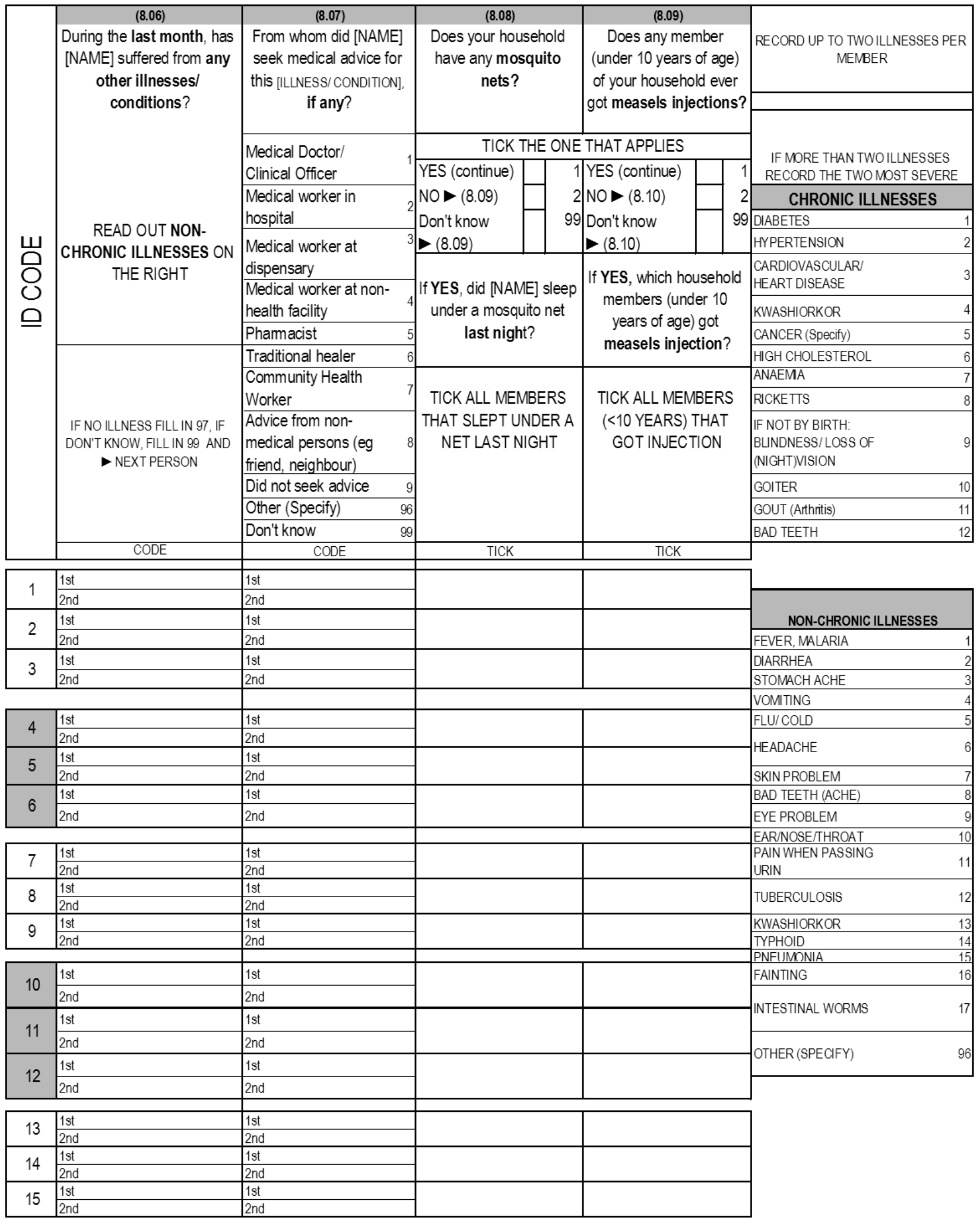




\section{SECTION 8: Health (3/3)}

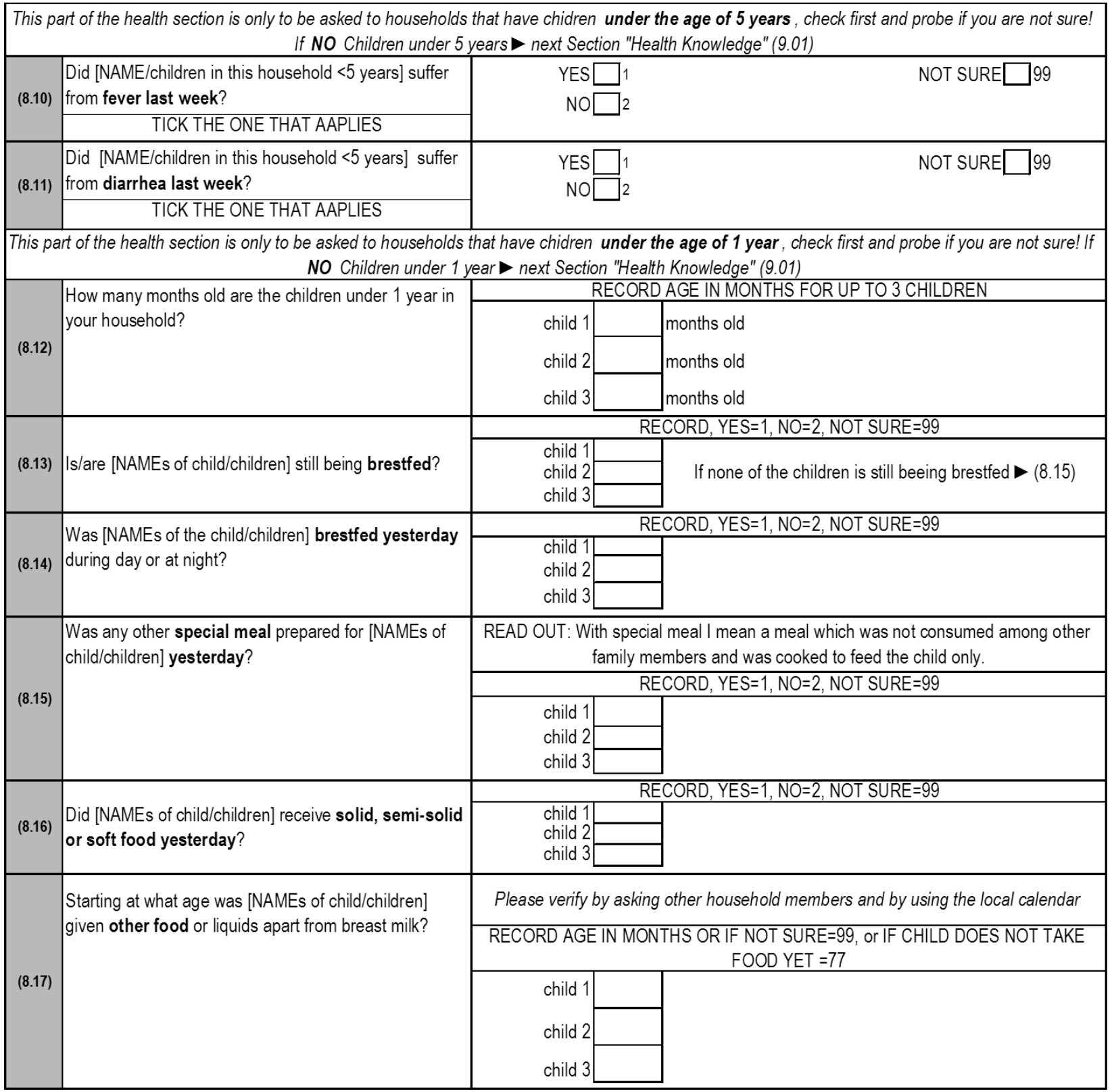




\section{SECTION 9: Health Knowledge (1/4)}

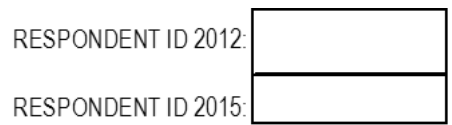

READ OUT: NOWI WOULD LIKE TO ASK YOU SOME QUESTIONS THAT WILL HELP US UNDERSTAND THE KNOWLEDGE ABOUT NUTRITION AND HEALTH OF THIS HOUSEHOLD. IF YOU ARE UNSURE ABOUT SOME QUESTIONS, PLEASE ALWAYS SAY SO AND DO NOT GUESS A RESPONSE.

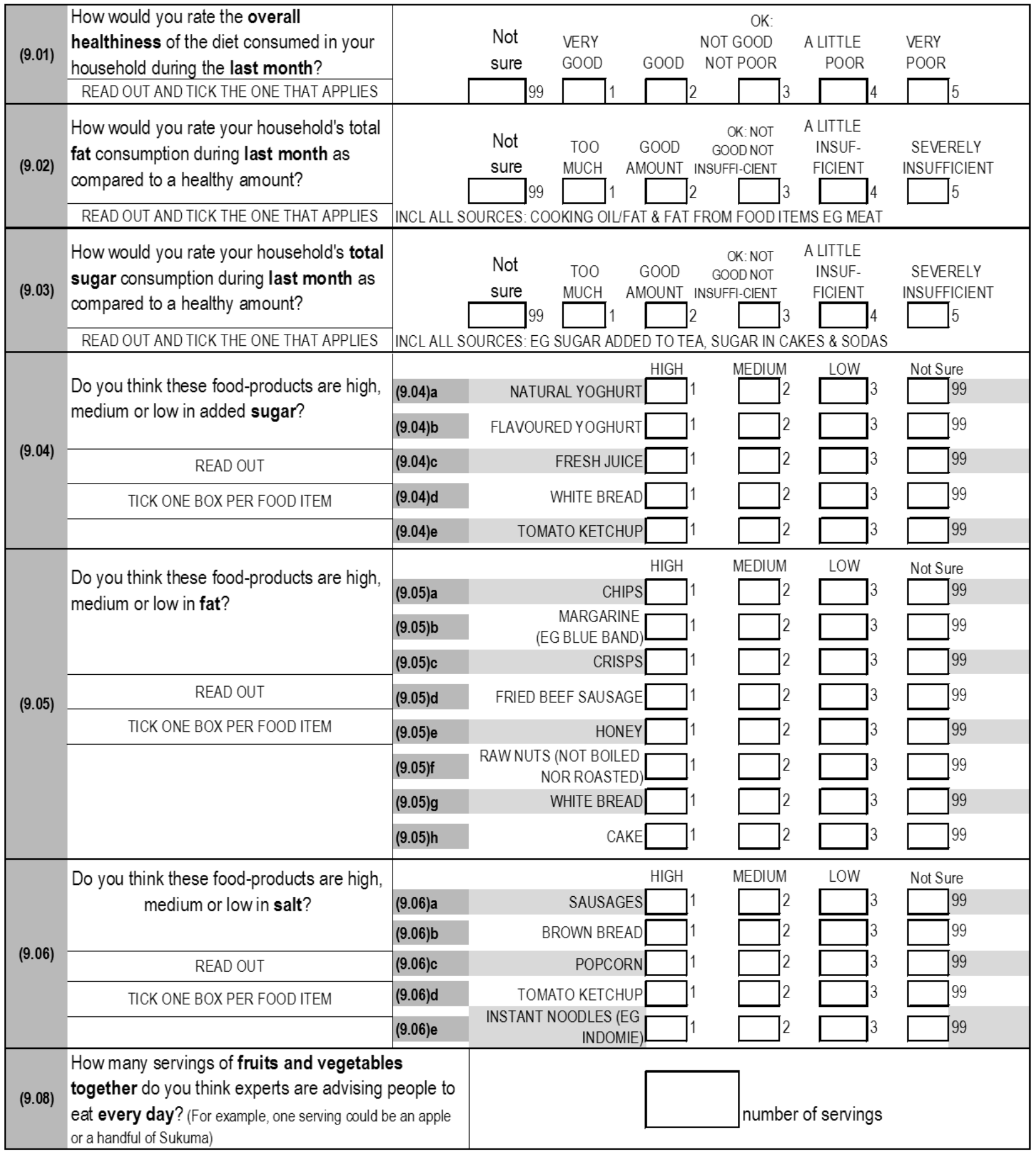




\section{SECTION 9: Health Knowledge (2/4)}

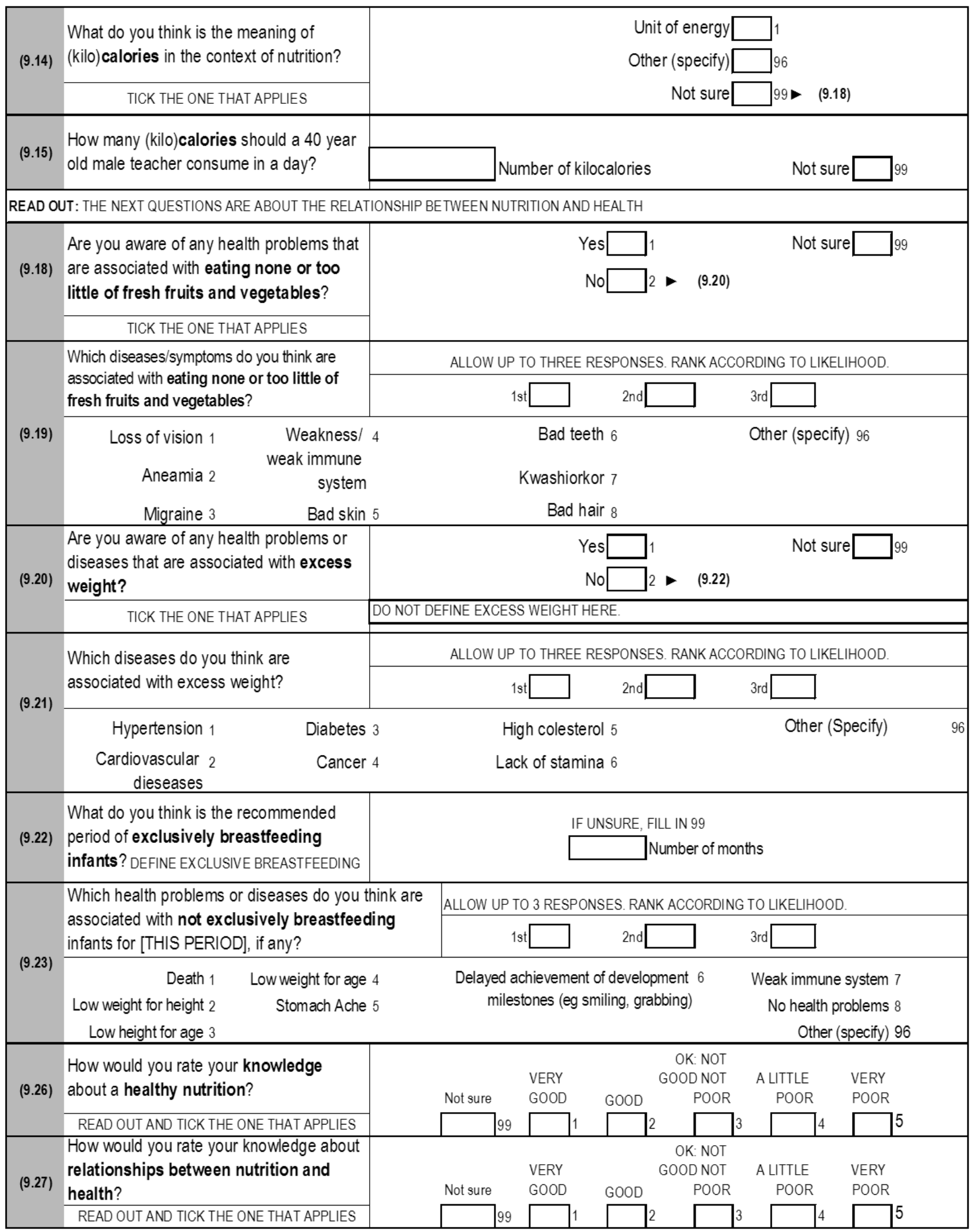




\section{SECTION 9: Health Knowledge (3/4)}

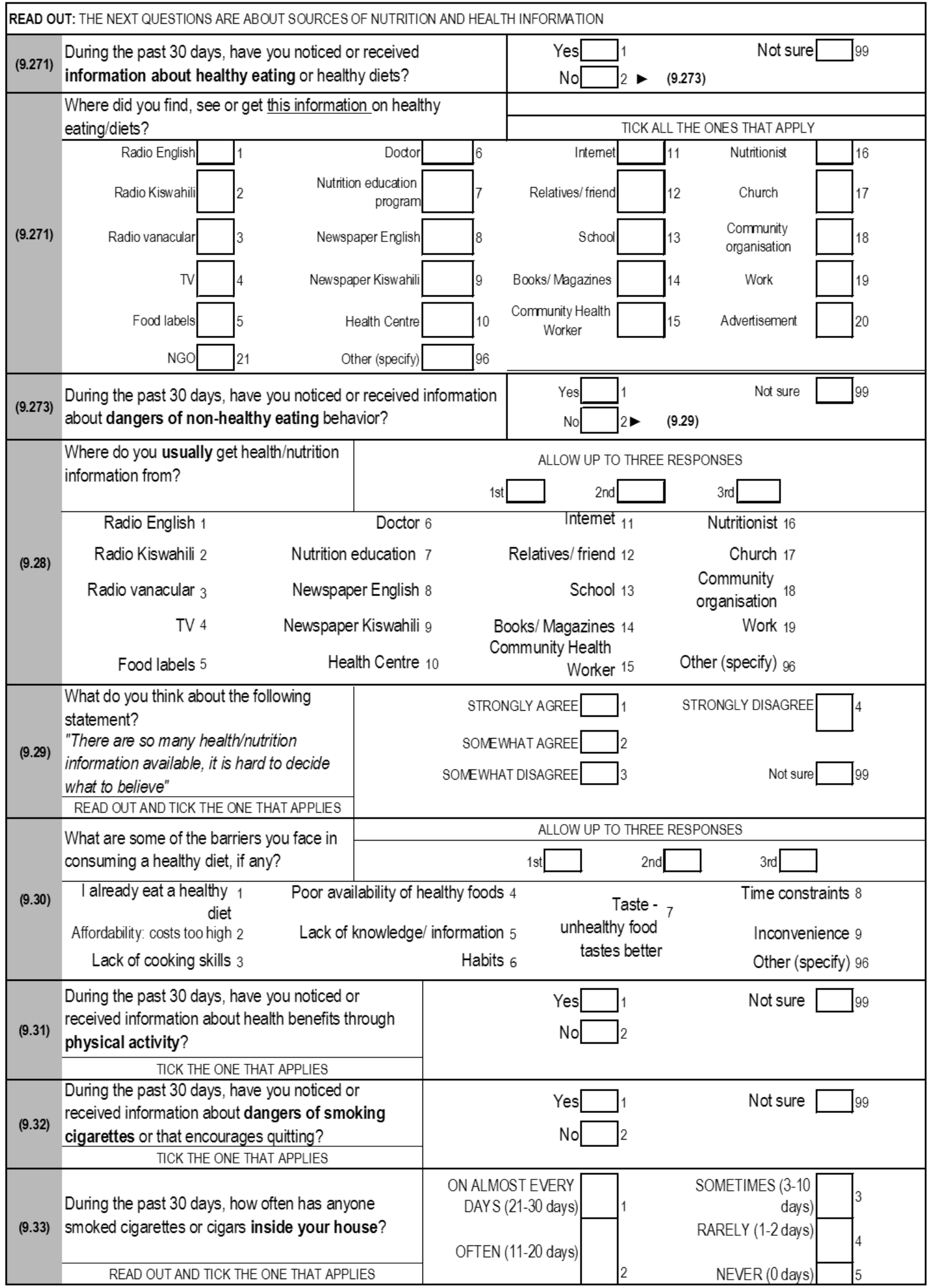




\section{SECTION 9: Health Knowledge (4/4)}

READ OUT: THE NEXT QUESTIONS ARE ON Y OUR HYGIENE BEHAVIOR

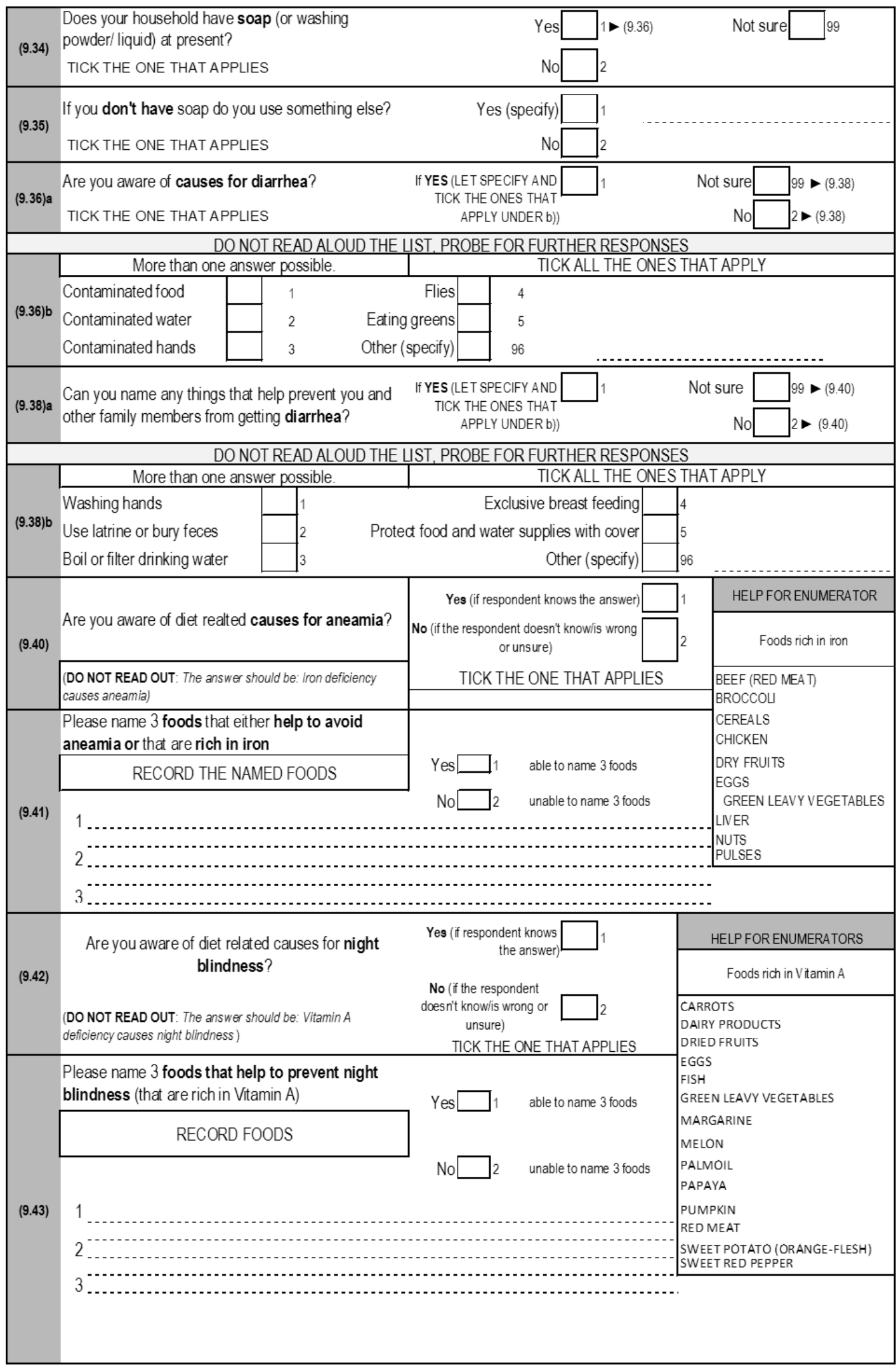


SECTION 10: Housing

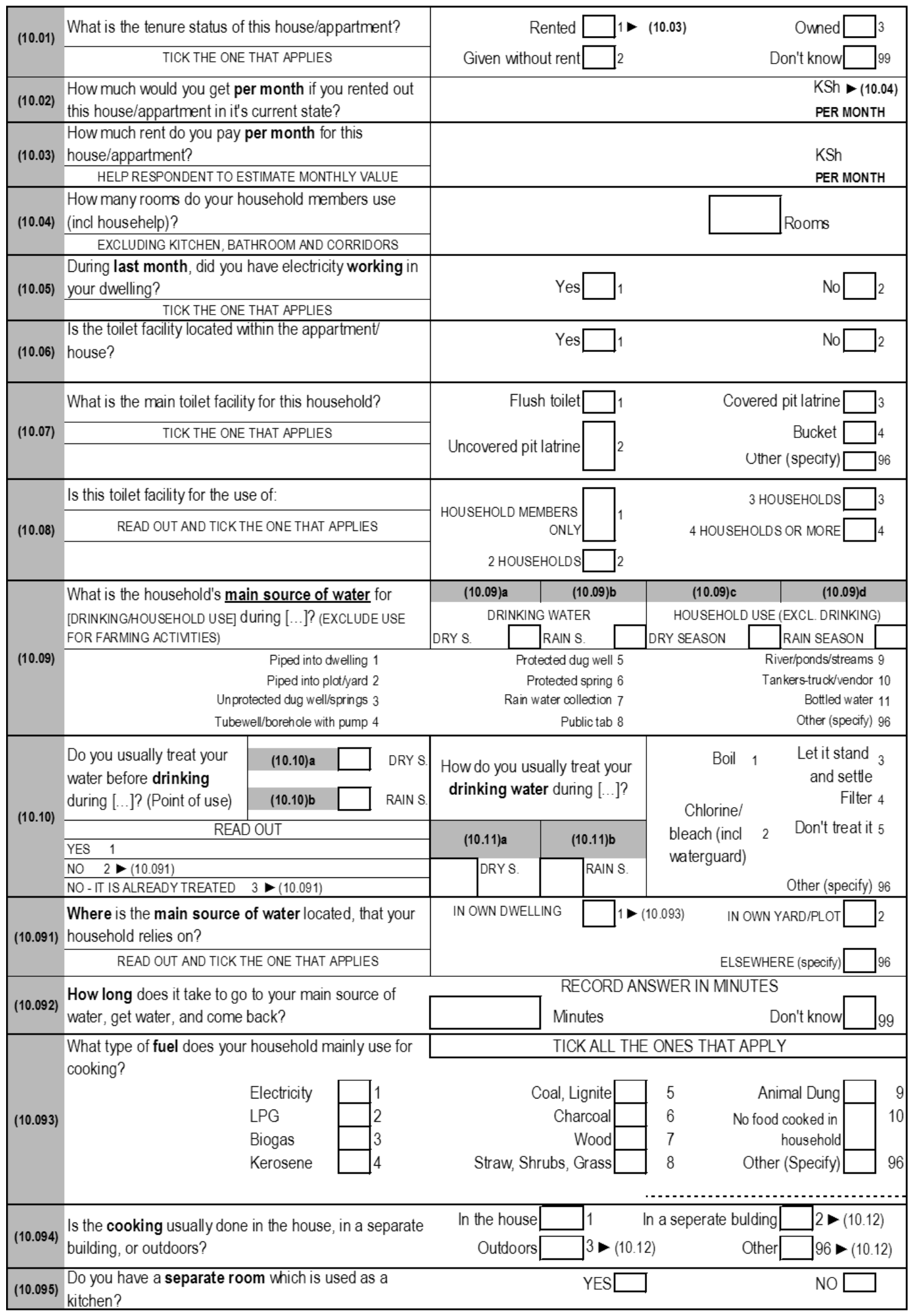




\begin{tabular}{|c|c|c|c|}
\hline \multirow{3}{*}{ (10.12) } & INTERVIEWER ONLY ASK IF UNABLE TO OBSERVE & \multirow{3}{*}{$\begin{array}{r}\text { Cement } \square \text { 1 } \\
\text { Tiles } \square 2 \\
\text { Wood } \square 3\end{array}$} & \multirow{3}{*}{$\begin{array}{r}\text { Earth } \square 4 \\
\text { Other (specify) } \square=96\end{array}$} \\
\hline & How is the floor of this house/appartment covered? & & \\
\hline & $\begin{array}{l}\text { IF SEVERAL TYPES, RECORD MATERIAL OF MAJORITY OF } \\
\text { FLOORS - TICK ONLY } 1 \text { ANSWER }\end{array}$ & & \\
\hline \multirow{4}{*}{ (10.13) } & INTERVIEWER ONLY ASK IF UNABLE TO OBSERVE & \multirow{2}{*}{$\begin{array}{l}\text { Tin } \square \text { 1 } \\
\text { Tiles } \square 2\end{array}$} & Improved iron sheets $\square 6$ \\
\hline & What is the roof of this house/appartment made of? & & ina \\
\hline & $\begin{array}{l}\text { IF SEVERAL TYPES, RECORD MATERIAL OF MAJORITY OF } \\
\text { ROOF - TICK ONLY } 1 \text { ANSWER }\end{array}$ & Concrete & Makuti \\
\hline & & $\begin{array}{r}\text { Asbestos sheets } \\
\text { Corrugated iron } \\
\text { sheets } \\
\end{array}$ & Other (specify) \\
\hline \multirow{3}{*}{ (10.14) } & INTERVIEWER DON'T ASK BUT OBSERVE & Flat & Shanty \\
\hline & $\begin{array}{l}\text { What type of house/appartment does your household } \\
\text { live in? }\end{array}$ & Maisonnet & Manyatta/Traditional Hut \\
\hline & TICK THE ONE THAT APPLES & House/Bungalow & Other \\
\hline \multirow{5}{*}{ (10.15) } & INTERVIEWER DON'T ASK BUT OBSERVE & Stone & Corrugated iron sheet [ \\
\hline & What are the outer walls of your house/appartment & Brick[ & Grass/Straw \\
\hline & made of? & Mud \& Wood & Tin \\
\hline & \multirow{2}{*}{$\begin{array}{l}\text { IF SEVERAL TYPES, RECORD MATERIAL OF MAJORITY OF } \\
\text { WALLS - TICK ONLY } 1 \text { ANSWER }\end{array}$} & Mud \& Ce & Stone \& Wood \\
\hline & & Wood only [ & Other (specify) \\
\hline
\end{tabular}

\section{SECTION 11: Assets}

INTRODUCTION: DO NOT COUNT PERMANENTLY BROKEN ITEMS. COUNT ITEMS OF ALL HOUSEHOLD MEMBERS.

\begin{tabular}{|c|c|c|c|c|}
\hline \multicolumn{3}{|c|}{$(11.01)$} & (11.02) & (11.03) \\
\hline & \multicolumn{2}{|c|}{$\begin{array}{c}\text { How many pieces of [ITEM] does your } \\
\text { household own, if any? } \\
\text { DO NOT COUNT ITEMS BORROWED. } \\
\text { IF NONE, FILL IN ZERO }\end{array}$} & $\begin{array}{c}\text { Since when does household own [ITEM]? } \\
\text { IF MORE THAN ONE, AKS FOR THE ONE } \\
\text { OWNED THE LONGEST }\end{array}$ & \multirow[t]{2}{*}{$\begin{array}{c}\text { How much would you get, if you } \\
\text { sold all [ITEMs] today? } \\
\text { IF MORE THAN ONE, GIVE TOTAL } \\
\text { VALUE } \\
\text { VALUE IN KSh }\end{array}$} \\
\hline & READ OUT & PIECES & YEAR & \\
\hline 1 & RADIO & & & \\
\hline 2 & TELEPHONE (MOBILE) & & & \\
\hline 3 & WRIST WATCH & & & \\
\hline 4 & IRON & & & \\
\hline 5 & MOSQUITONET & & & \\
\hline 6 & BED & & & \\
\hline 7 & TV & & & \\
\hline 8 & DVDNCR PLAYER & & & \\
\hline 9 & MEKO COOKER & & & \\
\hline 10 & ELECTRONIC KETTLE & & & \\
\hline 11 & MCROWAVE & & & \\
\hline 12 & 2 PLATES GAS COOKER & & & \\
\hline 13 & ELECTRIC/ GAS STOVE WITH & & & \\
\hline 14 & REFRIGERATOR & & & \\
\hline 15 & LAUNDRY MACHINE & & & \\
\hline 16 & LAPTOP OR COMPUTER & & & \\
\hline 17 & $\begin{array}{l}\text { WEIGHING SCALE FOR } \\
\text { PERSONS }\end{array}$ & & & \\
\hline 18 & GENERATOR & & & \\
\hline 19 & SOLAR PANEL & & & \\
\hline 20 & BICYCLE & & & \\
\hline 21 & MOTOR CYCLE & & & \\
\hline 22 & CAR & & & \\
\hline \multirow{4}{*}{ (11.07) } & \multirow{4}{*}{$\begin{array}{l}\text { Does any member of this } \\
\text { household have a bank } \\
\text { account? }\end{array}$} & & YES & \\
\hline & & & NO 2 & \\
\hline & & & NOT SURE 99 & \\
\hline & & & & \\
\hline
\end{tabular}


DEFINE PERIOD OF LAST 3 YEARS:

\section{SECTION 12: Mortality}

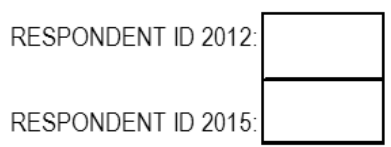

READ OUT: AS YOU KNOW; WE HAVE ASKED YOU QUESTIONS ABOUT HEALTH AND DISEASES IN THE PREVIOUS SECTIONS. WE ARE ALSO INTERESTED TO KNOW IF YOUR HOUSEHOLD HAS LOST MEMBERS THROUGH DEATH IN THE PAST FIVE YEARS DUE TO THE DISEASES WE PREVIOUSLY TALKED ABOUT. THIS IS WHY I WILL ASK YOU SOME QUESTIONS ABOUT DECEASED HOUSEHOLD MEMBERS AND CLOSE RELATIVES (PARENTS, GRANDPARENTS, CHILDREN AND SIBLINGS). PLEASE ANSWER AS ACCURATELY AS YOU CAN

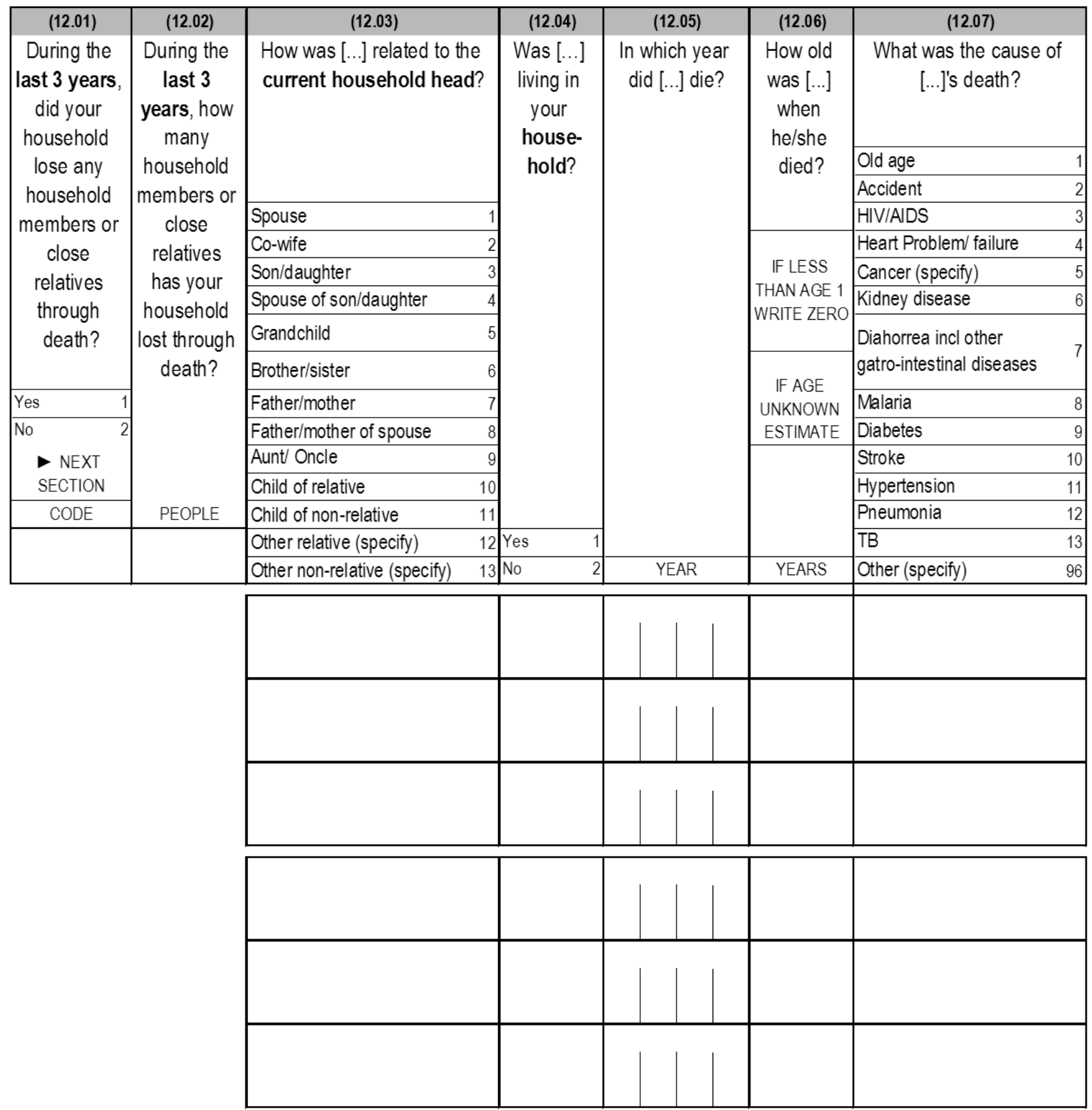




\section{SECTION 13: Weight and Health Related Behaviour and Food Eaten Away From Home (1/3)}

READ OUT: NOW, I WLL ASK YOU ABOUT YOUR INDIVIDUAL SPECIFIC CONSUMPTION, NOT THAT OF OTHER HOUSEHOLD MEMBERS

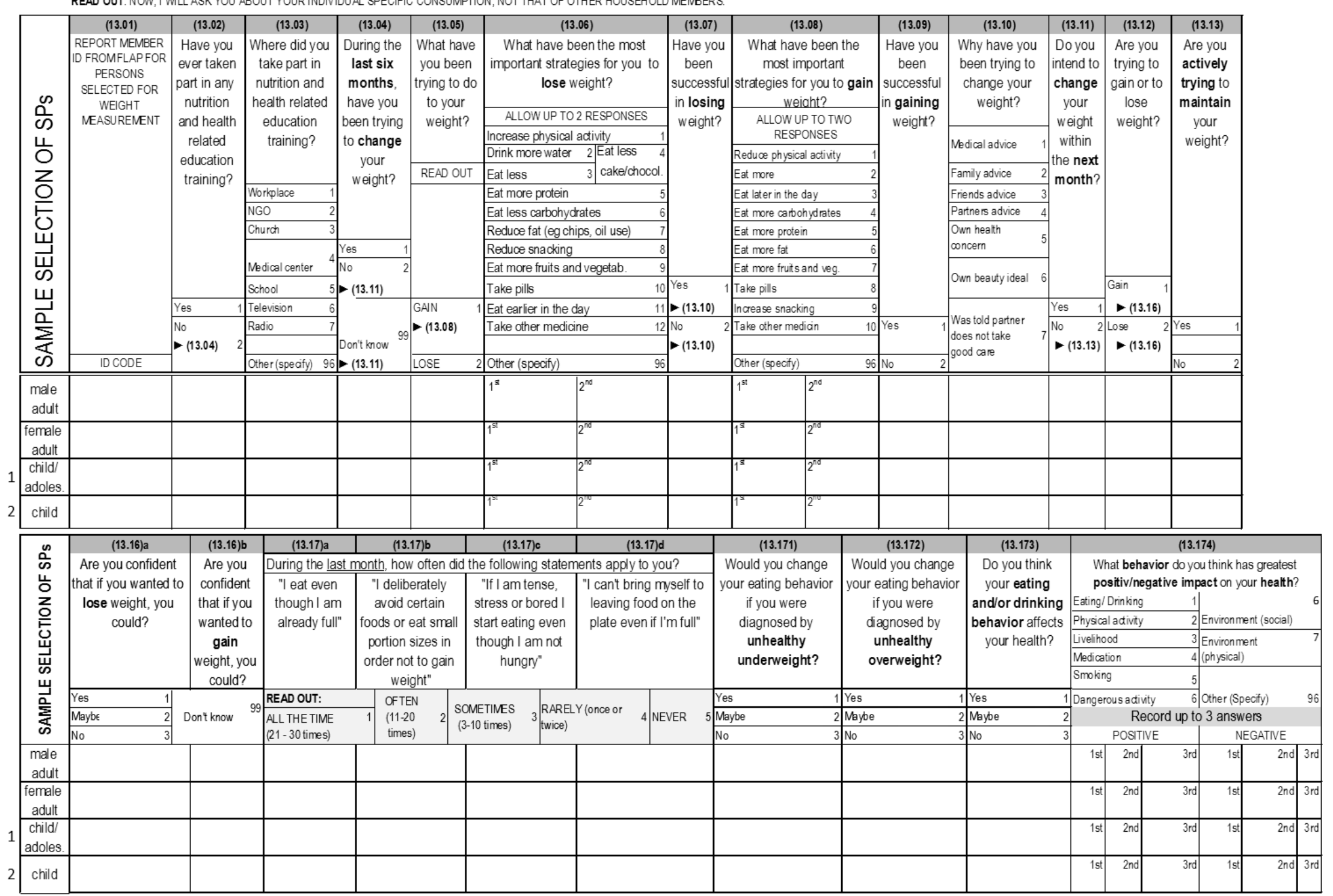


SECTION 13: Weight and Health Related Behaviour and Food Eaten Away From Home (2/3)

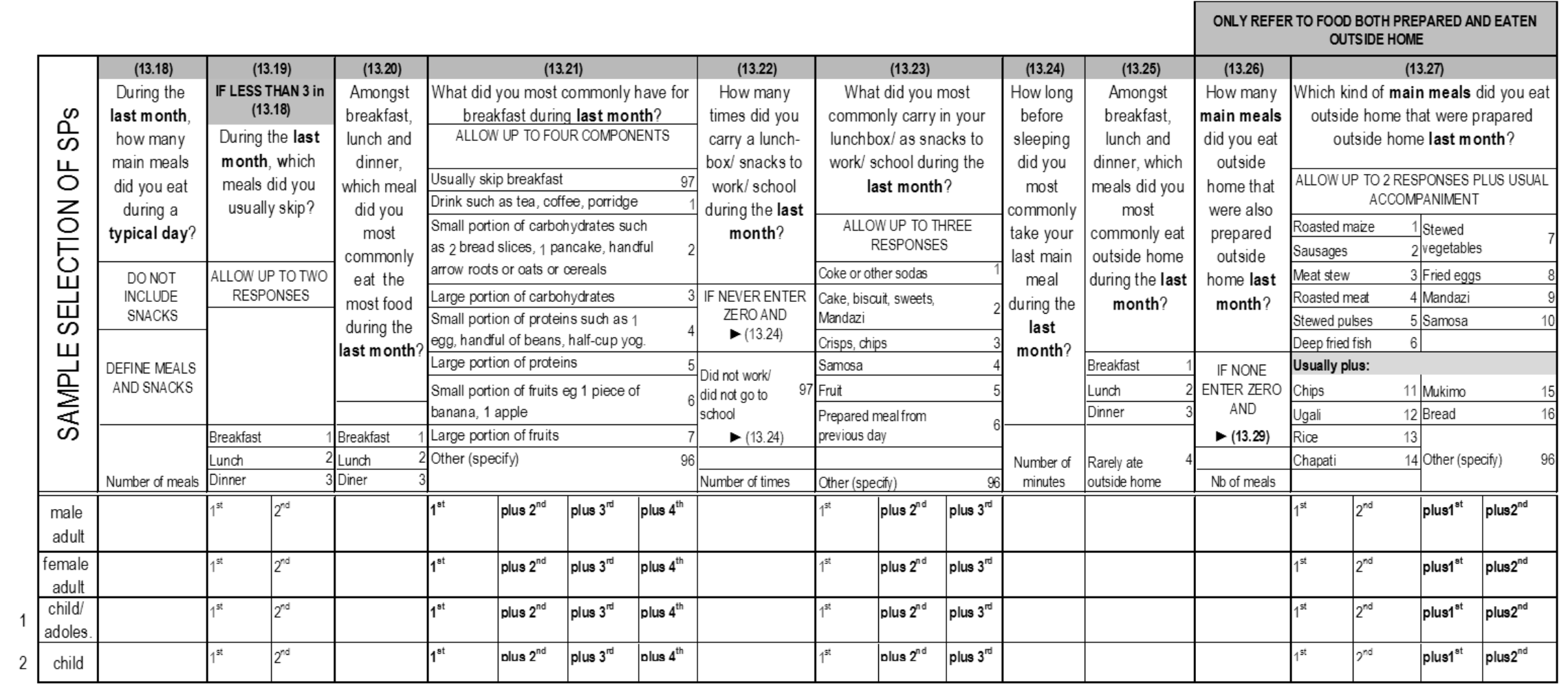




\section{SECTION 13: Weight and Health Related Behaviour and Food Eaten Away From Home (3/3)}

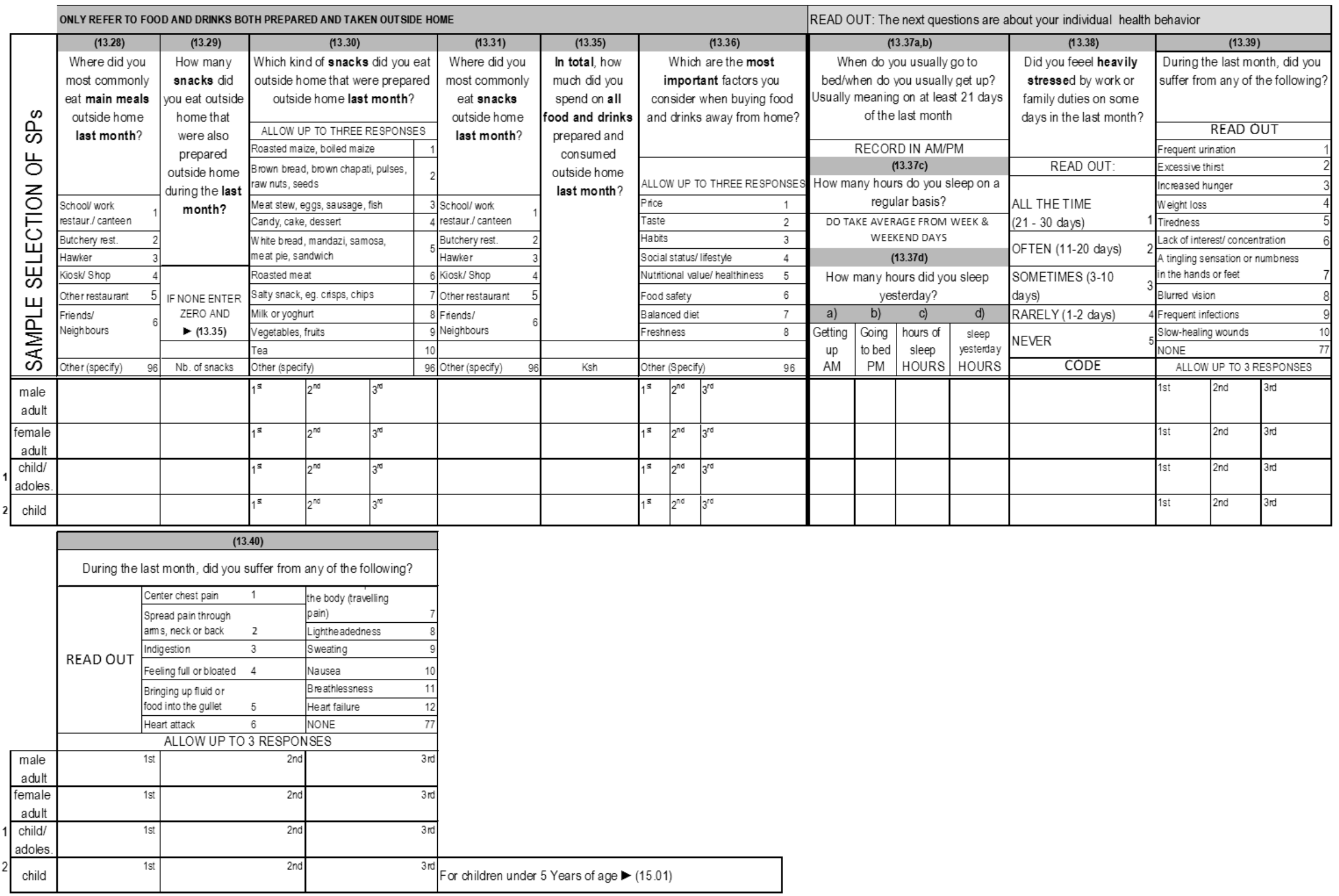




\section{SECTION 14: Physical Activity at Work}

CHILDREN $<5$ YEARS OF AGE SKIP SECTION $14-$ SECTION 15

READ OUT: NOW, I AM ASKING ABOUT WORK RELATED PHYSICAL ACTVITY. FOR THE RESPONSES, PLEASE CONSIDER THE PERIOD OF THE LAST 6 MONTHS. PLEASE CONSIDER ALL OCCUPATIONAL ACTIVITIES.

\begin{tabular}{|c|c|c|c|c|c|c|c|c|c|c|c|c|c|c|}
\hline \multirow{8}{*}{ 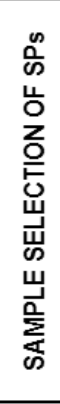 } & \multirow{7}{*}{\begin{tabular}{|c|} 
(14.01) \\
REPORT \\
MEMBER ID \\
FROM FLAP \\
FOR \\
PERSONS \\
SELECTED \\
FOR \\
WEIGHT \\
MEASUREM \\
ENT \\
\end{tabular}} & \multirow{2}{*}{\begin{tabular}{c|} 
HELP FOR \\
INTERVIEWER
\end{tabular}} & \multirow{5}{*}{$\begin{array}{l}\text { During the last } \\
\text { six months, how } \\
\text { many days did } \\
\text { you usually } \\
\text { work in a } \\
\text { typical week? }\end{array}$} & $(14.03)$ & (14.04) & (14.05) & $(14.06)$ & $(14.07)$ & (14.08) & $(14.09)$ & (14.10) & (14.11) & $(14.12)$ & $(14.13)$ \\
\hline & & & & \multirow{4}{*}{$\begin{array}{c}\text { During the last } \\
\text { six months, how } \\
\text { many hours did } \\
\text { you usually } \\
\text { work in a } \\
\text { typical working } \\
\text { day? }\end{array}$} & READ OUT STORY A & READ OUT STORY B & READ OUT STORY C & \multirow[b]{2}{*}{$\begin{array}{l}\text { How often do your } \\
\text { occupational activities } \\
\text { require lots of } \\
\text { physical effort in a } \\
\text { typical week? } \\
\text { INCLUDE ALL OCCU- } \\
\text { PATION. ACTNII IES }\end{array}$} & \multirow{6}{*}{\begin{tabular}{|c} 
Does your \\
job require \\
you to lift, \\
pull, or \\
push above \\
$5 \mathrm{kgs}$ (eg \\
more than \\
51 jerrycan \\
of water) \\
regularly?
\end{tabular}} & \multirow{5}{*}{$\begin{array}{c}\text { Does your job } \\
\text { require you to } \\
\text { lift, pull, or } \\
\text { push weights } \\
\text { more than } 0.5 \\
\mathrm{~kg} \text { but less } \\
\text { than } 5 \mathrm{kgs} \\
\text { regularly? }\end{array}$} & \multirow{5}{*}{$\begin{array}{l}\text { Does your } \\
\text { job require } \\
\text { you to } \\
\text { climb } \\
\text { stairs, } \\
\text { inclines, or } \\
\text { hills } \\
\text { regularly? }\end{array}$} & \multirow{5}{*}{\begin{tabular}{|c} 
Does your \\
job require \\
you to \\
stoop, \\
kneel, \\
bend over \\
or crouch \\
regularly?
\end{tabular}} & \multirow{5}{*}{$\begin{array}{c}\text { Does your } \\
\text { job require } \\
\text { you to reach } \\
\text { for supplies, } \\
\text { materials, or } \\
\text { balance } \\
\text { items etc. } \\
\text { regularly? }\end{array}$} & \multirow{5}{*}{$\begin{array}{c}\text { Does } \\
\text { your job } \\
\text { require } \\
\text { you to } \\
\text { walk } \\
\text { around } \\
\text { regularly } \\
?\end{array}$} \\
\hline & & \multirow[t]{3}{*}{\begin{tabular}{|l|} 
During the last \\
six months, \\
what kind of \\
work adivities \\
did you do in a \\
typical week?
\end{tabular}} & & & $\begin{array}{c}\text { How often do you } \\
\text { think A's occupational } \\
\text { activities require } \\
\text { lots of physical effort } \\
\text { in a typical week? }\end{array}$ & \begin{tabular}{|c} 
How often do you \\
think B's occupational \\
activities require \\
lots of physical effort \\
in a typical week?
\end{tabular} & $\begin{array}{c}\text { How often do you } \\
\text { think C's } \\
\text { occupational } \\
\text { activities require } \\
\text { lots of physical effort } \\
\text { in a typical week? }\end{array}$ & & & & & & & \\
\hline & & & & & ALL OF THE TIME & ALL OF THE TIME & ALL OF THE TIME & ALL OF THE TIME & & & & & & \\
\hline & & & & & MOST OF THE TIME & MOST OF THE TIME & MOST OF THE TIME & MOST OF THE TIME & & & & & & \\
\hline & & \multirow{3}{*}{$\begin{array}{c}\text { PROBE TO SEE } \\
\text { WHAT TO } \\
\text { INCLUDE } \\
\end{array}$} & \multirow{3}{*}{\begin{tabular}{|c|} 
INCLUDE ALL \\
OCCUPATIONAL \\
ACTIVITIES \\
\end{tabular}} & \multirow{3}{*}{$\begin{array}{c}\text { INCLUDE ALL } \\
\text { OCCUPATIONAL } \\
\text { ACTIVITIES } \\
\end{array}$} & SOME OF THE TIME & SOME OF THE TIME & SOME OF THE TIME & SOME OF THE TIME & & & & & & \\
\hline & & & & & \multirow{2}{*}{$\begin{array}{l}\text { NONE/ ALMOST NONE } \\
\text { OF THE TIME } \\
\end{array}$} & \multirow{2}{*}{$\begin{array}{l}\text { NONE/ ALMOST NONE } \\
\text { OF THE TIME }\end{array}$} & \multirow{2}{*}{$\begin{array}{l}\text { NONE/ ALMOST NONE } \\
\text { OF THE TIME } \\
\end{array}$} & \multirow{2}{*}{$\begin{array}{l}\text { NONE/ ALMOST NONE } \\
\text { OF THE TIME } \\
\end{array}$} & & \multirow{2}{*}{\begin{tabular}{|l|l|} 
Yes \\
Non
\end{tabular}} & \multirow{2}{*}{\begin{tabular}{|l|l} 
Yes \\
No
\end{tabular}} & \multirow[t]{2}{*}{ Yes } & Yes & \multirow{2}{*}{\begin{tabular}{|l|l} 
Yes \\
No
\end{tabular}} \\
\hline & ID CODE & & & & & & & & $4 \mid \begin{array}{ll}\text { Yes } \\
\text { No }\end{array}$ & & & & No & \\
\hline \multirow{2}{*}{\multicolumn{15}{|c|}{\begin{tabular}{c|}
$\begin{array}{c}\text { male } \\
\text { adult }\end{array}$ \\
female
\end{tabular}}} \\
\hline & & & & & & & & & & & & & & \\
\hline & \multicolumn{4}{|c|}{ ONLY ASK FOR AGE 10 AND ABOVE. } & \multicolumn{3}{|c|}{ FOR <13: ONLY ASK CAREGNER IF NOT ASKED ABOVE ALREADY } & & & & & & & \\
\hline & & & & & & & & & & & & & & \\
\hline
\end{tabular}

STORY A

Person A is a primary school teacher. Person A is teaching English and Math lessons.

Ais usually teaching 7 hours a day, 5 days a week. Person A does teaching mainly standing but sometimes sitting down.

RESPONDENT ID ON BEHALF OF CHILD IF CHILD IS BELOW 13:

1 day a week for 7 hours that day, Person A is operating the kiosk of hisher spouse.

\section{STORY B}

Person $B$ is a casual construction worker

B usually works 7 hours a day, 6 days a week.

Most of the times, $\mathrm{B}$ is responsible for providing coworkers with a sand cement mix. This involves transporting the ingredients to the mixing point, manually mixing sand, cement and water

and transporting the mix to the coworkers with a wheelbarrow.

\section{STORY C}

Person $\mathrm{C}$ works in a butchery.

C usually works 7 hours a day, 6 days a week.

C usually receives a full cow carcas three times a week that he has to cut into large pieces and hang. This takes him 30 minutes per cow.

When serving customers, $\mathrm{C}$ sometimes has to unhang the pieces. Most of the time $\mathrm{C}$ can cut the meat for the customers fromthe hanging pieces directly.

$\mathrm{C}$ also is responsible for weighing and wrapping the meat and cutting into small pieces if the customer wishes. 


\section{SECTION 15: Physical and leisure related activity}

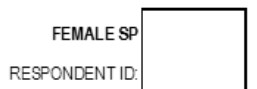

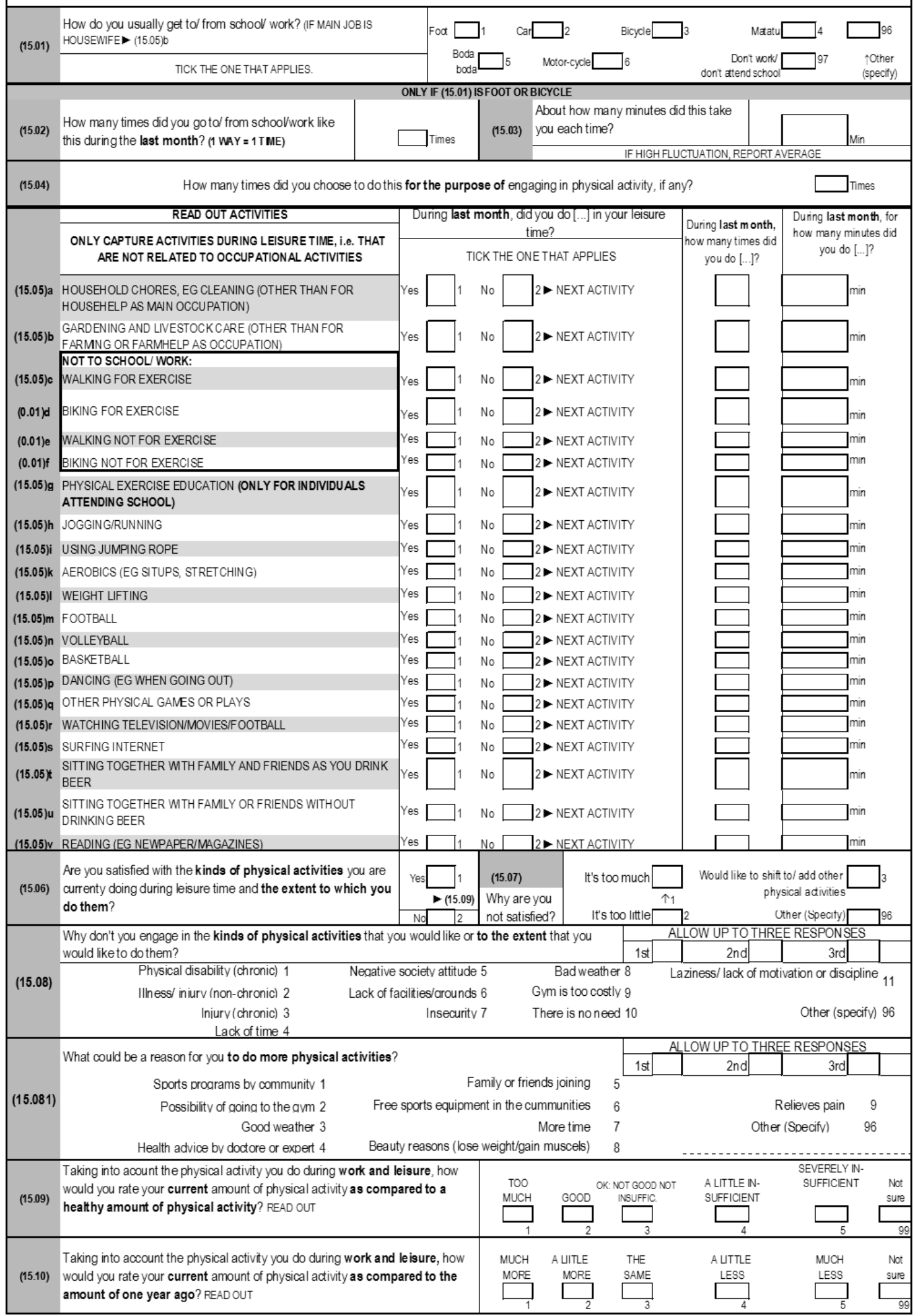




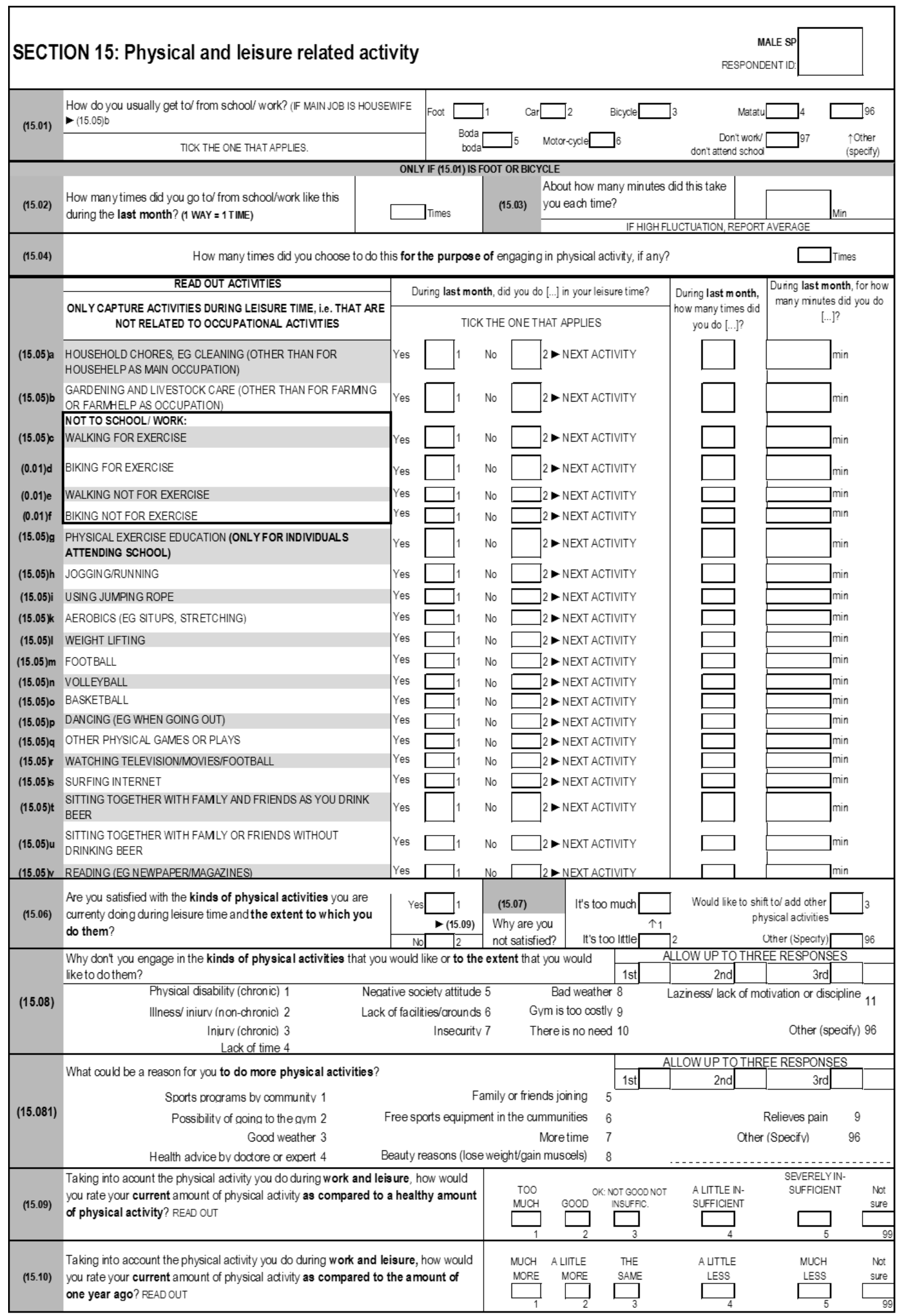




\section{SECTION 15: Physical and leisure related activity}

CHILD1 IADOLESC SP CAREGIVER RESPONDENT ID:

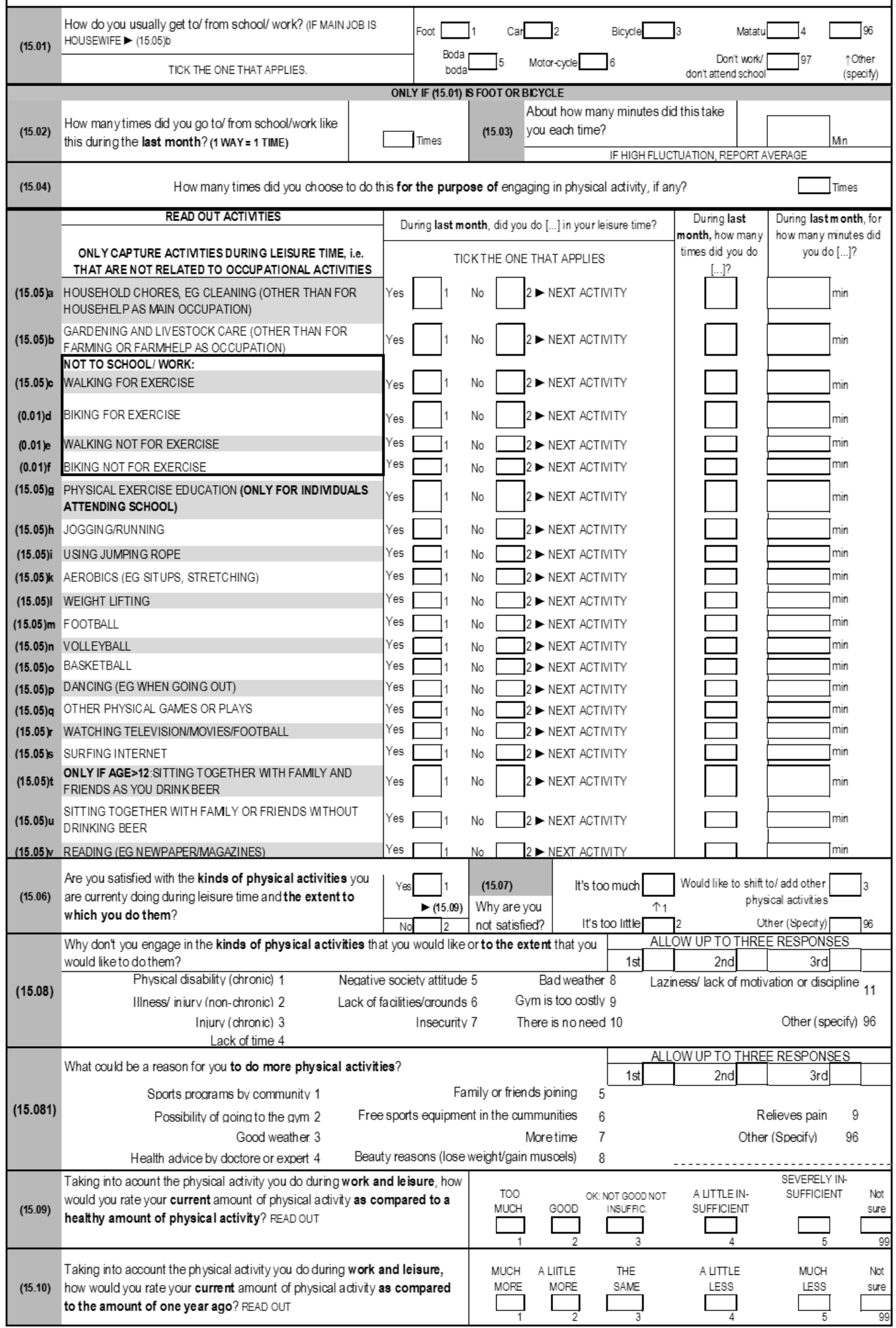




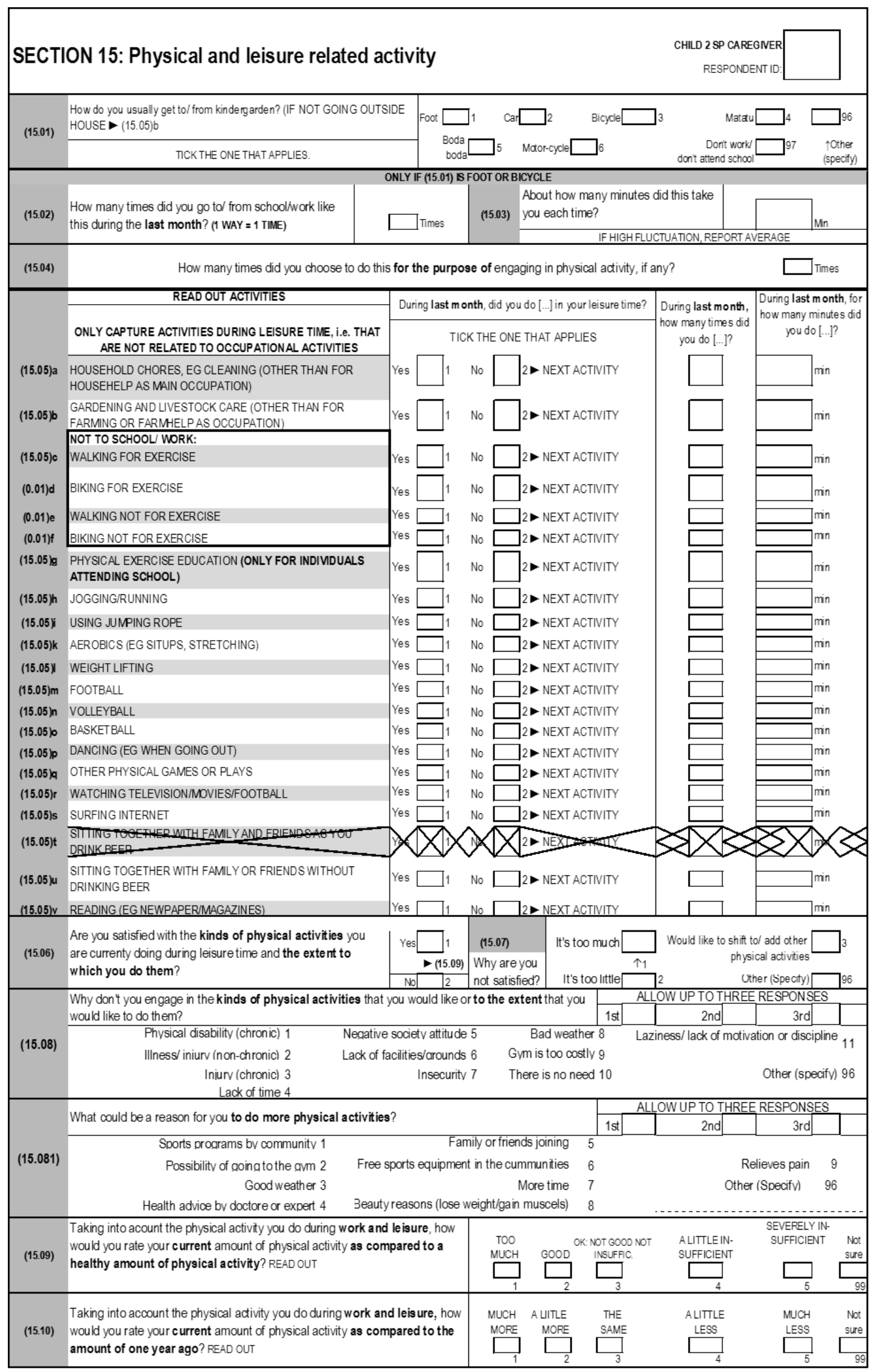


SECTION 15/2: Physical and leisure realted activity

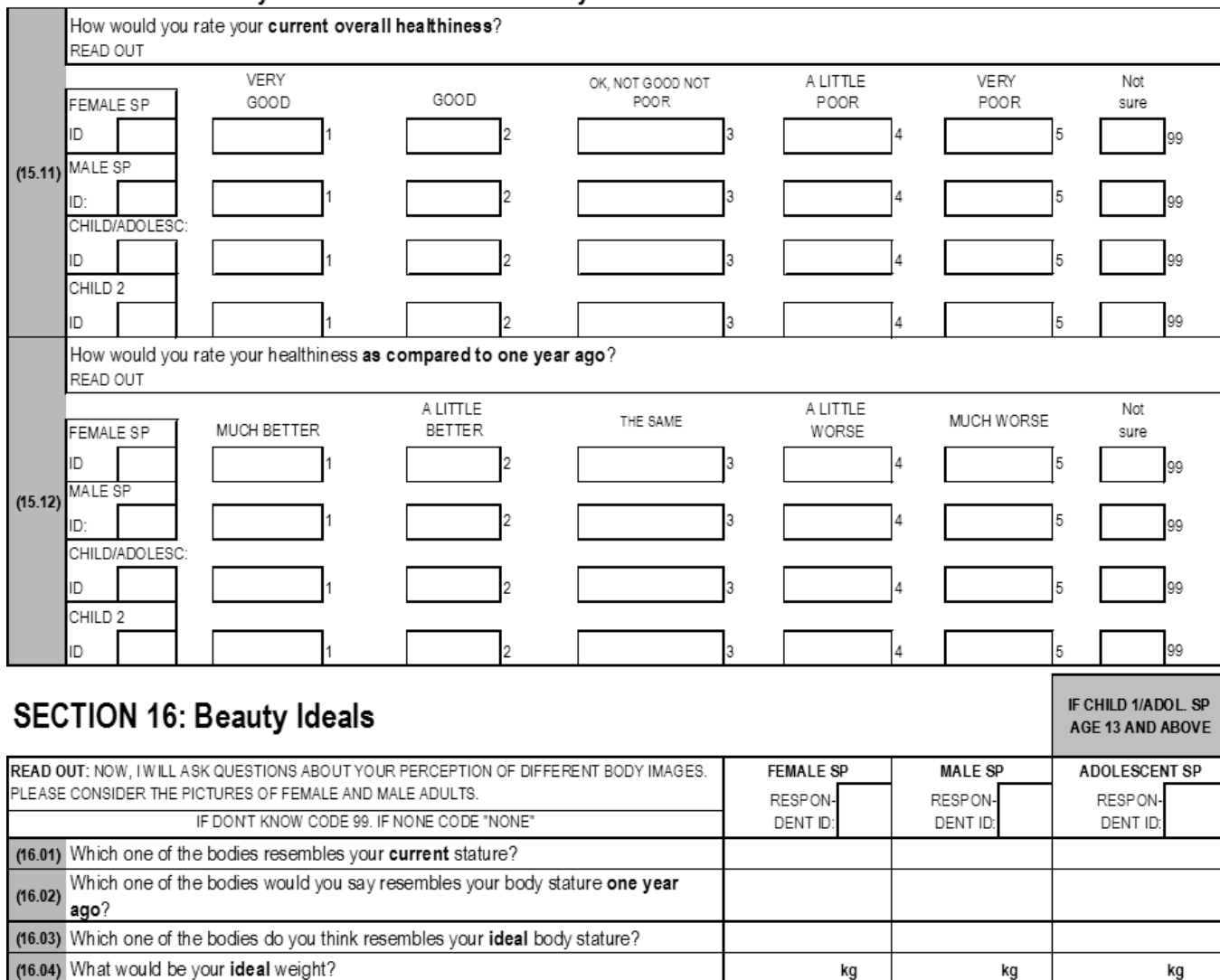
(16.04) What would be your ideal weight?

FOR ALL QUEST IONS BELOW: F YES, PROBE: "WHICH ONE(S)?". IF NO, CODE "NONE", IF not sure, CODE "99"

(16.05) Would you say that any of the female bodies is healthiest?

(16.06) Would you say that any of the male bodies is healthiest?

DEFINE EXCESS WEIGHT: WEIGHING MORE THAN BEST FOR HEALTH

(16.11) Would you classify any fe male body as having excess w eight? PROBE FOR. FIRS

ONE LOOKING FROM SKINNIEST TO BIGGEST BODY.

(16.12) Would you classify any male body as having excess weight? PROBE FOR FIRST

ONE LOOKING FROM SKINNIEST TO BIGGEST BODY

DEFINE STRONG EXCESS WEIGHT: WEIGHING MUCH MORE THAN BEST FOR HEALTH

(16.13) Would you classify any female body as having strong excess w eight? PROBE FOR

FIRST ONE LOOKING FROM SKINNIEST TO BIGGEST BODY.

(16.14) Would you classify any male body as having strong excess weight? PROBE FOR

FIRST ONE LOOKING FROM SKINNEST TO BIGGEST BODY

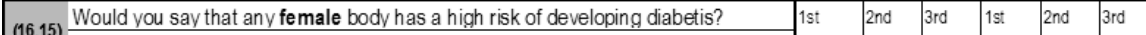

(16.15) ALLOW UP TO 3 RESPONSES. RANK ACCORDING TO LIKELIHOOD.

(16.16) Would you say that any male body has a high risk of developing diabetis?

ALLOW UP TO 3 RESPONSES. RANK ACCORDING TO LIKELIHOOD.

(16.17) Would vou sav that arv female bodv has a high risk of developing a heart disease?

ALLOW UP TO 3 RESPONSES. RANK ACCORDING TO LIKELIHOOD

(16.18) Would you say that any male body has a high risk of developing a heart disease?

(16.18) ALLOW UP TO 3 RESPONSES. RANK ACCORDING TO LIKELHOOD.

FOR CHILD 2 SP AND IF CHILD 1/ ADOLESESCENT SP AGE 5-12 ASK THE FOLLOWING QUESTIONS TO MOTHER OF THAT SP

READ OUT: PLEASE CONSIDER THIS PICTURE OF CHILDREN.

DEFINE EXCESS/ STRONG EXCESS/TOO LITTLE WEIGHT PRIOR TO

CORRESPONDING QUESTIONS

(16.23) Which one of the bodies would you say resembles an ideal body stature for boy?

(16.24) Which one of the bodies would you say resembles an ideal body stature for $\mathrm{g}$ irls?

FOR ALL FOLLOWING QUESTIONS: IF YES, PROBE "WHICH ONE". IF NO, CODE "NONE", IF not sure, CODE "99"

(16 25) Would classify any boy as having excess weight? PROBE FOR FIRST ONE LOOKING

FROM SKINNIEST TO BIGGEST

(16.26) Would classify any girl as having excess w eight? PROBE FOR FIRST ONE LOOKING

FROM SKINNIEST TO BIGGEST.

(16.27) Would classify any boy as having strong excess weight? PROBE FOR FIRST ONE

LOOKING FROM SKINNIEST TO BIGGEST

(16 28) Would classify any girl as having strong excess w eight? PROBE FOR FIRST ONE LOOKING FROM SKINNIEST TO BIGGEST

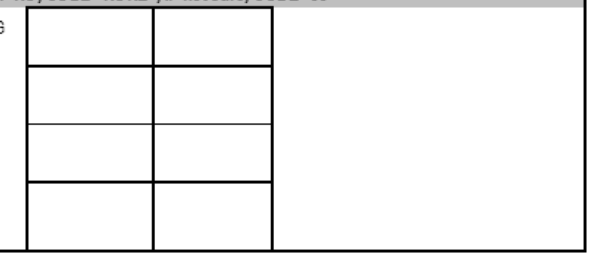




\section{SECTION 17/1: Weight Related Risk Factors}

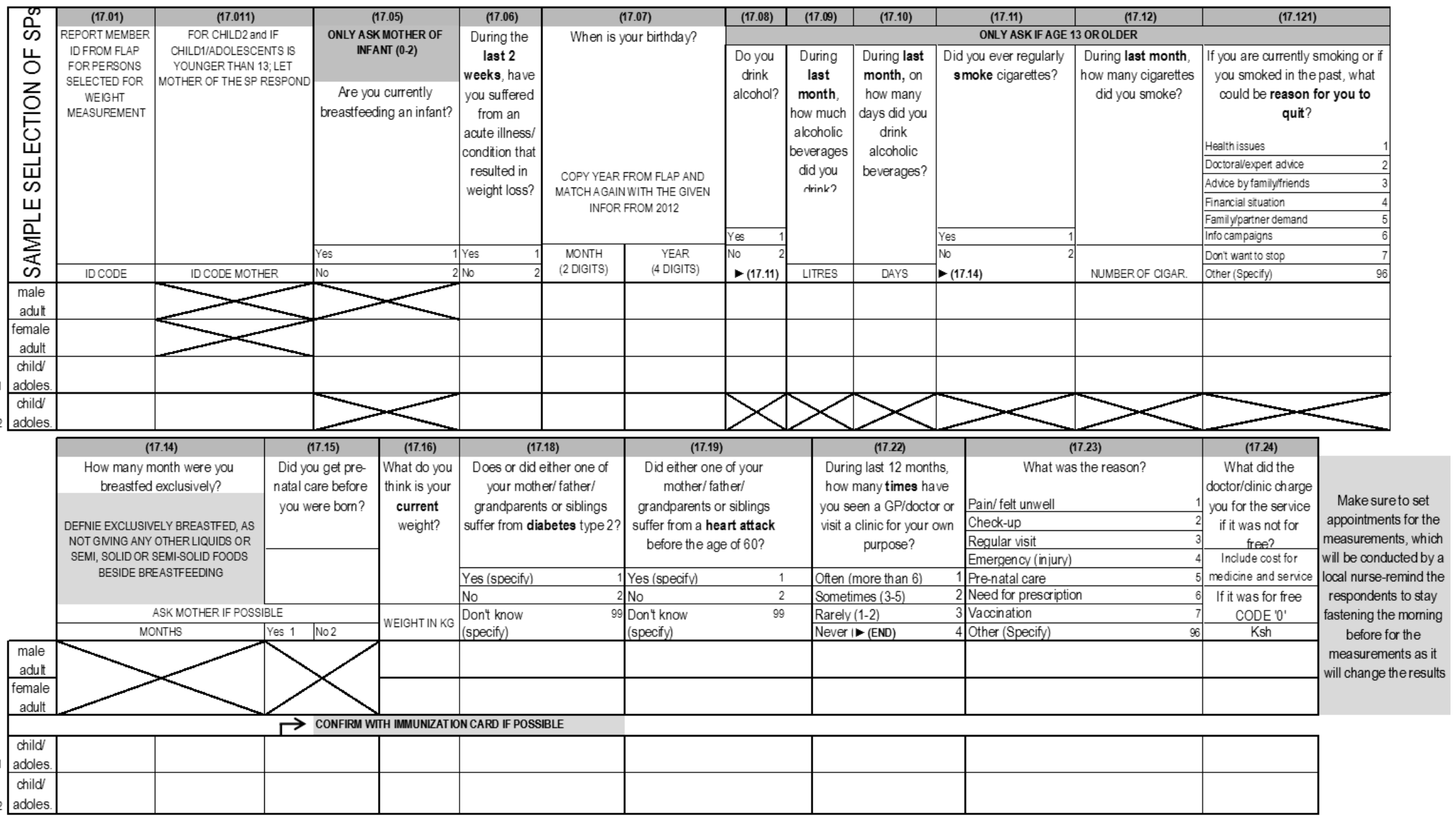


SECTION 17/2: Anthropometry and Bio-medical Measurements \begin{tabular}{|c|l|l|l|l|}
\hline \multirow{2}{*}{ Date of Measurements } & DAY & MONTH & YEAR & \multirow{2}{*}{ NURSE ID NAME } \\
\cline { 2 - 4 } & & & & \\
\hline
\end{tabular}

THIS SECTIONIS TO BE FILED BY NURSE; PLEASE START WITHEXPLANING THE MEASURENENTS AND GETING CONSENT AGANFFOM EVERY PARTIIIPANT (SP)

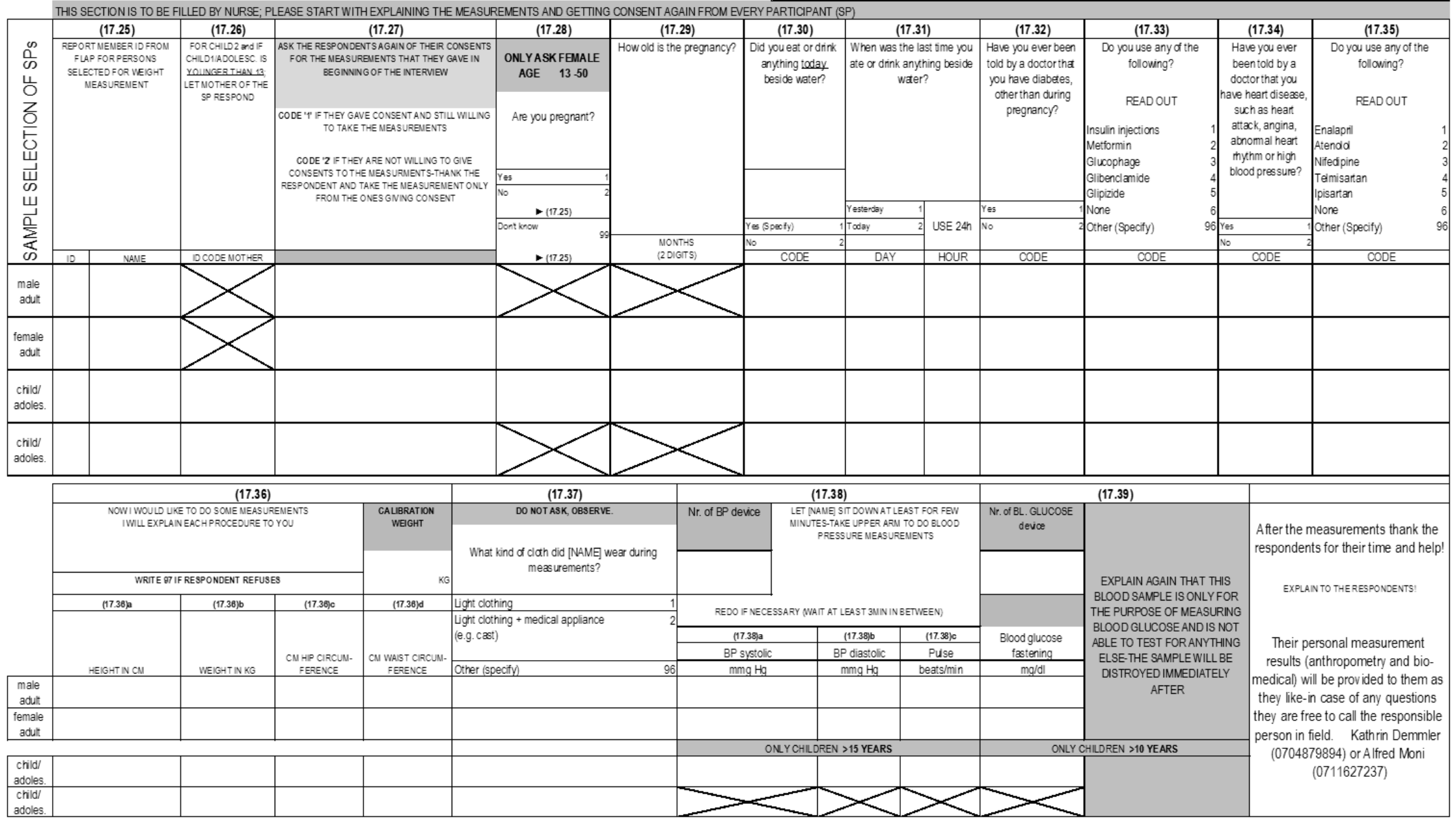




\section{Section 18: End of the Questionnaire}

Could you please give us your cellphone number and/or at least two other family members/relatives/friends of your household such that we can contact you if we need more information?

\begin{tabular}{|c|c|}
\hline NAME & PHONE NUMBER \\
\hline & \\
\hline & \\
\hline & \\
\hline
\end{tabular}

For the purpose of providing you with your measuremnet results could you please give us also the cellphone numbers of the respondents (or the responding mothers) from the measurement section members/relatives/friends of your household such that we can contact you if we need more information?

\begin{tabular}{|l|l|}
\hline \multicolumn{1}{|c|}{ NAME } & PHONE NUMBER \\
\hline SP MALE ADULT & \\
\hline SP FEMALE ADULT & \\
\hline SP CHILD 1/ADOLESC (OR MOTHER) & \\
\hline MOTHER OF SP CHILD 2 & \\
\hline
\end{tabular}

For enumerator's comments/notes

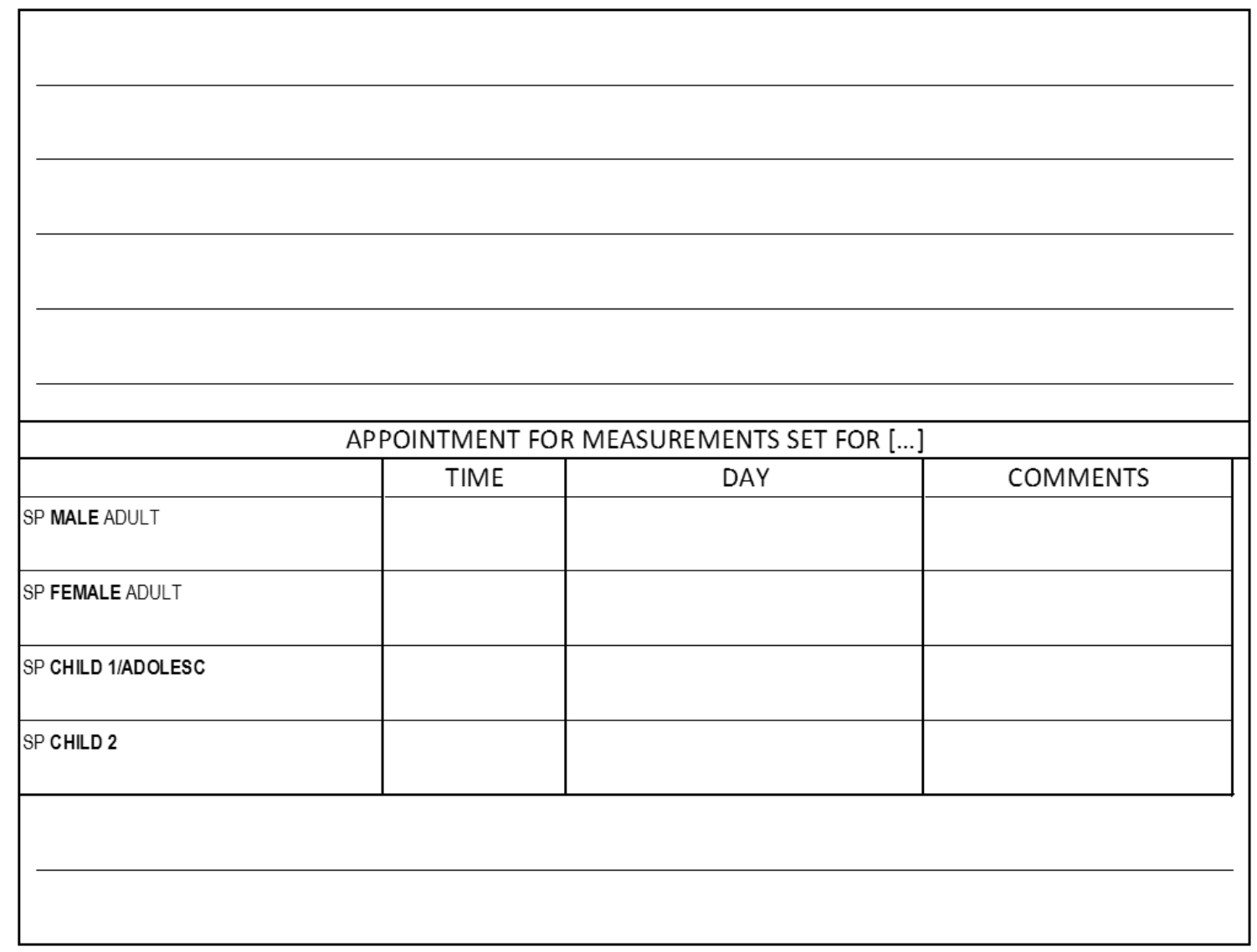




\section{Declaration of Consent}

1. I confirm that I have received information about the study and I understood the purpose of the study and procedure of measurements that will be taken in the survey: "Supermarket purchase, the nutrition transition, and the burden of non-communicable diseases: an analytical observation in urban Kenya".

2. I had enough opportunity to ask questions about the study and all my questions have been answered.

3. I agree that my body size, blood pressure, and blood sugar will be measured and that all my personal data will be coded with a number and not displayed with my name. I agree that my results are stored and publicized in the same manner, according to the Lower Saxony and federal data privacy act.

I feel completely informed and agree to the participation in the study "Supermarket purchase, the nutrition transition, and the burden of non-communicable diseases: an analytical observation in urban Kenya".

TOWN:

DATE:

.$/ 2015$

\begin{tabular}{lll}
\hline Name of the participant & Signature of participant /caregiver & code
\end{tabular}

Name of the participant

Signature of participant /caregiver

code

Name of the participant

Signature of participant /caregiver

code

Name of the participant

Signature of participant /caregiver

code

Name of responsible interviewer

Signature

code 